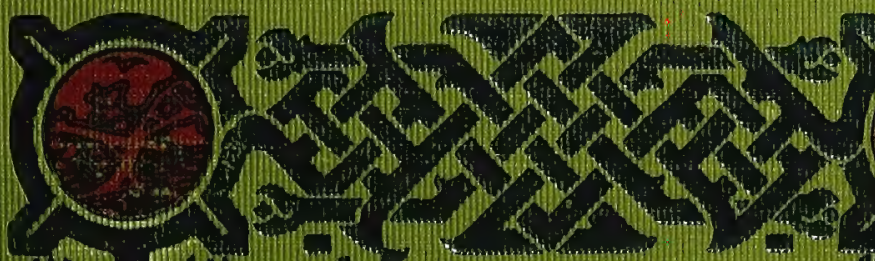

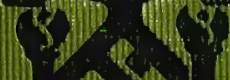

2
$(2)$

(iin) 2

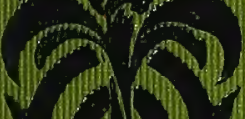

(2)

in th

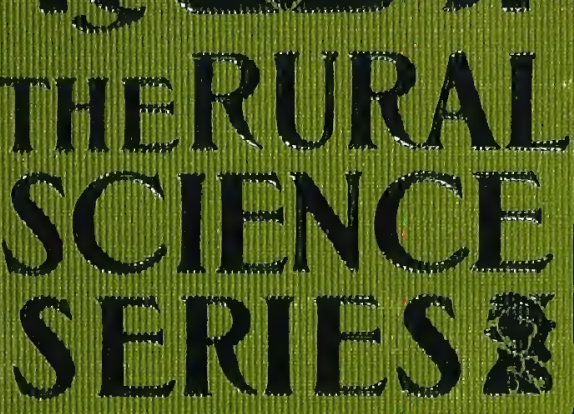

BY LH-BAILEY

$12 e^{2}$
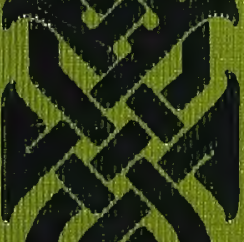

i ( $(5)$

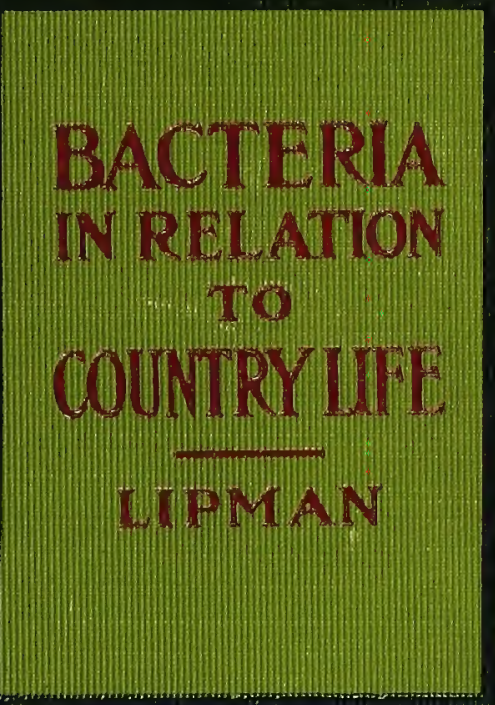

ing

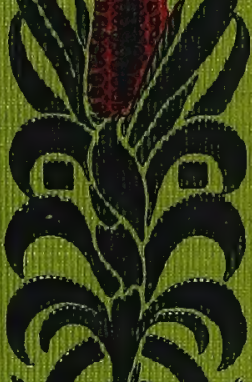

a vif

(f)

W

She

(1)

\section{COUNTRY LIFE}

W $(1))$

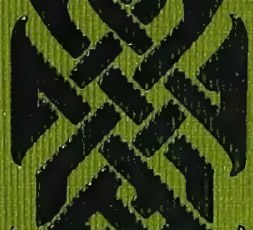

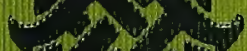

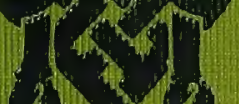

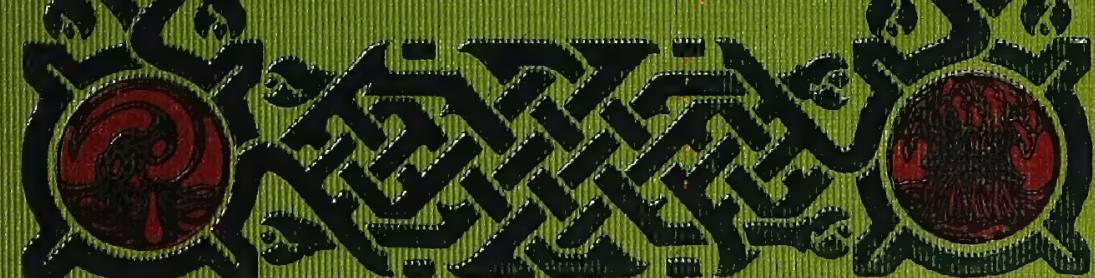




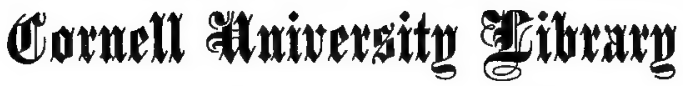

BOUGHT WITH THE INCOME FROM THE

\section{SAGE ENDOWMENT FUND THE GIFT OF}

\section{Henug พ⿴囗十. Sage}

$$
\text { r89x }
$$

0.251497

$3 \ldots$ 


\section{arV1268}

Cornell University Llbrary

Bacteria in relation to country life

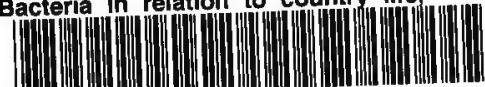

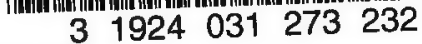
olin,anx 


\section{Cornell University Library}

The original of this book is in the Cornell University Library.

There are no known copyright restrictions in the United States on the use of the text. 


\section{BACTERIA IN RELATION TO COUNTRY LIFE}




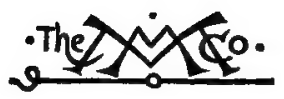

THE MACMILLAN COMPANY

NEW YORK - BOSTON - CHICAGO

ATLANTA - SAN FRANCISCO

MACMILLAN \& CO., LimrTED

LONDON - BOMBAY * CALCUTTA

MELBOURNE

THE MACMILLAN CO. OF CANADA, LtD.

TORONTO 



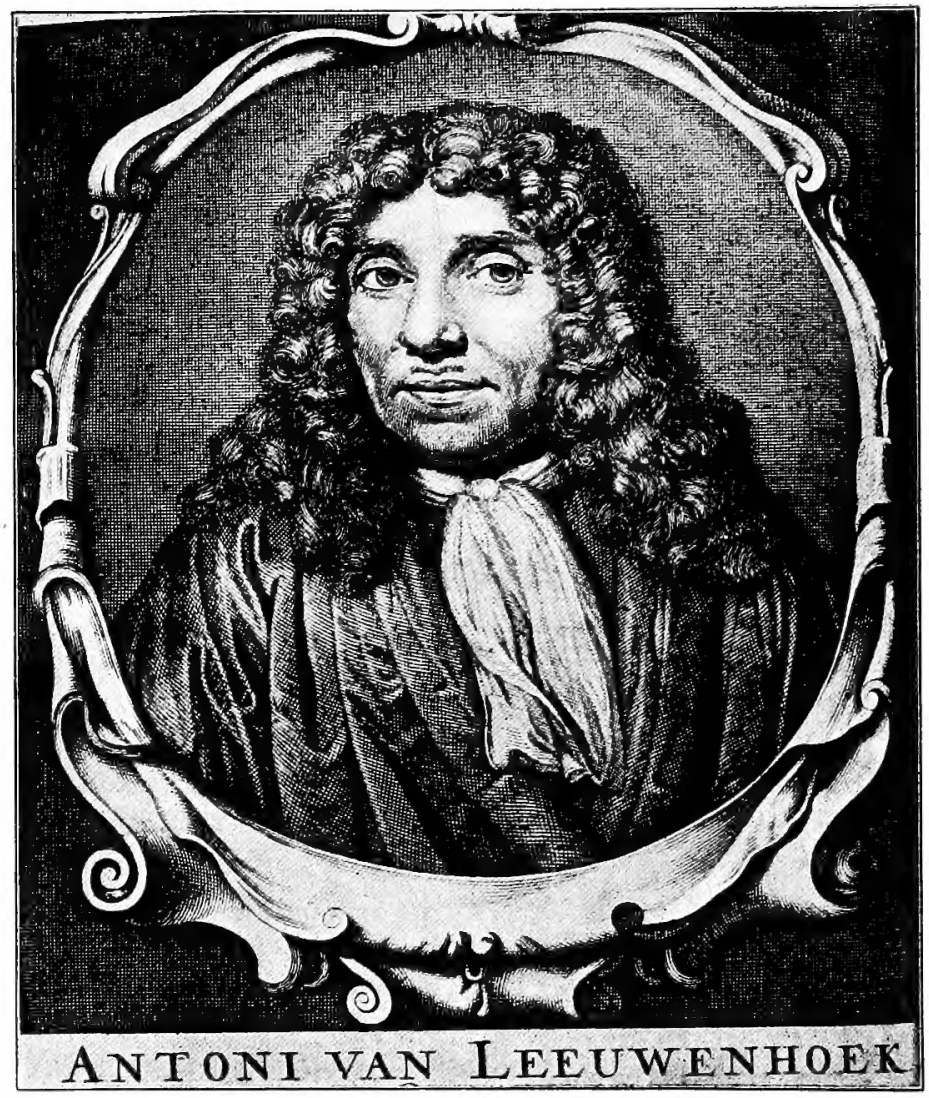

Leeuwenhoek (pronounced la -ven-hook), a Dutch naturalist, 1632-1723, is generally cited as the first to discover bacteria. See page 2. 


\title{
BACTERIA IN RELATION TO COUNTRY LIFE
}

\author{
BY \\ JACOB G. LIPMAN, A.M., Ph.D.
}

BOIL CHEMIST AND BACTERIOLOGIST FOR THE NEW JERSEY AGRICULTURAL IXPERIMENT STATION AND ASSOCIATE PROFESSOR OF AGRICULTURE IN RUTGRRS COLLEGE

THIRD EDITION

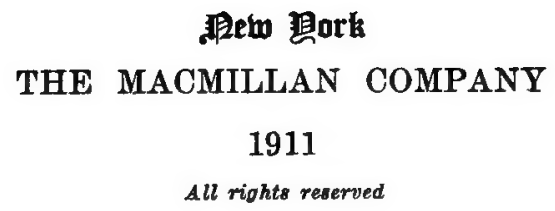


Coptright. igog

\section{By THE MACMILLAN COMPANT}

Set up and electrotyped. Published. Saptember, 1908 Reprinted July, 1909, January, 1911 


\section{PREFACE}

LIFE in the country, like that in the city, has been rendered less simple by inventions and scientific investigations. A whole series of new problems have arisen within a single generation and have called forth more or less successiui attempts at their solution. Among these new problems we may properly include that of the bacteria, those minute living things that float in the air that we breathe, that exist for our weal or woe in the water that we drink, that perform a mighty work in the soil and thereby make it possible for generations of plants and of animals to come and go.

The extreme smallness of the bacteria renders them invisible to the naked eye, and makes it difficult for the layman to think of them as definite living beings entrusted with an important task in the continuing of life. The deepening current of human existence now forces us to study the bacteria and other microörganisms. In so far as they are dangerous to our health and happiness we must learn to defend ourselves; we must learn to destroy them or to render them harmless. In so far as they are beneficial, we must learn to 
control them and to make their activities widely useful to human society.

The present volume is an attempt to treat, in a simple way, of the bacteria as they concern life in the country. It is an attempt to discuss the character of the bacteria in air, water, sewage, manure, soil, and food products. Technical terms and expressions have been eliminated.as far as practicable, and it is hoped that the general reader may find the book an aid in the understanding of the bacteriological problems as they affect the daily tasks on the farm.

The author wishes to express his indebtedness to Messrs. Percy E. Brown and Herbert Seidman for their assistance in the preparation of the index; and to Dr. Edward B. Voorhees for the permission to use a number of the photographs that appear in this volume.

JACOB G. LIPMAN.

New Jersey Experiment Stations,

New Brunswick, N. J.

June 22, 1908. 


\title{
CONTENTS
}

\author{
PART I \\ Structure and Growth of Bacterla. . . $1-45$
}

CHAPTER I

The Rise of Bacteriology . . . . . . . . . . . . 1-12

Contagion-Discovery of bacteria-Spontaneous generation-Spontaneous generation disproved-The physiology of bacteria-Bacteria as a cause of disease-The study of bacteria-Anthrax bacillus-New methods of studyBacteriology and agriculture.

\section{CHAPTER II}

The Form and Structure of Bacteria . . . . . . . 13-25

Irregular forms-Shape-Size-Motility and organs of motion-Zoögloea-Rate of increase-Conditions that retard bacterial growth-Spores-Spores as a means of preservation-Spore formation-Vitality of sporesClasses of bacteria - Sterilization and pasteurizationIntermittent sterilization.

\section{CHAPTER III}

Tine Chemistry of the Bacterial Cell . . . . . 26-29 The cell-wall and its contents-Content of the protoplasm-The absorption of food. 
The Food Requirements of Bacteria ....... . 30-35 The sources of carbon-The compounds of carbon in bacteria-The source of nitrogen-Enzymes-Pigments -Phosphorescence.

\section{CHAPTER V}

Conditions Affecting the Growth of Bacteria. $36-44$

Temperature-Thermophile bacteria-Effect of coldAttenuated cultures - Moisture content of the culture medium - Relation to oxygen - Action of sunlight-Electric light-Influence of electric currents-Influence of the concentration of the culture medium-The reaction of the culture medium-Importance of reaction of the soil.

\section{PART II}

Bacteria in Air and Water.... 45-103

\section{CHAPTER VI}

Bacteria in the Atmosphere

Bacteria on dust particles-Determination of the bacteria in the air-Pasteur's method of determinationValue of Pasteur's method-Quantitative methods. Influence of locality - Bacteria in city air-Bacteria in the air of the country. Influence of season climate, and altitude-Bacteria in the air at different seasons of the year-The influence of climate-The influence of altitude-Bacteria and respiration.

\section{CHAPTER VII}

The Relation of Water to Health and Disease . . 56-60 Ancient water-supplies-Relation of drinking-water and disease discovered-Epidemics of cholera and typhoid fever-Other sources of typhoid infection-Other diseases arising from use of impure water. 


\section{CHAPTER VIII}

Contamination of Streams and Lakes . . . . . 61-76

Soils contain bacteria-The character of the bacteria in water-The number of bacteria in water-Causes affecting the increase or decrease of bacteria in water-The supply of food-Temperature-Sunlight-Animalcules injurious to bacteria-Sedimentation-Dilution-The contamination of drinking-water by sewage.

\section{UHAPTER IX}

Purification of River and Lake Supplies . $77-89$

The quality of organic matter-Alkaline waterRiver-water and surface drainage--Self-purification of rivers-The storing and filtration of river-waterSand-filtration-Other methods of water purificationThe alum method-The Clark process-Purification by finely divided solids-The Woolf method-Purification by means of ozone-Filters for domestic purposesThe waters of lakes and ponds.

\section{CHAPTER $\mathrm{X}$}

Bacteria in Wells, Springs, Tanks and ICe . . . . .90-98 Bacteria and well-water-Deep wells and springsDriven wells-Artesian wells-Bacteria in the water of cisterns and tanks. Bacteria in ice.

CHAPTER XI

The Sanitary Examination of Water-Supplifg . . .99-102 


\section{PART III}

Bacteria and Sewage . . . . . 103-134

\section{CHAPTER XII}

The Problem of Sewage-Disposal $103-111$

The cess-pool-The new method of the nineteenth century -Bacteria in sewage-Growth of the problem-Inland communities and sewage-disposal-The source, composition and quantity of sewage.

\section{CHAPTER XIII}

Bacterial Purification of Sewage

Sewage-farms-Sewage tanks and filter beds-Progress in sewage-purification-Intermittent sewage-filtration -Separation of bacterial activities-Temperature and bacterial activities-Hydrolysis-Treatment of effluent -Temperature and filter efficiency-Inoculation-Kinds of bacteria in filter beds and septic tanks-Loss of nitrogen - Bacterial efficiency in sewage-purification Factory wastes and bacterial efficiency-The working capacity of bacterial filters.

\section{CHAPTER XIV}

Sewage-Irrigation

Economic value of sewage-irrigation-Sanitary value of sewage-irrigation-Kinds of irrigation-Broad irrigation-Intermittent and mixed irrigation-The crops grown on sewage-farms-Preliminary treatment of sewage for sewage-farms-Objections to sewage-farming - Sanitary efficiency of sewage-purification. 
Bacteria in Relation to Soll Fertility . $135-302$

\section{CHAPTER XV}

Number and Distribution of Bacteria in the Soll .135-143 Number of bacteria in soil-Distribution of bacteria in the soil.

\section{CHAPTER XVI}

The Relations of Bacteria and Humus $.144-154$

The quantity of humus as affecting number of bacteriaQuality of humus as affecting number of bacteria. Bacteria and the decomposition of soil-humus.

\section{CHAPTER XVII}

Bacteria and the Transformation of Soll-Nitrogen . 155-167 The source of nitrogen in the soil-Proportion of nitrogen in the soil-Nitrogen compounds in the soil-humusLoss of nitrogen in the soil-Availability of nitrogenConditions affecting availability of nitrogen-Soil bacteria-Ammonification- Ammonifying bacteria- Enzymes-Mutual relations of bacteria-Denitrifying bacteria-Influence of bacteria on one another-Ammonifying power of soils.

\section{CHAPTER XVIII}

Nitrification $.168-182$

True character of nitrification-Pure culture of nitrifying bacteria-Importance of nitrification-Conditions affecting nitrification-Loss of nitrates in the soilSources of nitrates-Early use of nitrates-Conditions influencing the formation of nitrates-Availability of nitrogenous materials-Influence of crop on availability. 
Denitrification

Early idea of denitrification-The cause of denitrification

- Value of modern discoveries-Modern conclusions concerning denitrification-The denitrifying bacteria.

\section{CHAPTER XX}

The Increase of Soll-Nitrogen $.190-196$

The ammonia theory-The nitrate theory-The bacteria theory.

\section{CHAPTER XXI}

The Non-Symbiotic Nitrogen-Fixing Bacteria . 197-205 Aërobic and anaërobic bacteria-The aërobic nitrogenfixing bacteria-Agricultural importance of the two classes of bacteria-Other nitrogen-fixing forms.

\section{CHAPTER XXII}

Symbiotic Fixation of Nitrogen. . $.206-220$

The value of legumes-The limitations of legumesLegumes and fertilizers-The cause of the soil-enriching qualities of legumes-Liebig's theory-Other theoriesThe solution of the problem-Nodules on the roots of legumes-The nature of the nodules-The bacteria of legumes-The relations between legumes and the nodule bacteria.

\section{CHAPTER XXIII}

Soll-Inoculation

Pure cultures-Nitragin-Agar as a food for culturesDifficulty in using pure cultures-Artificial culturesSoil-inoculation in the United States-Alinit. 


\section{CHAPTER XXIV}

\section{Green-Manuring}

Green-manures and humus in the soil-Leguminous green-manures and nitrogen in the soil-Greenmanures on sandy soils-The cowpea, soybean, sand vetch, crimson clover and velvet bean-Green-manures on loams and clay soils-Leguminous green-manures and the succeeding crops.

\section{CHAPTER XXV}

FALLOWing

Fallow crops-Fallow and cropped soils-Moisture and fallows-Aëration and fallows-Fallowing and plantfood-Bare fallows and nitrogen in the soil.

\section{CHAPTER XXVI}

Soll Bacteria in Relation to Mrnerals in the Soll . .275-302 Soil bacteria in relation to lime and magnesia-The causes of the migration of lime and magnesia-The liming of soils-The losses of lime-The importance of lime-Bacterial activities and lime. Soil bacteria in relation to phosphates and other compounds of phosphorus -Bacterial activities and phosphorus-Bacterial activities and phosphate fertilizers-Ground bone-The effect of using sulfuric acid-Thomas slag-Other sources of phosphoric acid. Activities of soil bacteria in relation to potash-Potash and the weathering process-Lime as an indirect source of potash-Humus in relation to soilpotash-Organic acids and the decomposition of rock fragments-Potash salts and bacteria. Bacteria in relation to sulfur-Sulfuretted hydrogen-Sulfate of limeThe work of bacteria-Sulfur and bacterial development. Bacteria in relation to iron-Iron rust and bacteria-The importance of iron bacteria - Iron in the soil and decay bacteria-Influence of iron on bacteria. 


\section{CHAPTER XXVII}

Manure: Its Composition AND Losses

Bacterial change in manure-Mechanical constitution and bacterial change-Chemical composition and bacterial change. Losses from farmyard manure-Value of manures-Losses of elements caused by digestionOther causes for losses-Importance of proper storingThe loss of nitrogen-Aërobic and anaërobic decomposition-Bacterial activities and money losses.

\section{CHAPTER XXVIII}

The Bacteria in Manure-Ammonification" $.318-325$

Changes in manure-bacteria-Three stages of changeBacteria and conditions affecting decomposition. Ammonification-Hippuric acid-Uric acid-The formation of ammonia in liquid excreta-Loss of ammonium carbonate-Urease-Other ammonia-forming bacteriaImportance of ammonification.

\section{CHAPTER XXIX}

Denitrification in Manures $.326-336$

Nitrates in manure-Denitrifying bacteria-Experiments in denitrification-The danger of denitrification. Losses of elementary nitrogen-The problem of the loss of nitrogen-Recent information on the problem. Soluble nitrogenous substances made insoluble-The change of available into unavailable nitrogen-Conditions affecting the change. Conclusion.

\section{CHAPTER XXX}

Nitrification in Manures

Nitrification in manures-Effect of liquid-The compost heap-The loss of humus-forming material. 
Gases in the manure pile. Litter and the development of bacteria in manure.

\title{
CHAPTER XXXII
}

The Conservation of Manurial Constituents . . . 348-356 Chemical methods-Gypsum-Burned lime, shell-lime, and limestone-Superphosphate-Kainit-Sulfuric acid -Value of chemical methods. Mechanical methodsEffect of moisture-The temperature of the manurePreventing the loss of ammonia.

\author{
PART VI \\ Bacteria in Milk and Related Products
}

$.357-430$

\section{CHAPTER XXXIII •}

Milk as a Food

Milk a medium for bacterial development.

\section{CHAPTER XXXIV}

Source of Bacteria in Milk $.360-368$

Bacteria in the udder-Bacteria in the air-Bacteria on the cow's body-The milker-The utensils-Milkingmachines-Milk-strainer.

\section{CHAPTER XXXV}

Kinds of Bacteria in MilK $.369-377$

Species of bacteria in milk-Lactic-acid bacteria-Sweet curdling-Harmless bacteria-Milk faults-Blue milkRed milk-Bitter milk-Ropy milk.

\section{CHAPTER XXXVI}

Milk Beverages

Kefir-Kumiss-Matzoon. 


\section{CHAPTER XXXVII}

The Keeping Quality of Milk $.382-396$

The so-called germicidal power-Temperature. Means for improving the keeping quality of milk-PressureCentrifugal force-Sterilization by heat-Pasteurization-Treatment with chemicals. Problems of transportation and distribution.

\section{CHAPTER XXXVIII}

Disfase Bacteria in Milk . . $.397-401$

Tuberculosis-Typhoid-Diphtheria and Scarlet fever.

\section{CHAPTER XXXIX}

Bacteria in Cream and Cream-Ripening $.402-410$ Starters.

\section{CHAPTER XL}

Bacteria in Butter $411-415$

The changes occurring in butter-Numbers and kindsDisease bacteria in butter-Butter faults.

\section{CHAPTER XLI}

Bacteria in Cheese

The ripening process-Enzymes and bacteria in the ripening of cheese-Soft cheeses-Hard cheesesCheese faults.

\section{PART VII}

Bacteria in Relation to Preservation of Food $.431-446$

\section{CHAPTER XLII}

Bacteria in Relation to Canning

The principles of canning-Development of the industry

-Losses through imperfect canning-Temperatures 
required for sterilization-Canned meat-Canned milk

-The use of preservatives.

\section{CHAPTER XLIII}

Other Mrans of Preserving Food Products.-Pickling 439-446 Low temperatures-Drying-Salting, pickling and smoking-Pickled fish-Sauerkraut-Dill-pickles.

\section{PART VIII}

Bacteria And Fermentation $. . .447-472$

\section{CHAPTER XLIV}

Bacteria in Bread-Making

..... $447-448$

Bread faults.

\section{CHAPTER XLV}

Bacteria in the Sugar Industry

Streptococcus mesenteroides-Clostridium gelatinosum.

\section{CHAPTER XLVI}

Bacteria in the Preparation of Hay and Other Fodders

Brown hay-Corn silage.

\section{CHAPTER XLVII}

Bacteria in Miscellaneous Agricultural Industries $\quad 456-457$ The retting of flax and hemp-The preparation of natto-Bacteria and agricultural products. 


\section{CHAPTER XLVIII}

Bacterial Diseases of Fermented Liquors

The "turning" of wine and beer-Ropiness in wine-Sarcina sickness-Loss of color in wine-Mannitic fermentation.

\section{CHAPTER XLIX}

Vinegar-Making $.463-472$

History of the art-Modern knowledge-The "mother of vinegar"-Acetic-acid bacteria-Methods of using acetic ferments-Pure cultures in vinegar-makingThe storing of vinegar.

INDEX AND GLOSSARY ......... . 473-486 


\section{BACTERIA IN RELATION TO COUNTRY LIFE}

\section{PART I \\ Structure and Growth of Bacteria}

\section{CHAPTER I}

\section{THE RISE OF BACTERIOLOGY}

BACTERIA are minute living things lying in the borderland between plants and animals. Their existence was undreamed of until times comparatively recent, yet their appearance on the earth antedates that of man. Plant and animal remains now turned to stone and dating back to early geological ages have been found to contain the petrified cells of bacteria, some forms of which closely resemble those of today.

We know that an almost endless number of plants and animals now extinct have run their course on this earth in passing from lower forms to higher, in adapting themselves to a new environment. We do not know of the cycles of change through which the bacteria have passed, nor do we know of the birth and the passing of forms long ago vanished. We know merely that in the world of today their name is legion, that they differ not only in form and size, but also in the chemical changes that they produce. The rivers, the sea, and the earth all 
have their specific bacterial inhabitants. There are bacteria that cause abnormal conditions or "disease" in plants or animals; there are others that are harmless; there are still others that are known to be distinctly beneficial and indispensable to the growth of higher organisms.

The existence of bacteria was not revealed until the perfecting of the compound microscope, toward the end of the seventeenth century. Yet, though unknown as such, they made themselves manifest many generations previous, by some of their activities. Decay, putrefaction and fermentation were familiar phenomena at the dawn of written history.

Contagion.-The diseases of man and of domestic animals are of very ancient origin. Great epidemics that devastated towns, cities, and entire kingdoms were more common once than they are now. 'Man learned long ago that disease may be spread from person to person, and that personal contact increases the degree of infection. So certain was this knowledge that attempts were not lacking even in biblical times, and perhaps earlier in old Babylonia, to establish isolation camps for diseased persons, particularly in the case of lepers. It will not be disputed, therefore, that not only were the phenomena resulting from bacterial activities known thousands of years ago, but that a certain suspicion was entertained in the case of human disease that the outbreak was due, in most cases, perhaps to some form of living contagion.

Discovery of bacteria.-Leeuwenhoek in Holland who, with his more perfectly constructed lenses, first beheld 
bacteria in 1675, designated them as "animalcules." He recognized differences in their appearance and size as well as in their mode of motion, and noted their presence in sea-water and well-water, as well as in various substances of animal origin. These observations, subsequently supplemented by others, gave rise to much speculation and heated discussion concerning the relations of the animalcules to animal diseases. Much interest was attached to the opinion already entertained by some that disease is due to a living contagium. A still greater interest, however, was attached, at this time, to the bacteria in connection with the question of spontaneous generation.

Spontaneous generation.-The belief in spontaneous generation is of ancient origin. Some of the philosophers of the Middle Ages were firm in this belief. Reference may be found in their writings to the spontaneous generation of mice, worms, maggots, and other forms of animal life. With the advance of knowledge, however, the correctness of their facts and conclusions was questioned, and their statements were, in time, discredited and refuted.

The discovery of bacteria seemed to bring new support to the theory of spontaneous generation. Needham announced in 1749 that he had observed the development of bacteria in beef-broth which had been boiled and kept, after that, in a well-stoppered flask. He reasoned that, since no living beings could withstand boiling, the appearance of the animalcules in the sterile broth must have been due to spontaneous generation. This apparent demonstration of sponta- 
ueous generation was not, however, implicitly accepted by all. Bonnet pointed out the possible existence of organisms, or their modifications, capable of withstanding boiling temperatures, and even suggested that Needham's flasks may have been improperly protected against the entrance of bacteria from without.

Spontaneous generation disproved.-In 1765 it was demonstrated by Spallanzani that the development of microörganisms in Needham's broth resulted from imperfect sterilization. By boiling the broth in the flask for a long time, both the container and the contents were thoroughly sterilized and no bacterial development occurred. But, not content with this proof, the believers in spontaneous generation now maintained that the liquid and the air above it had been so changed by heating as to preclude the formation of microörganisms. It was not difficult, of course, to demonstrate that the liquid itself had not lost the power of undergoing putrefaction. It was merely necessary to open the flask to the air in order to induce the appearance and development of bacteria in the liquid. The composition of the atmosphere was still unknown at that time, and no direct proof could, therefore, be adduced in this connection.

The matter thus rested, undecided, for several decades, when Schultze brought forward the proof in 1836 that it is not necessary to heat the air in order to deprive it of the microörganisms suspended in it. He proved that this could also be done by passing the air through strong acid or alkaline solutions. Schwann secured similar results in the following year by forcing 
the air through molten metal; and Schröder and Dusck. simplified the matter still further, in 1854 , by demonstrating that the air could be deprived of its microorganisms by being passed through a cotton plug. Hoffmann, and, likewise, Pasteur, went a step further, and proved that even the cotton filter was unnecessary for making the air incapable of setting up putrefaction in sterile meat broth. By drawing out the neck of the flask into a long, capillary tube, and by bending the latter, the dust particles in the air, and, among them, the bacteria, were made to settle out before they reached the liquid, and no putrefaction occurred in the latter.

Another proof of the falsity of the idea of spontaneous generation was given by Tyndall, when he demonstrated that perishable articles did not spoil on the tops of high mountains, due to the fact that the air in those altitudes contained no germs.

The belief in spontaneous generation was gradually shown to be untenable. Certain proof was supplied that no putrefaction and decay take place in the absence of bacteria. The occasional failure to secure complete sterilization by boiling was accounted for by Kohn's discovery in 1875, of spores,-certain resting stages in the growth of bacteria, more resistant to heat than the vegetative cells, and capable of withstanding boiling temperatures for some time.

The physiology of bacteria.-Pasteur's epoch-making investigations on fermentation shed a broader light on the activities of microörganisms. His work plainly indicated that various kinds of bacteria possess specific functions and differ in the chemical changes 
which they produce. This work may, therefore, be regarded as the starting point for much fruitful research, the foundation of an extensive knowledge on the physiology of bacteria, that is, the chemical changes involved in their life-processes. Bacteria were to be distinguished, henceforth, not by their appearance alone, but by the chemical transformations of which they are capable. They were to be regarded as chemical agents of wide significance, builders and destroyers in vegetable and animal substances, in organic and inorganic materials, in the presence or absence of air.

Bacteria as a cause of disease.-The study of bacteria, and of other microörganisms, as agents of decay, putrefaction and fermentation, gained in interest with the recognition that bacteria may also be the specific cause of disease. As far back as 1762, the belief was expressed by Plenciz, a Vienna physician, that disease is the result of infection by animalcules; and, more important still, that every disease has its particular germ. The views of Plenciz met with no acceptance, and were soon forgotten amid the clashing opinions on spontaneous generation. Towards the middle of the nineteenth century, the question of a living contagium in animal diseases again attracted wide attention. Bassi's demonstration, in 1837, that a certain disease of the silkworm is due to a specific germ, was the first of its kind, and carried much weight.

The question was placed on a broader basis by Henle's teachings on bacteria. He not only thought that infectious diseases are caused by bacteria, but he outlined the methods of inquiry and pointed out that 
no organism may be designated as the specific cause of any given disease unless it can be proved to be invariably present in every case, and can be isolated from the infectious materials. Henle's clear conception of bacteria as agents of infection was evidently too far advanced for his day. At any rate, his views failed to gain general recognition for a long time.

Pasteur's researches prepared the ground for such recognition. A further step in advance was made by . Lemaire when he showed that carbolic acid, poisonous to animals and capable of suspending putrefaction, could also stop pus-formation in wounds. Lister carried the work forward and developed his method of antiseptic surgery, a method through which medical science has achieved such splendid results. Lister's announcement of 1868 stimulated inquiry and brought to light important facts.

The investigations of Klebs during the Franco-Prussian War traced the entrance and the development of bacteria in wounds and their passing into the circulatory system. Klebs and other investigators also noted the constant presence of bacteria in diphtheritic infections. An apparent relation was likewise found between bacteria and other infectious diseases. For all that, much was surmise and speculation rather than certainty. The bacteriological methods for the isolation and identification of bacteria had not yet been developed, and no direct proof could be furnished for the facts observed.

The study of bacteria.-The systematic study of bacteria was furthered by the work of Schröter, published in 1872. In his studies of pigment-producing bacteria, 
he found that the organisms could be grown on solid substances, among them boiled potatoes. The bacterial masses which appeared on the potatoes could be employed for infection of new portions of sterile potato, whereby the distinct colors could be maintained. For this reason, Schröter was inclined to think that he was dealing with definite kinds of bacteria.

The nucleus was thus created for the opinion that, - among bacteria, as among more highly organized organisms, there exist definite species fairly constant in their structure and in their physiological activities. This opinion was given expression by Ferdinand Kohn, whose investigations and writings may be justly marked as the beginning of a new period in modern bacteriology. We owe to him not only the foundation of systematic bacteriology, but the stimulus and the methods for more advanced research. On this foundation, the genius of his pupil, Robert Koch, built a noble structure and established the science of bacteriology.

Anthrax bacillus.-In 1876, Koch demonstrated clearly and convincingly that anthrax in cattle is due to a specific germ, and thus confirmed a fact already indicated by the observations of others. He isolated the anthrax bacillus in pure culture, studied it under the microscope, and showed that he could produce anthrax in other animals by inoculation from such cultures.

New methods of study. - Soon after this, Koch developed new methods for the study of bacteria, and for the preparation of pure cultures. By the employment of solid media, he demonstrated the comparative ease with which a number of different bacteria in the same 
liquid may be separated from one another. He inoculated liquefied portions of sterile gelatine with slight quantities of material containing the bacteria which he wished to study, distributed the latter uniformly by shaking the liquid gelatine, and spread it out on a plate where it was solidified by cooling.

The germs fixed in isolated spots in the sheet of solid gelatine could multiply only in those particular spots until their numbers became so great as to form a little heap or colony visible to the naked eye. These colonies, each the offspring of a single cell, could furnish only one species of bacteria. When transferred with a sterile platinum needle to some liquid suitable for their development, the organisms furnished a so-called pure culture, that is, a growth of only one kind of bacteria, uncontaminated by other organisms. When doubt still existed as to the purity of the culture, new plates were prepared from the purified material and the work repeated several times until, at last, the growth could safely be regarded as pure.

In the course of time, new culture media were devised for organisms that would not grow on gelatine,culture media that made possible the isolation of soil and water bacteria, bacteria of milk and of other food products, and bacteria causing disease in plants. The use of aniline dyes, proposed by Wygert and adopted by Koch, made possible a differentiation of the cell structure of the organisms, while the inoculation of mixtures containing disease bacteria into experimental animals, like rabbits or guinea pigs, offered a new means for the identification and purification of disease germs. 
Diseases like tuberculosis, diphtheria, typhoid, cholera, pleuro-pneumonia and leprosy were proved to be due to specific organisms isolated and studied in pure culture.

The rapid advance of bacteriology within the last quarter of a century has carried investigations beyond the isolation of pure cultures of various bacteria. Chemistry has become a strong ally of bacteriology, and has

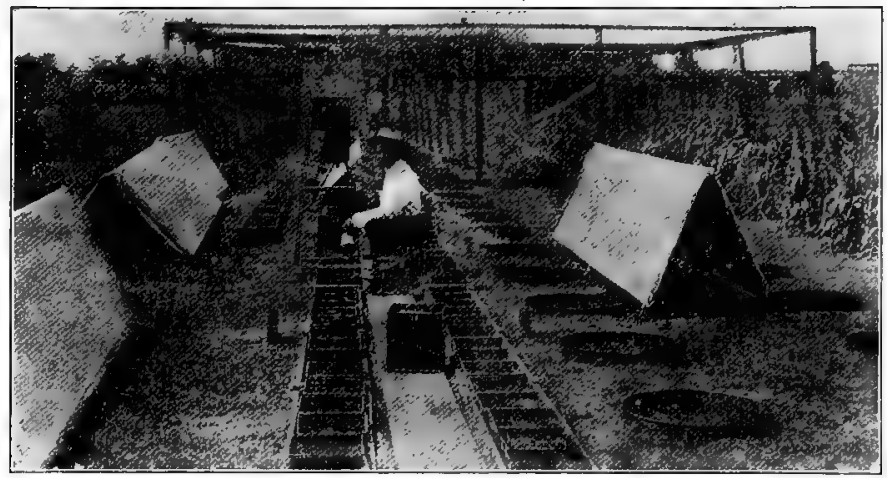

Fig. 1. Soil-bacteriological investigations at the New Jersey Experiment Station.

enabled the latter to recognize the chemical transformations effected by the microörganisms. Medical bacteriology saw a wonderful development in the study of toxins, the poisonous substances resulting from bacterial activities, and anti-toxins, capable of neutralizing these poisons. This, in turn, has been the starting point for far-reaching investigations concerning the invasion of the animal system by bacteria, and the protective machinery of the living body.

We have learned much concerning the powers of 
resistance possessed by animals, of natural and acquired immunity to disease, and of the methods whereby immunity may be secured. The mortality from some of the most dreaded diseases has been reduced to an astonishing degree, and, with the aid of sanitation, some of them have become almost unknown. The achievements of medical bacteriology, too vast to be reviewed here in detail, are only a promise of the still greater

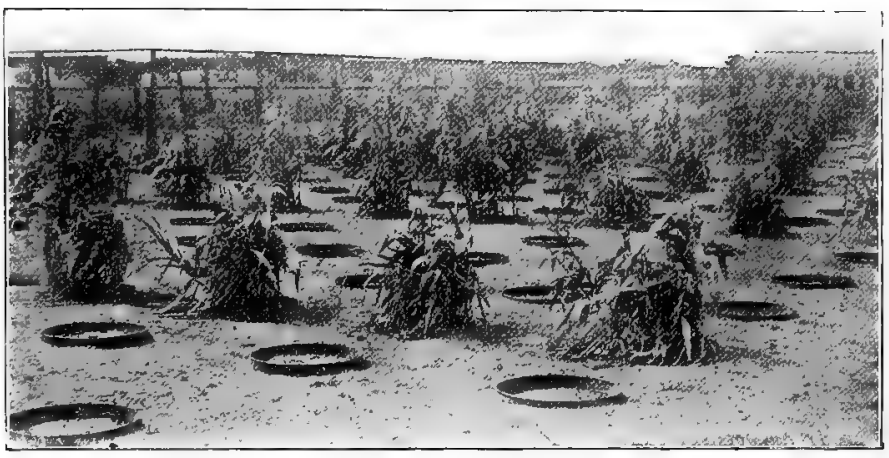

Fig. 2. Cylinders used for chemical and bacteriological investigations of soils. achievements to come, and a vindication of the views ret forth by the pioneers in the study, -Kohn, Pasteur, Lister and Koch.

Bacteriolog!! and agriculture.-In agriculture, the development of bacteriology has given us a new insight into the nature of soil fertility. We have learned to regard the soil as a culture medium with its almost endless number of species and varieties of bacteria, sperialized to do important work in the transformation of soil, nitrogen, carbon, hydrogen, sulfur; in the trans- 


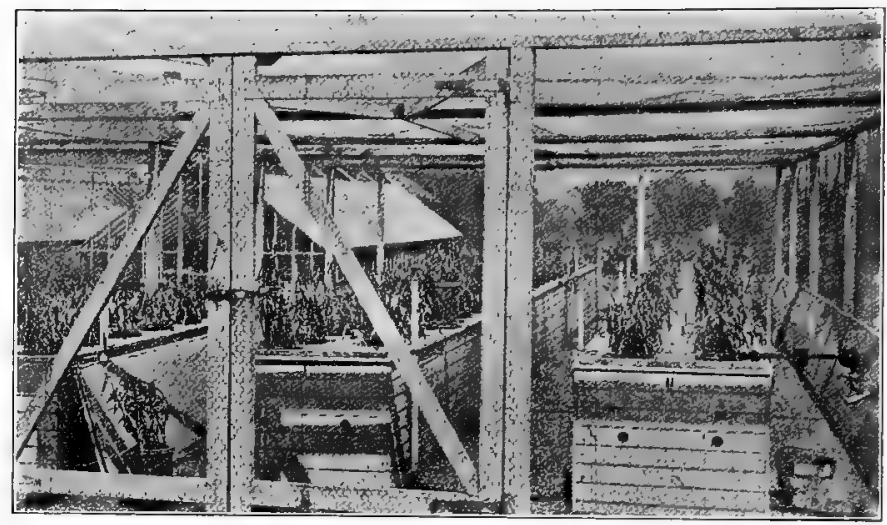

Fig. 3. Chemical and bacteriological investigations of New Jersey soils.

formation, also, of compounds containing lime, magnesia, phosphoric acid, and potash. We have learned to reckon with these organisms in our methods of soil-improvement, and have made some progress towards successful systems of soil-inoculation.

The bacteria concerned in industrial processes have received a not inconsiderable share of attention, and have fully repaid it. The canning industries, the brewing industries, the manufacture of wine, cider, and vinegar, the fermentation of tobacco, the retting of flax, the tanning of leather, the pickling of vegetable substances, and of fish, and, above all, the treatment of milk and its products, have been benefited by the study of bacterial friends and foes. We find, thus, that bacteriology, resting on the foundations laid in the latter half of the last century, touches human existence at many points and lights the way for new conquests. 


\section{CHAPTER II}

\section{THE FORM AND STRUCTURE OF BACTERIA}

The bacteria that may be observed under the microscope in a drop of stagnant water, or of decomposing beef-broth, may be grouped under three main types as regards form. They are, the spherical, the cylindrical, and the spiral forms. These types have been conveniently described as resembling billiard balls, lead pencils, and cork-screws. The organisms occur singly or in aggregations of two or more.
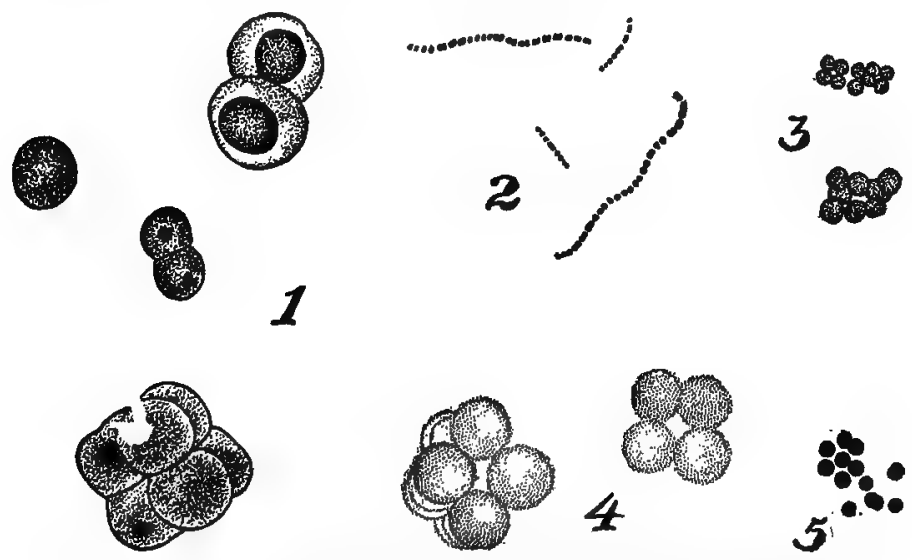

Fig. 4. Spherical bacteria,-1. Planosarcina urec; $\times 2,580$. (Beyerinck.) 2. Streptococcus, (Weigmann.) -3. Coccus lactis viscosi. (Gruber.) 4. Sarcina aurantiaca. (Pammel.) 5. Micrococcus Sornthalii; $\times 900$. (Adametz.) 
The spherical forms (Fig. 4) differ from the others in multiplying in two or even three planes; hence they may be observed, not only in chains of two or more, but in square or cubical packages, the latter appearing like
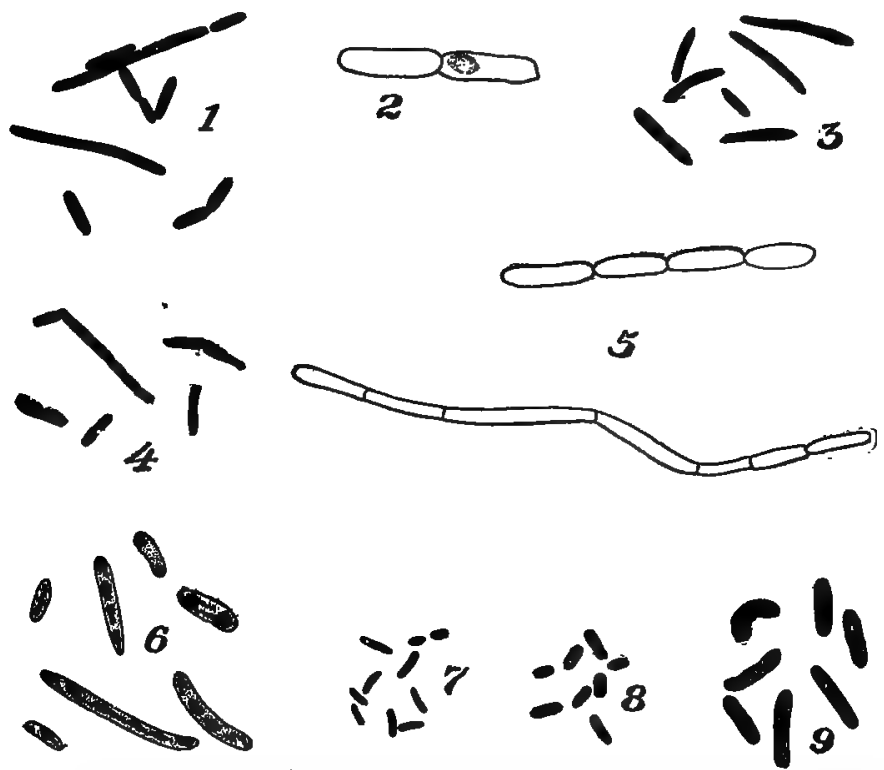

Fig. 5. Rod-shaped bacteria. - 1. Bacterium panis; $\times 1,000$. (Fuhrmann.) 2. Bacillus oxalaticus; $\times 1,300$. (Kuntze.) 3. Bacillus solanisaprus; $\times 1,500$ (Harrison.) 4. Bacillus casei; $\times 1,400$. (Freudenreich.) 5. Bacillus mycoides; $\times 1,000$. (Nadson.) 6. Pseudomonas trifolii; about $\times 1,500$. (Huss.) 7. Pseudomonas dermatogenes; $\times 1,000$. (Fuhrmann.) 8 Bacillus cerevisiae; $\times 1,000$. (Fuhrmann.) 9. Clostridium Pastorianum. (Winogradski.)

small bales composed of balls. It has been aptly said that bacteria may be considered immortal, since the same cell may go on multiplying indefinitely. After division, two organisms do not always separate, but 
sometimes remain attached to each other, giving rise, in time, to long chains of bacteria.

Rod-shaped and spiral-shaped organisms (Figs. 5, 6) increase only in one direction, and multiply by elongating and separating into two parts. The spherical species, on the other hand, are of the same diameter in length and breadth, and increase in numbers by dividing in either direction, lengthwise or crosswise, thus giving rise to square and cubical packets.

Irregular forms.- The three main types are not always well defined. The rod-shaped bacteria may become so short as to assume a spherical appearance. The spiral forms, also, may become shortened to such an extent as to disguise their true nature. Again, the rods may become thickened in the middle and seem to the eye like boat-shaped masses, designated as clostridia; or, they may become thickened at one end and assume the shape of drum-sticks or clubs. Under certain conditions, the organisms may become quite irregular in outline, giving rise to the so-called involution forms. A familiar example of irregular forms may be found in the growth of the organisms in the root nodules of legumes. The organism that penetrates the hair-root of the plant and gives rise to the formation of tubercles, is small and cylindrical in shape. Its offspring, on the other hand, are much larger and different in appearance, for they may not only look like irregular rods, but may also appear pear-shaped, club-shaped, or x- or y-shaped.

Shape.-Grouped as to shape, the spherical forms are designated as cocci; the rod forms as bacilli, or bacteria. 


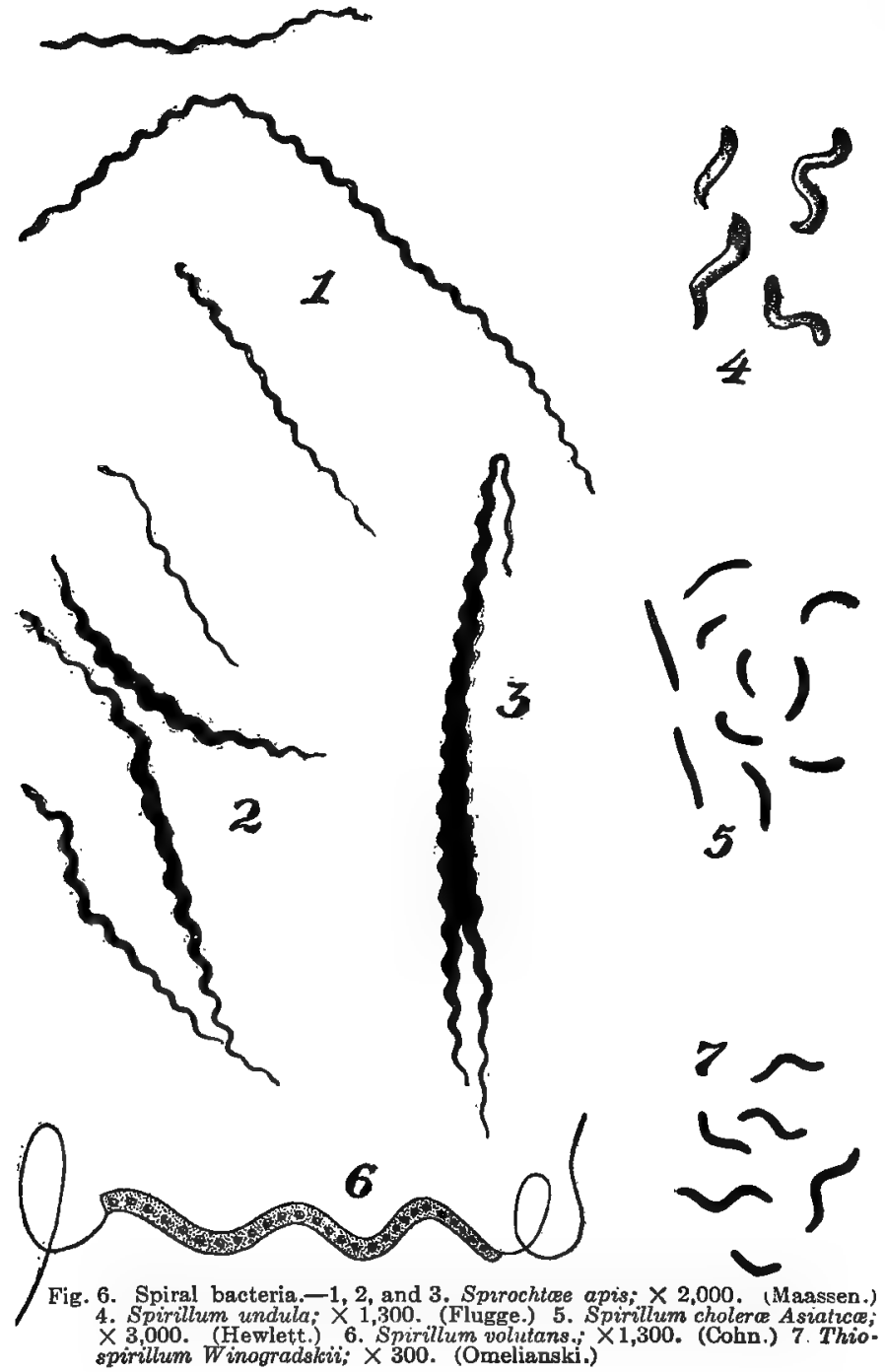


the spiral forms as spirilla. Besides these, there are also certain groups of bacteria that occur as chains, or aggregations of individuals, encased in sheaths, from which they may escape and go through the process of multiplication. These organisms are well represented by certain classes of the so-called ironbacteria.

Size.-There are great differences in the size of bacteria of the same species. Still greater differences in size, however, exist between those of different species. The spherical bacteria have an average diameter of about $\frac{1}{25000}$ of an inch, but those with a diameter of $\overline{\overline{5}_{0} \frac{1}{000}}$ of an inch are not uncommon. The rod-shaped bacteria and spirilla attain, in some instances, a much greater size,- - up to $\frac{1}{1000}$ of an inch in length-although such dimensions are very exceptional. The anthrax bacillus, a fairly large organism, is about $\overline{25} \frac{1}{0} \overline{0} \overline{0}$ of an inch wide, and $\frac{3}{25000}$ to $\frac{6}{25000}$ of an inch long.

There undoubtedly exist bacteria so small as to be practically invisible with the highest magnification. We know, at any rate, that some of them pass through unglazed porcelain filters whose pores are so small as to prevent the passage of ordinary bacteria.

Motility and organs of motion.-The bacterial body consists of a cell-wall surrounding the protoplasm. Protoplasm is the living substance of the organism. It may present a homogeneous appearance under the microscope, or it may be granular in structure. The cell-wall and the protoplasm within it are not of the same composition. Attached to the cell-wall are the bacterial organs of motion known as flagella (Fig. 7). 

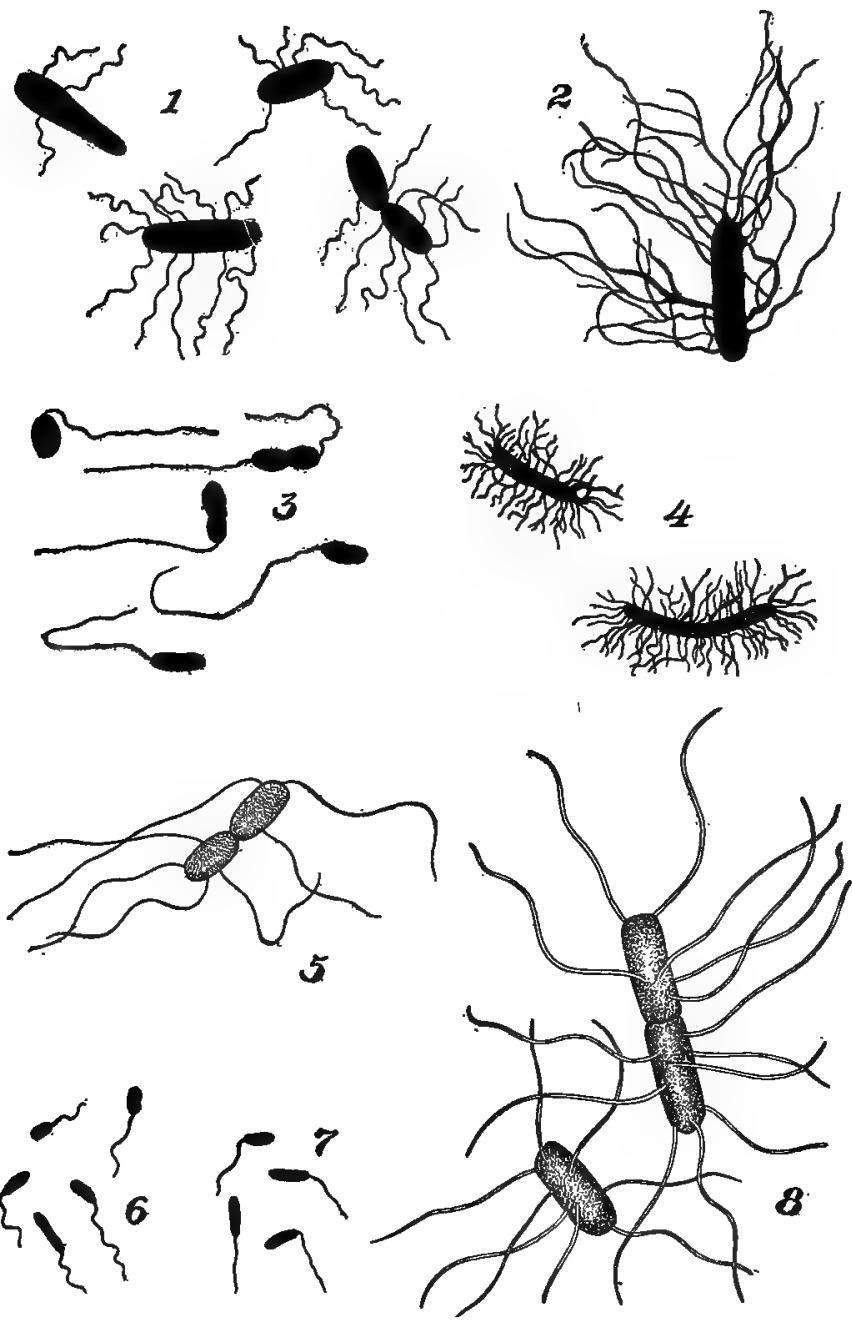

Fig. 7. Flagella.-1. Bacillus esterificans; about $\times 2,000$. (Huss,) 2. Bacillus alvei; about $\times 2,000$. (Masssen.) 3. Pseudomonas trifolii; about $\times 2,000$. (Huss.) 4. Bacillus Brandenburgiensis; $\times 1,300$. (Maassen.) 5. Bacillus robustus; $\times 2,800$. (Blau.) 6. Pseudomonas cerevisice; $\times 1,500$. (Euhrmainn.) 7. Pseudomonas dermatogenes: $\times 1.500$. (Fuhrmann) 8. Urobacillus miqueli; $\times 3,500$. (Beyerinck.) 
These may be short or long; at times they are much longer than the body of the organism.

Different species show very marked variations in the number of flagella and their arrangement on the body. There are a number of important organisms, among them the nodule bacteria of legumes, that possess only a single flagellum at one end. Such organisms are, therefore, designated as pseudomonas, while those with one flagellum at each end are classed as microspira. The spirilla frequently possess a bundle of flagella at each end, while the rod-shaped bacilli may have them attached at any place on the body.

The bacteria capable of moving about in a liquid are called motile; the others, non-motile. The latter include species which have, in some instances, been demonstrated to possess flagella. The form of the organism has, also, some relation to motility, for it has been found that among the spherical bacteria, motility is comparatively rare; whereas, among the rod-shaped species, this property is common to many.

Zoögloea.-In some instances, the cell-wall of the bacteria is surrounded by a zone of a gum-like substance, which may encourage the aggregation of cells into irregular, masses, callęd zoögloea. The formation of zoöglœa may occur in solid, as well as in liquid, media. Membrane formation on the surface of liquid media is characteristic of species that require the unhindered access of air for their development.

Rate of increase.-Bacteria multiply by splitting into halves. This process may be completed in onehalf hour; at times, even more rapidly. Under less 
favorable conditions it may be extended over a much longer period, determined by the food-supply and the character of the organisms. With division occurring every half-hour, a single individual could become, in one day, the ancestor of $280,000,000,000,000$ bacteria. Under actual conditions, multiplication never proceeds at such a rapid; uniform rate, for many of the cells die, and the food in the medium is exhausted.

Conditions that retard bacterial growth.-The multiplication of the organisms involves, not only a reduction in the food-supply, but, also, an accumulation of substances injurious to the bacteria. These injurious substances may be formed within the bodies of the bacteria and excreted into the surrounding medium, or they may develop outside of the bacterial bodies. In either case, the growth of the bacteria is retarded more and more as the quantity of these injurious materials is increased and finally comes to a standstill, even though all the food in the medium is not yet entirely consumed.

We find an analogy in the injurious effect on plants and animals of their own excretions, as, for instance, in the case of the uncomfortable feeling caused by the crowding of many people into a small room. Under such circumstances, the gaseous exhalations from the lungs and skin may become sufficiently great in amount to produce distress, and, in extreme cases, severe injury and death. A similar accumulation of excreta in their immediate environment reacts unfavorably on bacteria. Their life-processes become more sluggish, and not only is growth retarded, or entirely stopped, but many of the organisms perish and disintegrate. 

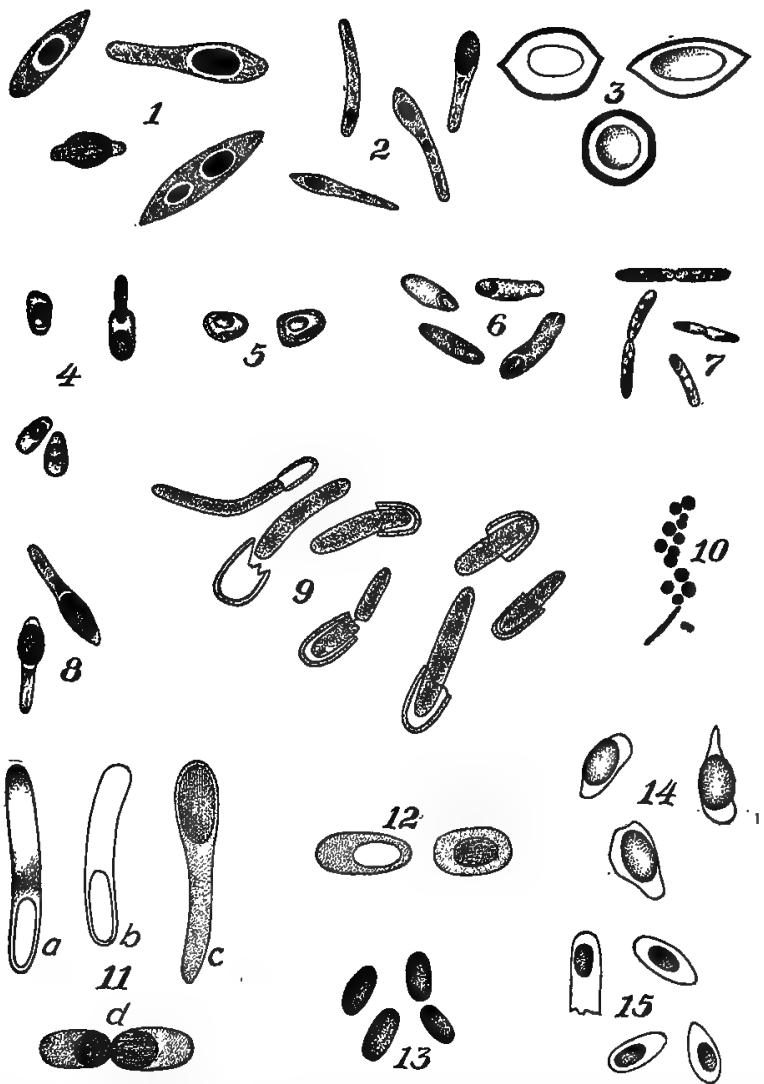

Fig. 8. Spores, spore formation, and spore lgermination.-1. Bacillus esırificans; about $\times 1,900$. (Huss.) 2. Bacillus esterificans; about $\times 1,800$. (Huss.) 3. Bacillus tumescens. (Meyer.) 4. Closiridium Pastorianum. (Winogradski.) 5. Clostridium Pastorianum, (Winogradski.) 6. Clostridium Pastorianum. (Winogradski.) 7. Bacillus oxalaticus; $\times 1,200$. (Kuntze.) 8. Bacillus esterificans; about $\times 1,800$. (Huss.) 9. Bacillus esterificans; about $\times 1,800$. (Huss.) 10. Bacillus methanicus; $\times 1,100$. (Omelianski). 11. ( $a, b$ and $c$ ) Bacillus cylindrious. (d) Bacillus robustus; $\times 2,800$. (Blau.) 12. Bacillus robushus; $\times 2,900$. (Blau.) 13. Bacillus esterificans; about $\times 1,500$. (Huss.) 14. Bacillus Ellenbachensis. (Kolkwitz.) 15. Bacilli from Armenian Matzoon. (Weigmann, Gruber, Huss.) 
Other unfavorable conditions, such as partial exhaustion of the food-supply, too great concentration of the culture solution, and abnormal temperatures, may contribute to check excessive multiplication.

Spores.-As a defense against adverse conditions, the bacteria have the power to produce cells known as spores (Fig. 8). These are much more resistant to destructive agents than are the ordinary cells. In forming spores, bacteria, at first homogeneous, gradually become granular. The granules thus formed coalesce into a single glistening mass, which surrounds itself with a cell-wall that is tough and not readily penetrated. The newly formed spore may remain in the empty cellwall of the parent organism, or may pass out into the surrounding medium. The number of such spores increases with the age of the culture.

Spores a means of preservation.--Spores may be called "bacterial eggs." They are, however, a means' of preservation rather than a means of multiplication. The entire organism is transformed into a single spore. Exceptions have been noted, in the case of one or two species, in which a single organism produces two sporesa fact that does not detract, however, from the truth of the general statement.

Spore formation.-Different species show variations in the method of spore formation. With some of them, the cells are transformed into boat-shaped or spindleshaped masses, containing the spore at one end or in the middle. With others, the cylindrical shape of the parent cell is retained on the spore located in the middle or at one end. With still others, there may be a thicken- 
ing at one end, giving rise to club-shaped or drum-sticklike cells, with the spores located at the extremity of the thickened part.

Vitality of spores.-The resistance of spores to adverse conditions is very great. They are not destroyed by drying, as are most of the ordinary bacterial cells, and may retain their vitality while in a dried state, for a long time. Well-authenticated instances are on record when bacterial spores germinated years after they had become dried out. When brought into liquids offering suitable conditions, the spores begin to swell, and, finally, burst open in one spot, giving rise to a new cell, which then elongates, and multiplies in the normal manner. Different species are not alike in their spore germination. Aside from their resistance to drying, bacterial spores can withstand other injurious conditions, such as high temperatures, and the action of destructive chemical agents. They are not destroyed by boiling, hence, complete sterilization cannot be effected simply by immersing the contaminated articles in boiling water.

Classes of bacteria.-Spore formation has been employed as a means of differentiation, and bacteria are, therefore, classified as spore-forming and non-sporeforming. A number of the well-known disease-producing, or pathogenic organisms, such as of typhoid, tuberculosis, diphtheria, and cholera, do not produce spores in artificial cultures. This cannot, however, be accepted as absolute proof that they produce no spores under any circumstances whatever.

Sterilization and pasteurization.-The formation or 
non-formation of spores is utilized in our methods of sterilization in the laboratory, the dairy, and the can-

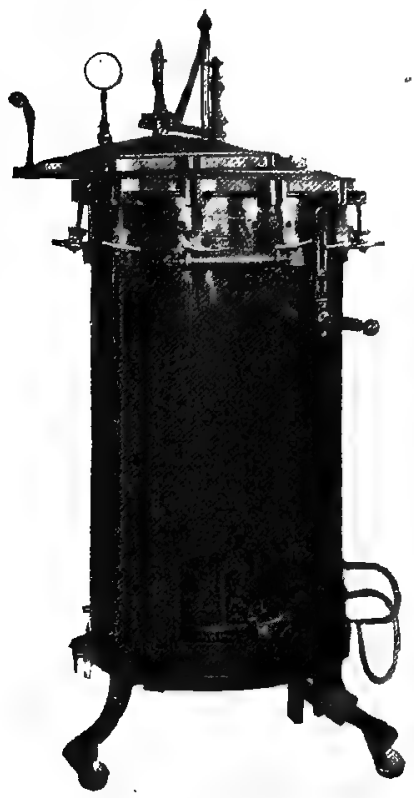

Fig. 9. Autoclave. ning industries. A distinction is drawn between pasteuriza- tion, in which the temperature is raised sufficiently high to kill all of the bacterial cells except the spores, and sterilization, in which the temperature is considerably higher,-enough to insure the destruction of all the bacterial cells. In the case of milk, pasteurization is adequate for the complete elimination of the disease germs enumerated above.

Intermittent sterilization. The method of intermittent. sterilization is employed in bacteriological laboratories. It consists in heating the material to be sterilized for one-half hour at a time on three successive days, at the temperature of boiling water. The first heating destroys all of the cells except the spores. The material is then allowed to cool, the spores germinate, and the new vegetative cells thus formed are destroyed by the second boiling on the following day. If any of the organisms escape the second heating, they are destroyed on the third day. Intermittent sterilization is not, however, always effective in practice. 
When possible, more certain methods are employed, among them sterilization by superheated steam at increased pressure (Fig. 9) or sterilization by dry heat (Fig. 10) at a greatly increased temperature.

Many incubators and other devices are now employed for the cultivation of bacteria, in order that they may be studied under proper conditions of temperature and control. Fig. 9 represents a sterilizing apparatus and not a culture oven.

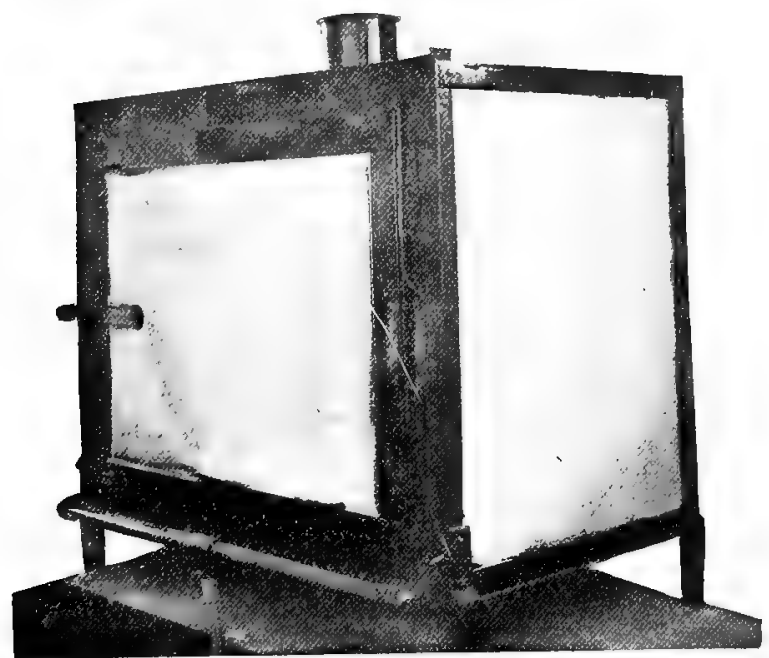

Fig. 10. Hot-air sterilizer, in which articles containing bacteria may be heated until all germs are destroyed. 


\section{CHAPTER III}

\section{THE CHEMISTRY OF THE BACTERIAL CELL}

There are certain chemical elements essential to the existence of bacteria. Being composed of protein, carbohydrates, fats and waxes, the bacteria must have the elements that enter into the building of these substances. Hence, carbon, nitrogen, hydrogen, oxygen and sulfur are indispensable for their development. Aside from these, they require, like the higher plants, lime, magnesia, phosphoric acid, potash and, perhaps, iron. The proportion of some of these constituents taken up by bacteria may be so slight as to preclude their recognition, even by the most refined chemical tests. Moreover, the proportions taken up are affected both by the species of bacteria and by the composition of the culture medium.

Certain classes of bacteria-among them the species found in drinking-water-can develop and multiply on quantities of nitrogen compounds so minute as to be altogether insufficient for hundreds of other species. Similarly, certain groups of soil bacteria are known to require much larger quantities of lime and phosphoric acid than are required by other groups. This fact is of great significance in the struggle for existence among the bacterial inhabitants of the soil. 
The cell-wall and its contents.-. It is not known exactly what substance or substances enter into the composition of the cell-wall. In some cases, cellulose seems to be the main con:tituent. In the majority of cases, however, cellulose does not seem to be present, but, rather, a

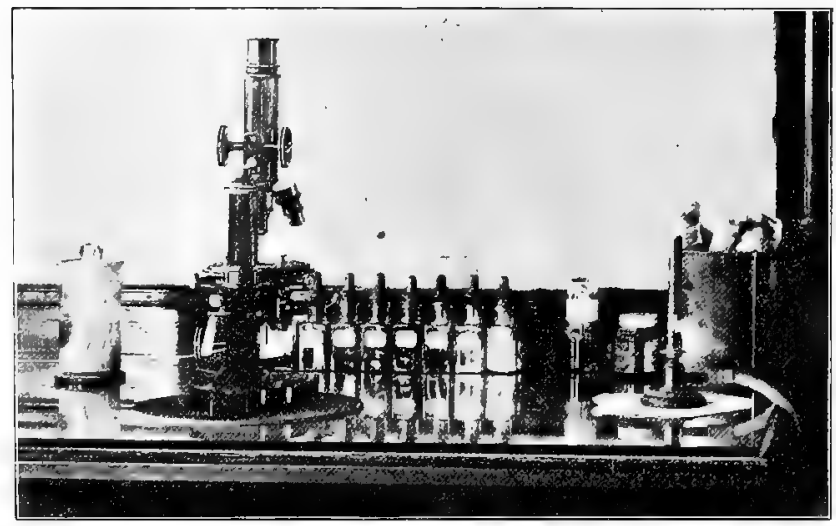

Fig. 11. Microscope and accessories for bacteriological work. '

horny, chitinous matter, the elements of which are as yet unknown.

Inclosed within the cell-wall is the protoplasm, a semi-fluid protein substance which is the seat of the chemical changes produced within the cell. The living force in the protoplasm provides for the building up and the tearing apart of chemical compounds, for the processes of assimilation and decomposition.

Content of the protoplasm.-The protoplasm of some species is characterized by its content, glycogen, a kind of sugar-found also in the human liver. Glycogen is 
present in a considerable number of species, among them the nodule bacteria of the legumes. It is apparently stored up by the organisms as a reserve foodmaterial. Another carbohydrate, designated as granulose, has been found to occur in a well-defined group of organisms.

Fats and wax-like substances may also constitute a more or less considerable portion of the bacterial cells.

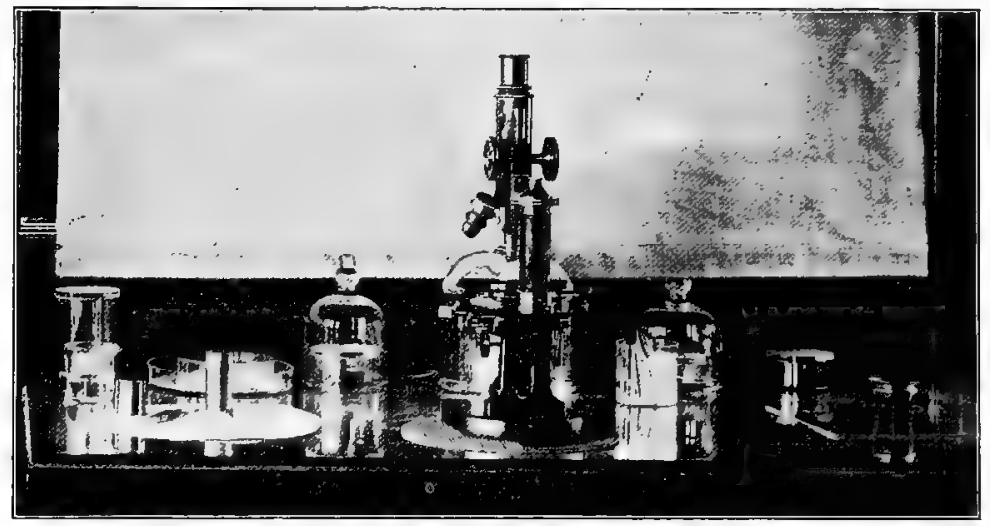

Fig. 12. Microscope and accessories for bacteriological work.

In the germ of tuberculosis, the cells have been found to contain 26.5 per cent of fat and wax in their dry substance. The nitrogen-fixing organisms of the azotobacter group frequently store up very considerable quantities of fat in their cells. Some species are observed to do this more than others.

The so-called sulfur bacteria, found in some sulfur springs and in the sea, deposit within their bodies little 
granules of sulfur which they later burn up for the sake of the energy that can be thus derived.

The protoplasm also contains various amounts of organic and inorganic salts in solution, derived from the surrounding medium, and compounds formed from these by the bacterial protoplasm.

The absorption of food.-The substances dissolved in the culture medium pass, without difficulty, through the cell-wall, and the latter is, therefore, said to be permeable to the dissolved substances. On the other hand, the protoplasm is penetrated to only a slight extent, and is, therefore, said to be impermeable. These physical properties are of vital significance, not only in the nutrition of the organisms, but also in their resistance to the entrance of injurious substances. 


\section{CHAPTER IV}

\section{THE FOOD REQUIREMENTS OF BACTERIA}

The tissues of higher plants contain a large proportion of carbon, as may be readily ascertained by charring the substances. Rye straw contains more than half of its weight of fiber, of which 40 per cent or more is carbon. It has been estimated that an acre of beech forest assimilates nearly a ton of carbon annually. All of this carbon is obtained from the invisible gas, carbon dioxid, which constitutes from .03 to .04 per cent of the total volume of dry air.

By means of the green coloring matter, chlorophyl, contained in their leaves, the higher plants decompose the carbon dioxid, and cause its carbon to enter into various combinations, such as starches, sugars, fats, gums and proteins. Lower plants, among them the microscopic algæ, are enabled by virtue of their chlorophyl, or of other coloring matters allied to chlorophyl, to decompose the carbon dioxid of the air, and to build out of the carbon various and numerous complicated organic substances.

The decomposition of the carbon dioxid, by means of chlorophyl, can be effected only in the presence of sunlight, for this furnishes the energy for the breaking up of the carbon dioxid molecules. In this way, simple 
mineral salts and water derived from the soil, and carbon derived from the air, are changed into the numerous and almost endless varieties of substances found in the vegetable kingdom.

The sources of carbon.-The bacteria classed among plants with very few exceptions produce no chlorophyl, and cannot, therefore, invoke the aid of sunlight for the decomposition of the carbon dioxid of the atmosphere. They must depend for their carbon on compounds other than carbon dioxid, and they find it in numerous combinations of vegetable and animal origin. We see, thus, that the great majority of bacteria differ from green plants in their inability to decompose the carbon dioxid of the atmosphere. There are, however, a few important exceptions to this rule.

The study of the nitrifying bacteria, the organisms which produce nitrates, has demonstrated that they are able to use carbon dioxid as their only source of carbon. Other organisms, recently discovered, can apparently utilize carbon monoxid (coal gas) in a similar manner, while still others may use methane, or marsh gas, for their growth. After making due allowance for these exceptions, we still find it to be true that bacteria differ from green plants in relation to their carbon food.

While sugar is undoubtedly an acceptable source of carbon for many species of bacteria, it is not the only source. Preference is frequently given to other carbon compounds. In fact, there are bacteria that are actually hindered in their development, or entirely suppressed, by the presence of sugar in the culture medium. For instance, the germ of cholera, and that of typhoid, are 
injured or suppressed by comparatively slight amounts of sugar, and the failure of putrefying organisms to develop in milk under ordinary conditions is ascribed directly or indirectly to the influence of the milk-sugar. The range of carbon compounds used by bacteria as a source of food is very large. Grape-sugar, cane-sugar, milk-sugar, malt-sugar, and mannite, a compound closely related to the sugars, are readily used by many organisms, as are also such compounds as starch, dextrin and cellulose, capable of being changed into sugar.

The compounds of carbon in bacteria.-The energy stored up in these substances is employed for the manufacture of the compounds found in the bacterial body. In other words, the bacteria burn up the sugars and allied materials in a manner analogous to the burning up of the food in the animal body.

- The carbon compounds enumerated consist of three chemical elements-carbon, hydrogen, and oxygen. There are, however, still other classes of carbon compounds seized upon with even greater avidity by important groups of bacteria. The compounds in question are the proteins-composed of carbon, nitrogen, hydrogen, oxygen, and sulfur, - and substances derived from the proteins and composed of carbon, nitrogen, hydrogen and oxygen. The numerous species of decay- and putrefaction-bacteria are especially favored in their development by protein compounds and grow rapidly in meat and meat extracts, egg-albumin, and other materials of animal or vegetable origin, rich in protein. For this reason, beef-broth, supplemented by mineral salts, is used almost universally in bacteriological labora- 
tories. Pathogenic bacteria, in particular, seem to require protein compounds as their source of carbon, and some species will not develop without it.

Generally speaking, therefore, different species of bacteria are not alike in their preference for one or another source of carbon. Some species will develop in solutions of cane-sugar fully as well as in solutions of grape-sugar, while others will grow in solutions of grape-sugar, but not in solutions of cane-sugar. Analogous relations may be observed in the case of other sugars. Again, there are species, like certain kinds of denitrifying bacteria, which will develop perfectly in culture solutions containing salts of citric acid as the only source of carbon, while other organisms will not grow in such solutions at all. Similarly, there are bacteria that will utilize pure cellulose, when the vast majority of microörganisms will utterly fail to develop. These examples will suffice to show that there are deepseated differences in the chemical machinery of the bacterial cells and in the methods by which the carbon compounds are transformed and assimilated.

The source of nitrogen.-Relations like those just described exist also in the assimilation of nitrogen food by bacteria. Just as in the case of field crops, some plants prefer ammonia and others nitrate, as a source of nitrogen, so anong bacteria, different species show analogous preferences. Certain species reject both ammonia and nitrate nitrogen, and demand for their growth some organic nitrogenous compound (preferably protein), or substances derived from protein and known as amino-compounds. The so-called nitrogen- 
fixing bacteria can readily utilize the nitrogen gas of the air, which is inaccessible to the other species.

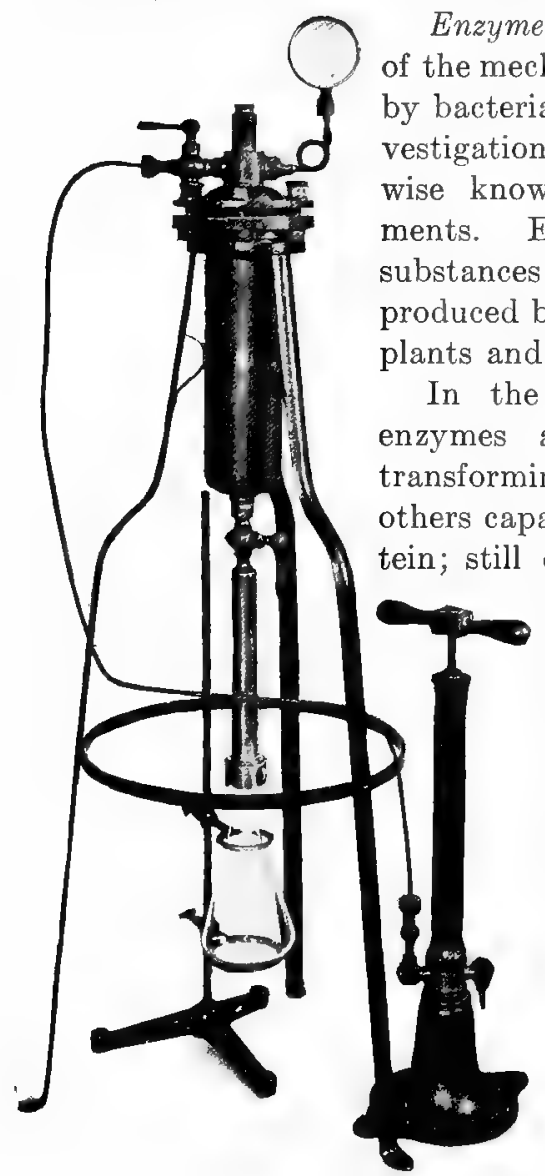

Fig. 13. Apparatus for filtering cultures. tegrating fats, and preparing them for assimilation. The enzymes in the saliva, stomach, liver, and pancreas, are secreted by the animal body for a specific purpose in aiding the digestion and assimilation of food. A familar instance of enzyme action is that of pepsin, the function of which is to change protein into simpler substances. 
Plants and bacteria also possess their enzymes. With the aid of these they are able to carry on their life-processes. The different enzymes produced by bacteria are numerous. Produced within the bacterial cell, they may pass outward through the cell-wall and attack the substances in the culture medium, which serve as food for the organisms. Thus, in the case of the cellulose ferments, the inert and insoluble fiber is changed into sugar by the enzyme. The sugar, being soluble, gradually passes into the protoplasm and is used by the latter for the building of other substances.

Pigments.-Intimately connected with the life processes of bacteria is the ability of some species to produce pigments. The coloring matters produced by different species include golden yellow, orange, red, blue, pink, violet, green, brown, and black substances. Blue or red milk, and even bluish or yellow pus in wounds may be produced by bacteria.

The production of coloring matter is affected by the food and the culture conditions. Temperature, likewise, plays an important rôle in this relation.

Phosphorescence.-The ability to produce phosphorescence is a property held by certain species of bacteria in common with some members of the animal kingdom. These bacteria, designated as photobacteria, are, so far as is known, all inhabitants of the sea. The phosphorescence of sea-water, a phenomenon much commented upon, is due largely, though not entirely, to bacteria. It is these organisms, also, that produce phosphorescence in decaying fish and meat. 


\section{CHAPTER V}

CONDITIONS AFFECTING THE GROWTH OF BACTERIA

THE conditions that favorably or unfavorably-affect the growth of bacteria, include temperature, moisture, aerration, light, pressure, and the presence or absence of injurious substances. The first of these (temperature) is an important influence, since the living protoplasm can perform its functions only within a comparatively narrow range of heat and cold. Just as a few degrees of temperature may hasten or retard the germination of seeds, or the development of fruit-buds, so a similar variation in temperature may increase or diminish the intensity of bacterial development. There are well-defined limits below or above which no bacterial growth whatsoever will occur, yet within these limits there are considerable variations among the different species. Important differences as to suitable growing temperatures occur between the soil and water bacteria, on the one hand, and most of the disease bacteria in warm-blooded animals, on the other.

Thermophile bacteria.-There is a third class of bacteria, known as thermophile that are remarkable for the high-temperature limits within which they will grow. Thermophile bacteria have been isolated from the soil and manure heaps, with the result that it has 
been learned that, under the direct rays of the sun, the temperature in such places may reach, for short periods at least, the optimum or best for these bacteria. All of the thermophile bacteria form spores. They can, therefore, resist unfavorable conditions for their development by remaining dormant for more or less considerable periods.

Effect of cold.-Temperatures below the minimum suspend the bacterial activities, but are not very effective in destroying the organisms. Disease bacteria, frozen in ice, are as active as ever after the temperature is raised. It has been demonstrated experimentally that extremely low temperatures injure the bacteria only after prolonged exposure. Even immersion in liquid air does not always succeed in destroying them.

Temperatures beyond the maximum lead, on the contrary, to a rapid destruction of the organisms. The non-spore-forming bacteria perish when subjected to a temperature of $130^{\circ}$ to $140^{\circ} \mathrm{Fahr}$., for ten minutes, and in less time when subjected to still higher temperatures. Spore-forming bacteria are much more resistant to heat because of the inert character of their spores. They will withstand dry heat well above $250^{\circ} \mathrm{Fahr}$., and, while not as resistant to moist heat, will sometimes withstand boiling for an hour or more.

Attenuated cultures.-When bacteria, or their spores, are subjected to heat insufficient to destroy them entirely, yet considerably above their maximum, they may become weakened to a very marked degree. The injury to the organisms may appear then in their less vigorous growth, or in their impaired power to produce 
characteristic chemical substances, such as pigments, enzymes, and toxins. Heating within certain limits may, therefore, serve as a means for the production of so-called attenuated or weakened cultures. These may also be produced by other methods, particularly by the limited action on the organisms of germicides, as corrosive sublimate, carbolic acid, and chloroform.

Moisture content of the culture medium.-Bacteria growing in solid substances will discontinue their growth when the proportion of moisture in the medium reaches a certain minimum. Studies on the decay of humus in the soil have shown that the decomposition processes are practically at a standstill with 2 to 3 per cent of moisture; that with 4 to 5 per cent they are more active; and that they finally reach a maximum beyond 25 to 30 per cent of moisture. In vegetable and animal substances, the minimum amount of moisture required for the development of bacteria is much higher, scarcely any growth occurring when the moisture content is less than 25 per cent.

Relation to oxygen.--Bacteria show widely different relations in their behavior towards the oxygen of the air. Some species will not develop at all when air is excluded or its supply limited beyond a certain point. These organisms are designated as aërobes. Many of the most common soil and water bacteria are strict aërobes, or obligate aërobes (to use a term in vogue among bacteriologists), and they include decay bacteria, nitrifying bacteria, and nitrogen-fixing bacteria.

There are, on the contrary, numerous other species that require the entire exclusion of air for their proper 


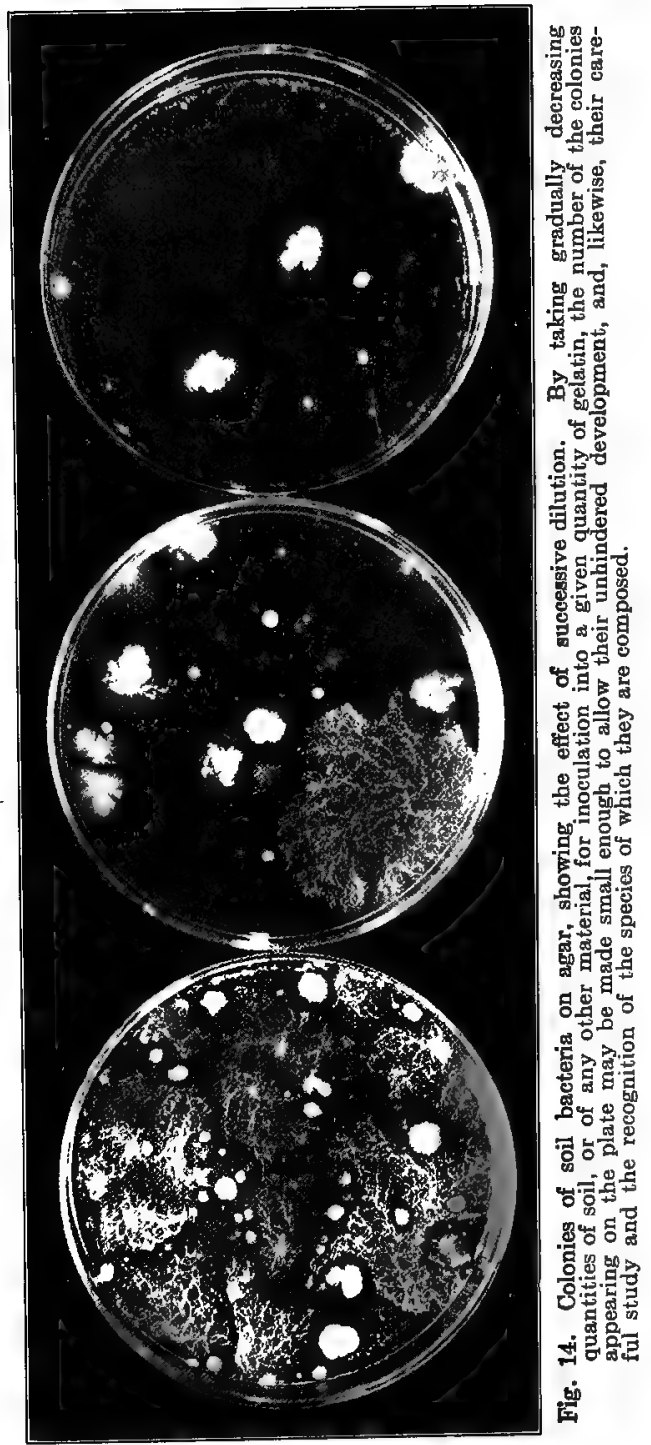


development. They are designated as anaërobes, or obligate anaërobes. The obligate anaërobes in the soil include, among others, the cellulose ferments, the nitrogen-fixing butyric ferments, and the lock-jaw bacillus.

Organisms that will develop preferably with an unhindered access of air, but also will grow when it is excluded, are designated as facultative anaërobes. In other words, they are both aërobes and facultative anaërobes. A number of denitrifying bacteria are prominent members of this class. It has been shown that they will not destroy the nitrate when freely supplied with oxygen, but that they will derive the latter from the nitrate when atmospheric oxygen is excluded.

Still other organisms are designated as facultative aërobes, that is, they will grow, preferably, when oxygen is excluded, but will exist also when it is present.

Aërobes and anaërobes are found together in water, soil, and elsewhere in nature, and there is no doubt that the first of these facilitate the development of the others by using up the oxygen in the medium. Such relations evidently exist between aërobic and anaërobic water and soil bacteria and account for the abundant presence of anaërobic nitrogen-fixing bacteria even in open and well-ventilated soils.

Action of sunlight.-Direct sunshine exerts a more or less destructive action on living cells. The destructive action of direct sunlight is readily observable also in the case of bacteria, sunshine being regarded as one - of the most potent forces in nature in the destruction of pathogenic and non-pathogenic germs. A liquid or solid culture of bacteria exposed in thin layers to 
the direct action of the sun's rays may become sterile within a few hours. Hence, in the bacteriological laboratory, the cultures are kept either, in the dark, or in subdued and diffused light.

In the soil and in sheets of water, also, strong sunlight exerts some destructive action. Soil exposed in thin layers loses some of its nitrifying power, and very shallow sheets of water in tropical countries become poor in bacteria probably on account of the prolonged exposure to intense sunlight. Direct sunlight affects only the very uppermost layers of soil and water, and its germicidul effect is not, under such conditions, as great as might be expected.

Electric light.-Very strong electric light has been observed to possess germicidal properties. 'It is asserted, for instance, that cultures of Bacterium prodigiosum, exposed to the ultra-violet rays of the arc light, were found to be sterile at the end of twelve minutes.

Influence of electric currents.-Experiments on the influence of electric currents on the activities of bacteria have not revealed any marked injury to the organisms. Experiments with both induction and galvanic currents in the soil showed no injury either to the decay or nitrifying bacteria. Similar results were obtained with some of the pathogenic organisms. Weak electric currents in solutions cause motile bacteria to gather about the negative pole. When the current is reversed, and the positive pole made negative, the organisms change their position and flock toward the new negative pole.

Pressure.-A more or less injurious action on bacteria 
is exarted by high pressure. It has been found that a gradually insreasing pressure up to 2,904 atmospheres fails to destroy many of the bacterial species. When, however, the pressure is raised and lowered successively a number of times, the bacteria are considerably weakened, as shown by less active motility, an impairment or loss of the ability to multiply, and impairment or loss of ability to produce typical reactions. Some of the species prove to be more susceptible than others.

Influence of the concentration of the culture medium.Large amounts of soluble salts in the culture solution lead to the injury or destruction of the bacteria. Many substances, when present in small proportion, may serve as food to bacteria, or may be harmless to them, while in greater concentration they may act as poisons. Apart from such substances as alcohol, carbolic acid, or salicylic acid, which are recognized as germicides, there are many neutral salts that are commonly used as nutrients in the preparation of culture media, and yet they are poisonous to the bacteria when present in greater concentration.

Common salt and saltpeter (potassium nitrate), both being used as preservatives in the pickling of meats and of other organic materials, may serve as examples of such substances. Because of greater resistance to the injurious action of salt, some species are enabled to develop in herring brine and similar substances, investigations having demonstrated the presence of a rich bacterial flora in such brines containing as much as 20 per cent of salt.

Among other substances used for the preservation of 
food products is sugar. As is well known, this is employed in the manufacture of condensed milk, as well as in the making of preserves. It seems that the concentration of the material to which large amounts of sugar are added precludes the development of the bacteria.

Still another instance of the depressing effect of excessive concentration may be found in the relation of the nitrifying bacteria to large amounts of soluble organic matter. The development of these bacteria may be entirely suspended by quantities of soluble organic matter not in the least injurious to other bacteria. Thus the growth of nitrifying bacteria in manure heaps does not begin until the litter and animal excreta have been largely decomposed by the great hosts of decay bacteria and until the soluble organic materials have been changed into insoluble modifications.

The reaction of the culture medium.-The reaction of the culture medium, that is, the amount of free acid or base present in it, is of the utmost importance for bacterial growth. The same condition, or acidity, of a culture medium may be remedied by the addition of a base, that is, of a substance which has properties opposite to those of an acid. Lime, soda, or potash may be given as examples of bases. All of these may be employed for the neutralization of acidity.

A culture medium which is neither acid nor basic (alkaline) is said to be neutral, and is best adapted to the growth of many species. There are numerous organisms that prefer a faintly acid medium, among them some of the common inhabitants of milk. There are others that prefer a slightly alkaline medium. In 
a few instances, bacteria will develop vigorously in distinctly acid media. This is particularly true of the acetic-acid bacteria. On the whole, however, acid media are not acceptable to the bacteria, and, in the struggle for existence, they are replaced in such media by molds better adapted for growth in acid substances.

Importance of reaction of the soil.-The reaction of the soil is of vital importance in crop production, because it determines what species shall predominate. It determines, also, the rate of decomposition of the soil-humus and the rate of nitrification, or, in other words, it determines the rate at which available nitrogen is supplied to the crop.

The application of lime frequently stimulates plant growth because of the correction of acid conditions, and the favorable influence on decay and nitrifying bacteria. A similar favorable effect may be produced by liming on other desirable bacteria, among them the nodule organisms of clover and other legumes. It should not be supposed that excessive alkalinity is harmless. A large number of experiments have been recorded which show that excessive applications of caustic lime injures the decay and nitrifying bacteria in the soil. This conclusion is further reinforced by the fact that carbonate of lime, which is not so caustic as the burned lime, has been found to be less injurious to the soil bacteria. 


\section{PART II \\ Bacteria in Air and Water}

\section{CHAPTER VI}

\section{BACTERIA IN THE' ATMOSPHERE}

The air that surrounds our earth is never at a standstill. It is kept in motion by its waves and storms, and is affected by season, climate, and proximity to human habitation. Mingled with the gases and vapor of which it is composed, there is a quantity, at times very great, of dust particles, derived from the soil, the water, and the streets of cities. These dust particles of varying degree of fineness are borne hither and thither by the changing winds, and, as they pass from place to place, carry with them their minute bacterial passengers.

The richness of the air in dust particles is easily perceived as we watch the rays of the sun pass into a dark room through a hole in the window curtain. The light reflected from the countless number of these particles shows them to be suspended and restless. The wind, as it sweeps over the bare fields and roadsides, raises clouds of dust, particles of soil and of vegetable and animal materials, and carries them away on a more or less distant journey. The fine spray from the ocean, as it dashes against the shore, and the spray from river and lake, 
raised by the churning action of innumerable vessels; the busy life of the city, with its hurrying feet, its rattling wheels, and its never-resting chimneys, all show that there is ample cause for the existence of the many dust particles in the air.

Bacteria on dust particles.-The bacteria of the soil, water and city streets, are carried along with the dust. A single particle of dust, or the few salt crystals from a drop of water, may carry one or more bacteria. This may be easily demonstrated by exposing sterile plates of gelatin to the air for brief periods of time. The bacteria on the dust particles, as they fall on the nutrient gelatin, begin to grow and form colonies. It frequently happens that a single spot may show a mixed growth of two or even three species, an indication that there were, at least, that number of bacteria on a single dust particle.

The dust-laden air currents may, therefore, become the means for conveying bacteria from place to place, sometimes over great distances. Various disease germs including those of typhoid, pneumonia, and tuberculosis, may thus be carried away and become a source of infection. Similarly, the nodule bacteria of legumes may be transported from field to field in the soil-dust, may affect soil-inoculation, and may thus lead gradually to the establishment of new legume species in places where they were previously unknown. This may, in part, help to explain the appearance of some of the nodules in newly established alfalfa fields. This assumption seems to be supported by the fact that in pot-cultures with legumes (particularly peas) nodules frequently 
appear on the young plants notwithstanding the most thorough sterilization of the seed and soil.

Number of bacteria in the air.-The number of bacteria in the atmosphere, while constantly augmented from the various sources enumerated, does not become very large in the open air. This circumstance is readily accounted for by the inroads made upon the bacteria by sunshine and drying. Already dry when raised from the fields and the streets, the bacteria suffer further from the direct light of the sun and succumb to it sooner or later, unless they exist in the spore state.

Pasteur's method of determination.-Pasteur's early investigations concerning the bacterial content of air demonstrated that the number of organisms in the atmosphere is not very large and that it is influenced by season, climate, altitude and human activities. Pasteur prepared large flasks partly filled with culture solution, drew the neck out to a fine tube, and boiled the contents until all of the air was expelled by the steam. The neck of the flask was then sealed with the aid of a blast lamp, and, on cooling the flask, a partial vacuum was created in it by the condensation of the steam. Such sealed flasks could be taken to any place the atmosphere of which it was desired to examine. On breaking off the neck of the flask, the latter was at once filled with air. The neck was then sealed again. The bacteria, yeasts, and molds present in the air drawn into the flask, soon settled into the liquid and developed there, giving rise to the characteristic turbidity. When the contents of the flask remained clear, the conclusion was inevitable that there were either no microörganisms in that par- 
ticular sample of air, or, at least, none that would grow under those special conditions.

Value of Pasteur's method.-This method of Pasteur merely showed whether there were any microörganisms at all in a given volume of air. It did not show how many there were in it, since the resulting growth could have been due to one or to several organisms. Other methods

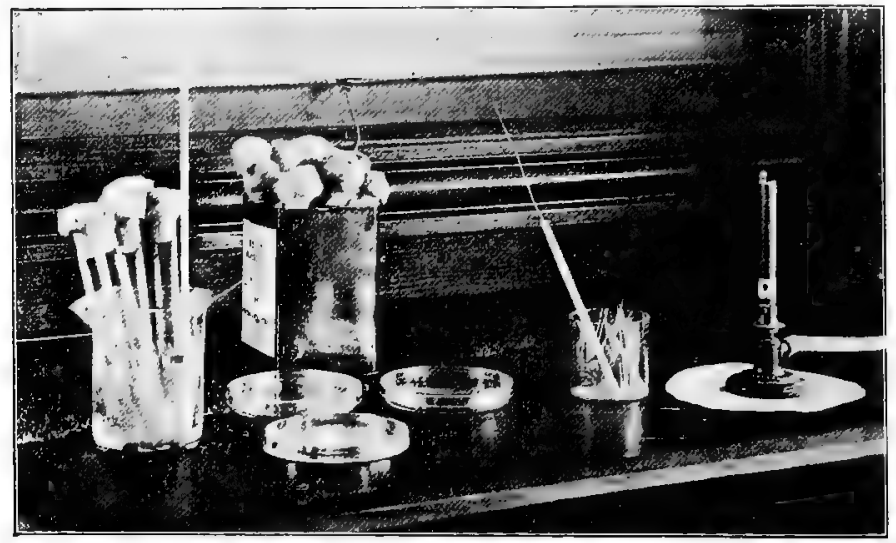

Fig. 15. Liquefied agar ready for inoculation and pouring into sterile Petri dishes.

have been employed, therefore, to show, not only the mere presence, but, also, the number and kind of bacteria in a given quantity of air.

Quantitative methods.-The methods employed for this purpose consist in passing measured quantities of the air to be examined through vessels or tubes, whose walls are lined with nutrient gelatin, or through small quantities of solid materials, or of liquid. In the former case, the microörganisms of the air gradually fall on 
the nutrient gelatin and, developing there, produce colonies whose number can be counted, and the character of whose organisms can be further investigated. In the second method, the liquid is mixed with nutrient gelatin, the latter spread out on sterile plates of gelatin, and the colonies that gradually appear are counted and studied in a similar manner. Investigations of this nature, with the overwhelming evidence they bring as to the occurrence and the distribution of bacteria, and of other microörganisms in the atmosphere, soon swept away the last vestige of belief in the theory of spontaneous generation.

\section{INFLUENCE OF LOCALITY}

It was observed by Pasteur that the proportion of flasks that showed growth was variable and strongly influenced by the locality whence the air was taken. The air from the city contained more germs than the air from the country, while the air from mountains was poor in bacteria.

Bacteria in city air.-The more exact and extensive researches of Miquel have confirmed the observations made by Pasteur. Miquel found in several examinations an average of 3,480 bacteria per cubic meter in the air of the Paris streets, an average of 7,420 in the laboratory air, an average of 36,000 in the air of old houses, and an average of 79,000 in the air of one of the Paris hospitals. These figures are important in showing how human activities lead to an increase of the bacteria in the air. The number of germs in human habitations is undoubt- 
edly affected not only by conditions more favorable for their development, but, also, by the degree of ventilation. Buildings whose air is renewed more frequently, and whose windows allow a free access of sunshine, contain fewer germs than similar buildings that are less favorably situated.

The dust of the city streets is very rich in bacteria. It is natural to expect, therefore, that the air overlying the streets will also be well stocked with them. An examination of the air over the London streets showed it to contain approximately from 300,000 to 500,000 dust particles per cubic centimeter, while the corresponding determination of the bacteria showed that there was only one germ to every $38,300,000$ dust particles. As stated by Fischer, an examination of the street dust in the city of Freiburg showed it to contain from 5 to 17 different species of bacteria included in from 24,000 to $2,000,000$ germs per gram.

This examination brought out the interesting fact that the sprinkling of streets increases to a very marked extent the number of bacteria in the dust. The sprinkled streets contained a minimum of $1,450,000$ germs, and a maximum of 2,896,000 per gram of dust, while the unsprinkled streets contained a minimum of 24,000 and a maximum of 48,000 germs. There is a difference, not only in the number of germs in the sprinkled and unsprinkled dust, but, also, in their resistance to the destructive effect of drying. The less resistant forms perished in the unsprinkled dust in four days, while, in the sprinkled dust, they survived for fourteen days. Fischer observes, with much justice, that the sprinkling 
of streets, even though it increases the number of germs in the road dust, is none the less valuable from the hygienic standpoint. He evidently refers to the reduction in the amount of dust in the air caused by sprinkling, whereby the number of pathogenic germs carried by the wind is very materially lessened. The great value of sprinkling is that it keeps the germs in the road dust from being blown about by the wind.

Bacteria in the air of the country.-Comparing the number of bacteria in the air of the city and country, we find, according to the examinations of Miquel, very considerable differences. The average for his analyses showed 300 bacteria per cubic meter of air taken outside of the city of Paris, and 5,445 bacteria per cubic meter of air taken within the city. Similar results were secured elsewhere, thus confirming the conclusions reached by Iiquel. In the country, the number of bacteria in the air is affected, among other things, by the presence or absence of large forests. It has been demonstrated that the latter may act as filters and hold back a portion of the bacteria brought to them by the wind. This seems to account for the fact that the air within forests is poorer in bacteria than the air on their outskirts.

Like the air of the forests, the air over the sea is also poor in bacteria. The greatest number of bacteria was found in sea-air taken in the vicinity of land. With the increasing distance from the coast, the number of bacteria diminished until there was less than one germ per cubic meter of air. Even poorer in germs than sea-air was that from the polar regions, where but few could be detected by repeated examinations. 


\section{INFLUENCE OF SEASON, CLIMATE, AND ALTITUDE}

The investigations of Miquel, extending over a period of years, show conclusively that seasonal influences are an important factor in the increase or decrease of bacteria in the air. There is an evident increase from winter to spring and from spring to summer, and a decrease from summer to autumn. Yet, while the temperature and other seasonal influences can be easily traced in these averages, there are temporary disturbances that threaten to obscure the general results. For instance, the number of bacteria diminishes after a rain, and increases rapidly as the soil begins to dry at the surface. When, however, the drying period continues for ten or fifteen days, the number of bacteria decreases again.

The causes for these variations are not far to seek. The number of bacteria in the air decreases in periods of rainfall because of their being carried down by the rain. Similarly, in periods of dry weather, the wind carries away some of the finer particles of the surface soil; among them, the bacteria that have multiplied rapidly under favorable moisture conditions. Prolonged drying, on the contrary, and the accompanying germicidal action of direct sunlight, involves the partial destruction of the bacteria floating in the air, as well as of those in the dust mulch at the very surface of the soil; and for these reasons the dust-laden atmosphere of droughts may not be rich in germs.

The seasonable influences are also noticeable in the atmosphere of densely populated districts, although the number of organisms found here is much greater than 
that found in the open air. The same increase from winter to summer, and decrease from summer to autumn are present, - an evidence that the relative influence of heat, moisture and sunshine is the same in the city as it is in the country.

In human dwellings, also, the bacteria in the air are readily affected by seasonal changes. In this instance, however, the differences do not run parallel to those obtained in relation to the open air. Examinations of the air in Paris hospitals demonstrated that there was a steady decrease in the number of bacteria from March to August, and a steady increase from August to November. These apparent discrepancies find a ready explanation in the fact that the open windows during the warm months allowed a more thorough ventilation of the hospital rooms, and, therefore, a more rapid removal of the organisms suspended in the air. An important point in this connection is the large number of bacteria found in the air of hospitals. It is safe to assume that a considerable portion of the organisms suspended there were pathogenic, and that they were a source of infection to the patients and attendants.

The influence of climate. - It is a self-evident truth that the number of bacteria in the atmosphere of any region bears a direct relation to the climate of that region. In warm tropical countries with an abundance of rainfall, the multiplication of bacteria in the soil, water, and all vegetable and animal matter proceeds with great rapidity. Under such conditions, the particles of dust raised from the earth's surface carry an abundant number of bacteria and enrich the atmosphere to a very 
marked extent. On the other hand, the frequent and copious rainfall tends to remove the bacteria from the air, while the direct tropical sunshine largely contributes to their destruction.

There are, thus, two distinct and opposite tendencies, one favoring the accumulation of bacteria in the atmosphere, the other hastening their destruction. In dry, tropical countries, the number of bacteria in the air must, of necessity, be limited, a fact also true of dry, cold countries. In countries with temperate or cold climates, the number of bacteria present in the air in the winter is small, because of the retarded or suspended development of the organisms. This is true, also, because of the covering of ice and snow which prevents the removal of the bacteria from the soil and the surface of lakes and streams into the atmosphere.

The influence of altitude.-The air over mountain peaks contains scarcely any bacteria at all. Their number diminishes as the distance from the level of the sea is increased. Evidently, the lower temperature prevailing in the mountains retards bacterial development, even when conditions are otherwise favorable. Moreover, bare rock is an unsatisfactory place for bacterial development. Again, the distance from the floor of the valleys is frequently too great to allow the transportation of any large number of their bacteria to the air of the higher peaks.

Bacteria and respiration.-The number of bacteria in the air over the ocean, over high mountains, in polar regions, or in countries of scant rainfall, is relatively very small. Conditions there prevent both the additio: 
of large numbers to the atmosphere, as well as the survival of the bacteria already there. On the contrary, the air of city streets and of human dwellings is particularly rich in microörganisms owing to conditions favoring both the addition of large numbers to the atmosphere and their survival there.

These facts are of very considerable moment from the standpoint of hygiene and sanitation. We know that, notwithstanding the large number of bacteria in the atmosphere, the air expired from the human lungs is practically germ-free. This means that the microörganisms are retained in the nose, mouth, and throat, and that many of them are carried with the dust particles into the lungs. Enormous numbers of bacteria are thus retained, and it is obvious that, everything being equal, the danger from infection is greatest when the number of bacteria in the air is greatest. Persons leading an indoor existence, and those living in large cities, inhale more bacteria and are more exposed to infection than people living in the country.

It does not follow, at the same time, that the danger of contracting a disease, say tuberculosis, is greater in the summer than it is in the winter, simply because there are more germs abroad. After all, most of the bacteria in the air are harmless, and it is very likely that the actual number of the germs of tuberculosis and pneumonia in the winter air is greater than that in the summer air. 


\section{CHAPTER VII}

THE RELATION OF WATER TO HEALTH AND DISEASE

THE human body contains nearly 60 per cent of water. Some of the individual organs, as the kidneys, heart, liver and pancreas, contain a much larger proportion, and all are dependent on a sufficient supply of it for the proper performance of their functions.

The human race in its very infancy sought out the springs and streams that yielded a generous supply of cool, refreshing water; it made its home within reach of them; it followed the water-courses to the sea, loath to lose sight of them; and, as it grew in wisdom, it learned to find in them food as well as drink. Long before the dawn of written history, men knew of the life-giving qualities of water, and of its often deadly effects. Experience taught them to preserve it against periods of scanty rainfall, to guard it against pollution, to measure it out with a careful hand to the thirsting crops.

Ancient water-supplies.-In selecting their source of drinking-water, the ancient builders of reservoirs and aqueducts were guided by considerations of quality and salubrity. It was known to them and to others before them that there is some relation between drinking-water and health and disease. Certain springs were peculiarly noted for their reputed curative proper- 
ties, while other waters were known to be poisonous to man and beast. These observations were, however, for the most part, purely local in character, and could not, in the nature of things, lead to broad views on the general relation of water to health. No general conception could arise then as to the significance of color, hardness, taste, and turbidity, nor as to the more deepseated distinctions revealed to us by modern research.

Individuals, as Hippocrates, who lived four hundred years before the beginning of our era, pointed out the dangers of pollution, and even advised boiling and filtering contaminated drinking-water; yet such views met with no general acceptance. In the centuries following, if any relation was observed between the character of the drinking-water and the great epidemics of cholera. and typhoid, which broke out in Europe from time to time, the popular views and the methods of sanitation, such as they were, were not sensibly affected thereby. In the early centuries of the present era, and through the period of the Dark and the Middle Ages, there prevailed a vague belief that the outbreak of disease had some connection with the use of water from wells and springs, and many a reputed witch lost her life for the alleged poisoning of drinking-water.

Relation of drinking-water and disease discovered.-Slowly the relation of drinking-water to disease began to be better understood. In the early part of the nineteenth century, repeated ref-
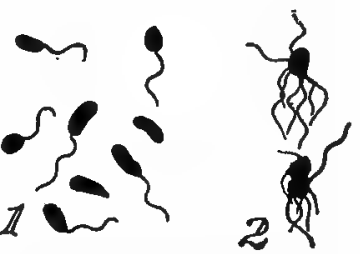

Fig. 16. Two dangerous bacteria that may occur in water.-1. Vibrio cholera; $\times 2,000$. 2. Bacillus typhi; $\times 2,000$. (After Emmerling.) 
erences were made to drinking-water as the cause of malaria and diarrhea. Towards the middle of the century the accumulation of recorded facts prepared the way for the belief expressed in 1855 by Doctor Michel in France, that there is a seeming relation between the character of drinking-water and the prevalence of typhoid fever.

The bacillus of typhoid isolated by Eberth in 1880, and studied in greater detail by Gafky in 1884, is now generally regarded as the specific cause of the disease (Fig. 16). The organism has been repeatedly isolated from the stools of typhoid patients, and a number of instances are on record when the bacillus was directly isolated from polluted water. The germ of cholera was isolated by Koch in 1884 from the stools of cholera patients, and from the intestinal contents of persons who died from the disease (Fig. 16). He also found this germ in water from a tank in India. Both of these organisms have been shown to invade the human system through the medium of drinking-water, and the latter has, therefore, become the object of more thorough care and inspection in all civilized communities.

Epidemics of cholera and typhoid fever.-The study of the history of epidemics of cholera and typhoid is both interesting and instructive, as marking the growth of our knowledge of these diseases from the standpoint of sanitation. Europe and America have had no serious outbreak of cholera for many years, but epidemics of typhoid are, unfortunately, still too frequent. The relation between typhoid fever and drinking-water may be readily traced in the epidemics that have occurred 
within the past twenty-five years. The evidence as to the relation of typhoid fever and drinking-water is further strengthened by a mass of statistics showing a marked decrease of typhoid since the introduction of better water-supplies in the cities.

There is an enormous amount of data that might be added to the above as further proof of the intimate connection existing between drinking-water and typhoid epidemics, yet enough has already been said to bring out the importance of this relation.

Other sources of typhoid infection.-It should not be supposed that drinking-water is the only source of infection, or even the only important source. Milk has been repeatedly shown to be a very serious source of infection, and uncooked vegetables, fruit, and oysters have undoubtedly served as carriers of the disease. There is scarcely a doubt, likewise, that flies have often been responsible for the spread of the disease, particularly in army camps. This will explain why the greater care of the water-supplies is not always followed by a corresponding decrease in the number of typhoid fever cases, as is demonstrated, for instance, by the experience of Washington, D. C., and of Youngstown, Ohio.

Other diseases arising from use of impure water.Apart from cholera and typhoid, the use of polluted or otherwise impure water may induce serious intestinal disturbances as a result of the activities of other bacteria. Outbreaks of dysentery of serious proportion are not uncommon in camps.

The better care of drinking-water has been responsible for a very marked decrease in the ravages of dysentery 
in temperate climates. It is estimated that the mortality from dysentery in England towards the end of the last century was but a fraction of a per cent of that at the middle of the century. In the United States, the death rate from dysentery was 6.32 per cent of the total mortality in $1850 ; 2.65$ per cent in $1860 ; 1.60$ per cent in 1870; and less than 1.5 per cent in 1880 .

To sum up, therefore, drinking-water is a factor of great moment in the spread of certain diseases and may become the carrier of the germs of cholera, typhoid, and certain forms of dysentery. Its purification and protection from pollution have necessarily become important features of modern sanitation. 


\section{CHAPTER VIII}

\section{CONTAMINATION OF STREAMS AND LAKES}

BaCteria find their way into drinking-water from numerous sources. The dust particles floating in the air, and the bacteria attached to them, are washed down by the rain. The winds that pass over the land carry away with them not inconsiderable numbers of bacteria, and deposit a part of them in the water over which they pass. The surface washings and drainage waters that reach the rivers and lakes contribute to their water a goodly number of bacteria.

Soils contain bacteria.-All soils contain large numbers of bacteria, usually several hundred thousands per gram. In the case of fertile lands, the number may reach several millions per gram of soil. Hence, the rainwater that drains off the surface of the fields, or percolates downward and escapes as subsoil drainage, comes in contact with enormous numbers of bacteria and removes many of them to the water-courses. Anything, therefore, that tends to increase the number of bacteria in the soil will also tend, indirectly, to increase their numbers in the neighboring streams. The applications of heavy dressings of animal manure, the plowing under of green crops, the turning under of sod, or the application of lime and fertilizer, stimulate bacterial develop- 
ment in the soil and, therefore, encourage larger additions of bacteria to the surface waters of the region.

Another fruitful source of bacteria for drinking-water is the sewage which finds its way into it. Owing to its origin, sewage is extremely rich in bacteria, frequently containing tens of millions of them in every cubic centimeter. In view of the enormous volume of sewage poured into some streams, the number of bacteria added to the water is frequently beyond computation (page 73).

All of these additions, made more or less constantly, or at irregular intervals determined by the amount of rainfall, provide an abundant supply of bacteria to drinking-water. Various species are thus introduced into the water, some of them capable of adapting themselves to the new conditions and of multiplying even to a greater or slighter extent.

The character of the bacteria in water.-The various classes of bacteria in water exist there in different proportions. As living organisms they are affected by conditions favorable or unfavorable to their survival. The kinds that are best adapted to their environment will emerge victorious from the struggle for existence. Hence, there are groups of bacteria that may be regarded as normal inhabitants of water. These are encountered in large numbers in all dirinking-waters.

There are others that are brought to the streams in great masses from time to time, but, owing to the competition of other bacteria, or to insufficient or improper food, they die out very rapidly. They do not multiply, and so disappear after a longer or shorter period. Such are the numerous species of soil and sewage bacteria, 
which, though frequently found in drinking-water, must be regarded as strangers there. They are not normal inhabitants of water. This class of bacteria may again be divided into two groups. The first includes all the harmless kinds that could produce no illness, even if swallowed in very large numbers. The second is composed of disease bacteria proper, such as cholera, typhoid, and dysentery. Since many of the bacteria are not normal inhabitants of water, and since they tend to die out when introduced there, it follows that their presence in large numbers is a certain sign of recent pollution.

The number of bacteria in water.-The number of bacteria in water is affected by its composition, by the amount and frequency of rainfall and the resulting drainage, by the contamination with sewage, by the season and climate, the amount and intensity of sunshine, the depth of the water, the velocity of the current, and still other factors. Because of the natural variations thus introduced, the number of bacteria in fairly pure river-water may range from a few hundreds, or even less, per cubic centimeter to several thousands.

The differences in the bacterial content of water between the winter and summer months are largely attributed to the greater amount of surface drainage in the fall and winter, whereby enormous numbers of bacteria are carried to the streams from the forests, fields, and city streets. In the summer months, on the other hand, much of the lighter rainfall is taken up by the growing vegetation, and a larger portion of it is evaporated from the soil, thus decreasing the amount of surface drainage. The streams must then depend 
for their main supply on springs, which, as will be shown later, are comparatively poor in bacteria.

The determination of the number of bacteria in water may be of distinct advantage in two directions. It has been demonstrated that surface waters are influenced by the character of the soil over which they flow and by the drainage that they receive, thus giving rise to marked variations between one stream and another, even when no actual pollution exists. Yet, in the same stream, and within the limits of seasonal variation, the character and number of bacteria are fairly constant. Hence, any sudden and abnormal increase in the number of organisms in any particular stream should be regarded with suspicion, and as possibly, though not necessarily, due to pollution with sewage.

The counting of bacteria in water is also of value in measuring the efficiency of filters whose purpose it is to remove the organisms. It is therefore customary to count the number of bacteria in the unfiltered, as well as in the filtered water, and a measure is secured thereby of the proportion retained in the filter. Still, even here, mere numbers are not considered a sufficient proof of the efficiency of filtration, and attempts are made to determine the proportion of certain kinds of bacteria that are retained during the process.

Causes affecting the increase or decrease of bacteria in water.-The familiar appearance of certain grasses in the meadow, of certain weeds in the fields, and of certain trees in the forest, is largely the outcome of natural selection. The fact, for instance, that sorrel appears in quantity in acid soils is attributed to its adaptation 
to conditions under which other plants do not thrive. In the struggle for existence, therefore, the sorrel is enabled to crowd out the others when they are not already crowded out by their own inability to grow. Similarly, the addition of lime or gypsum to the soil is followed by the appearance of white clover. This is an indication that conditions have been created favoring the vigorous development of the clover and favoring the suppression by it of other plants not so well adapted to the changed character of the soil.

Something of the same nature occurs in water. Just as soils of different origin and composition have their own kinds of weeds, and their own proportions of the different weeds, so waters of different origin and composition have, though in a more limited sense, their own kinds of bacteria, and their own proportions of the different kinds. Just as there are certain grasses and other plants widely distributed where they are not interfered with by man, so there are certain kinds of bacteria almost universally distributed in our lakes and rivers. They include the normal inhabitants of drinkingwater, as well as others which are not, strictly speaking, water bacteria, but are so universally distributed in the soil or in the intestinal tracts of birds, mammals and insects as to gain constant access to surface water. There is, however, an important difference between the normal water bacteria and the others just mentioned. The former can readily multiply in ordinary drinkingwater, while the latter are strangers there and perish sooner or later.

It thus becomes interesting to inquire why some 
groups of bacteria find a congenial medium for their development in water, and why others are crowded out and disappear. The factors that influence this are the supply of food, the temperature and sunlight, and the presence of certain products more or less injurious to some of the species.

The supply of food.-The first of these factors is of great significance particularly as regards the proportion of organic matter in the water. It should be remembered that, with very few exceptions, bacteria cannot subsist on simple mineral salts. They must have for their development organic matter elaborated by other organisms - plants or animals. There is, however, a wide range of adaptation as to the minimum amounts of organic matter required for the growth of different species. Some organisms will actually multiply in distilled water containing mere traces of organic matter, others will not grow unless there be present large quantities of nitrogenous organic matter. Quite naturally, streams flowing over sandy strata, poor in organic matter, and receiving no additions of sewage, will offer but little food to the latter class of organisms, while streams polluted with sewage and receiving the drainage from fertile soils will offer more favorable conditions for their growth. The organic matter added to surface waters from the drainage area does not long remain unchanged. It tends to disappear, owing to the very class of bacteria that uses it as food. The disappearance of the organic matter necessarily involves, also, the disappearance of the bacteria which prey upon it. Hence, the process of self-purification that occurs in 
streams, lakes, and reservoirs, and the process of purification that occurs in filter beds are both connected with the destruction or removal of the organic matter.

On the other hand, the processes of purification that depend upon the destruction of the bacteria themselves, without the accompanying destruction of the organic matter, are wholly inadequate. For instance, the bacteria in water could be killed by boiling, or by the addition of chloroform, yet after the water becomes cool again, or after the chloroform evaporates, other bacteria may gain access to the liquid, and, with the help of the organic matter which the heat or the chloroform had not destroyed, they may multiply as rapidly as ever. The organic matter may be compared, in this case, to il cask of gun-powder and the bacteria to a spark. While the gun-powder is protected from the spark there is no danger of explosion, yet great care must be exercised to keep the two apart. Perfect safety can be assured only by the removal or the destruction of the gunpowder.

The increase of bacteria in drinking-water, due to the additions of organic matter, does not necessarily involve also the increase of typhoid germs that may find entrance to it. On the contrary, a large number of investigations seem to indicate that the typhoid germs and allied species'survive in water but a short time. Furthermore, it actually appears that larger amounts of organic matter in the water and the resulting active multiplication of certain bacteria inhibit the growth of typhoid germs to a greater extent than when the amounts of organic matter are smaller. At the same 
time, the presence of readily decomposable organic matter may prove undesirable because it favors the growth of other bacteria probably responsible for less serious intestinal disturbances.

The presence of larger amounts of organic matter is also undesirable because its decomposition gives rise to the formation of nitrates and of other inorganic matter which serves as food for microscopic plants known as alga. This is especially true of lakes and sluggish streams in which the rapid increase of the algæ may result in the formation of a green scum on the surface. Under such conditions, the water loses its clear sparkling appearance and acquires a fishy taste, or other undesirable odors and flavors. Since algæ, like the green plants, will grow only in the presence of sunlight, their development may be suppressed by keeping the water in the dark. This applies particularly to the storing of drinking-water in reservoirs where the algæ are more likely to develop. In a number of European cities, covered reservoirs have been used successfully for years, and the growth of algæ has been thus eliminated, even in waters rich in mineral salts.

Temperature.-The temperature of the water is, undoubtedly, an important factor in the increase and decrease of its bacteria. In so far as the introduction of organisms from outside sources is concerned, it has already been shown that surface waters contain fewer bacteria in the summer than in the winter, at least in moderately temperate climates; and that the greater number of organisms in the winter is due to the greater amount of surface drainage. It may be assumed that 
with an equal amount of surface drainage in the summer, the bacterial additions to the surface waters will be much greater than those in the winter.

In the water itself, on the other hand, the development of the bacteria is more intense in the summer than it is in the winter. This involves a more rapid destruction of the organic matter and the corresponding disappearance of the bacteria introduced from outside sources. In the winter, on the other hand, the destruction of the organic matter is practically at a standstill. Then the outside bacteria do not suffer so much from the competition of the normal water bacteria, for both are quiescent, and the reduction in the total number of bacteria is not favored to such an extent. This view is encouraged by a number of experiments that show that typhoid germs disappear from unsterilized water more quickly in summer than in winter.

It is to be further noted in this connection that the normal water bacteria, as well as the great bulk of soil bacteria, develop easily at $68^{\circ}$ to $72^{\circ} \mathrm{Fahr}$. The bacterial inhabitants of the intestinal tract of warm-blooded animals, however, develop best at blood temperature. It is but natural to expect, for this reason, that these intestinal bacteria will find themselves at a disadvantage when introduced into drinking-water in sewage or in other materials. These organisms actually perish within a comparatively short time, owing largely to the competition of the other bacteria. This competition, reacting unfavorably on typhoid germs and other intestinal bacteria, may be regarded from two different standpoints. 
In the first place, it may be considered that the destruction of the intestinal bacteria is accomplished by the formation by the other bacteria of substances injurious to them. In other words, the growth of the water and soil bacteria may lead to the formation of substances toxic (poisonous) to the intestinal bacteria. That the excreta or by-products actually formed by bacteria or plants may actually prove poisonous to themselves or to other organisms when accumulated to a large extent, can be well illustrated. An instance of this is the necessity of frequently supplying fresh water to plants grown in water-culture, even when an abundance of available plant-food exists.

The other standpoint leads us to assume that the intestinal bacteria are not destroyed by the poisonous excreta of the others, but by actual contact. There is some evidence to thow that in case of the typhoid germs, at least, the latter mode of action may serve as the destructive agents. But whether we regard the disappearance of the intestinal bacteria in drinking-water from one or the other standpoint, it remains certain that the activities of the other organisms contribute largely to their rapid disappearance.

Numerous experiments carried out with cultures of the typhoid germ prove conclusively that the organisms survive for a longer time in sterilized than in unsterilized water. It was shown, for instance, that typhoid germs introduced into unsterilized water from Lake Michigan, survived for only seven or eight days, whereas, in the same water, previously sterilized, they remained alive for twenty-five days. In other experiments, it was 
demonstrated that a number of soil bacteria and also of water bacteria injuriously affected the typhoid germs, and that such injurious effects were not observed when the typhoid germs were alone. Furthermore, the injurious action was found to be dependent to a great extent on the temperature to which the bacteria were exposed.

Sunlight.-This is another factor which undoubtedly plays some part in the increase or decrease of bacteria in water. Reference has been made to the germicidal action of direct sunlight, and it has been pointed out that in the deeper layers of water such action can be of only small moment. It is still uncertain to what extent direct sunlight actually contributes to the decrease of bacteria in water. There can be scarcely any doubt, however, that during the long hours of bright sunshine in the summer months, and, particularly in shallow bodies of water, the germicidal action must be of considerable significance. Furthermore, some consideration must also be given to the indirect action of sunlight in the development of the algæ. The latter withdraw in their growth considerable quantities of nitrates and other food material from the water, and thereby render the conditions less favorable for the development of the bacteria.

Animalcules injurious to bacteria.-The number of bacteria in water is likewise affected by certain animalcules that use them as food. It is interesting to watch these little organisms which, though giants in size as compared with the bacteria, are still so small as to require magnification by a powerful microscope lens 
before they can be seen. When properly magnified, they may be observed rapidly moving about in the drop of water and stirring up currents in it by means of which the bacteria are drawn into the mouth of these animalcules. Their transparent bodies show the bacteria within them in a more or less advanced state of decomposition. The development of these animalcules, designated as protozoa, is affected, of course, by the prevailing temperature, and it is quite apparent, therefore, that in the summer months their consumption of bacteria is a factor to be reckoned with, whereas, in the cold months of the winter their activities are practically suspended.

Sedimentation.-The solid particles suspended in water tend to sink to the bottom when the velocity of the current is reduced. As the stream becomes more sluggish, the diameter of the particles still in suspension becomes smaller and smaller until only the finest fragments of silt, clay and organic matter remain floating in the water. When the water is at a standstill, a large proportion of even these finest particles fall to the bottom. This gradual settling out of the solid matter in suspension is known as sedimentation, a process which plays' an important rôle in reducing the number of bacteria in rivers, lakes and reservoirs.

The dêcrease in the number of bacteria is encouraged by sedimentation in a twofold manner. In the first place, the settling: out of the suspended matter, which includes, also; a large portion of the organic substances, reduces the quantity of food available to the bacteria and their growth is thereby hindered. In the second 
place, the sedimentation process carries down large numbers of bacteria which have become entangled in the organic matter.

The advantages of sedimentation in reducing the number of bacteria in water have long been recognized in municipal sanitation. Many towns and cities employ either settling basins alone, or settling basins in connection with filter beds for the purification of their drinkingwater. The efficacy of sedimentation in removing the bacteria from water has been demonstrated by careful investigation.

Dilution.-The influence of sedimentation and of the other factors in reducing the number of bacteria in water, is reinforced by that of the dilution. The water of any river or lake containing large numbers of bacteria, shows a relative decrease of the latter when pure water is added to it from any source. Under actual conditions, the purer water of tributaries frequently serves to reduce, to a very considerable extent, the relative number of bacteria in large rivers.

The contamination of drinking-water by sewage.The vast number of bacteria in sewage, averaging, at times, more than $10,000,000$ per cubic centimeter, is frequently a direct source of increase in the number of bacteria in drinking-water. Sewage-polluted streams and other bodies of water show a high bacterial content for the double reason that they are supplied with both the bacteria and the organic matter serving as food for the latter. However, the mere increase of bacteria in water used for drinking purposes cannot be accepted as an infallible proof of sewage contamination, for it has 
already been pointed out that enormous numbers of harmless bacteria may be derived from the soil.

To prove that a water-supply has actually been contaminated by sewage, it is necessary to resort to methods other than the mere counting of the bacteria in it. Chemical methods, bacteriological methods, or both, may be employed for the purpose. The chemical methods are based on the detection of certain substances contained in a considerable proportion in sewage. Unfortunately, the chemical methods prove insufficiently delicate when the sewage is strongly diluted by the water to which it is added. The bacteriological methods used at present, with considerable success, are more delicate, and are based on the detection of certain kinds of bacteria never absent from sewage, but not regarded as normal inhabitants of pure water. The species of bacteria most widely employed as an indicator of sewage pollution is called Bacillus coli communis, or the colon bacillus, a normal inhabitant of the intestinal tract of man and of domestic animals.

Frequent examinations of sewage in this country and in Europe have shown that the colon bacillus is always present in numbers ranging from a few thousand to fifty thousand per cubic centimeter. In occasional instances, this number is greatly exceeded. These results are not surprising in view of the nature and origin of sewage. It has been shown, also, that the colon bacillus can develop and increase in numbers in sterilized sewage, an indication that the sewage itself is adapted for the development of this organism. Under actual conditions, however, the sewage is not sterile, but is inhabitated. 
by hosts of other bacteria whose presence is inimical to the survival of the colon bacillus.

The examination of soils of different origin has demonstrated that in those not recently manured the colon bacillus is present in slight numbers or not at all. On the other hand, greater numbers were found in soils that had recently received applications of horse-manure, but the tendency for their gradual decrease was observed here also. Soils which were experimentally inoculated with this organism, were not found, on the whole, to be favorable to its development. It is not, apparently, able to withstand the competition of bacteria normal to cultivated soils, and, while in exceptional cases, it may even increase to a slight extent, its gradual decrease in numbers is inevitable. Water bacteriologists, therefore, agree, for the most part, that the presence of large numbers of the colon bacillus is a certain indication of recent pollution with sewage.

Taking the foregoing facts in their entirety, we find, therefore, that the colon bacillus is present in enormous numbers in the excreta of man and of domestic animals; that it is present in large numbers in sewage because this contains human and animal wastes; that it is not present in ordinary soils, except occasionally, or in slight numbers. We are thus forced to the conclusion that our surface waters, used for drinking purposes, do not receive large numbers of the colon bacillus from the soils with which they come in contact. The presence of these organisms in surface waters must indicate either recent sewage contamination, or the possible multiplication of the colon bacillus in the water itself. 
The presence of large numbers of the colon bacillus becomes thus a danger signal, an indication that it may have been accompanied by the typhoid bacillus. Hence, both the chemical and bacteriological methods employed in the examination of drinking-water aim to detect pollution and its extent, if possible. The best results are secured when the two are combined and a measure thereby secured of the probable addition of sewage materials, on the one hand, and, on the other, of sewage bacteria, some of which may be carriers of disease. Of late years the bacteriological methods have been the subject of much careful study and give promise of becoming more widely applicable in the sanitary examination of drinking-water. 


\section{CHAPTER IX}

\section{PURIFICATION OF RIVER AND LAKE SUPPLIES}

THe composition of river-water is influenced by the geological nature of the region through which it flows, and by the surface drainage it receives. Streams passing through limestone regions carry in solution considerable quantities of lime. Their waters are, therefore, called hard waters. Those that pass through heavily wooded regions and through swamps and meadows acquire large quantities of organic matter, often to such an extent as to give their water a distinct color. Streams that pass over strata rich in iron may, similarly, be noted for their high content of iron salts, while others may be distinguished for their high content of various salts, as is true of rivers that constantly receive the seepage of alkali soils.

The differences in the composition of river-water are not without important influences on the bacteria inhabiting them. It is well known, for instance, that the proportion of lime in the soil affects intimately the character of its bacterial flora. It would be but reasonable to expect analogous relations in surface waters. It still remains to be determined to what extent the varying proportion of lime in water affects the character of its bacteria. 
The quality of organic matter.-It has already been noted that the amount of organic matter in river-water is of paramount importance from the bacteriological standpoint. Something should also be said concerning the quality of the organic matter. There are streams whose waters are brown or almost black on account of the peaty or other vegetable matters dissolved in them. Many such streams furnish a clear, wholesome drinkingwater in spite of the high content of organic matter. This is true of some rivers along the Atlantic seaboard.

It seems that the organic matter derived from swamps does not decompose as readily as the organic matter derived from sewage. In fact, the organic substances in such waters may exert, to a certain extent, pronounced antiseptic properties, like those of the peat itself. . The development of bacteria in such water must necessarily differ from that in water deriving its organic matter from sewage. The value of the two from the sanitary standpoint must, likewise, be different. However, experts do not entirely agree as to the wholesomeness of peaty water for drinking purposes. Instances are cited when such water has been used for years without ill effects. Instances are likewise cited when the general use of peaty water has led to a markedly increased mortality from intestinal diseases.

Alkali water.-But little is known of the bacteriology of waters charged with alkali salts. Such waters are used for drinking purposes when the content of alkali is not too high. Apart from their somewhat laxative effects these waters do not appear to be detrimental to health. 
River-water, and surface drainage. - The differe--ces in the compositon of river-water, as well as their influence on the water bacteria, may be further modified by the quantity and quality of the surface drainage. When the surface drainage includes notable additions of sewage, the influences on the bacterial flora of the stream may be quite far-reaching. The modifying effect of sewage may be due to its quality as well as to its quantity. For example, the sewage of European cities is more concentrated than that of American cities because of the larger volume of water used by the latter. It is to be expected that equivalent quantities of the two will not have the same effect on any given stream. Moreover, the ratio between the volume of sewage added to a stream, and the volume and velocity of the latter, is of direct significance. A slight quantity of sewage added to a large river would not contaminate the water to such an extent as the addition of a large volume of sewage to a small stream.

Self-purification of rivers.-The activities of the water and sewage bacteria rapidly exhaust the store of readily decomposable organic material. The less readily available residues do not furnish the large quantities of food required by vast numbers of bacteria, and the less resistant species are rapidly eliminated in the struggle for existence. The gradual disappearance from the water of the organic substances, as well as of the bacteria introduced with the sewage into flowing streams is designated as self-purification.

Differences of opinion still exist as to the extent to which self-purification may be depended upon for 
the protection of the public health. The older views on the subject are represented in the statement of Pettenkoffer on the one hand, and in that of the sixth report of the Rivers' Pollution Commissioners of Great Britain, on the other. Pettenkoffer believed nature could be trusted to purify polluted river-waters, provided the amount of sewage added does not exceed $\frac{1}{15}$ of the volume of the stream, and that the velocity of the latter is fully as great as that of the stream of sewage. The Commissioners held, in their report, that nature can not be relied upon to do the work properly, even when the sewage is greatly diluted by pure river-water, and that "it is impossible to say how far such water must flow before the sewage matter becomes thoroughly oxidized." Their inference was that no river in England was long enough to assure the complete destruction of sewage by oxidation.

Modern views steer the middle course between these opposing opinions. We have strong proof that the process of self-purification is quite variable, even in the same stream, and that the destruction of the polluting substances may be rapid or slow according to conditions. In the water there is (1) decomposition of the organic matter by bacteria, (2) a removal of a portion of it by sedimentation, (3) and the destruction of disease germs by other bacteria, by sunlight, and by animalcules and other creatures feeding upon them. Gradually, but surely, the putrescible matter largely disappears from the water, and, with it, great hosts of injurious and harmless bacteria. The organic matter carried down by sedimentation is, in its turn, attacked by the classes 
of bacteria capable of growing in the absence of air, and is destroyed. The bubbles of gas which rise to the surface testify to this.

The decomposition of the organic matter in the water and in the mud at the bottom of rivers, lakes and ponds, as well as the destruction of the disease germs introduced with the sewage cannot, however, be depended upon to purify the water so as to make it absolutely safe. The typhoid germs may be destroyed in a few hours or in a few days in sewage-polluted waters, as numerous investigations have clearly demonstrated; yet, under other conditions, they may survive for weeks, or even months, and there is no assurance that twenty, thirty, or even fifty miles of flow would be sufficient for their removal under all circumstances. There is a general agreement on this point among sanitarians and for this reason the practice of pumping sewage-polluted water directly in the city mains is strongly discouraged.

The storing and filtration of river-water.-When brought to rest in large reservoirs, river-water is subject to the sedimentation process as it is in rivers, lakes or ponds. The suspended particles in such stored waters settle out gradually. Not only is there a subsidence of the suspended particles, but, also, a partial decomposition of the organic matter in solution, and a very marked general reduction in the number of bacteria.

The reservoirs for unfiltered water, or settling basins, as they are often called, appear thus to be a very important means for the purification of drinking-water. The settling basins of the city of Washington, which, before the installation of the filtration plant, were the 
only means for the bacterial purification of the Potomac water used in the city, showed a bacterial efficiency of 70 to 90 per cent. The city of Baltimore still depends upon the settling basins and the prolonged storage of the drinking-water for the elimination of the typhoid germs from its water.

Notwithstanding the marked decrease of the bacteria in stored water, it is generally conceded that settling basins alone should not be depended upon for the protection of the community against typhoid fever. A small proportion of the disease germs might survive, and, probably, do survive, the sedimentation process. It has become necessary, therefore, to supplement the latter with more efficient means for the elimination of typhoid and other intestinal germs. As a result of this conviction, many modern water-purification plants include in their equipment both settling reservoirs and filter beds, and, likewise, additional reservoirs for the storing of filtered water.

Sand-filtration.-After remaining in the settling reservoirs for a greater or shorter length of time, the water is passed through the filters in order to destroy most of the remaining organic matter, including most of the sewage bacteria. It should not be supposed, however, that the action of the filters is purely mechanical. . On the contrary, they owe their efficiency to the bacteria that establish themselves in the upper layers of the bed and act there as very vigorous scavengers. For this reason, the sand filters do not attain their highest efficiency until some days after they are put in operation. It is found then that the grains of sand which compose 
the upper layer of the filter bed have become covered with a gelatinous film, which has been found to be the seat of the bacterial scavengers.

The nitrifying bacteria are found to be quite prominent in the filter beds, and it is their function to change the ammonia formed in the processes of decay, into the soluble nitrates. Since the nitrifying bacteria are distinctly aërobic, requiring a plentiful supply of air for their development, the filter beds must be so constructed as to allow the air ready admission. For this reason, layers of coarse materials are placed at the bottom, and on top of that other layers of successively greater fineness until the uppermost layer is reached. This consists of sand whose grains are fairly uniform in size. It is recommended that the thickness of the sand layer be about 24 inches and, in any case, not less than 12 inches. Because of the gradually increasing thickness of the gelatinous film around the grains of sand, the filters are apt to become clogged in the course of time. To obviate this difficulty, the surface portion of the sand is pared off from time to time, and the removed material thoroughly cleaned and purified.

It has been found in practice that the best results are secured when the filters are worked intermittently,that is, when they are given periods of rest in order to allow a more thorough aeration of the bed. It has been demonstrated, likewise, that the efficiency of the filters depends, to a great extent, upon the rate at which the witer is made to pass through them.

Other methods of water purification.-The bacteria present in drinking-water may be removed or destroyed 
by methods other than sedimentation and sand-filtration. Some of these involve the removal of the bacteria by chemical substances added to the water, although the process by which this is effected may be, in itself, largely mechanical.

The alum method.-One of the methods in question is based on the ddition to the water of alum at the rate of $\frac{1}{4}$ to $\frac{1}{2}$ grain per gallon. In the presence of the carbonate in the water, the alum is decomposed with the formation of a jelly-like mass, which gradually subsides and carries down with it the suspended particles, including the bacteria. It appears, moreover, that not only are the bacteria carried down by the alum, but that the latter exercises a deleterious effect on their subsequent redistribution in the upper layers of the liquid. The alum possesses the further advantage of combining with the organic substances dissolved in the water and of decolorizing it.

After being clarified by the precipitated alum, the water is made to pass through layers of sand. Thus it receives the benefit of careful filtration. When the water is soft and deficient in carbonates for the decomposition of the alum, the filtering material is made up of a mixture of sand and crushed marble. In the praccal application of the method care is taken, of course, not to add an excess of alum lest a portion of it be carried over into the purified water. It is asserted that water purification involving the use of alum is both efficient and economical, particularly on account of the saving of space that results from its use.

The Clark process.- There are other methods of 
water purification based either on the formation of precipitates which subsequently carry down the suspended matter, or on the direct action of the subsiding particles in carrying down the bacteria. One of these, known as the Clark process, involves the use of limewater and is intended primarily for the softening of hard waters. The lime-water added reacts with the dissolved bicarbonate of lime. The precipitate thus formed gradually subsides, carrying with it, as in the case of alum, the particles in suspension.

The efficiency of this method was investigated and it was found that the subsidence of the precipitated matter in open tanks was so rapid as to render the water fit for distribution in three hours. The bacteriological examination of samples of softened and unsoftened water gave the following results:

Bacteria in one cc.

Unsoftened water .322

Water after softening and two days' subsidence drawn from the main service pipes 4

Reduction in the number of bacteria, 99 per cent.

Purification by finely divided solids.-Still other methods of water purification that have been proposed are based on the direct removal of the bacteria by agitating the water with finely divided solids. Spongy iron, animal and vegetable charcoal, coke, ground limestone, chalk, infusorial earth, and the like, have shown a more or less high efficiency in this respect. Spongy iron, charcoal and coke are particularly adapted for this purpose because of their structure. 
The Woolf method.--Considerable success has attended the use of methods that are distinctly chemical in their action, but involve the employment of electricity. One of these, known as the Woolf method, is based on the decomposition of weak salt solutions by a current from the dynamo, whereby the compound sodium hypochlorite is formed. Sodium hypochlorite has a marked germicidal effect, and the addition of the electrolyzed solution to the water causes the destruction of the bacteria in the latter. Because of the quantities of material required to effect the sterilization of water, this method can hardly be regarded as economically practicable.

Purification by means of ozone.-There is more practical significance in the purification of water by means of ozone. When electrical discharges occur in the air, a portion of its oxygen is converted into ozone. This phenomenon is utilized in the purification of water. Electric sparks are passed through dry air, and after the latter is ozonized it is made to bubble through the water to be purified. The method is reported to be efficient with water containing moderate quantities of organic matter. The bacteria are readily destroyed, tests with Bacillus coli having demonstrated their entire elimination in a number of instances. The organic matter itself is partly oxidized, and the ammonia converted into nitrates. With water rich in organic matter, the ozonization method does not appear to be as satisfactory as could be desired.

Filters for domestic purposes.-There are various types of small filters for domestic use. It is well known 
that most bacteria are held back by filters made of unglazed porcelain. Some species exist, however, that are so small as to pass the minute pores of these filters. For practical purposes, nevertheless, unglazed porcelain may be regarded as bacteria-tight, and water which passes through it as sterile. This fact has led to the use of such filters for the purification of water used in the home. With many people no doubt seems to exist as to their permanent efficiency. Unfortunately, however, there are conditions under which such filters are not bacteria-tight. To be sure, the organisms can not pass through them directly, yet it has been demonstrated quite forcibly that they can grow through them.

Any of these filters, kept moist for some time, and accumulating organic matter on the inside and in their pores, will, finally, become pervious to the bacteria in them. Typhoid germs, as well as other microörganisms, may thus find their way into the supposedly pure water and cause disease. To render the porcelain filters absolutely safe it is necessary to burn them out from time to time, so that all of the organic matter contained in them may be destroyed. Unglazed porcelain filters that can be thus renovated with but slight danger of breaking are now being made.

Other filters for domestic use, made of charcoal or blocks of sandstone, possess the same defects noted in the porcelain filters, and should not be depended upon for the purification of drinking-water for any considerable length of time. They should be thoroughly cleaned and boiled at least once a week if their efficiency is to be assured. 
The waters of lakes and ponds.-These are subject to the same phenomena of purification already noted in the preceding pages in connection with the water of rivers. In lakes, as in rivers, the action of dilution, sunlight, sedimentation, and the decomposition of the organic food bring about the decrease in the numbers of bacteria. In some directions, however, there are important differences, if not in kind, at least in degree. The influence of sedimentation is more strikingly apparent in lakes than it is in rivers, for the velocity of the current, so important a factor in the latter, plays but a subordinate part in them.

The water of small lakes and ponds is more liable to be affected than that of larger lakes by the growth of algæ, and by the drainage from adjacent land. Another important influence that is of more consequence in this connection is that of sunlight and circulation. The slighter depth of the water allows a more thorough aëration of the bottom layers, and the more frequent interchange between the surface and bottom water undoubtedly exerts a direct effect on the bacteria.

The development of plant life in shallow lakes and ponds is, at times, so great as to modify, to a marked degree, the numbers and kinds of bacteria, and the general character of the water becomes such as to produce diarrhea in most persons who drink it. In smaller ponds, animals frequently come to modify the bacteriological character of the water to their own injury. Comparisons made between ponds to which animals had free access and other similar ponds from which they were excluded showed very marked differences in the bacteriological 
composition. The fact is thus emphasized that the animal excreta which find their way into ponds may become a bacteriological factor of importance from the standpoint of the health of the animals.

Intestinal disturbances among young animals, assuming, at times, the proportions of an epidemic, may undoubtedly have their origin in the polluted water of ponds and brooks. 


\section{CHAPTER $\mathrm{X}$}

BACTERIA IN WELLS, SPRINGS, TANKS AND ICE

WITH the introduction of public water-supplies in towns and cities, the use of water from domestic wells has become more restricted. The result of the change is apparent in the gradually dimishing mortality from typhoid fever, as is illustrated, for instance, by the reduction of the typhoid death rate from 34 per 10,000 to 1.1 in the city of Vienna within three years after the installation of a municipal water-supply of good quality. The change in the typhoid fever death rate in Massachusetts is fully as striking.

\section{BACTERIA AND WELL-WATER}

Extended observation in many places justifies the belief in the connection existing between the use of water from shallow wells and an increased death rate from typhoid fever. It is a matter of common knowledge that domestic wells are frequently located in places where pollution from various sources is not excluded. It is not, however, generally realized how large a proportion of such wells may receive polluted materials without manifesting it in the taste or appearance of the water. The brightness and sparkle of well-water 
is largely due to the carbon dioxid contained in it, the latter being derived from the decomposition of organic matter. Soils rich in organic substances, particularly those contaminated with sewage, produce more carbon dioxid than those poor in organic matter, and the brightness of well-water is, therefore, far from being a guarantee of its purity.

Soil may be regarded as a good filter. It holds back undissolved organic materials including bacteria, and, to a marked extent, also materials in solution. The water of springs and deep wells is, at times, almost germ-free, largely because of the filtering power of the soil. With that much granted, however, it still remains true that the soil cannot be entirely relied upon to prevent the passage of typhoid or other disease germs from cess-pools and privy-vaults into shallow wells located a short distance from them. This fact has long since forced itself upon the attention of municipal authorities, and has led to the establishment of regulations calling for a minimum distance of 20 to 50 feet between wells and cess-pools or privy-vaults. Unfortunately, the distance of 25 feet, frequently allowed by the municipal regulations, is a very uncertain security against the entrance of disease bacteria into wells.

The soil is not a solid mass of material, but an aggregation of particles of various sizes, separated by pores, or spaces filled with air. The rain that falls on the soil makes its way downward past the solid particles until it reaches a point where the pores are filled with water instead of air. The depth in the subsoil beyond which the ground is thus saturated with moisture is known 
as the water-table. Wells are made by digging down some feet into this saturated zone.

It frequently happens that the cess-pool situated at a distance of 25 feet or less from the well is made to discharge its contents into the latter. The liquid from the cess-pool, which is not as deep as the well, gradually passes downward until the water-table is reached. The air in the ground above the water-table offers more or less resistance to the downward passage of the sewage, and the latter will flow more readily towards the points where the resistance is least. The air in the well, subject to expansion and contraction with changes in temperature, causes the well to become the center of least resistance, and encourages the inflow of water from the surrounding soil. The removal of water from the well also st:mulates further additions from the adjacent portions of the saturated zone.

When cracks exist in the ground, the passage of water into the well from the surrounding soil becomes even more rapid, and, under such conditions, wells have been known to become polluted from sources several hundred feet distant. Should the cess-pool receive additions of disease germs from the house, the well-water nearby is then exposed to serious infection,the more so since, in sewage-polluted soil, the normal soil bacteria are crowded back by the sewage bacteria, and the disease germs may survive for a longer time under such conditions.

It is scarcely necessary to emphasize the evident significance of these observations. They help us to understand why it is so difficult to eradicate the disease, 
and prove convincingly that shallow wells situated near cess-pools and privy-vaults should be regarded with suspicion. Past freedom from disease germs can never serve as a guarantee of future safety. It has been shown, time and again, that such germs may ultimately find their way into the well, and outbreaks of typhoid may occur, not only on account of the direct use of the water, but, also, on account of the use of such water in the washing of milk cans and other dairy utensils. It happens that milk is a good culture medium for typhoid bacilli. A few drops of well-water containing a single typhoid germ may be sufficient for the production of vast numbers. Some severe typhoid epidemics have been traced directly to the consumption of infected milk.

Deep wells and springs.-The thorough filtration of the ground-water which finds its way into deep wells makes it almost germ-free. Numerous examinations of such waters have shown them to contain usually less than 50 bacteria per cubic centimeter. At times the number does not exceed 4 or 5 per cc., and it is very seldom that as many as 100 or 150 per cc. are found. This does not mean that deep-well-water is incapable of supporting a vigorous growth of bacteria. On the contrary, samples of deep-well-water, when allowed to stand for a few days, frequently show an enormous multiplication of their bacteria, while similar samples of surface water containing a much larger number of organisms, show a development decidedly more feeble. The difference is probably due to the fact that the organisms in the surface water suffer from competition among themselves, and, likewise, from the 
attack of animalcules which devour them in great numbers; hence the decrease.

Deep wells, improperly protected from surface washing, may also contain considerable numbers of bacteria. It has been observed that the first portions of the water pumped out of wells contain large numbers of bacteria, whereas the portions brought up later contain comparatively few. The phenomenon in question is explained by the rapid multiplication of the bacteria in the slimy layer covering the walls of the well, and their washing down into the surface water. Hence, when the water in the well had been left undisturbed for some hours, the accumulation of the bacteria in the surface layer may be quite considerable. Later on their numbers will tend to decrease again, owing to the action of sedimentation. The influence of sedimentation in this direction is made evident in the comparison of the bacteria in the undisturbed and the disturbed water. When the bottom layers of the well-water are thus disturbed, the number of bacteria per cc. may increase to a very striking extent.

Springs.-The bacterial nature of spring-water does not differ much from that of deep-well-water. When contamination from the surroundings is excluded, it is not unusual to find the samples germ-free, or containing a few organisms per cubic centimeter.

Driven wells.-Wells of this class have the advantage over open wells in that they are better protected against pollution from surface drainage. Under certain conditions, however, surface washings may pass downward along the tube until the ground-water is reached. 
Moreover, they do not exclude infiltration of sewage liquids below the water-table, and, when the distance from cess-pools, stables, or privy-vaults is slight, pollution may occur in a manner noted in connection with open wells. When pollution is excluded, the water from driven wells contains but few bacteria, and, from deeper wells, it may be practically germ-free.

Artesian wells.-The water of artesian wells is derived from sources more or less distant, and makes its way between two impervious strata towards lower levels. When the upper stratum is punctured, the water is driven to the surface with a force proportional to the elevation of the region whence it is derived. A porous layer of sand or gravel, situated between two layers of rock or clay, and placed in a vertical position, may thus collect large quantities of rain- or snow-water and convey it hundreds of miles to the plain below. Owing, however, to the efficient filtering action of the waterbearing stratum, the comparatively small number of microörganisms derived from the rain or snow are not carried far, and artesian waters are, therefore, generally very poor in bacteria.

\section{BACTERIA IN THE WATER OF CISTERNS AND TANKS}

In regions where the ground-water is difficult to reach, or where it contains a large proportion of undesirable substances, like bicarbonate of lime, or other salts, the collection and use of rain-water is generally resorted to. Its freedom from lime makes it highly desirable for laundry purposes. When carefully collected 
and carefully kept, it makes, also, a good and healthful drinking-water.

Cistern-water is collected by allowing the rain that falls on the roof to run into receptacles made of wood, stone, concrete, or metal. This method of collection exposes the water to more or less contamination, for, apart from the dust particles and bacteria in the air, carried down by the falling rain, the roof itself supplies varying quantities of dust, droppings of birds, insects, and other objectionable materials. Small animals, birds, and insects may also find their way to the cistern itself, thus adding still further to the amount of contamination. When we remember that the particles of dust borne by the winds may contain disease germs still capable of development, for example, those of typhoid, tuberculosis, and diphtheria, we realize at once that cistern-water may become a carrier of disease.

To make matters worse, the cisterns are frequently located in the ground near sources of pollution, and are not always impervious to infiltration from adjacent soil. Cisterns made of wood, brick, or stone, may thus become polluted from nearby cess-pools and privy-vaults. This is not a mere assumption, but a fact repeatedly demonstrated by actual examination. Cases of typhoid, sometimes several in one family, have been traced to the use of cistern-water. Numerous instances of other intestinal disturbances are also on record. A large proportion of the cisterns examined have been found to contain the colon bacillus and, likewise, considerable numbers of other bacteria. This condition is not at all surprising in view of the very infrequent cleaning of 
such cisterns, and the large amount of filth that may have accumulated in them.

\section{BACTERIA IN ICE}

Freezing temperatures destroy a large proportion of the bacteria in the water. They cannot, however, be depended upon to destroy all of the bacteria, and thus render the water sterile. This has been repeatedly demonstrated by various investigators. Careful studies have been made in this connection with the typhoid bacillus, the cholera germ, the anthrax bacillus, and a number of non-pathogenic organisms. It has been proved that ice may become a source of infection and disease. The process of freezing is often, in itself, insufficient for the complete destruction of all the bacteria present in the water.

Under certain conditions, the longevity of the typhoid germs and other bacteria may be considerably reduced. This is particularly so when the process of freezing is not continuous, but consists of alternate periods of freezing and thawing.

Such intermittent freezing may lead to the destruction of the typhoid, cholera, and other organisms within a few days; whereas, spore-producing species, like the anthrax bacillus, are not thus destroyed, owing to the great resistance of the spores. Everything considered, then, ice made from polluted water must be regarded with suspicion. Artificial ice, on the other hand, when made from distilled water, is almost free from bacteria, and may be used safely in the household. Artificial ice made from river-, well-, or spring-water contains a 
variable number of bacteria, depending on the purity of the water employed.

Bacteriological examinations of thick cakes of natural ice have shown that, as the freezing proceeds from the top downward, the number of bacteria included in the ice diminishes. The greatest proportion of bacteria has been found to occur in the snow-ice, although, on the whole, there seems to be no uniform distribution of the bacteria in any one layer. Their number may vary from less than one hundred to several thousand per cubic centimeter. As the ice melts, the number of bacteria in the ice-water begins to increase, attaining at times, very considerable proportions. One instance is reported in which a piece of ice was melted and immediately examined. The number of organisms per cubic centimeter was 1,020 , whereas, eleven days later the ice-water was found to contain 220,000 bacteria.

The partial destruction of the bacteria by freezing, and their subsequent multiplication in the ice-water, may have a direct bearing on the typhoid question, since it has been observed that not all of the bacteria are affected to the same extent by freezing. It is quite possible that the disease germs may survive in much greater proportion than the harmless bacteria, and may subsequently multiply as the ice melts. Typhoid germs do not appear to suffer from the competition of other bacteria at lower temperatures so much as they suffer from it at higher temperatures. Savage states that "At the temperature of the ice-chest, the typhoid germ may grow in the by-products of other germs, which, at higher temperatures, are quickly fatal to it." 


\section{CHAPTER XI}

\section{THE SANITARY EXAMINATION OF WATER-SUPPLIES}

$\mathrm{ON}_{\mathrm{N}}$ account of the important interests at stake, sanitary examinations of water-supplies should be thoroughgoing and complete as far as it is practicable. It is not sufficient to determine whether pollution of drinkingwater has actually occurred: the inspection should extend to possible future pollutions and the value of sources of supply judged accordingly.

Streams that once supplied pure water are now grossly polluted by towns and cities that have grown up within recent years. The expanding limits of cities and the development of industries are calling for greater and greater quantities of pure water and are disposing of a constantly growing volume of waste. The problem is thus complicated in both directions. Its solution must be found ultimately in accordance with the statement made by Mason that "a land should be looked upon as watered by its smaller lakes, its springs, and its brooks, and sewered by its great, especially its navigable, rivers. Its water-sources should be protected by law with exceeding care, and no river or stream should be added to its list of drains except after proper consideration by the State Board of Health, followed by legislative permission."

Larger cities are carefully guarding the area from which their drinking-water is drawn. In some instances, 
the entire water-shed is fenced in and men and animals are excluded. In other instances, a careful record is kept of the dwellings on the water-shed, and the cases of typhoid occurring there are isolated as far as possible. In still other instances, such inspections are either not made at all, or made in a very incompetent, or perfunctory manner, to the ultimate detriment of the community. It is scarcely necessary, therefore, to emphasize here the importance of the topographical inspection of the area whence a city's water-supply is derived. It is necessary to determine whether sources of pollution exist on the water-shed, and the extent to which the drinking-water may become contaminated from such sources. This much established, the aid of chemical and bacteriological methods may be invoked for the measure of the pollution that has already taken place, and, to some extent also, for the measure of pollution that may take place.

The chemical examination seeks to discover in the water certain substances derived from human wastes. For instance, sewage contains a much larger proportion of common salt than does pure water, since salt is always used in the kitchen. If the salt content of the drinkingwater is found to be greater than that of water known to be pure and derived from the same locality, it may be safely assumed that pollution has occured. Great care must be exercised, however, in the interpretation of the results, for the amount of salt present in the surfaceand well-water of different regions is variable. In some localities, deposits of rock-salt exist, and their wellwaters contain, therefore, considerable quantities of 
salt, enough to condemn the water as polluted had they been derived from other localities.

It is evident, therefore, that, in judging the purity of a sample of water by its salt-content, we must be informed previously as to the normal salt-content in the waters of that locality. Similarly, in the case of free ammonia, albuminoid ammonia, and nitratessubstances which serve as indicators of pollutionthe source of the water must be known to allow an intelligent interpretation of the analytical results.

Common salt, and other substances readily detected in water, may also be employed as an indicator of possible pollution. If it is desired to know, for instance, whether the contents of a certain well make their way into a stream, or whether the contents of a certain cess-pool make their way into a well nearby, it is merely necessary to add larger quantities of salt to the well or to the cess-pool in question, and to examine, subsequently, the supposedly polluted water for an increase in its salt-content.

When the pollution is slight, the chemical methods may fail to show it. For example, a typhoid fever patient may be located within a few hundred yards of a stream used as a source of drinking-water, and some of the infected wastes may find their way into the stream. The quantity of polluting material being slight, and the amount of dilution great, the chemical methods would prove to be not delicate enough for the detection of this pollution. A count of the total number of bacteria growing on ordinary media would probably prove unsatisfactory, because of the natural variations in the 
bacterial content of the water. On the other hand, the determination of the number of Bacillus coli and, perhaps, also of other characteristic intestinal bacteria, would probably show definitely the extent of pollution. It will be seen, therefore, that topographical, chemical, and bacteriological examinations may each serve to throw some light on the problem. The topographical examination must show whether danger of pollution exists, the chemical and bacteriological examinations must show whether pollution has taken place.

That thoroughgoing inspections of the water-supplies are a good investment of time and money is evidenced by the data on the cost of typhoid epidemics, as collected by Mason. According to him, the cost of the typhoid epidemic at Plymouth, Pennsylvania, was:

Loss of wages for those who recovered. . . . . . \$ \$30,020 80 Care of the sick. . . . . . . . . . . . . . . 67,100 17

Yearly earnings of those who died . . . . . . 18,419 52

The epidemic started on account of the improper protection of the water-supplies from the wastes of a single typhoid fever patient; and the figures just cited are eloquent as a condemnation of municipal negligence. 


\section{PART III \\ Bacteria and Sewage}

\section{CHAPTER XII}

\section{THE PROBLEM OF SEWAGE-DISPOSAL}

EARLY in his history man learned to know that the committal to earth of his waste products was quite effective in rendering them harmless and inoffensive. As long as he retained his nomadic existence, and kept moving from place to place, the problem of refusedisposal was not a vital one. The time came, however, when he established himself more or less permanently in camps and villages. It then became necessary for him to protect himself against being poisoned by his own excreta. Trenches and pits were therefore located outside of the habitations to receive the waste and offal capable of undergoing putrefaction.

But the tent and the hut were finally replaced by the more permanent home. Human life itself became more complex. Man's mind developed and his wants, straightway, became more numerous. He began to cook his food, to wear garments, to wash them, and to use conșiderable quantities of water for purpoșes other than drinking. The shallow trench being no longer suf- 
ficient for the reception of the solid and liquid refuse, larger and deeper pits had to be dug-such was the origin of the cess-pool. Later on, it was found necessary to build a roof over the cess-pool to keep out the rain, and to provide an opening in the roof for the escape of the gases generated in the putrefying masses. Still later, it was found desirable to line the pits with brick and stone, in order to prevent, to some extent, the diffusion of the offensive liquid into adjoining soil, and as a protection against the pollution of shallow wells. Subsequent improvements in the construction of cess-pools made them less unsightly architecturally and more easily accessible from the house.

The cess-pool.-The contents of the cess-pools and privies had to be removed from time to time by scavenging. In the pail system, as well as in the dry-earthcloset system, it was aimed to render the human excreta less offensive by covering them up with ashes, lime, or dry earth, and to remove them from time to time. In the dry-earth system, particularly, the organic matter was rapidly destroyed by bacteria and the same earth could be used over and over again. The waste materials removed by scavenging were either buried in trenches or used as fertilizer on tilled land. Generally speaking, therefore, these methods of disposal depended on bacterial action. It was the bacteria in the soil and in the water that effected the rapid and'satisfactory decomposition of the waste products.

From the agricultural standpoint, much may be said in favor of these methods, since they proyided for the return to the earth of the plant-food that had been 
taken from it. They also prevented the squandering of much national wealth. The impoverishment of large tracts of once fertile soil in Europe and America may be contrasted with the undiminished fertility of the cultivated lands in China and Japan, where great care is taken to return the waste products from towns and villages to the soil.

The rapid growth of cities in the nineteenth century, the increasing density of population, and the constantly growing volume of human waste, created conditions which, in the course of time, became a menace to health. The numerous cess-pools made the soil in cities black and soggy with fetid, undecomposed wastes; the shallow wells became polluted by surface washing and infiltration, and the death-rate from typhoid and other intestinal diseases became abnormally high. The old methods of sewage-disposal were no longer adequate for the changed needs of modern life. Sewerage systems, based on the dilution and removal of the human wastes in water, came into existence; the privy and cess-pool were, to a great extent, abolished in the larger cities. The sanitary conditions at once showed a marked improvement.

The new method of the nineteenth century.-It was not long, however, before the new method of sewage-disposal gave rise to serious misgivings. The rivers into which the constantly growing volume of sewerage was being poured became grossly polluted and frequently offensive to sight and smell. Fish could not live in such water, and complaints came from towns and cities farther down on the streams that their water-supplies werc being poisoned. These conditions finally forced munici- 
pal and state authorities to pass regulations for the treatment and purification of sewage previous to its discharge into rivers or lakes.

The early legislation on sewage-purification was antecedent to the development of modern bacteriology. The Rivers Pollution Act, which made it compulsory for some communities to take steps toward the purification of their sewage, was passed in England in 1865. It was but natural at that time to seek in chemical methods a means for the proper purification of sewage, and we find, accordingly, a number of such methods suggested, or actually employed for the purpose. A patent for the chemical purification of sewage by the lime process had been taken out in 1846 by Higgs. Other patents were taken out by Wickstead in 1851 and in 1854, and a company was organized at Leicester for the manufacture of fertilizer out of sewage. In 1852 a patent was taken out for the treatment of sewage by means of alumina and charcoal. Similar patents were granted in the period from 1853 to 1860 . All of these processes are based on the more or less thorough removal of the organic matter in the sewage, thus making it non-putrescible. The salts of alumina or of iron react with the substances present in the sewage and form flocculent masses, which gradually settle out to the bottom, dragging down the bacteria entangled in them.

The chemical methods of sewage-purification proved satisfactory up to a certain point. They freed the sewage from the suspended matter and reduced the number of bacteria in this way, producing effluents in some casses, which did not putrefy as readily as the 
original sewage. They were incapable, however, of freeing the sewage from most of the putrescible matter, for the reason that about one-third of the organic nitrogen and about one-half of the carbonaceous matter in the sewage are contained in the suspended solids. The rest is held in solution. The dissolved substances in the clear effluents were still liable to create serious pollution of surface water. The disease bacteria, also, that were not carried down by the chemicals, still retained their virulence. Moreover, the machinery, chemicals, and labor required for the chemical treatment of sewage, involved considerable expense, and the sludge removed from the sewage did not prove as valuable for manurial purposes as was anticipated. In some instances, companies that had been organized for the recovery of fertilizer substances from sewage were compelled to dispose of their plants after sustaining large monetary losses.

More recently, bacteriological methods for the purification of sewage have come into more general use, and have already demonstrated their efficiency when properly applied. Reference has been made to the selfpurification of streams, a process dependent upon the activities of microscopic organisms. Similarly, in sewage, the vast number of bacteria attack and destroy both the suspended and dissolved organic matter, and render the liquid non-putrescible and inoffensive. However, this process is gradual and, under natural conditions, gives rise to foul odors in its early stages.

The artificial methods in the bacteriological purification of sewage aim to intensify the activities of cer- 
tain groups of bacteria by which the organic matter is rapidly destroyed without giving rise to undue offense. The purified sewage is thus comparatively free from putrescible substances and contains comparatively few of the intestinal bacteria whose presence in drinking-
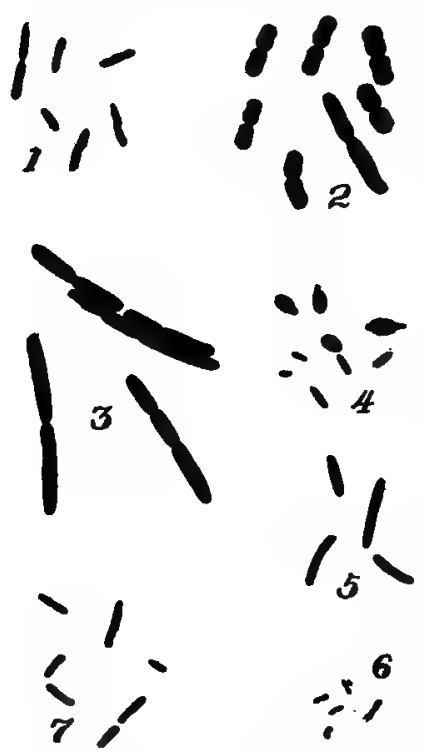

Fig. 17. Sewage bacteria.-1. B a c terium mesentericus, $\times 2,000$. (Rideal.) 2. Bacterium subtilissimus; $\times 2,000$. (Rideal.) 3. Bacterium membraneus fatulus; $\times 2,000$. (Rideal.) 4. Bacterium fusiformis;. $\times 2,000$. (Rideal.) 5. Bacterium entiritidis sporogenes; $\times 2,000$. (Hewlett.) 6. Bacterium coli communis, $\times 2,000$. (Hewlett.) 7. Proteus vulgaris; $\times 2,000$, (Rodella.) water is objectionable. The bacteriological methods of sewage-purification promise to be more economical and more efficient from the sanitary standpoint than the older chemical methods.

Bacteria in sewage.-Sewage may become a menace to public health for the twofold reason that it contains organic substances and disease germs. The disposal of sewage with the least danger to public safety becomes, therefore, a problem of great moment. By sterilizing sewage, by means of heat or antiseptics, all the bacteria contained in it can be destroyed, and, by keeping it sterile, its decomposition can be prevented. The fact cannot be ignored, however, that sterilized sewage, when discharged into any body of water, will 
immediately begin to clecompose, because of the presence in the air and water of certain bacteria that find the organic matter in the sewage proper food for their development.

Sewage can be made entirely harmless only by the destruction of its organic matter, as well as by the destruction of the disease germs contained in it. Since the destruction of the organic matter is almost exclusively a bacteriological process, whether taking place naturally in the self-purification of streams, or more or less artificially in sewage-purification plants and sewagefarms, it is evident that the matter, to be properly understood, should be regarded from the bacteriological rather than the chemical standpoint.

Growth of the problem.-The problem of sewagedisposal, like that of water-supply, has grown in magnitude within the last few decades. The gathering of vast numbers of people on comparatively small areas, and the diversified interests of the city with its human and manufacturing wastes, are rendering the proper solution of this problem more and more difficult. Like a dread specter, threatening disease and destruction, it has disturbed the peace of inland cities. Notwithstanding the progress of modern sanitation, it still continues to be the subject of careful inquiry. Even communities like that of Greater New York, favored in their situation on the ocean coast, are not entirely free from the care and anxiety of rendering their sewage harmless to human health and comfort.

Inland communities and sewage-disposal.-Away from the coast, the problem of sewage-disposal is rendered 
more or less complicated and difficult by the fact that the rivers and lakes used as a source of water-supply by some communities receive the sewage of other communities. Progressive legislation in this respect in some states has contributed much towards a rational solution of the problem. The pollution of rivers by sewage is prohibited in some states, exception being made only in the case of rivers already much polluted before entering the boundaries of the state.

It is unnecessary to add proof of the growing realization of the importance of proper sewage-disposal, and of the awakened public interest in the matter, as expressed in recent legislation. The work is, nevertheless, still in its very beginning.

The source, composition and quantity of sewage.-City sewage consists of human and animal excreta, refuse from the kitchen and laundry, various manufacturing wastes, and the dust and dirt of streets and roads, distributed in a greater or slighter quantity of water. Some cities provide a separate system for storm water, thus facilitating the purification of the sewage, when this is found necessary. For instance, in the city of Paris, where the sewage is utilized for irrigation purposes, a large portion of the water used for flushing the streets finds its way back to the Seine without previous purification.

The composition of sewage is variable. Variations in sewage of the same town occur at different periods in the day. The sewage that is produced in the forenoon and afternoon shows the influence of human activities in the greater volume and in the greater amount of 
substances in suspension and in solution. At night, the volume of sewage is diminished and its composition likewise modified. Different sewers in the same town may, likewise, show well-marked differences in the character of their sewage as affected by the density of population and its mode of life. The quantity of sewage produced in any town or city is affected by the water- supply, as well as by the nature and extent of their industries.

From the sanitary standpoint, the composition of sewage is to be considered both chemically and bacteriologically. The solid matter held in suspension and solution is potential food for bacteria and other microorganisms. It may undergo putrefaction and become offensive to sight and smell and may lead to the destruction of large quantities of fish in inland waters. From the bacteriological standpoint, it may act as a carrier of disease germs, and may be the cause of serious outbreaks of disease, even when diluted with a large volume of bacteriologically pure water.

The chemical examination of sewage serves to indicate the extent of possible pollution when it is added to a given volume of surface water. It serves still another purpose when employed in connection with the various methods of sewage-purification. It becomes a means, then, for the gauging of the efficiency of these methods. The analyses performed at the different stages of every process show clearly to what extent the objectionable materials are removed or rendered harmless. This procedure finds an analogy in the bacteriological examinations in which the numbers and kinds of certain groups of bacteria are determined. 


\section{CHAPTER XIII}

\section{BACTERIAL PURIFICATION OF SEWAGE}

THE decomposition of manure and humus in the soil, the destruction of organic matter in surface waters, and its gradual disappearance in the cess-pool, filterbeds, or septic tanks, are all brought about by the same forces-the vital activities of bacteria. The universal distribution of the microörganisms in the air, dust, water and soil, assures a speedy inoculation of all materials capable of undergoing decay. Over and above these sources of inoculation, sewage contains enormous numbers of bacteria derived from human excreta and kitchen wastes. It is no wonder, therefore, that sewage becomes foul so rapidly.

Sewage-farms.-The purifying power of soil, due to its bacteria, was recognized in early times. Hence, when the purification of sewage was absolutely necessary for a number of cities, land treatment was one of the first means considered for such purification. Sewage-farms thus came into existence after the middle of the last century. Some of these have been successfully managed to this day. In many towns, however, there were no suitable areas of land available for this purpose and sewage-irrigation was entirely impracticable.

Sewage tanks and filter beds.-It was discovered that 
large volumes of sewage can be exposed to bacterial activities in specially constructed tanks and filter beds, and the organic matter destroyed in a comparatively short time. This discovery, the outcome of widely scattered observations, has finally led to the evolution of the modern plants for the bacteriological purification of sewage.

In September, 1881, a patent for "The Automatic and Odorless Scavenger" was granted to Mouras in France. The American patent granted to Mouras is dated November 28, 1882. The patents were preceded by twenty years of practical experience, which left no doubt as to the remarkable efficiency of the process in destroying organic matter. The construction of the "Scavenger" was very simple. It consisted of an airtight, hermetically sealed tank, supplied with a feedpipe to receive evacuations, kitchen wastes, and the like, and an outlet in the upper part of the tank for the discharge of the sewage. Both of the pipes dipped under the surface of the liquid in the tank, which was completely filled with water before being placed in service. When anything was discharged into the feed-pipe, an equal volume of liquid was expelled from the tank. The liquid expelled contained disintergrated and largely decomposed material. From the inventor's description of the process, it is evident that the organic matter introduced into the tank was destroyed by anaërobic bacteria. So rapid was the process of decomposition that the excreta was dissolved in eighteen days, while resistant substances, like paper, disappeared in a comparatively short time, with the formation of products 
largely gaseous in character. The Mouras "Automatic Scavenger" may thus be regarded as the predecessor of the modern "septic tank," an important feature of all efficient sewage-purification plants.

In 1895, Cameron, then City Surveyor of Exeter, England, introduced his so-called "septic tank" as an efficient medium for the treatment of sewage. The septic tank constructed by him consisted of a cemented pit, arched over, covered with sod, and provided with a vent for the gases generated from the decomposing materials. The crude sewage was introduced five feet below the surface of the liquid, so as to disturb it as little as possible, and made to pass through the tank so slowly as to occupy about twenty-four hours in the process. In the absence of air and light, the anaërobic organisms soon attained an intense destructive activity. A leathery scum was observed to have formed on the surface, thus excluding the air still more effectively, while from the interior of the liquid, bubbles of gas arose in large volume and the solid matter was constantly undergoing liquefaction. The sediment accumulated very slowly, being scarcely sufficient in amount to require removal at the end of a year. Subsequent experiments, conducted elsewhere, demonstrated that it is not even necessary to cover the septic tank, for the leathery scum at the surface is evidently adequate for the exclusion of air. On the whole, however, the covered tank is preferable to the open tank, as furnishing more uniform conditions for the undisturbed action of the bacteria.

Progress in sewage-purification.-In the period during which the septic tank was gradually evolved from the 
Mouras "Automatic Scavenger," bacteriological purification of sewage saw notable progress in other directions. The fact that sewage may be partly purified by filtration through sand or other finely divided material, was a matter of common observation. Yet it was believed in the third quarter of the last century that the purifying effect of such filtration was entirely mechanical and due to the retention of the suspended matter by the filter. Chemical analyses soon showed, however, that the filtration process led to marked changes in the composition of the sewage. The opinion was expressed that the finely divided material of the filter facilitated the union of atmospheric oxygen with the constituents of the sewage.

At the beginning of the seventies, the study of microorganisms had made sufficient progress, and the work of Pasteur had made an impression deep enough, to raise the question in the minds of some as to the relation of bacteria to the purification of water and sewage. In 1877, the French chemists, Schlösing and Müntz, demonstrated that nitrification is a biological process, thus confirming the opinion expressed some years previously by Alexander Müller in Germany. Other investigators demonstrated that the putrefaction of nitrogenous materials is brought about by microöganisms. The ground was thus prepared for a better understanding of the changes that take place in sewage.

Intermittent sewage-filtration.-Practical experience with the land treatment of sewage demonstrated that the greater purifying effect, as well as the best plant growth, was secured on rather porous soils properly 
underdrained. On heavy, ill-drained soils, the sewage became foul and was purified but little. Moreover, even the lands adapted to sewage-farming could not be forced beyond a certain point in purifying the sewage applied. A proper supply of air was apparently necessary for the rapid and thorough purification of the liquid wastes, and the most satisfactory results were obtained when the land was worked intermittently, that is, allowed periods of rest and aëration.

With the discovery of the biological nature of nitrification, and the further demonstration by Schlösing and Müntz in France, and Warrington in England, that the nitrifying bacteria need a plentiful supply of air for their development, new light was thrown on the efficacy of intermittent filtration.

The system of intermittent filtration is based preeminently on the action of aërobic bacteria. The Mouras scavenger and the septic tank depend for their efficiency on the work of anaërobic organisms. The earlier installations of bacterial filters relied largely on the activities of the former class of organisms. The most satisfactory results were secured when the sewage had been previously subjected to screening and chemical precipitation. When this preliminary treatment was left out the filters showed a marked reduction in capacity, due to the deposition of solid materials around the grains of the filter. In other words, the total pore-space between the solid particles of the filter was reduced on account of the accumulation of materials which the aërobic bacteria were evidently unable to destroy. On further examination, these substances were found to consist of woody 
fiber, like straw, chaff, paper and fragments of the wooden pavements. Here, then, is an important difference between aërobic and anaërobic action. In the case of the latter, organic matter is almost completely destroyed in the septic tank with the formation of a very slight amount of sediment.

In view of these facts, a sewage-purification plant that provides for the activities of both classes of bacteria will allow more complete decomposition of the organic matter than can be accomplished by either the septic tank or the aërobic filter alone. Furthermore, the septic tank will dispense with the preliminary chemical treatment for the removal of the suspended matter, since the latter not only settles out in the tank, but is also liquefied by the anaërobic bacteria.

Separation of bacterial activities.-Thus the gradual development of sewage-purification methods, as based on bacterial activities, may be noted. The clearer understanding of the chemical reactions caused by the various microörganisms and of the part played by atmospheric oxygen in these reactions, made possible the differentiation of the aërobic and anaërobic changes. Following this differentiation came the septic tank, reserved for the activities of anaërobic germs alone, and the aërobic filters, reserved almost entirely for the aërobic bacteria. While in the contact beds the two processes were somewhat mixed, the conditions were so adjusted as to favor one or the other set of changes.

In more recent installations, greater heed has been paid to the separation of the anaërobic and aërobic 
activities, and the septic tank has been accorded a prominent rôle in the purification of sewage.

Temperature and bacterial activities.-The low temperature of the winter months seriously retards bacterial activities. The rising temperatures of spring and summer stimulate these activities to such an extent as to permit the organisms to regain the lost ground. Some classes of bacteria are more susceptible than others to cold weather, yet all are retarded in their growth, as is proved by the diminished efficiency of the bacteriological processes in very cold weather.

Warm countries offer favorable conditions for continuous and intense bacteriological development, and permit the completion of the biological changes in a shorter period. Due consideration should always be given to the paramount influence of temperature in the biological purification of sewage (page 120).

Hydrolysis. - The anaërobic changes that take place in the septic tank involve the breaking down of the complex nitrogenous substances known as proteins, or albuminoids. This transformation, which may be accomplished by a large variety of anaërobic ferments, is known as hydrolysis. The nitrogen of the protein bodies is changed to a large extent into ammonia and other nitrogenous substances somewhat more complicated than the latter, yet simple in composition as compared with the proteins themselves. The non-nitrogenous substances, including the starches, sugars, and cellulose, are also decomposed and transformed, for the most part, into gaseous products. On account of the absence of atmospheric oxygen in the septic tank, these gases are 
still capable of comb ning with oxygen. In other words, they are combustible. Hence, the gases generated in the septic tank and consisting of nitrogen, carbon dioxid, marsh gas and hydrogen, are, in a number of places, used for illumination purposes after the previous removal of the inert carbon dioxid.

Treatment of the effluent.-When the sewage is very strong, the effluent from the septic tank may contain a high proportion of ammonia and other decomposition products, and the concentration may be great enough to retard, for a time, the development of aerrobic bacteria. With proper aëration, however, and with dilution in extreme cases, the effluent may be subjected to further rapid change in the contact beds, or filters. Contact beds, when worked on the intermittent plan, do not exclude the activities of aërobic bacteria. The alternate filling, emptying and resting interfere, however, with the best development of either aërobic or anaërobic organisms. In the filters proper, on the contrary, adequate underdraining and intermittent working permit a better aëration and higher aërobic efficiency.

The latter is further enhanced by sprinkling the effluent over the entire surface of the filter. By reducing the amount of liquid passed through the filter, so as to admit a large volume of air, or by forcing air through the filter by some artificial means, the oxidation processes may be made quite intense. The nitrifying bacteria become more aggressive under such conditions and change the ammonia in the septic-tank effluent into nitrites and nitrates in an incredibly short space of time. The destruction of the organic matter in the 
sewage is then almost complete and the effluent from the filter beds is non-putrescible, and not'injurious to fish.

Temperature and filter efficiency.-The efficiency of the aerrobic filters, like that of the septic tank is affected by changes in temperature. The aërobic decay bacteria, and the nitrifying bacteria in the filters, multiply more and more slowly, and cause less and less chemical change as the. temperature falls. Still, their activity is not entirely suspended, even after a coating of ice has formed on the surface. It may not, however, be vigorous enough to produce the desired transformation. In order to remedy this retarded bacterial action in the winter months, it has been proposed to raise the temperature of the beds by artificial means. In some of the filters designed for this purpose, the filter beds are provided with steam-pipes. However, considerable expense is involved in such treatment-expense not always justified by the circumstances.

It is well known that, among the aërobic as well as among the anaërobic bacteria, there are races that can grow at lower temperatures than others. This leads to a natural selection and the establishment of certain combinations of species under any given set of conditions. It follows, therefore, that the breaking down of the animal and vegetable materials in the septic tank is not necessarily accomplished by the same species in the different localities, or even in two different septic tanks.

Inoculation.- Aside from the temperature, the establishment of definite kinds of bacteria in the tank or in the beds is influenced by the composition and concentration 
of the sewage and the kind of germs native to the water and soil. It thus comes about that the best results from septic tanks, or contact and filter beds, are not obtained until after a more or less prolonged period of preparation. In order to facilitate the process, septic tanks have been inoculated with sewage from old tanks in active operation, and gratifying results have been secured thereby.

Kinds of bacteria in filter beds and septic tanks.-While there is thus a natural variation in the kinds and proportions of bacteria occurring in different sewagepurification plants, and an accompanying variation in the amounts and composition of the products formed by them, it still remains true that certain definite groups of bacteria may be found in all septic tanks and filter beds. The septic tanks all contain rod-shaped, sporeforming cellulose ferments that can destroy woody tissue with the formation of the combustible gases, hydrogen and marsh gas. They also contain several kinds of rodshaped putrefaction-bacteria, and a small proportion of spherical organisms. The contact and filter beds contain, among others, a number of species of small rodshaped bacteria forming no spores and developing preferably in the presence of atmospheric oxygen. They contain, also, the nitrous and nitric ferments whose function it is to change ammonia into nitrites and nitrates, as will be described more fully in the discussion of soil bacteria. Moreover, the bacterial beds likewise contain denitrifying bacteria-organisms that have the power to destroy the nitrates already formed. In the filter beds, a thorough aëration and comparatively small proportion of ammonia may favor the activities of the 
nitrifying bacteria. In the same filter beds, under different conditions, a less thorough aëration and a larger supply of soluble organic matter, may encourage the growth of the denitrifying bacteria and the destruction of the nitrates already formed.

Loss of nitrogen.-The extent of denitrification, that is, the extent of destruction to which the nitrates are subjected, is naturally variable. The same may be said of the bacterial processes in the septic tank and beds, which involve losses of gaseous nitrogen in the course of putrefaction and decay occurring there. Economically, the differences in question are of some moment, especially when the effluents are used for irrigation purposes. It seems, therefore, that with the better understanding of the bacteriological changes in sewage-purification, means will be found to avoid unnecessary losses of nitrogen without detracting from the efficiency of the process. Nitrogen-fixing bacteria have also been found in the bacteria-beds, and actual gains of combined nitrogen observed. Information on this point, however, is very meager.

Bacterial efficiency in sewage-purification.-The capacity of bacteria-beds for the purification of sewage depends on the numbers and kinds of bacteria present there, as well as on the vigor of the organisms. But the bacterial work accomplished in the filter beds is by no means determined by the numbers alone. It may readily happen that 1,000,000 bacteria in one filter bed will perform as much work as $2,000,000$ or $3,000,000$ of the same kind in another bed. The difference is in vigor, or, to use a more exact term, in physiological efficiency. 
Climatic conditions and the methods of construction of filter beds are, therefore, important in so far as they affect the numbers and physiological efficiency of the bacteria.

It will be readily perceived, then, that in tropical and sub-tropical countries, the work of bacterial decomposition is intensified by the more rapid multiplication of the organisms. Furthermore, conditions favorable for the rapid multiplication of bacteria are also favorable for the development of a high degree of physiological efficiency. On the other hand, cold weather retards the multiplication of the organisms and also reacts unfavorably on their physiological efficiency. As an illustration of this are the observations made in Massachusetts in the year following the very severe winter of 1903-1904. When cold weather set in, the filters showed a marked falling off in their efficiency and did not fully recover during the following year.

Factory wastes and bacterial efficiency.-The numbers and physiological efficiency of the organisms may be affected by factors other than temperature and aëration. In industrial centers where the factory wastes are added to the sewage, a favorable effect may be exerted on the sewage bacteria in occasional cases. More frequently, however, such factory wastes are decidedly injurious, and may seriously interfere with the proper working of the bacterial filters.

The use of acids in many industrial processes leads to the production of acid sewage. When the volume of such sewage forms a considerable proportion of the total, the bacteria which are very sensitive to even a 
slight excess of acid in their medium, may be injured or entirely destroyed. Injury may also be caused by other substances not necessarily acid. Thus, the ammoniacal spent liquors from gas works and coke ovens, when forming 1 per cent of the total volume of sewage, apparently do not prevent or retard the purification processes in the bacterial beds. When, however, the spent liquors form as much as 3 per cent of the entire volume of sewage, the injury to the bacteria is at once apparent.

The working capacity of bacterial filters.-There are natural variations in the working capacity of filters of different construction and location. Apart from the thorough digestion in the septic tank and the skilful construction of the filters, the high efficiency in some cases may be ascribed to the favorable temperatures that prevail throughout the year. 


\section{CHAPTER XIV}

\section{SEWAGE-IRRIGATION}

THE application of sewage to the land may be prompted by economic or sanitary considerations, or by both. In countries of slight rainfall, sewage possesses a certain value entirely apart from the plant-food it may contain, since it may be advantageously employed for the sake of its water alone. The arid and semi-arid lands of the West yield profitable returns from sewageirrigation for this, if for no other reason. Even in regions of more abundant rainfall, the application of sewage to light, sandy soils with small capacity for retaining water, is very beneficial. Soils of this type need large and frequent applications of water for the production of maximum crops, even when plant-food is abundant. On the sandy soils of southern New Jersey, irrigation has been found to increase the yields notwithstanding the forty-five to fifty inches of annual rainfall.

Economic value of sewage-irrigation.-Sewage possesses a still further interest, economically, on account of the plant-food constituents contained in it. The nitrogen, phosphoric acid, potash, lime and other plantfood removed by the crops from the soil are carried in part to the city to be discharged ultimately into the sewers and thence to the sea. The land is thus gradually 
deprived of its fertility, and loses, in time, its power to produce profitable harvests when none of the fertility is restored.

It has been estimated by Crookes that England alone wastes in the sewage and drainage of her cities, nitrogen to the value of $\$ 80,000,000$ a year. It has been computed, also, that the conversion of 90 per cent of the nitrogen in the sewage into nitrates, and their utilization, would add $\$ 70,000,000$ annually to the wealth of England. We see, thus, that the value of combined nitrogen and of other plant-food drained away from the cities, towns and villages, must be truly enormous. Hilgard states that nearly $5,000,000,000$ tons of mineral matter in solution are annually removed by the rivers from the earth's surface, and that the amount of sediment similarly carried away is much greater. It is safe to assume that the drainage from human habitations forms an appreciable portion of the substances thus constantly added to the sea.

Knowledge of these facts has naturally encouraged attempts to utilize the manurial ingredients of sewage for crop-production. Efforts have not been wanting to encourage the utilization of the sludge obtained by treating sewage with lime, alumina, or salts of iron. However, the fertilizers manufactured by these processes did not meet with favor among farmers, and the cost of their preparation rendered profitable production difficult. From time to time, enthusiasts still appear who would, in one way or another, extract the valuable fertilizer constituents from sewage.

But, while the extraction of the manurial constituents 
of sewage by chemical means has been found unprofitable on account of the slight concentration of the liquid their utilization for crop growth is occasionally found profitable on sewage-farms. Profitable sewage-farming is, however, exceptional. By far the greatest number of sewagefarms do not yield a profit. Especially is this the case when the initial outlay for land and equipment is included in the charges. The failure of sewage-farms to return a profit is not difficult to understand if we remember that the land near large cities is very costly, that large areas are required for sewage treatment, and that the range of crops grown is frequently limited. Moreover, the proportion of manurial constituents in sewage is, after all, so slight as to make the application of very large quantities necessary in order that an adequate supply of plant-food may be furnished to the soil. At a generous estimate, English sewage may be allowed a value of three or four cents per ton; while American sewage cannot be valued at much more than a cent per ton on the basis of its manurial ingredients. "As Professor Anderson suggested long ago," says Storer, "it would be about as reasonable to expect the farmers to manure their land with the smoke of cities as with sewage; for, as every one knows, enormous quantities of ammonia must be lost in the aggregate from cities where domestic fires are fed with soft coal. But precisely as it is with the smoke, so it is with sewage; that is to say, the fluid is so very dilute that it cannot be put to use."

Sanitary value of sewage-irrigation.-While sewageirrigation has little to recommend it from the economic 
standpoint, as indicated by the facts just noted, more may be said in its favor from the sanitary standpoint. The soil readily retains a large portion of the materials suspended or dissolved in the sewage, and, under favorable conditions, purifies it to such an extent as to make the effluent resemble good drinking-water. The substances retained in the soil are rapidly decomposed by the bacteria and rendered harmless, while the plant-food contained in them is made available. The purifying power of the soil was well known, of course, in ancient times, and utilized to a large extent in protecting the health of man. With the growth of cities in the last century, and the establishment of sewage systems, the large streams became the receptacles of much sewage until the resulting serious pollution.called forth protests and led to remedial legislation. Many communities were thus compelled by law to purify their sewage before discharging it into surface waters. They turned to land treatment as a convenient method for their purpose.

Kinds of irrigation.-The application of sewage to the land is designated as broad irrigation when the liquid is distributed over a large area in order to promote the growth of some cultivated crop. It is designated as intermittent irrigation when much larger quantities are applied, at frequent.intervals, to open, well-underdrained soil. In this case, the land may be seeded and cultivated, or left uncropped. When the volume of sewage is large, and the area of soil available for broad irrigation limited, the two methods may be combined, giving rise to the mixed system of irrigation. 
The early experience with sewage-irrigation soon taught that soils differ strikingly in their ability to effect purification. It was also noted in those days that the purifying power of peat and heavy clay soils was rather limited. We readily see now why this should have been so, for the acid character of the peat retards the growth of decay bacteria, and, more particularly, of nitrifying bacteria. The retarding action in the heavy clay soils is due, on the other hand, to their compact nature and improper aëration, which is a serious hindrance to the aërobic nitrifying ferments. The best results in the purification of sewage were obtained with light sandy soils underlaid by a porous gravelly subsoil, and provided with a sufficient amount of lime. Additions of the latter to the land were found to intensify its purifying power.

Broad irrigation.-The amount of sewage that may be successfully treated by broad irrigation is limited by the area available. Land to which too much sewage is applied, ceases to purify it. It becomes wet and foul; the aerrobic bacteria, whose function it is to accomplish much of the purification, are crowded out, and the sewage runs off unpurified. Matters are made worse even in suitable soils, by the deposition at the surface of various organic materials. These form a felt-like layer and tend to keep out the air. This circumstance necessitates the occasional stirring of the surface soil, as well as the limiting of the amounts applied per given area within a limited time. It is estimated that one acre of land should not receive the sewage from more than one hundred persons. This is, of course, only an arbitrary measure, 
for the character of the land and of the sewage, as well as the climatic conditions, necessarily play here a predominating part.

The effectiveness of broad irrigation in sewagedisposal is further affected. by the constant supply of sewage, irrespective of the season or the needs of the crops. It should be remembered that in the summer there is a rapid evaporation of moisture, not only from the soil, but also a transpiration of water from the foliage of growing plants. The pumping action of the latter is extremely important in quickly disposing of excessive moisture, since it is estimated that about three hundred tons of water must be transpired through the foliage in the production of one ton of dry matter. Moreover, the summer temperatures stimulate the activities of the soil bacteria and make possible thereby a rapid decomposition of the organic matter. In the winter months, on the other hand, the evaporation of water directly from the soil is greatly reduced, the removal of moisture by transpiration entirely discontinued, and the decomposition of the organic matter markedly retarded. It frequently happens, thus, that offensive conditions are created in the vicinity of sewageirrigated farms in the fall and winter months, even when no cause for complaint exists in the summer.

Intermittent and mixed irrigation.-In intermittent irrigation, the business of crop-production becomes of secondary moment. The purpose sought here is to secure the greatest efficiency for any given soil area in the purification of sewage. Porosity, aëration, and a vigorous bacterial flora are the main desiderata here. The land 
is prepared carefully by thorough underdrainage, and the influences injurious to intense bacterial activity are eliminated as far as possible. The treatment of sewage by intermittent irrigation is, therefore, much akin to its treatment in bacterial filters.

Satisfactory results from sewage-irrigation are secured when broad and intermittent irrigation are combined. A portion of the land, properly prepared and underdrained, is employed for intermittent irrigation when the sewage cannot be used to advantage on the growing crops. In this manner, the land is not made to receive more sewage than it can readily purify. Moreover, the entire process becomes, in a way, intermittent, since the application of sewage is not too frequent, nor too severe to permit adequate aëration.

The crops grown on sewage-farms.-These must be capable of transpiring large quantities of water, and must otherwise be adapted to the soil conditions. Italian rye grass has been grown extensively on the sewagefarms in England and Scotland. It grows very rapidly, crowds out weeds, and yields several heavy cuttings in one season. It requires reseeding every three years, although usually it is succeeded at the end of that time by other crops, like mangolds or cabbages. On some of the irrigated meadows the rye grass has been replaced by a mixture of native grasses which likewise produce heavy yields of dry matter. Alfalfa has also been grown successfully on sewage-irrigated lands near Paris and in our western states. Like the Italian rye grass, it transpires enormous quantities of water. On the whole, however, leguminous crops are not adapted for sewage-farms. 
Preliminary treatment of sewage for sewage-farms.The clogging of the surface soil by the suspended matter in the sewage has led, in some places, to its preliminary treatment with chemicals. The suspended solids are precipitated by means of lime, or salts of alumina and iron, and the resulting deposit (sludge) is removed. The clear liquid still contains a considerable amount of organic matter in solution. When allowed to stand, it undergoes decomposition and gives rise to the same offensive conditions created by the untreated sewage. When applied to the land, however, it decomposes more readily, does not clog the soil to such an extent, and is evidently more suited than untreated sewage to promote the activities of the nitrifying bacteria. This is particularly true of the sewage that has been clarified by lime, for the latter promotes the desirable changes.

The advantages of preliminary treatment, aside from those already mentioned, include the greater capacity of any given area for sewage-purification. For instance, the official regulations in England required one acre of gravelly loam soil for every one hundred persons when the sewage was untreated, but allowed one acre for every four hundred persons when preliminary treatment was carried out. The favorable influence of the preliminary treatment of the decomposition of the sewage in the soil is offset by the accumulation of large quantities of sludge that results. When left to itself, the sludge does not dry rapidly, but undergoes putrefaction and creates a nuisance. It must be disposed of in one way or another, thus involving considerable expense to the community. 
Objections to sewage-farming.--Objections have been raised against sewage-farming on account of the possible dangers to public health arising therefrom. It has been urged that the dust particles and tiny drops of moisture carried away by the wind from the sewage-irrigated land may contain disease germs that may be thus brought to the city. It has been urged likewise that the disease germs may be carried away from the irrigated land by flies and other insects that frequent it. It has been asserted, furthermore, that there is great danger in using the vegetables and other products raised on sewagefarms, because the germs in the sewage readily cling to the leaves, stems and roots of the plants. The cows pasturing on the meadows, or consuming the grass and root crops from the irrigated land are liable to come in contact with the disease bacteria.

Actual experience in sewage-irrigated districts has failed, however, to confirm these fears. The very considerable number of gardeners on the sewage-farms near Paris and Berlin show no greater amount of disease than the people in the city. The grass from the sewageirrigated meadows near. Edinburgh have been used for many years in large dairies as well as by owners of single cows, yet there is no record of any outbreaks of sickness that could be directly attributed to the consumption of such crops. Individual cases of sickness may, however, have thus arisen in the past. If any serious danger at all exists in this direction, it is the danger that a portion of the sewage will escape unpurified into wells or surface water used for drinking purposes, a dangè which sewage-irrigation shares with other methods. 
Sanitary efficiency of sewage-purification.-The various methods of biological treatment of sewage are, to a great extent, effective, in that they destroy the organic matter and produce a non-putrescible effluent. Purified effluents of this character do not seem to affect injuriously the potable qualities of the surface waters to which they are added. Instances are even recorded in which they actually improved the water into which they were discharged. The water that drains away from the sewage-irrigated lands near Paris is clear and sparkling. It is used for drinking and fish thrive in it.

When sewage-purification is considered as a means for the destruction of the disease germs contained in it, there is no certainty of its absolute reliability. In this case it is not so much the number as the kind of bacteria that survive the purification process, that is of importance. Much work has been done in the study of this problem, but the results are somewhat conflicting. It has been shown that the growth of the sewage bacteria is inimical to the survival of typhoid germs. Cultures of the latter, introduced into unsterilized sewage, tended to disappear rapidly, and only an occasional individual survived.

In order to eliminate any possible contamination of drinking-water by the disease germs, it has been proposed to treat the effluents with what Rideal calls finishers, that is, substances that will effect the sterilization when added to the purified sewage at the rate of a few grains per gallon. Ozone could probably be used for the same purpose, as recent experiments indicate. It remains to be demonstrated whether large volumes of effluents can be thus treated effectively and economically. 


\title{
PART IV
}

\section{Bacteria in Relation to SoIl Fertility}

\author{
CHAPTER XV
}

NUMBER AND DISTRIBUTION OF BACTERIA IN THE SOIL

THERE are species of bacteria so common in cultivated soils as to constitute a definite bacterial flora. This flora may vary with climatic conditions, the composition of the soil, and the methods of tillage and cropping. However, it shows fairly constant characteristics. By agitating a small quantity of fresh soil with some sterile water, a turbid liquid, in which the bacteria remain in suspension for a considerable length of time, is obtained. When placed under the microscope, a drop of this liquid will be found to contain not merely a large number of microörganisms, but, also, numerous species, as indicated by differences in shape and size. Rod-shaped, spherical, spiral and boat-shaped forms may be distinguished among them without great difficulty. The rod-shaped organisms will be present in by far the greatest proportion. As in the case of water and sewage, some of the organisms are endowed with the power of motion and others are devoid of it. There will also be spore- 
forming and non-spore-forming organisms, and aërobic and anaërobic bacteria.

But whatever interest is attached to the size and shape of the soil bacteria as viewed under the micro-

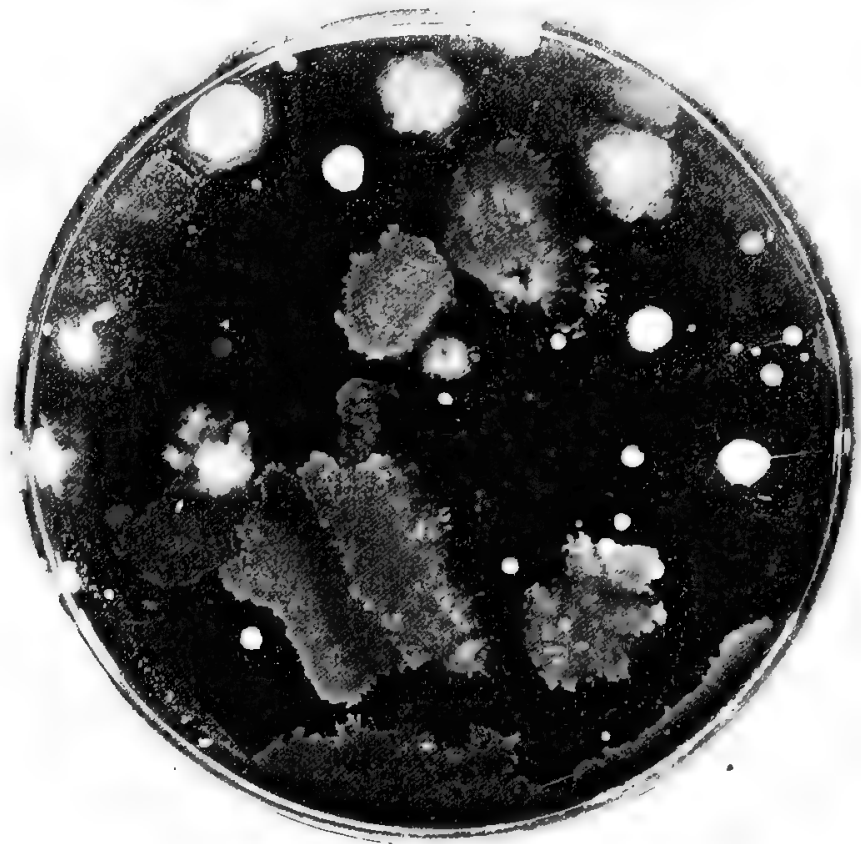

i

Fig. 18. Colonies of soil bacteria.

scope, it must be remembered that there is reserved for them a certain task, upon the proper performance of which depends the well-being of more highly organized creatures. They are the connecting link between the 
world of the living and the world of the dead. They are the great scavengers intrusted with restoring to circulation the carbon, nitrogen, hydrogen, sulfur, and other elements held fast in the dead bodies of plants and animals. Without them, dead bodies would accumulate, and the kingdom of the living would be replaced by the kingdom of the dead. And yet the soil bacteria are not mere destroyers, for there are among them species that do constructive work, also indispensable.

Number of bacteria in soil.-The number of bacteria in arable soils is large, ranging from several hundreds of thousands to several millions per gram of soil (about $\frac{1}{28}$ of an ounce). In dry, sandy soils, very poor in humus, their numbers may be low, scarcely more than a few thousands per gram. In rich loam soils, they may reach the enormous total of fifteen to twenty millions per gram. In soils polluted with sewage, the number of bacteria may, at times, exceed one hundred millions per gram.

There is a very intimate relation between the moisture content of the soil and the number of its bacterial inhabitants. Periods of rainfall are followed by a very marked increase in the number of soil bacteria. Periods of drought are inimical to their development. The temperature of the soil has also a very direct relation to the number of its bacteria. Like higher plants, they need a certain degree of warmth for the manifestation of their vital activities. They cannot grow in the frozen earth, and they must wait for moisture and warmth to wake them up and to stir them into activity.

With the coming of spring and of the longer hours of sunshine, the water moves more freely through the 
soil; the rock particles give up some of their constituents which serve as nourishment for the soil bacteria, as well as for the higher plants. The microörganisms, under such conditions, grow in numbers and vigor.

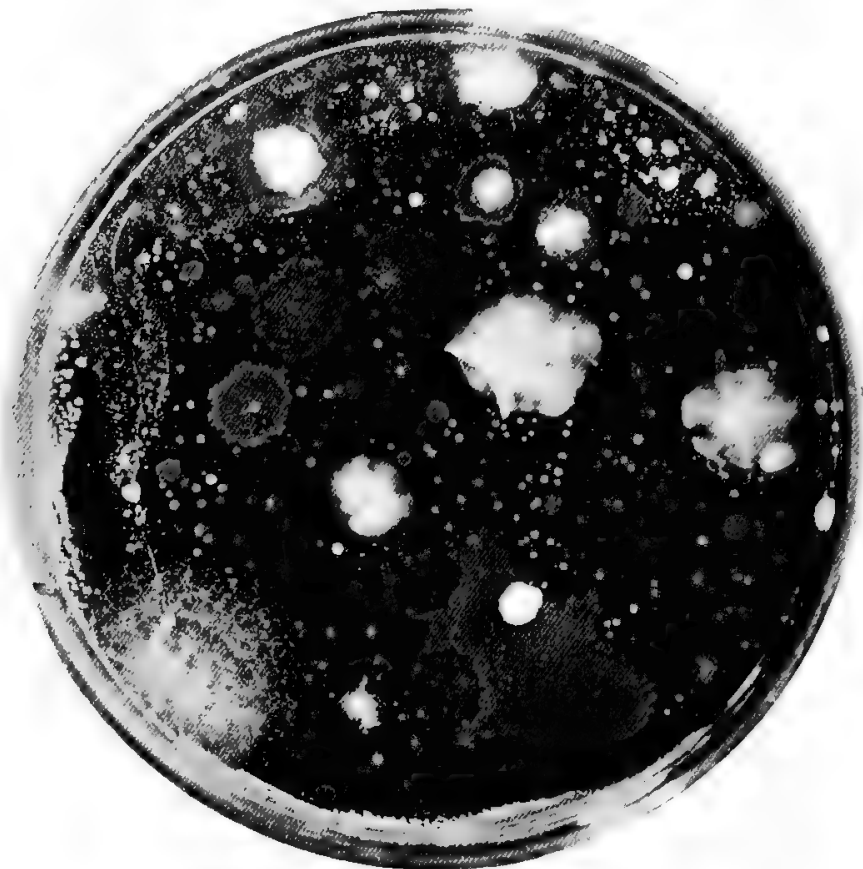

Fig. 19. Colonies of soil bacteria.

It is for this reason that in the warm summer months the moist soil is in slighter need of additional fertilization. The chemical and bacterial activities are then intense enough to provide for an adequate supply of 
food for the growing crop. On the other hand, the colder months of early spring do not provide the best conditions for the rapid transformation of plant-food in the soil.

There is a certain relation between the character of the soil and the numbers and kinds of bacteria growing in it. Sandy and sandy loam soils allow the air to penetrate them rather freely. Thus the development of the so-called aërobic species, that is, the kinds of bacteria that will not grow when the supply of air is excluded or limited, is favored. Heavy clay soils and clay loams do not permit the air to circulate freely in them. For this reason the aërobic bacteria do not find in them the best conditions for their development. However, the anaërobic species, that is, the kinds that grow by preference when the supply of air is cut off or limited, are favored in their growth. It happens thus that the proportion of the aërobic and anaerrobic species is not the same in the two classes of soil.

The altitude of the field is of some importance in determining the numbers and kinds of its bacteria. The distance above sea-level affects the pressure and, therefore, the circulation of the air in the soil. The bacteria in the soil may also be affected to some extent by the character of the prevailing winds and the exposure of the land. Mountain slopes and hill-sides turned to the south offer different conditions for the growth of soil bacteria than those offered by northern exposures.

There exists unquestionably an important relation between the crop on the soil and the numbers and kinds of bacteria within it. For one thing, the leafy crops that 
shade the soil create conditions as to moisture, temperature and light that are different from those created by cereal crops. The differences do not, by any means, stop there. The crops take plant-food and moisture from

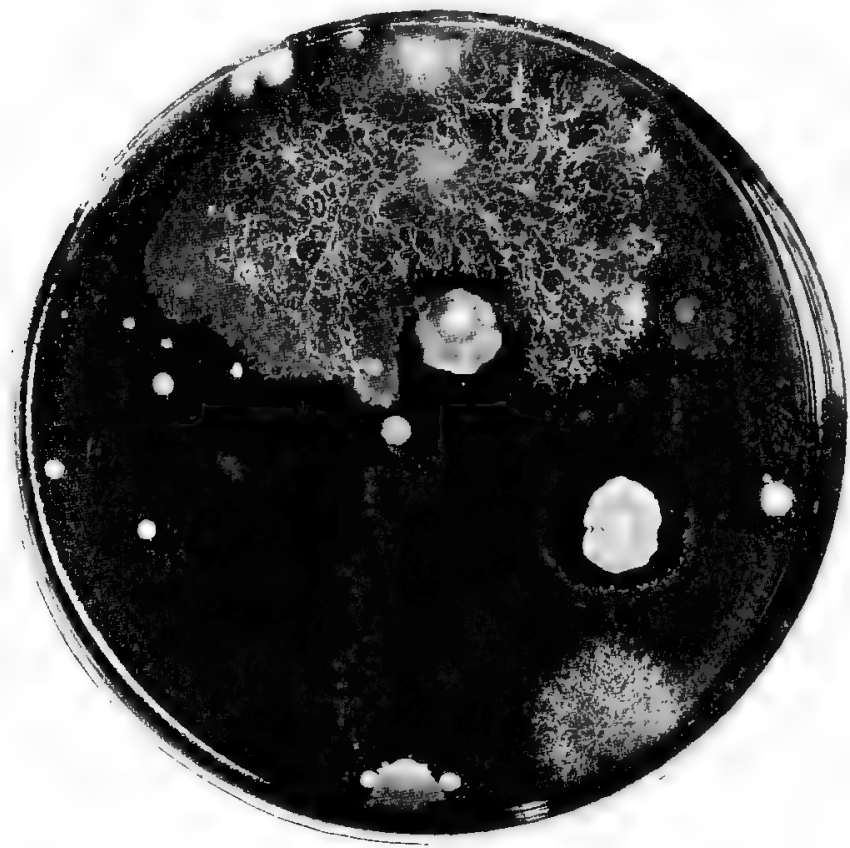

Fig. 20. Colontes of soil bacteria.

the soil and give back to it some of their substance, something that passes out of the roots and into the soil. Our knowledge of the amount and nature of the substanstances thus given up to the soil by the plants is meager. It is not known as yet to what extent these secretions 
influence the numbers and kinds of bacteria in the soil. There is reason to believe, however, that a decided influence is thus exerted by the growing crops. These affect the growth of soil bacteria in still another way.

It is a well-known fact that different crops do not take out of the store of available constituents in the soil the same amounts and proportions of plant-food. For this reason, they affect the composition of the soil to an unequal extent and unequally change the numbers and character of the soil bacteria. The effects of different systems of cropping are clearly distinguishable both in the size and quality of the harvests and in the endurance of soil fertility. The pernicious effects of the continuous growing of cereals were noted generations ago, and led gradually to the introduction of rotation systems. It seems that the evil effects of continuous grain-growing are due in part to the one-sided and wasteful changes in the soil-humus caused by bacteria. On the other hand, a succession of different crops, including members of the legume family, creates conditions favoring an economical transformation of the soil-humus. It will thus be seen that there is a direct relation between the crops on the soil and the bacteria in the soil.

The number of soil bacteria varies likewise with the methods of tillage. All of the mechanical operations, such as plowing, harrowing, disking, hoeing, and rolling, which affect the evaporation from the soil, the penetration of air, or the supply of moisture from the subsoil by capillary action, affect the rate of increase of the soil bacteria. The numbers of bacteria in the soil are readily affected by the application of manures and fertilizers as 
well as by the turning under of green-manures. When any of these manurial substances are introduced into the soil, there are changes produced in its content of soluble salts, and, likewise, modifications in its moisture and aëration conditions. An additional factor is introduced in the case of barnyard manure, since the latter is a material rich in bacteria. An application of several tons of manure per acre introduces into the soil many millions of bacteria, and not only adds thus to the numbers already present there, but also influences the rate of subsequent increase.

The kinds and numbers of bacteria in the soil bear also a certain relation to the processes of irrigation and drainage, to subsoiling, to the once prevalent practice of paring, burning, sanding, or claying, and, more particularly, to the important processes of marling and liming. The application of lime, or of lime marl, exerts a far-reaching effect on the numbers and species relationsh:ps of the soil bacteria. The effect of such application may be observed for years in the size and quality of the crops grown.

Distribution of bacteria in the soil.-After the middle of the last century, when the universal presence of bacter a began to be more widely recognized, bacteriologists turned their attention to the soil as a breeding-place for various microörganisms. Miquel in France showed in 1879 that the soil, at a depth of several inches below the surface, may contain very large numbers of bacteria. Several German investigators who studied the subject in the eighties of the last century confirmed Miquel's results. It was demonstrated by them that the greatest 
numbers of bacteria are present, not immediately at the surface, but at a slight distance below it. It was also shown that the number diminishes rapidly as the distance from the surface is increased.

The smaller number of bacteria at the surface, as compared with that four or five inches below, is due, largely, to less favorable conditions in regard to moisture and organic matter. Beyond the zone of root-development, the decrease of humus naturally involves a rapid decline in the number of bacteria. Moreover, the air is not renewed as readily at greater depths from the surface, and the aërobic organisms find conditions there unfavorable for survival. There is a tendency, of course, for the bacteria to be carried to the deeper soil layers by the rain-water percolating downward. Yet this tendency is checked by the filtering action of the soil, the organisms being held back in the fine pores of the latter. It is evident, likewise, that in the more open sandy soils the bacteria are not filtered out as rapidly, and are, therefore, scattered through a greater depth. 


\section{CHAPTER XVI}

\section{THE RELATIONS OF BACTERIA AND HUMUS}

Humos is defined as "decaying organic matter in the soil." It is the seat of all the important bacteriological activities for the very reason that it furnishes food and energy to the microörganisms. The bacteria are unlike the green plants in that they do not depend for their food on the roots, stubble and other remains of plants and animals. These organic remains are capable of furnishing nourishment and energy to the bacteria. In other words, they possess potential energy. It follows, therefore, that, everything else being equal, the greater the amount of humus in the soil, the greater the number of its bacteria.

The quantity of humus as affecting number of bacteria.Besides furnishing food to the bacteria, the soil-humus also favors their development by providing better moisture and temperature conditions. Because of its great water-holding power, the humus enables the soil to retain greater quantities of moisture. The latter, in turn, provides for a more uniform temperature. It has been demonstrated by experiment that soils well provided with humus do not become warm, or cool as quickly as do similar soils poor in humus.

The application of barnyard manure multiplies the 
soil bacteria since it not only adds directly to their number, but also furnishes food for their further development. On the other hand, green-manures and organic fertilizers, like cottonseed meal, castorpomace, or tankage, do not add as great numbers of bacteria to the soil, and are chiefly valuable for the food they furnish to those already in the soil.

Arid and semi-arid soils oontain smaller proportions of humus than those found in humid soils. It would seem, therefore, that aside from the moisture conditions in the former, the two classes of soils must show very considerable bacteriological differences.

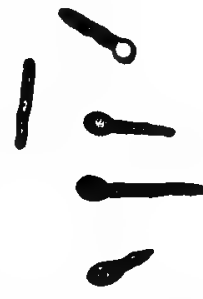

Fig. 21. Bacillus tetani (Lack jaw bacillus), occurring in the soil; $\times 3,000$ (Hewlett.)

Quality of humus as affecting number of bacteria.The influence of the quality of humus on the soil bacteria is also important. The so-called mild humus, or mull, of arable soils, or of woodland, is different in its composition from the raw humus of heaths, meadows, and swamps. It influences in an entirely different way the numbers and character of the bacteria. The differences observed are due largely to the origin and mode of formation of the two classes of humus substances. The mild humus is formed under conditions admitting the free access of air and through the activities largely of aërobic organisms. It is either neutral or alkaline in reaction. The raw humus is formed through the process of putrefaction rather than that of decay. It is acid in reaction, and is not a suitable medium for the development of most bacteria. It has been shown that peat 
lands contain a relatively slight number of bacteria before they are reclaimed and placed under cultivation. When drained and limed, the number of bacteria soon increases from a few thousands to many millions per gram of soi .

\section{BACTERIA AND TiHE DECOMPOSITION OF SOIL-HUMUS}

The dark-colored humus substances in the soil, the extensive deposits of peat in certain localities, and the beds of bituminous and anthracite coal have a common origin. They are all derived largely from atmospheric air.

The atmosphere that surrounds our earth is a mixture of transparent gases, two of them, nitrogen and oxygen, being present in large proportions. A third, carbon dioxid, is present only in a small proportion,- - three of four parts in ten thousand parts of dry air. It is believed that at an earlier period in the history of our earth the atmosphere contained a larger proportion of carbon dioxid. Owing to the latter, and to an abundance of moisture, the plants of that period grew more luxuriously and accumulated an enormous amount of vegetable matter which was transformed, in the course of many centuries, into bituminous and anthracite coal.

The growth of plants in our own day, while not so luxuriant as that in the carboniferous era, still takes place in accordance with the same laws. The colorless gas, carbon dioxid, is decomposed by green plants into its constituent parts, carbon and oxygen. The carbon is utilized by the plants for the building of their tissues. 
It thus comes to pass that plants lock up in their bodysubstance enormous amounts of carbon combined with other elements, chiefly oxygen, hydrogen, and, to a smaller extent, nitrogen. When the plants die and mingle with the soil, their carbon becomes a part of the latter as soil-humus. Hence, soil-humus, the decaying remains of plants, owes its existence to the carbon and nitrogen of the air, as well as to the hydrogen and oxygen derived from the water-vapor of the atmosphere.

But if the vegetation of forests, meadows, and prairies continued indefinitely to draw upon the comparatively small amount of carbon dioxid in the air for their carbon, the time would come when the atmosphere would have but little left. The surface of the earth would become covered with vast accumulations of fallen trees and tangled herbs, and, in time, plant and animal life would cease because of the exhaustion of the carbon dioxid in the atmosphere.

Fortunately, however, there is provision in nature for the restoration of this carbon dioxid. In the burning of wood and of coal, the carbon of these materials is changed again into carbon dioxid; in the respiration of animals the carbon of their food is changed to carbon dioxid, and, more important still, in all the processes of decay and putrefaction carbon dioxid is formed. Indeed, life could not persist without decay. The dead tissues must be resolved into simple substances that new life may arise and find expression in an almost endless variety of material forms.

The vastly important processes of decay and putrefaction are biological in character. They would not take 
place in the absence of bacteria and of other microörganisms. The bacteria are thus the great scavengers of the living world, supplementing the work of the green plants. These are the builders of organic materials, the bacteria are the tireless destroyers. Under their

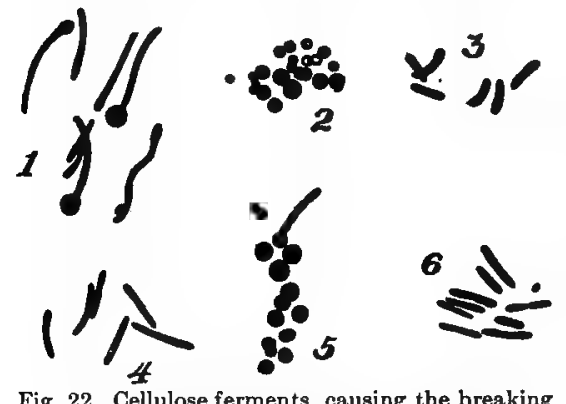

Fig. 22. Cellulose ferments, causing the breaking down of woody tissue $-1,2$, and 3 . Hydrogen bacillus; $\times 2,000$. (Omelianski.) 4,5 and 6. Methane bacillus; $\times 2,000$. (Omelianski.) attack the roots and the stubble of cultivated crops, the leaves and twigs of forest trees, or the bulk of barnyard and green-manures are changed slowly into darkcolored humus substances. Without bacteria and other microörganisms such changes would not take place at all, or else very slowly.

It has been demonstrated time and again that soils sterilized by heat, or treated with antiseptic substances, like chloroform, carbon bisulfid, or carbolic acid, either cease to give off carbon dioxid, or yield only minute quantities of it. Similar soils, not sterilized, continue to form large amounts of this gas. Furthermore, soils or quantities of manure that have been sterilized begin to give off carbon dioxid in large quantity soon after they are inoculated either with pure cultures of certain bacteria, or with mixtures of several species. It has thus been established that the decomposition of vege- 
table and animal substances in the soil, and the return of the carbon dioxid to the air, are accomplished by bacteria. To them has been assigned the important task of maintaining the proper circulation of carbon in the living world, and, from the very beginning of organized life, they have unceasingly worked at their task.

The rate at which the soil-humus decays is of vital concern to the farmer. Under certain conditions it

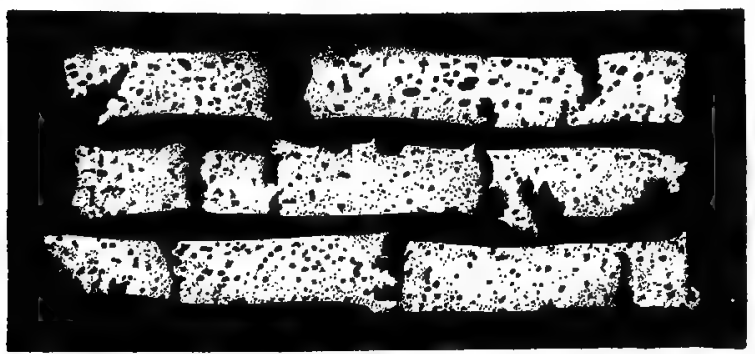

Fig. 23. Strips of filter paper (woody fiber), showing gradual decomposition by cellulose ferments. (Omelianski.)

vanishes from the soil quite rapidly, notwithstanding the utmost efforts of the farmer to enrich his soil. Large applications of animal manures and the turning under of green crops seem to leave no lasting effect. The soil remains light in color, and capable only of retaining a small fraction of the rainfall. Under other conditions, the soil does not seem to digest its humus properly. It becomes sour to an increasing extent, and its crops languish. The same manures that rapidly disappear from one soil accumulate in another. The different results thus noted should be attributed to the microorganisms of the soil. 
The soils that allow a rapid disappearance of their humus are usually sandy or sandy loams, warm and well drained. The air circulates freely in them down to a considerable depth; the soil bacteria, particularly the aërobic species, develop in great numbers, and the carbon of the humus is returned to the air as carbon dioxid. Decay, under such conditions, is really slow burning, and the organic matter is, in time, reduced to a little heap of ash, as if it had been destroyed by fire. The term "eremakausis," which means slow burning, has been applied to this process.

It has been demonstrated by analyses of air contained in the soil that its oxygen is used up rapidly in this bacterial burning of the humus. Such soil-air has been found to contain as much as 9 per cent of carbon dioxid and only about 11 per cent of oxygen, instead of the 20.90 per cent of oxygen and .03 to .04 per cent of carbon dioxid found, on the average, in the air above the soil. The average of nineteen analyses of soil-air, made by von Fodor, showed 2.54 per cent of carbon dioxid and 18.33 per cent of oxygen; whereas, the air above the soil contained .04 per cent of carbon dioxid and 20.96 per cent of oxygen.

All this goes to show that not only is the carbon in the humus changed to carbon dioxid, but that this is accomplished at the expense of the oxygen in the soilair. When the oxygen is thus used up rapidly, the decomposition of the humus is checked somewhat, and it is conceivable that soil-air deprived of all, or nearly all, of its oxygen will no longer supply the proper conditions for decay. It happens, however, that in the open 
sandy soils the interchange of gases between soil and overlying air is rapid, the supply of oxygen is renewed without great difficulty, and the processes of decay go on uninterrupted.

In fine-grained, compact soils, the conditions are different. These soils do not part as readily with the rain that falls upon them; their power of lifting water from the subsoil is greater, and a larger portion of their air-space is therefore occupied by water. Furthermore, because of their compactness, the air does not enter them or circulate in them as freely. Hence, the decay. processes in such soils are not so intense. In extreme cases, the humus accumulates more rapidly than it is destroyed. This is true of water-logged soils, of swamps and meadows, and also of upland moor and heath soils.

In the presence of excessive moisture the aërobic bacteria are almost entirely suppressed, and the anaërobic species become prominent. The decomposition process then partakes of the nature of putrefaction, which does not involve as far-reaching destruction of the organic matter. The air being argely or entirely excluded, the carbon of the humus is changed only partly to carbon dioxid, and that at the expense of the oxygen derived from decomposing vegetable matter. Another portion of the carbon passes off as marsh-gas, while.a third portion remains in the soil in the form of sour compounds-so-called humic acids. The humic acids and other substances formed with them are more or less antiseptic in character. Peat, for instance, is a material that is resistant to decay even after it is removed from the swamp. The sour humus of upland 
moors and heaths is due not so much to absence of air as to absence of moisture. The place of the bacteria is taken, in this case, by various molds and fungi which, in their development, give rise to the formation of acid compounds.

When the soil-moisture is neither excessive nor deficient, fine-grained soils, like those of coarser texture, allow the change of their carbon to carbon dioxid, but at a less rapid rate. For this reason, the disappearance of humus from such soils is comparatively slow, even when the land is frequently tilled. The effects of barnyard manure, or of green-manure, may be observed years after the influence of similar treatment is no longer apparent on sandy soils. Taking it altogether, then, clay soils, or clay loams do not part with their humus as rapidly as do sandy soils or sandy loams. When they are very compact, the normal rate of decomposition is too slow for profitable crop-production, and resort is then had to drainage, liming, or manuring,operations which serve, among other things, to admit more air into the soil. The soil bacteria are then permitted to develop more rapidly, and to cause the desired changes.

In most soils under cultivation, the exhaustion of humus is rapid. To offset this loss, the soil is seeded down to grass from time to time, and receives, also, applications of barnyard manure. The undisturbed sod diminishes the aëration of the soil and reduces the rapid oxidation of the humus. The latter is thus allowed to increase in quantity. Barnyard manure furnishes humus-forming material and serves to replenish the 
depleted stores. The roots and stubble added every year are a further addition to the soil-humus. Hence, the losses and gains bear a certain relation to one another. The crop residues and small or moderate applications of manure on heavy soils may be sufficient to maintain them in a satisfactory physical condition for many years. The supply of commercial fertilizers alone may prove adequate under such conditions for profitable crop-production.

On the other hand, the crop residues and small applications of manure on sandy soils are not adequate in replenishing their humus. Humus-forming material must be applied in large amounts if the soil is to remain fertile. Hence, the practice of market-gardeners on such soils, of buying manures, or of raising green-manuring crops. It is because of the more rapid work of soil bacteria in the well-aërated, light soils that the latter have shown themselves capable of profitable cultivation under systems of green-manuring. They digest the organic matter rapidly and can, therefore, in a comparatively short time, unlock the insoluble plant-food contained in it, and place it at the disposal of the growing crop.

As the fresh roots and stubble, turned under from the green crop, or the animal manures applied, are attacked by the soil bacteria, they begin to change rapidly at first, and more and more slowly as time goes on. From practical experience and from vegetation experiments it is known that these materials usually benefit the crop most in the first year after their application. In the second growing season the benefit is less pronounced, 
and in the third, still slighter. This diminishing effect from the application of the manures is due partly to the reduction of their plant-food by the first crop and partly to the gradually decreasing availability of the remaining portion.

It seems that the bacteria first attack the substances they can destroy most readily. After these are used up, they cannot grow very fast on account of the greater difficulty in securing their food from the residues. In the course of time, only the most resistant portions of the soil-humus remain, portions that change so slowly as to prohibit normal crop growth. Chemical analysis shows that the carbon disappears from the humus at a more rapid rate than does the nitrogen. Hence, in old humus, a smaller proportion of carbon is found, and a larger proportion of nitrogen. In regions of scant rainfall, the proportion of humus in the soil is much smaller than that in humid regions. But the humus of arid soi $\mathrm{s}$ is richer in nitrogen to such an extent as to be able to supply a sufficient amount of it to the growing crops in the irrigated districts. 


\section{CHAPTER XVII \\ BACTERIA AND THE TRANSFORMATION OF SOIL-NITROGEN}

Nitrogen is one of the essential elements. There can be no life without it. It makes up nearly four-fifths of the gaseous envelope surrounding the earth, there being about thirty-five thousand tons of it over every acre of ground. Like the air above the ground, the soil atmosphere contains almost four-fifths nitrogen. This nitrogen, however, cannot ordinarily serve as food for plants. It must be combined with other elements in order to do so.

The source of nitrogen in the soil.-The crops growing on the land must depend for their supply of nitrogen on the humus, for this contains practically all of the combined nitrogen in the soil. There is but one exception to this, - the plants of the legume family. These possess the power of utilizing free nitrogen for their growth. But even they are deprived of this power in the absence of certain bacteria.

Proportion of nitrogen in the soil.-Cultivated soils contain, on the average, 0.1 to 0.2 per cent of nitrogen in the surface portion. Taking the average weight of an acre of ground to a depth of nine inches to be about $3,000,000$ pounds, we find 3,000 to 6,000 pounds of combined 
nitrogen per acre to that depth. Smaller, but still considerable, quantities of nitrogen are found in the subsoil. It has been estimated that in some of our rich prairie soils there are present in every acre of ground 25,000 pounds of nitrogen to a depth of three or four feet. All this nitrogen exists in the humus in the decaying tissues of plants that once grew in the soil.

The interesting question arises as to the origin of all this nitrogen. We know that the phosphorus and potash, as well as all the other mineral ingredients of plant-food, are derived from the rocks of which the soil is made. We know, also, that the rocks of the earth's surface do not, as a rule, contain any compounds of nitrogen. We must conclude, therefore, that all of the combined nitrogen in our soils is derived from the nitrogen in the air. Soil bacteria have played, throughout many ages, a predominating rôle in the accumulation of humus-nitrogen. The activities of other soil bacteria, that concern the various changes that the humusnitrogen undergoes, are varied and numerous.

- Nitrogen compounds in the soil-humus.-The nitrogen compounds in the soil-humus are complex. They are akin to the protein substances of food, and, as such, cannot be utilized by the crops. They must first be broken down and changed into simple substances,ammonia, nitrites and nitrates. The breaking down of the nitrogen compounds in the humus is accomplished by bacteria and fungi in the soil. For them is reserved the task of providing building-material for the tissues of higher plants. These destructive activities of the soil bacteria mean so much to cultivated crops that it be- 
comes proper to inquire whether the transformations due to them may not, at times, be wasteful.

Loss of nitrogen in the soil.-Many facts recorded in agricultural science prove that under certain conditions the nitrogen removed by crops forms but a small portion of the total quantity lost from the soil. Investigations show that in the continuous cultivation of wheat the changes in the humus may be so wasteful as to constitute a most serious drain on the nitrogen resources of the soil. The losses thus occasioned bear a certain relation to the physical character of the soil, to its waterholding power, to its chemical composition, to the methods of tillage to which it is subjected, and to the crops grown upon it. The bacterial digestion of humus proceeds quite rapidly in the open sandy soils. The decomposition processes there may be so rapid as to preclude the accumulation in them of any considerable quantities of humus. Under such conditions, the organic nitrogen applied is changed more or less wastefully.

Availability of nitrogen.--In assigning a certain degree of availability to nitrogenous substances from one source or another, the significant part played by the soil and its bacteria in the transformation of such substances is frequently overlooked. Barnyard manure, green-manure, or tankage, that show a high rate of availability in one soil may prove much less available in another. For instance, out of every one hundred pounds of nitrogen applied in barnyard manure, the crops of one soil may recover thirty-five pounds in the first year, ten pounds in the second year, and five pounds in the third year. The same crops may recover from the 
same manure in a different soil twenty pounds in the first year, five pounds in the second year, and two or three pounds in the third year. Evidently, the transformation would be more economical in the first instance; and the differences noted might be attributed to a greater proportionate loss from the soil, or the change of a greater proportion of the manure nitrogen to very inert combinations.

The losses responsible for a low rate of availability may be twofold. They may be due to the setting free of gaseous nitrogen in the course of decomposition, or they may be due to the leaching out of the soluble nitrates. In the first instance, there are conditions extremely favorable to rapid decay, that is, a rapid union of the carbon and hydrogen of the humus with atmospheric oxygen. The humic nitrogen is not allowed to retain its hold on the hydrogen, as it would do when the processes of decay are more gradual; hence, it is forced to return to the atmosphere in the gaseous state.

Rapid decomposition of this character can only occur in very open soils in which the aërobic bacteria may develop unhindered in the presence of sufficient moisture. The losses from the leaching of nitrates will depend again upon the amount of rainfall and the character of the crop. Excessive precipitation may wash the nitrates into the subsoil beyond the reach of the roots, and thus diminish the proportion of nitrogen available to the crop. Some crops possessing a deeper root system will forage more thoroughly in the soil, and will prevent large losses of nitrate.

It is thus evident that the economical utilization of 
humus- or manure-nitrogen is affected by the character of the soil, by climatic conditions, and by the crop. The character of the soil bacteria is also important. The soil bacteria accomplish their work because of their vast numbers, but the amount of work accomplished is not necessarily proportionate to their numbers. The soil bacteriologists have come to realize, more and more, that bacteria, like higher plants, show differences in vigor and in their ability to survive the competition of other species. A cultivated field abandoned to itself is soon overrun by weeds; a certain number of the latter become more prominent than others, and a characteristic flora is, in time, established. The nature of this flora is determined by soil and climate, and likewise by the adaptation of the predominant species to soil and climatic conditions.

Something of the same nature holds good in regard to the bacteria of our soils. The natural methods of selection bring about not only a predominance of certain species under given conditions of soil and climate, but also endow these species with varying degrees of vigor which may find expression in the rate of increase or in the ability to form characteristic products. For instance, there are certain species of bacteria capable of fixing atmospheric nitrogen. Two strains of these bacteria may be apparently alike in every particular, one multiplying as rapidly as the other. The amount of nitrogen fixed by these two may show considerable differences. We find analogous conditions when, by breeding or selection. a strain of wheat, corn or potatoes is developed that yields larger amounts of plant substance. In con- 
sidering the work of soil bacteria, therefore, not only numbers must be considered, but, also, physiological efficiency.

Conditions affecting availability of nitrogen.-In the decomposition of soil-humus and in the economy of its nitrogen transformation, it has been seen that soil and climatic conditions may modify the numbers, physiological efficiency and species relationship of the soil organisms. Certain conditions may not only favor the predominant development of certain species, but also a decided increase in the physiological efficiency of the latter. There is reason to believe that in the breaking down of the complex nitrogenous substances in the humus some species may occasion slighter losses than others. For this reason, the wasteful change of humusnitrogen may be due to certain species rather than to others. Some of them are capable of causing intense oxidation processes; that is, extremely rapid decay, while others have but a feeble power in this direction. Hence, the greater losses of free nitrogen under certain conditions already noted.

It seems highly important and desirable, in view of the facts just stated, that our knowledge of the various conditions of decay in the soil and of the manner in which the bacteriological transformation of humusnitrogen is affected by soil, manuring, cultivation, and crop-rotations, be increased. Such increased knowledge would enable us to provide for a better conservation of soil-nitrogen, and would add greatly to the economy of crop-production.

Bacteria as chemical agents.-The soil bacteria are 
not destroyers only. To some extent, they are also builders, for any change caused by them. in the soilhumus, whether it be ammonification, nitrification, or denitrification, involves necessarily their multiplication. Since, however, the bacterial bodies are complex in their structure, they add to the soil considerable quantities of highly organized materials derived from the simple decomposition products of humus. Soil bacteria, like higher plants, utilize for their growth the soluble mineral salts in the soil, particularly the soluble phosphates and sulfates. They also make use of the ammonia, and, particularly, the nitrates derived from the humus for the building of their bodies. Indeed, certain bacterial species, which can rapidly transform large quantities of nitrate nitrogen into organic combinations, have been isolated from the soil.

It may thus happen that the soil bacteria actually compete with the crop for the available nitrogen, and conditions probably exist in which the crop-yields are considerably reduced on account of the transformation of the soluble nitrogen compounds in the soil into the insoluble portions of the bacterial bodies. Soil bacteria are, then, the indispensable agents in the breaking down of the soil-humus, and in the supplying of simple compounds of nitrogen to higher plants. They may perform this work economically or wastefully, depending upon soil and climatic conditions whereby their physiological efficiency becomes greater or less. By proper methods of cultivation, crop-rotation, or manuring, the bacteriological efficiency of these organisms can be controlled to advantage. The withdrawal of soluble 
plant-food from the soil-moisture by certain species to the disadvantage of the crop is an important factor in cultivation of the soil.

Ammonification.-Plants take up most of their nitrogen in the form of nitrates, which are simple substances when compared with the humus from which they are drawn. According to our present knowledge, the change of humus-nitrogen into nitrate cannot be accomplished by a single kind of bacteria. There are at least three well-defined steps in this process of change, each accomplished by a different species. The first step in the transformation involves the production of ammonia, the second, the change of ammonia to nitrite, the third, the change of nitrite to nitrate. The last named is the final product of these combined activities which may serve as a splendid illustration of the specialization in the work of soil bacteria. In the course of many ages there has been established this division of labor by the adaption of certain bacteria to only one kind of work. The microörganisms that can change protein nitrogen to ammonia cannot transform the latter to nitrite; nor can the nitrite bacteria change nitrite to nitrate. The formation of ammonia as the first step in the decomposition of protein substance is designated as "ammonification."

Ammonifying bacteria.-The bacteria capable of producing ammonia out of protein compounds are called "ammonifying bacteria." There are many kinds of ammonifying bacteria. Some of them are aërobic others are anaërobic. Some can produce large amounts of ammonia in a given time, others but a slight amount 
of it. There are differences in the chemical processes by means of which the different species produce ammonia. The protein substances from which it is derived are complex and insoluble, and the bacteria cannot use them as food in this insoluble form. The bacteria are like higher plants in this respect, and can only draw their food from the dissolved materials in the medium in which they live.

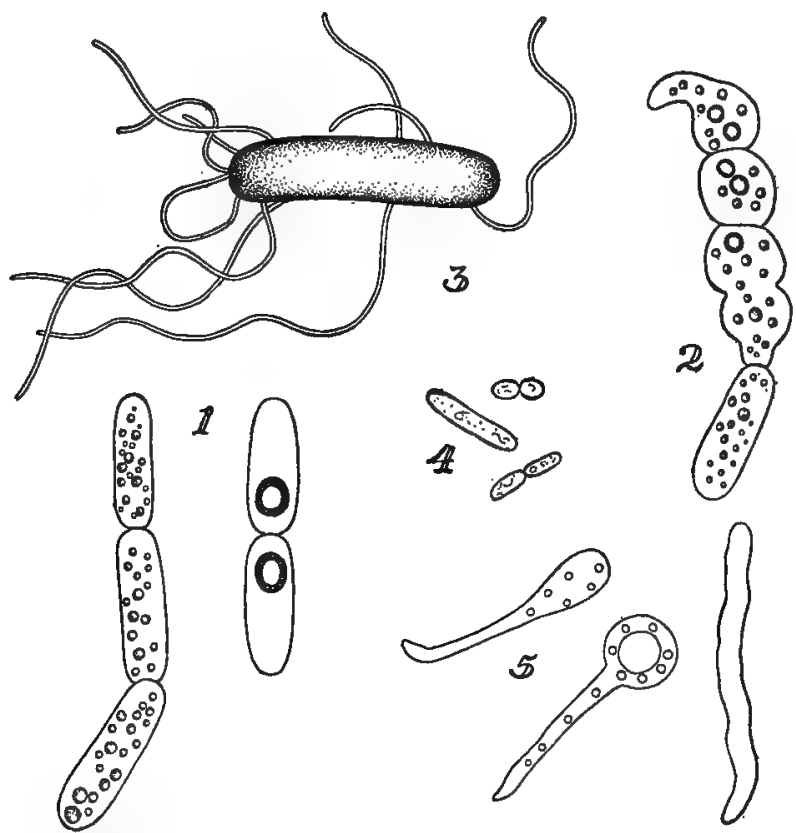

Fig. 24. Anmonifying bacteria.-1. Bacterium mycoides; $\times 3,000$. (Nadson.) 2. Baclerium mycoides; involution forms; $\times 3,000$. (Nadson.) 3. Bacterium tumescens. (Myer.) 4. Proteus vulgaris; $\times 3,000$. (Nadson.) 5. Proteus vulgaris; involution forms; $\times 3,000$. (Nadson.) 
Enzymes.-In order to hasten the solution of the protein, many bacteria produce chemical ferments called "enzymes." The latter are like the pepsin, or trypsin, produced for the same purpose in the animal system. The bacteria, like animals, must digest their food before they can assimilate it. However, animals digest their food after it is eaten, whereas the bacteria digest their food before it is eaten. In other words, the animals have special organs in which the processes of digestion are conducted, while the bacteria, as single cells, have no special digestive organs; hence, the soluble enzymes produced by them pass out through the cellwall and cause a chemical change in the protein substances that happen to be present in the material in which the bacteria are developing.

The bacteria possessing the ability to produce enzymes are known as "peptonizing" organisms. Peptone is one of the products formed in the breaking down of protein by means of enzymes. It is soluble and much more simple in composition than protein, and is readily changed still further with the production of ammonia. Since the bacteria differ not only as to the amount, but, also, as to the quality of the enzymes produced by them, they must, necessarily, show marked differences in their ability to decompose protein substances.

Mutual relations of bacteria.-The decomposition of . protein substances and the production of ammonia should not be regarded as the result of the independent activities of several kinds of bacteria. Living in the same soil with many other species, each kind is influenced by its neighbors. The struggle for existence develops a 
combination of species designated the "bacterial flora." adapted in each case to any particular set of soil and climatic conditions. In the competition for food, the various species in this combination hold one another in check and influence, thereby, the degree and kind of the chemical changes produced. For instance, any one kind of anärobic bacteria living by itself will not develop under conditions where air is freely admitted, because they cannot stand the presence of free oxygen. When, however, aërobic species are living with them, they begin to grow and multiply as if no oxygen were present. This phenomenon is explained by the fact that the aërobic organisms use up the oxygen in the immediate vicinity of their anaërobic neigh-
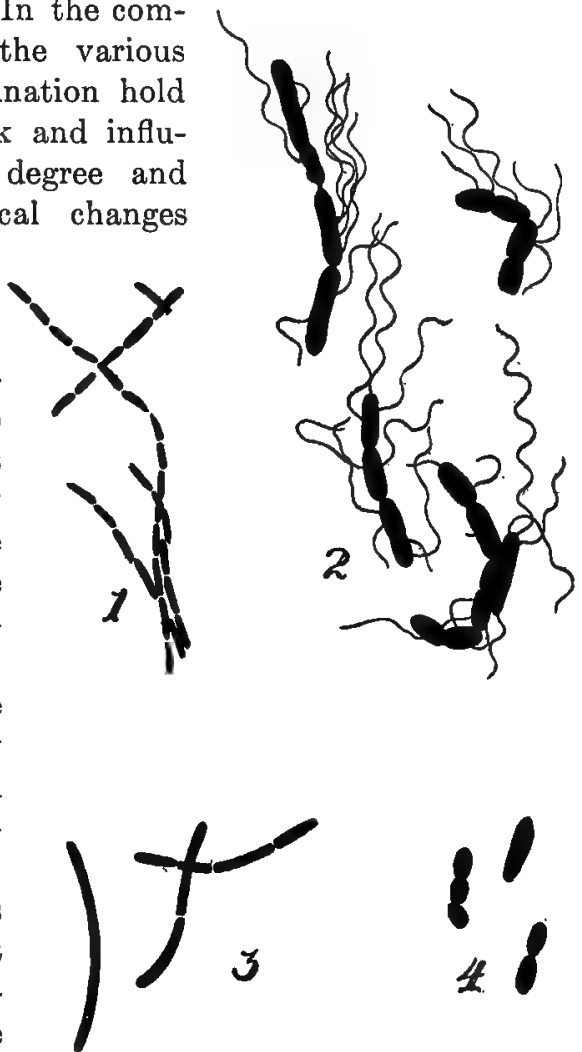

Fig. 25. Ammonifying bacteria-1. Proteus mulgaris; $\times 2,600$. (Rodella.) 2 . Bacillus megatherium; $\times 2,600$. (Hinterberger.) 3, Bacillus mycoides; $\times 2,600$. (Emmerling.) 4. B acillus cereus; $\times 2,600$. (Wilhelmy.) 
bors, and the latter are enabled thereby to grow normally.

Denitrifying bacteria.-There are in the soil certain bacteria capable of breaking down nitrates and of returning their nitrogen to the air in the gaseous state. These organisms are called "denitrifying" bacteria. There are other organisms in the soil which possess this power only in a limited degree. Some of them can reduce nitrates to nitrites, or to ammonia; others can reduce nitrites to nitrogen gas. But when two of these species are living together the destruction of the nitrates may be complete, since each performs part of the work the other cannot do. The combined work of the two or more species, which may be referred to as "associative action," is seen, also, in the ammonification of humusnitrogen. There are species that are incapable of producing ammonia in the soil, even in slight amounts, yet are capable of developing a marked ammonifying power in the presence of other organisms, or of influencing favorably the ammonifying action of their neighbors.

Influence of bacteria on one another.-There is still much to be learned concerning the influence of the different kinds of bacteria on one another. We are still ignorant of the manner in which the associative action is modified by climate and the mechanical and chemical constitution of the soil. In the case of ammonification, we know that the transformation of the humus-nitrogen may be rapid or slow, that it may be accompanied by large or slight losses of nitrogen in the gaseous state. We know, also, something of the conditions that hasten 
or retard such losses. We know next to nothing of the bacterial relationships under the changing conditions. Ammonifying power of soils.-Attempts are being made now in soil-bacteriological laboratories to measure the ammonifying power of different soils under varying conditions of tillage and fertilization. Attention is being given, likewise, to the separation of certain species from their neighbors in different soils. To use the expression employed in the bacteriological laboratories, pure cultures of the same species are made from different soils, and compared as to their vigor in the production of ammonia. That this work is of considerable importance is evident from the fact that ammonification is an essential step in the transformation of soil-nitrogen. Soils that have but a feeble ammonifying power will not allow a healthy growth of crops, irrespective of the vigor of any of the other important soil bacteria. Proper and profitable plant development is dependent on the rapid and economical transformation of the humus-nitrogen; also, on the rapid and abundant supply of ammonia to the bacteria that change it into nitrites and nitrates.

Nitrification.-The processes involved in the change of nitrogen compounds are at least three (page 161): Ammonification, nitrification, and dentrification. Ammonification we have just discussed. The other two processes are so important that we shall consider each of them in a special chapter (XVIII, XIX). 


\title{
CHAPTER XVIII
}

\author{
NITRIFICATION
}

THE term nitrification is used to designate the change of humus-nitrogen, or of any nitrogen in vegetable and animal substances, into a nitrate. It is also used, at times, to designate the change of ammonia, or of nitrites, into nitrates. The first definition is broader and includes the work not only of the nitrifying bacteria proper, but, also, that of the ammonifying bacteria. A nitrate $\left(\mathrm{NO}_{3}\right)$ contains one more atom of oxygen than does a nitrite $\left(\mathrm{NO}_{2}\right)$.

Until within a generation ago it was not known that nitrification is a bacterial process. The transformation of organic nitrogen into nitrate was regarded as a purely chemical reaction and was extensively stidied from that standpoint. Important economic issues were involved in such studies. The matter was of lively concern, not only to agriculture, but, also, to military organizations. Since gunpowder is composed largely of saltpeter (nitrate of potassa, or potash), some process whereby this could be obtained was eagerly sought. Numerous methods were discovered and employed with various degrees of efficiency.

The fact that saltpeter has its origin in organic substances was suspected by at least a few chemists early in the eighteenth century. It was stated in 1717 that 
this salt is present in vegetable and animal materials in a disguised state, and is set free when the substances decay. Notwithstanding this view, there were many chemists a hundred years later who believed that nitrates are formed by the oxidation of the gaseous nitrogen of the air in the soil, or in the compost heap.

The studies conducted by Kuhlmann between 1825 and 1838 indicated that nitrates are not formed in the soil out of nitrogen gas, but out of ammonia. The experiments carried on by Boussingault between 1858 and 1871 showed that nitrates in the soil are formed at the expense of the humus-nitrogen and not out of nitrogen gas. It was thus demonstrated that nitrification in the soil, or in compost heaps, depends on the decomposition of the organic substances containing nitrogen and the formation of ammonia. Nevertheless, it was still believed that the process of nitrification was purely chemical in its nature and that the superior nitrifying powers of some soils were due to their content of certain compounds of lime, iron, and the like.

True character of nitrification.-After the brilliant investigations of Pasteur, in the sixties of the last century, on the nature of fermentation, the ground was prepared for the understanding of the true character of nitrification. Indeed, in the early seventies, the belief was expressed by at least one investigator that nitrification is of bacteriological origin. The proof for this assumption was furnished in 1877 by two French investigators, Schlösing and Müntz. In passing diluted sewage through glass tubes filled with soil, they found that after some days the liquid that had passed through 
the soil had lost its ammonia, and had gained an equivalent quantity of nitrate. On treating the soil with chloroform vapors, nitrification was discontinued and the ammonia in the sewage passed through unchanged. The process of nitrification was reëstablished after the soil had received fresh soil in which nitrification was

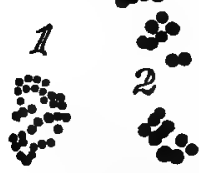

Fig. 26. Nitrifying bacteri $a,-1$. Nitrous ferments; $\times 2,000$. 2. Nitric ferments; $\times 2,000$. (After Burri and Stutzer.)

active. Similarly, the nitrification of ammonia in the soil was stopped by boiling. This showed that the change of ammonia to nitrate was of bacterial origin, since the process could be suspended by antiseptics and by boiling, and reëstablished by the addition of very minute quantities of fresh soil. These experiments were amply confirmed by other investigations.

Pure culture of nitrifying bacteria.-With the bacterial nature of nitrification thus demonstrated, attempts were soon made to secure pure cultures of the nitrifying organisms. For a number of years such attempts were not crowned with success. To be sure, various investigators claimed to have detected the ability to produce nitrates in one or another of the soil bacteria studied by them. More careful examination showed, however, that, in all probability, they did not work with pure cultures. To Warrington belongs the credit of having isolated, after many years of study, organisms capable of changing ammonia to nitrites. He observed other organisms also capable of changing nitrites to nitrates. Warrington's investigations indicated that the oxidation of ammonia occurs in two distinct stages. 
The first reaction involves the change of ammonia to nitrite, the second change of a nitrite to a nitrate.

The Russian bacteriologist, Winogradsky, not only confirmed Warrington's observations, but, by a series of highly ingenious experiments, made clear the causes of the failure of other bacteriologists. He showed, in 1890 and 1891, that the nitrifying-organisms do not develop in the culture solutions and on the gelatine plates employed for the isolation of various soil bacteria. He was, therefore, led to employ culture media containing only min-

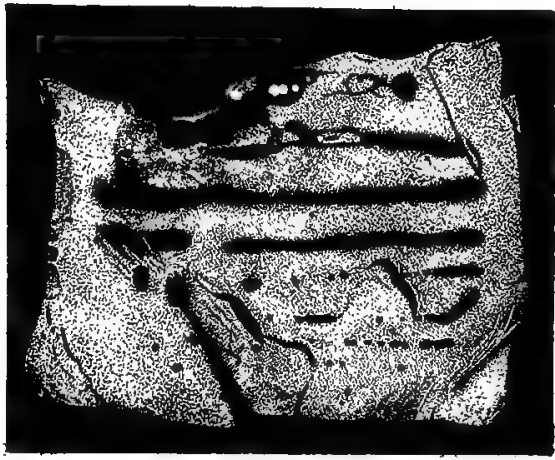

Fig. 27. Nitrite bacteria, showing the spherical form of individual cells. eral salts. The gelatin was replaced by the mineral silica jelly, on which colonies of the nitrifying bacteria developed without great difficulty.

The organisms capable of changing ammonia to a nitrite were found by him in two varieties, one from the Old World, which he named Nitrosomonas, the other from the New World and named Nitrosococcus. Both of these belong to the group of nitrous ferments and are spherical in shape. The so-called nitric ferments, those capable of changing nitrites to nitrates, were designated by him as Nitrobacter. The latter are small, 
rod-shaped organisms. The demonstration was thus furnished that the oxidation of ammonia to nitrites is performed by two distinct groups of organisms found in all soils. They seem to work in unison, since the nitrites are changed into nitrates almost as fast as they are formed. Under abnormal conditions favoring the growth of the nitrous ferment, but not of the nitric ferment, there may be an accumulation of nitrites. Recently it was announced by Kaserer that he had isolated an organism capable of changing ammonia directly into nitrate. This discovery, if substantiated by other investigators, promises important revelations concerning the transformation of nitrogenous organic materials in the soil.

Importance of nitrification. - The vast practical significance of nitrification processes is apparent from the

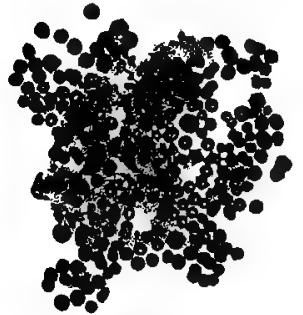

Fig. 28. Nitrite bacteria; growth of the organisms on the specially prepared agar.

fact that most of the nitrogen used by crops is taken up in the nitrate form. While there is much evidence at hand to show that many plants are capable of utilizing ammonia as readily as nitrate nitrogen, yet, because of the very rapid conversion of ammonia into nitrate, the latter is almost the exclusive source of nitrogen. The rapidity with which ammonia salts are changed in the soil to nitrates is attested by the experience at Rothamsted in England. It was the practice there to apply the nitrogen on certain plots in the form of ammonium sulfate in the fall. It was soon noticed, how- 
ever, that, notwithstanding the lateness of the season, the ammonia was rapidly converted into nitrate as shown by the increased content of the latter in the drainagewater from those plots. In fact, the application of the ammonia salts was practically equivalent to the application of nitrate, and, in order to guard against the loss of nitrogen, the fall applications of ammonia salts were discontinued.

Loss of nitrates in the soil.-The soil-nitrates all dissolve in water; diffuse themselves readily in the soilmoisture, and, when not taken up by the crops, are liable to be washed into the drains. This property of nitrates accounts for their presence in comparatively slight amounts in the soil. In certain rainless regions of the earth there are large accumulations of nitrate. This is particularly true of the extensive deposits of nitrate of soda in some provinces in Chile, South America. This salt, known also as Chile saltpeter, occurs in crystal form throughout a considerable thickness of solidified earth, and is secured from the latter by the crushing and leaching of the earthy material, and subsequent crystallization of the nitrate from these leachings.

Sources of the nitrate deposits.-Various theories have been proposed to account for these deposits. One of these theories, accepted by many, assumes that, in the gradual rising of the coast of western South America, a portion of the sea was cut off, forming a great inland bay whose waters could be replenished by the ocean only at high tides. Immense quantities of seaweed developed in this shallow bay, and, on their decay, were changed by the nitrifying bacteria into nitrate. 
Owing to the warm climate, the decay of the organic matter must have proceeded very rapidly, while the absence of rain prevented the nitrate formed from being leached out and carried away in the drainage of the country. The natives of Peru and Chile have known the agricultural value of the nitrate for a long time, and have probably used it to stimulate plant growth. The first ship-load of nitrate of soda was taken to England in 1827. Another was taken there in 1830, but there was scarcely any demand for it on account of the high price. As its value in agriculture and in the chemical industries was recognized, the demand for it increased rapidly until in 1903 it showed a consumption - of $1,429,150$ tons, including the 264,000 tons brought to the United States.

Considerable quantities of nitrates, particularly nitrate of potash, are also derived from other sources. After the rainy season, portions of the plains of the Ganges river in East India, become covered with a deposit of white crystals consisting largely of nitrate of potash. Evidently, the abundant moisture and favorable temperature encourage the vigorous development of the nitrifying bacteria, and a rapid production of the nitrates of lime, magnesia and potash. As the moisture brought up by capillary action from the subsoil is evaporated at the surface, the nitrates it contains are left behind in crystalline form. The nitrates of lime and magnesia have, however, a great affinity for water-vapor, which they absorb from the air, and do not, therefore, crystallize out to the same extent as the nitrate of potash. 
Early use of nitrates.-The natives of India recognized long ago the stimulating action of nitrate in plant growth. It is stated that the natives of certain districts in Bengal, "particularly a caste called Quirees (hereditary gardeners), who cultivate the best lands and produce the best crops, are in the habit of irrigating their fields with water from wells so strongly impregnated with saltpeter and other salts as to be brackish. They consider onions, turnips, and peas to be most benefited by this irrigation." Saltpeter is also believed to have been used as a manure by the peasants of Mantua, and is known to have been employed by Digby in England in the reign of Charles I. It was likewise recommended as a top-dressing by Evelyn in the reign of Charles II. Early in the nineteenth century, the use of saltpeter was slight, but not uncommon, in England, and a few decades later the application of Chile saltpeter was resorted to by many farmers to supplement the natural production of nitrates in the soil.

Conditions influencing the formation of nitrates.-The rapidity with which nitrates are formed from the soilhumus is determined largely by soil and climatic conditions. The nitrifying bacteria must have sufficient moisture and a favorable temperature for their development. They must have the proper supply of humus as the source of nitrogen; they will not develop in the absence of lime or magnesia, which serve, in the average soil, to neutralize the nitric acid formed by the bacteria. The presence of lime and magnesia, or of other basic substances, as they are called, is of extreme importance. They combine with the nitric acid produced by the bac- 
teria to form nitrates of lime, magnesia and, potashsubstances not injurious to the bacteria even when present in the soil in considerable quantities. In the absence of basic substances, the nitric acid produced by the nitrifying ferments accumulates and reacts injuriously on the latter.

Small amounts of nitric acid are sufficient to retard seriously the nitrification processes in the soil. The supply of air also exerts a direct influence on these processes. Nitrates are formed most rapidly in sandy loam soils well supplied with humus. On the other hand, heavy clay soils are too compact and fine-grained to allow satisfactory aëration; hence they allow a gradual nitrification of their humus-nitrogen. In fairly open calcareous soils, the nitrification processes may proceed with great intensity, whereas, in coarse sandy soils they may be quite irregular on account of the rapid depletion of the soil-moisture.

The process of nitrification in cultivated lands is influenced by the chemical and mechanical composition of the soil as well as by the prevailing climatic conditions. We are indebted for much of our knowledge on the subject to the careful researches at Rothamsted, England. Many interesting facts contributed by these investigators show that, among other things, the production of nitrates takes place almost exclusively in the surface soil. It was found at Rothamsted that drain gages situated at a depth of 40 inches and 60 inches respectively, yielded no more nitrates than did the drain gages situated at a depth of 20 inches. It is not difficult to account for this fact, since the nitrifying 
bacteria will develop only where there is a supply of air and of nitrogenous material capable of being converted into nitrate.

It seems, therefore, that in the more open sandy loams, or sandy soils, where the air circulates more freely at greater depths, the development of the nitrifying bacteria is favored somewhat in the deeper layers of the soil. In regard to the material capable of nitrification, it is true that in the soil this consists of roots, stubble, and other plant residues accumulated mostly in the surface soil. For this reason, the nitrifying bacteria will grow almost exclusively in the place where these accumulations are concentrated, that is, in the surface soil. Indeed, it has been shown, experimentally, that samples of soil from depths greater than three feet usually fail to cause nitrification in nitrifiable materials.

Soil bacteriologists are now endeavoring to compare the nitrifying power of different soils under identical conditions, and to study the various influences that encourage or discourage the bacteriological activities in the soil. The fact has been recognized for some time that not only are the nitrogenous materials nitrified at a different rate in different soils, but that the order of nitrification may be different. For instance, it has been observed that sulfate of ammonia is usually changed to nitrate more quickly than dried blood or cottonseed meal. Nevertheless, soils are occasionally met with in which the reverse seems to be true. According to the views held at present, the organic nitrogen in dried blood or cottonseed meal must be changed first to am- 
monia by ammonifying bacteria before it can be utilized by the nitrous and nitric ferments. The nitrogen of ammonium sulfate can be attacked directly. It follows from these facts that there must exist a certain relation between the ammonifying and nitrifying bacteria in the soil, of which we know very little.

The determination of the nitrates, at Rothamsted, in the drainage wastes from soils that had been kept fallow, showed an average annual removal of 40.2 pounds of nitrate nitrogen per acre. The least amount of nitrate nitrogen in the drainage waste was found in the spring, the greatest amount in July. In the soil which had borne crops, and received applications of nitrogenous materials, the production of nitrate bore a direct relation to the amount and character of the substances applied. The least amount of nitrates was found in the soil receiving annual applications of barnyard manure at the rate of fourteen tons per acre. The soils receiving applications of nitrate of soda and of ammonium salts showed a higher content of nitrate than the corresponding unmanured soil.

The differences may be due to two causes. In the first place, the soils receiving nitrogenous materials contain more nitrate because these substances contribute directly some nitrogen to the soil. The nitrogen thus added may be in the nitrate form, as in the case of the applications of nitrate of soda, or it may be in a form capable of more or less rapid conversion into nitrate, e.g., sulfate of ammonia, or barnyard manúre. Not all of the nitrate nitrogen thus contributed is removed by the crops or in drainage. In the second place, the 
crops growing on the manured land are more yigorous and leave greater amounts of root and stubble residue in the soil, hence, also, more nitrifiable material. It has been demonstrated that the nitrogen of organic matter is not all capable of nitrification to an equal extent. A portion will change to nitrate quite readily, the following successive portions less and less readily, until, finally, a stage is reached when the remaining nitrogen nitrifies with extreme difficulty. The great resistance to the activities of nitrifying bacteria is characteristic of the humus in exhausted soils. On the other hand, the nitrogen of ammonia salts, of liquid manure, or of such compounds as dried blood, nitrifies very rapidly.

It has already been stated that the application of ammonia salts in the fall is wasteful because of its ready conversion into nitrate, even in the late fall. In fact, nitrification seems to go on until the soil is almost frozen. When a crop is occupying the land, the nitrate as it is formed is taken up by the plants and but little allowed to escape into the drains. When the land is kept bare, the nitrates formed are washed into the deeper layers of the soil and may be carried off by the drainage. It is for this reason partly that the continuous growing of wheat is a wasteful procedure. The land is kept bare at a time of the year when the nitrification processes in the soil are most active, resulting, in the loss of very considerable quantities of nitrates. Investigations have shown that in the continuous growing of wheat there may be four to six pounds of nitrogen lost from the soil to every pound removed in the crop. 
Acid soils.-There is an intimate relation between the amount of lime and magnesia and the nitrifying power of the soil. It should be remembered that the activity of the organisms leads to the formation of acids; that is, of sour substances, and that in the absence of lime the acids accumulate and react injuriously on the bacteria. The deleterious effects of acid substances may be. seen readily on light soils, naturally poor in lime, and upon which applications of sulfate of ammonia are made from time to time. A comparatively large amount of lime is required to neutralize the acids formed in the transformation of ammonia salts to nitrate. Because, also, of the severe drain on the lime resources of the soil, the acid conditions become more pronounced. In soils in which large amounts of nitrogen are being nitrified there is a continuous production of the nitrates of lime and magnesia, which are either taken up by the crops or removed in the drainage. It is well known, also, that soils yielding large amounts of nitrate, that is, those rich in humus, lose their lime in still other ways. One in par'ticular is on account of the formation of bicarbonate of lime, which is soluble in the soil-water. It becomes necessary, therefore, on practically all but limestone soils, to apply lime from time to time, lest the soil become sour and the nitrification processes feeble.

Difference in organisms.- When favorable conditions for nitrification exist, there comes to be established in time a vigorous combination of nitrifying organisms, capable of accomplishing much work in a short time. This circumstance accounts for the marked differences in the nitrifying power of bacteria from different soils. 
The increased vigor, due to long-continued development under favorable conditions, may, in a measure, become fixed in the bacteria. There are facts, at least, that point strongly in that direction. The significance of this circumstance will be discussed under soil-inoculation.

Availability of nitrogenous materials.-The relation must play an important part in determining the relative availability of the various nitrogenous materials employed for manuring purposes. Agricultural chemists and practical farmers know that substances like dried blood, meat meal and ground fish yield their nitrogen rather rapidly to the growing crop, while other substances like leather-meal, wool and peat are a very unsatisfactory source of nitrogen to plants. The first of these are designated as available, while the last are called unavailable, or difficultly available. Experience and investigation have arranged such nitrogenous substances in the order of their availability in somewhat the following fashion:

Nitrate........................... 100

Ammonium sulfate .................. 90

Dried blood, horn meal, green clover......... 70

Fine bone meal, ground fish, meat meal ...... 60

Manure ........................... 45

Wool waste......................... 30

Ground leather..................... 20

This table brings out the existing relations in a general way. It should not be forgotten, however, that the absolute and relative availabilities are modified by soil and climatic conditions. The differences in availability as brought out in the table are determined largely 
by bacteriological activities. Some of these substances are more resistant to the attacks of the organisms and are converted into ammonia and nitrate slowly, while others are changed rapidly. It may also be that in the process of ammonification and nitrification, gaseous nitrogen is set free, and that these losses are different with different substances. The available substances, that is, those that nitrify rapidly, are more like nitrate in their action than are the slowly available substances.

Influence of the crop on availability.-It has been demonstrated in the case of some plants that the crop may favor or retard nitrification, not only by withdrawing greater or slighter amounts of moisture from the soil, but, also, by modifying, however slightly, the chemical nature of the latter. It was thus shown, in the case of wild mustard, that the nitrifying action of the soil had been diminished, the effect showing also in the following season. An interesting field of inquiry is thus opened to us. Studies in this direction will undoubtedly prove of great value, and will help us to understand, perhaps, the beneficial effect of crop-rotations in so far as they concern the soil bacteria. 


\section{CHAPTER XIX}

\section{DENITRIFICATION}

Denitrification is the reverse of nitrification. The latter process has been defined as the gradual changing of the nitrogen of vegetable and animal substances (organic nitrogen) into nitrates. It is therefore, an oxidation process, involving the addition of oxygen to the nitrogen through the activities of the nitrifying bacteria. Denitrification is a reducing process whereby the nitrate is made to part with some or all of its oxygen, and is changed to a nitrite, to ammonia, or to nitrogen gas. A distinction should be drawn, therefore, between the complete destruction of nitrates with the formation of nitrogen gas, and the partial decomposition in which a nitrite or ammonia is formed. The first instance, which represents denitrification proper, is of much greater importance from the economic standpoint, since the nitrogen, once returned to the air, is lost to the soil and crops. On the other hand, the reduction to nitrite, or ammonia, does not remove the nitrogen from the soil. It is still there, though in a changed form, and may again be oxidized to nitrate.

Early idea of denitrification.-The earlier observers who noted the reduction of nitrates ascribed.it to reactions purely chemical. In the sixtics of the last cen- 
tury, a number of investigators were already familiar with the fact that such reductions of nitrate are likely to take place in the presence of organic matter. They were not a little puzzled at the apparently contradictory properties of soils.

The fact that the reduction of nitrates in the soil is more likely to occur when the latter contains an excess of moisture, or an excess of organic matter, was recognized by these men. They did not know, however, that microscopic organisms in the soil are intimately connected with the reduction processes. The German scientist, Schönbein, suggested in 1868 that the reduction of nitrates might be due to fungi and bacteria. A few years later his views were confirmed by the observations of others, particularly as to the reduction of nitrates in sewage and in drinking-water.

The cause of denitrification.-These views found strong support in the studies of the French investigators, Gayon and Dupetit. They actually observed, at the beginning of the eighties, cultures of a bacillus, or "ferment," as they called it, that was found capable of reducing nitrates with the production of nitrogen gas. In 1886, they described two denitrifying ferments that they had isolated and studied under varying conditions. Cultures of a denitrifying bacillus were also prepared by Giltay and Aberson in Holland. The latter found that when grown in meat broth or other solutions containing nitrate, this organism is capable of reducing nitrate with the transformation of almost all of its nitrogen into gas. It was thus demonstrated that soil contains bacteria that cause reduction of nitrates, 
Value of the modern discoveries.-No practical significance was attached to these discoveries until 1895, when the statement of Wagner, in Germany, that the use of barnyard manure leads frequently to serious losses of nitrogen from the soil recalled the attention of chemists, and bacteriologists to the subject. It was held by Wagner that the application of manure and nitrate is a very wasteful practice, since the denitrifying bacteria, present in large numbers in the manure, cause the destruction of the nitrate in the fertilizer. Furthermore, they reduce the nitrates formed from the soil-humus by the nitrifying bacteria. Wagner's statement naturally aroused much comment and stimulated extensive investigations in Germany, England, France, the United States, and elsewhere.

Modern conclusions concerning denitrification.-The conclusions as they were reached after five or six years of study may be summarized briefly as follows: It was demonstrated that under certain conditions the applications of large quantities of manure may really decrease the yields, in some cases to a very serious extent. The injury thus occasioned may be due to the direct action of the organic materials in the manure on the plants, or it may be bacteriological in character. As to the former source of injury, it should be remembered that excessive amounts of soluble organic materials like those in liquid manure may, of themselves, prove injurious to the plants. In ordinary field practice the amounts of manure applied are never large enough to cause such injury. In market-gardening, or in greenhouse work, in both of which applications of as much as 
fifty tons of manure per acre are at times made, there is some probability of injury thus resulting. When such injury does occur, it cannot, however, be designated as denitrification.

The depression of the crop-yields arising out of bacteriological causes may be due to the suppression of nitrification in the soil, to the transformation of the nitrate into organic nitrogen by certain classes of bacteria, or to the actual reduction of the nitrate by soil or manure bacteria. It is well known that nitrifying bacteria are quite susceptible to the presence of soluble organic substances. This may be easily demonstrated by the addition of a solution of sugar to a soil in which nitrification is taking place. When large amounts of manure are added to the soil, the soluble materials in it will discourage nitrification. The striking influence of soluble organic materials on nitrification in the soil is particularly apparent when sewage-irrigation is practiced.

Effect not permanent.-The depressing effect on nitrification is not permanent. After a longer or shorter interval, the nitrifying bacteria become active again, and the supply of nitrates proceeds normally. The length of the period during which nitrification is suspended, or is very feeble, is determined by the amount of organic matter applied; hence very large applications of manure will suppress nitrification for a longer period than smaller applications. During this time the conditions for crop growth are not favorable. When ordinary applications of manure are made, that is, in amounts not exceeding twenty or even thirty tons per acre, the interference with 
nitrification is scarcely appreciable. When such interference does occur, on account of excessive applications of manure, the injury to crop growth cannot be ascribed to denitrification.

Bacteria that consume nitrates.-Crop growth may also be affected unfavorably by certain classes of soil bacteria that use up the nitrate for their own growth. This circumstance will be less confusing if we remember that bacteria are plants competing, at times, with the higher plants for their food in the soil. When conditions peculiarly favor the development of these nitrateconsuming bacteria, the higher plants are rapidly deprived of a part of their food, for the bacteria change the nitrate into organic nitrogenous materials that do not again become available until after the bacteria are decayed and their bodies nitrified. We are still in ignorance as to the soil and climatic conditions that will favor the rapid increase of these bacteria in the soil, nor do we know to what extent they are economically important. Even assuming that they do, at times, interfere with plant growth, their activities. cannot be designated as denitrification.

The denitrifying bacteria.-Finally, the injurious action from excessive applications of animal manures, or of other organic materials, may be really ascribed to denitrification. Animal manures, particularly those mixed with straw, contain vast numbers of denitrifying bacteria. When a quantity of such manure is placed in a solution of nitrate, and the latter kept in a warm place, the nitrate is rapidly destroyed. Within two or three days, the surface of the liquid will be found 
covered with a fine foam produced by the small bubbles of nitrogen gas passing out of the liquid. A chemical examination will show that the nitrate has all disappeared. No denitrification occurs when both the manure and solution are sterilized.

Applications of manure carry with them to the soil millions of denitrifying bacteria. It has been shown that the soil itself contains several species of denitrifying organisms. In the presence of large quantities of manure or of other organic matter, therefore, these bacteria find favorable conditions for the destruction of the nitrates applied with the manure, or formed from the soilhumus. Large quantities of organic matter are essential for the rapid growth of the denitrifying bacteria. When these are absent, the microörganisms fail to find enough food and energy for the destruction of the nitrates. It is for this reason that, under ordinary soil conditions, denitrification does not play a significant part in the nitrogen-feeding of crops.

It has been demonstrated that annual applications of cow manure at the rate of sixteen tons per acre, together with quantities of nitrate equivalent to 320 pounds per acre, fail to cause any appreciable loss of nitrogen that can be directly attributed to denitrification. The destruction of nitrates by denitrifying organisms does not occur, therefore, in arable soils under ordinary conditions of farm practice. These losses may take place, however, in greenhouse or market-garden soils on account of the excessive amounts of manure used, and because of the activities of the denitrifying bacteria in the manure and soil. These bacterịa need 
large amounts of organic food for their development, and are, therefore, most injurious when developing in the presence of large quantities of fresh vegetable or animal matter. Hence. denitrification may also occur at times when abundant green-manuring crops are turned under. It is not advisable, therefore, to topdress the soil with nitrate of soda shortly after large applications of manure or of other organic material.

After the organic matter has partly undergone decay, the denitrifying bacteria no longer find in the residues an acceptable source of food for their rapid development. For this reason, well-composted manure is not liable to cause denitrification in the soil, even when applied in large amounts. The same applies also to vigorous crops of green-manures which cease to be a source of danger after they have undergone partial decay.

Denitrification is favored by the exclusion of air. The denitrifying bacteria, it seems, require a certain amount of oxygen for their growth. When it is absent they take it out of the nitrates. This explains the reduction of nitrates in the deeper layers of the soil, or in water-logged surface soil. It accounts also for the greater tendency to denitrification in heavy, compact soils as compared with the more open, sandy loams.

Drainage, liming, and thorough tillage greatly lessen the danger from denitrification by improving the circulation of air in the soil. Even when air is excluded, the presence of nitrate and of easily decomposable organic matter is a prerequisite for the rapid growth of the denitrifying bacteria. Soils poor in humus, therefore. are not liable to cause the reduction of nitrate. 


\section{CHAPTER $\mathbf{X X}$}

\section{THE INCREASE OF SOIL-NITROGEN}

SCIENTIFIC agriculture has been called on within the last one hundred years to solve an almost endless number of problems. Some of these have been solvea without difficulty, others only after they have taxed the efforts of many men of science. Many are yet to be solved. Of all the problems that have been at last made clear, none has created so much discussion or stimulated so much research as that concerning the source of nitrogen to plants.

Since it became known, toward the end of the eighteenth century, that we are moving about at the bottom of a great ocean composed mainly of two gases, nitrogen and oxygen, the question as to the part played by the former in the growth of plants has been before scientists. Chemists realized in the early years of the last century that the rocks of the earth's crust do not ordinarily contain compounds of nitrogen. Not many years later, it became known that very productive soils contain five to ten thousand pounds of nitrogen per acre to a depth of one foot, that many soils contain much greater amounts, and that all this vast quantity of combined nitrogen in the earth's surface has been derived in some way from the gaseous nitrogen of the air. 
As they became more skilled in analytical methods, the chemists could not remain blind to the fact that there is a constant drain on the nitrogen resources of the soil. They knew that much nitrogen is removed in the crops. They have learned that, in the decomposition of humus, some nitrogen returns to the air in the gaseous state, that another part is changed to soluble combinations and finds its way to the rivers and the sea. Here then is a puzzling problem. Bare, nitrogenless rock falls into fragments under the attack of the sun, the winds and the rain. It crumbles more and more and living things come to find lodgment in it. The weathered part becomes deeper with the passing years, and its vegetation grows in splendor. The rock loses its identity and becomes soil, the receptacle of enormous amounts of humus and nitrogen. In what manner does the free nitrogen gas floating in the atmosphere pass into the plant body, and, on the death of the latter, into the soil-humus? What means are there in nature's laboratory for replacing the constant losses of soilnitrogen?

It seemed simple enough, at first, to assume that the great aërial ocean furnished nitrogen directly to all green plants. Such an assumption agreed well with ancient traditions. The experience of many generations had forced into the consciousness of the farmer the belief that certain crops possessed soil-enriching qualities. The scientific men of a hundred years ago were inclined to ascribe these to the utilization of atmospheric nitrogen. Further investigations demonstrated apparently that plants cannot make use of nitrogen 
gas for their growth. It seemed that the nitrogen must be combined with other elements to form either ammonia or nitrate before it could be employed by plants.

The ammonia theory.-Toward the middle of the nineteenth century the opinion came to prevail that ammonia is the important source of nitrogen to plants. Liebig, in Germany, known as the father of agricultural chemistry, demonstrated that ammonia is a constant constituent of the atmosphere. He maintained that the natural supply of ammonia is usually sufficient for the growth of crops. According to him, the exhaustion of soils should be ascribed to their decreased content of mineral ingredients rather than to decrease in nitrogen.

When careful study of the composition of the atmosphere, conducted in France, England, and Germany, had proved that the amount of ammonia brought down to the earth by rain and snow scarcely exceeded a few pounds per acre annually, Liebig maintained that plants are capable of directly absorbing ammonia by means of their leaves. He pointed out that the beneficial effects of nitrogenous manures are most apparent in the case of cereal crops with a comparatively short vegetation period, and least apparent in the case of leafy crops with a long vegetation period. Experience had taught the farmer, he said, that it was useless to apply nitrogenous materials to clover. No benefit at all, or only slight benefit, was likely to result therefrom. The long vegetation period of crops like clover allowed the gradual utilization of the ammonia in the air, and no artificial supply was necessary. On the other hand, 
crops with a short vegetation period had a limited power for accumulating ammonia from the air, and gratefully responded to applications of nitrogenous materials.

So great was the weight of Liebig's authority that his views were widely accepted in spite of many facts, rapidly growing in number, that seemed to be contrary to these views. Lawes and Giibert, of England, denied Liebig's claims on the strength of their experiments at Rothamsted. They soon became involved in a controversy with the great German chemist. It was not always free from bitterness. The investigations stimulated by this controversy proved that ammonia does not directly feed the crops, that the amounts brought down in rain or snow are but slight, and that the atmosphere contains but minute quantities of it. The adherents of the ammonia theory sought to strengthen their position by pointing to experiments that, apparently, proved the extensive formation of ammonia in nature. They asserted that either in the burning of organic materials containing no nitrogen, or in the decay of such substances in the soil, ammonia was always formed.

The German chemist, Schoenbein, thought he had demonstrated that nitrate of ammonia is formed in the simple evaporation of water in shallow vessels. Further investigation, under more rigid experimental conditions, disproved these statements. The experiments of Boussingault in France, and of Lawes, Gilbert and Pugh in England, conducted in the fifties of the last century, seemed to have established with certainty that gaseous nitrogen cannot be used by plants. There remained, therefore, but one logical explanation of the 
supply of nitrogen to plants. All of the nitrogen of crops, so it appeared, was taken up by them from the soil either in the form of ammonia, or of nitrates.

The nitrate theory. - It thus came to be believed, in the sixties and seventies, that the soil and the soil alone could feed the plants with nitrogen. But, assuming that all of this nitrogen food was derived from the humus by the formation from the latter of ammonia and of nitrates, how could the maintenance of the nitrogen store in the soil be explained? The harvests remove annually twenty to forty pounds of nitrogen, - in the case of crops like clover, as much as one hundred pounds. At times, double that quantity is withdrawn. The drainage waters, moreover, frequently carry away from the land as much nitrogen as is removed by the crops. Surely, with the atmospheric nitrogen not available, the origin and maintenance of the supplies of combined nitrogen in the soil seemed shrouded in mystery.

Thus, after the middle of the last century, men came to believe more and more that the evident ability of the soil to restore its lost nitrogen was connected in some way with the formation of nitrates. This belief was strengthened by the experiments of Boussingault, who showed that nitrates were readily utilized by plants, that the growth of the latter was in proportion to the nitrate supplied, and that humus-nitrogen in its unchanged state offered no nitrogen food to plants.

The conviction grew, therefore, that soils possess the ability not only to form ammonia and nitrates, by the decay of their humus, but, also, to produce nitrate directly by the condensation of the nitrogen and oxygen 
present in the soil-air. It was assumed, therefore, that the production of nitrate in the soil out of the gases, nitrogen and oxygen, was affected by certain compounds of iron, by ozone, and by sulfate of lime. It was assumed, also, that the electrical discharges in the atmosphere not only caused the formation of small quantities of nitric acid which was washed into the soil by rain, but that electrical discharges led also to the formation of nitric acid in the soil itself.

The bacteria theory. - The proof furnished in 1877 by Schlöesing and Müntz that nitrification is a bacteriological process and that it does not take place in sterile soil, disproved the claim that nitrogen and oxygen are directly condensed in the soil to nitric acid. The earlier experiments were recalled that indicated the formation of nitrates only when nitrogenous organic materials were supplied, and the non-formation of nitrates in soils devoid of humus. It was remembered that the nitric acid brought down in the rain scarcely exceeded three or four pounds per acre, annually, and the wonder grew again as to the manner in which the supply of combined nitrogen in the world is maintained.

The existing uncertainty was dispelled in 1886 with the announcement of the German investigator, Hellriegel, that certain plants are capable of using for their development the nitrogen gas of the air, but that they are enabled to do so only with the aid of bacteria which live in their roots. The power of thus gathering atmospheric nitrogen was confined, with few exceptions, to the plants of the legume family. A few years later, the Russian bacteriologist, Winogradsky, furnished the 
proof that there is in the soil and living outside of plants still another class of bacteria that are capable of utilizing nitrogen gas for their growth.

Thus it was learned that the supply of combined nitrogen to the plant world would soon fail but for the activities of bacteria which, living either within the roots or in the soil by themselves, provide for the continuance of life on this earth. They are different from the other classes of bacteria already considered in that they are concerned with the addition of nitrogen compounds to the resources of the plant and animal world, and are known, therefore, as nitrogen-fixing, or nitrogen-gathering bacteria. The others can only change the form of combination, and are concerned only with the transformation of soil-nitrogen, a process that frequently involves considerable losses of nitrogen.

The nitrogen-transforming bacteria we have already discussed. We will now turn our attention to the very important nitrogen-fixing kinds.

The nitrogen-fixing bacteria may be divided broadly into two classes, non-symbiotic and symbiotic. The former live in the soil itself and develop there even when no crop is growing upon it. The latter may also grow in bare soils, but attain a pronounced power of gathering atmospheric nitrogen only after they had invaded the roots of some leguminous crop and had attained a certain development there. The term symbiotic is derived from the word symbiosis, which means living together. It is applied to describe a condition in which two organisms, rather different in character, live together to the advantage of both. 


\section{CHAPTER XXI}

\section{THE NON-SYMBIOTIC NITROGEN-FIXING BACTERIA}

The non-symbiotic nitrogen-fixing bacteria thus far known may be divided into two classes: (1) Anaërobic ferments, first described by Winogradsky in 1893; (2) aërobic bacteria described by Beyerinck in 1901 . Anaërobic bacteria.-The anaërobic ferment described by Winogradsky and named by him Clostridium Pastorianum (Fig. 29), is a rod-shaped organism, developing in the absence of air (anaërobic), and producing spores and boat-shaped masses (clostridia). Pure cultures of this organism, when grown in solutions of sugar and the necessary mineral salts, but containing no nitrogen compounds, develop rapidly and assimilate the free nitrogen of the air. This may be readily demonstrated by analyzing the cultures at the end of ten days or two weeks, when considerable quantities of combined nitrogen will be found in the liquid. While Clostridium Pastorianum is a distinctly anaërobic organism, it is yet capable of developing under conditions allowing a more or less ready access of air, provided other bacteria are present. Under these circumstances, the accompanying bacteria use up the oxygen in the solution, and thus make it possible for the anaërobic Clostridium Pastorianum to develop properly. 
Winogradsky showed also that the amount of nitrogen fixed bears a certain relation to the amount of sugar supplied. In other words, the bacteria employed used the sugar not only as food, but also as fuel, the energy of which was utilized partly for making the free nitrogen of the air to combine with other elements. Winogradsky demonstrated, likewise, that the fixation of nitrogen is discouraged when nitrogenous substances are present in the culture medium. Thus, when salts of ammonia.
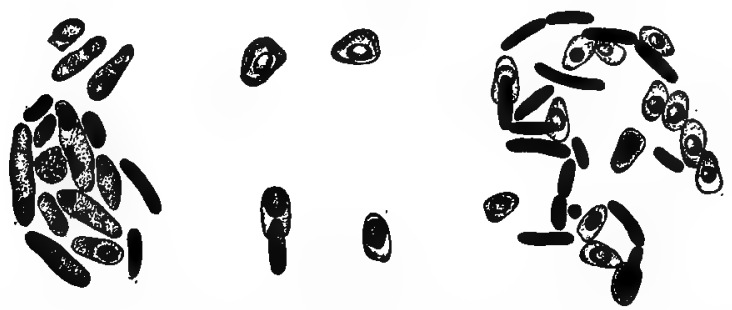

Fig. 29. Non-symbiotic nitrogen-fixing bacteria.-Rods, clostridia, and spores of Clostridium Pastorianum. (Winogradski.)

were purposely added, the fixation of free nitrogen decreased in proportion to the combined nitrogen supplied. A point was finally reached when there was practically no fixation of nitrogen by the bacteria. This fact is of great interest in teaching us that the nitrogengathering bacteria, like leguminous plants, prefer to employ the nitrogen compounds already at hand, and turn to the atmosphere only when combined nitrogen is not to be had.

Clostridium Pastorianum has been isolated also by other investigators. It seems to be widely distributed in cultivated soils, although we are still in ignorance of the 
actual work performed by these organisms in the field. We do not know how they are affected by various modes of soil treatment, tillage, and crop-rotation. We know that they are influenced in their growth by the mechanical composition of the soil, by the amount of humus present, and by the proportion of moisture. While found in both open and compact soils, their growth is favored by the less thorough aëration of the latter. As to their distribution in the different soil layers, it will probably be found that they occur at greater depths in sandy loams than in heavy clays or clay loams.

The aërobic nitrogen-fixing bacteria.-These organisms, described by Beyerinck in 1901, consisted of two species, Azotobacter chroöcoccum and Azotobacter agilis (Fig. 30). Three additional species, making five in all, were described by the writer in 1903 and 1904. They were all large bacilli, quite characteristic in their appearance, and widely distributed in arable soils. Being distinctly aërobic in character, they develop only when air is freely admitted. Their power to fix atmospheric nitrogen is more pronounced than that of Clostridium Pastorianum, and the highest yield of combined nitrogen thus far recorded has been given by Azotobacter Vinelandii (Fig. 31), isolated from a New Jersey soil.

From the standpoint of crop-production, this circumstance is of great significance, since the fixation of nitrogen is accomplished at the expense of the humus. The latter furnishes the food and energy to the bacteria and they use it up in their growth. For the fixation of nitrogen a smaller quantity of humus suffices for the azotobacter species. Azotobacter Vinelandii can fix, 
with a given quantity of humus, two or three times as much nitrogen as can be fixed by Clostridium Pastorianum. The differences in the nitrogen-fixing power of the anaërobic and aërobic bacteria are due to the differences in their mode of action. The chemical processes which they employ are not the same, hence the results cannot be expected to be the same. However, the power of fixing atmospheric nitrogen is quite vari-

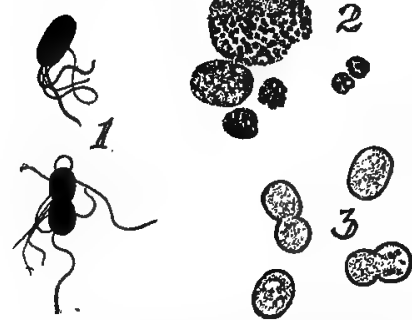

Fig. 30. Non-symbiotic nitrogen-fixing bacteria.-1. Azotobacter agilis; $\times 2,000$. 2. Azotobacter chroöcoccum; degeneration forms; $\times 1,600$. 3. Azotobacter agilis; $\times 2,000$. (Beyerinck.)

able in either class of organisms. It is modified essentially by soil and climatic conditions, and may be increased by favorable soil conditions, or decreased by unfavorable conditions.

The quantity of lime in the soil bears a striking relation to the development of azotobacter. Being more susceptible to acid conditions than Clostridium Pastorianum they will not develop in soils that are more or less sour. They grow best, therefore, in soils containing an abundance of lime. It has been found that they can be most readily secured by inoculating culture solutions of the proper composition with small pieces of undecomposed lime carbonate found in the soil. Investigations carried on in Germany and in Sweden show the importance of lime for the development of these organisms. The unlimed soils in these experiments failed, for the most part, to yield a 
growth of azotobacter even when the land was in good condition. It is not at all impossible that the persistent fertility of limestone soils is due in part to their vigorous flora of azotobacter species and the consequent steady gains of nitrogen through the activities of these organisms.

Much interesting light is still to be thrown on the relation of azotobacter to other soil bacteria. There is good reason to believe that this relation is important, not only from the standpoint of nitrogen-fixation (addition) but also from the standpoint of nitrogentransformation. Beyerinck thought at first that azotobacter have not, by themselves, the power of fixing atmospheric nitro-

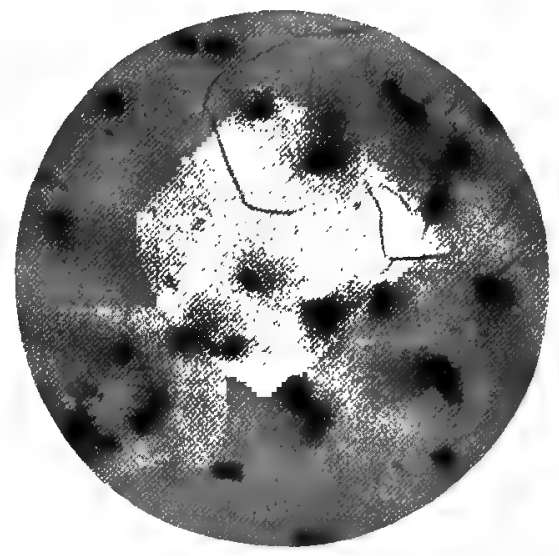

Fig. 31. 4zotobacter vinelandii: $\times$ 1,000.-One of the non-symbiotic nitrogen-fixing bacteria. gen, and that they become endowed with this power only in the presence of certain other soil bacteria. Subsequent investigations by others demonstrated the fallacy of his views, and the writer showed experimentally why Beyerinck came to hold such views.

But, while azotobacter can undoubtedly fix atmospheric nitrogen when in pure culture, its power of nitrogen-fixation is enhanced by other species themselves 
not nitrogen-fixing organisms. The writer demonstrated that the increased power thus lent to the nitrogenfixing bacteria may be very considerable, and that the several azotobacter species show differences in this

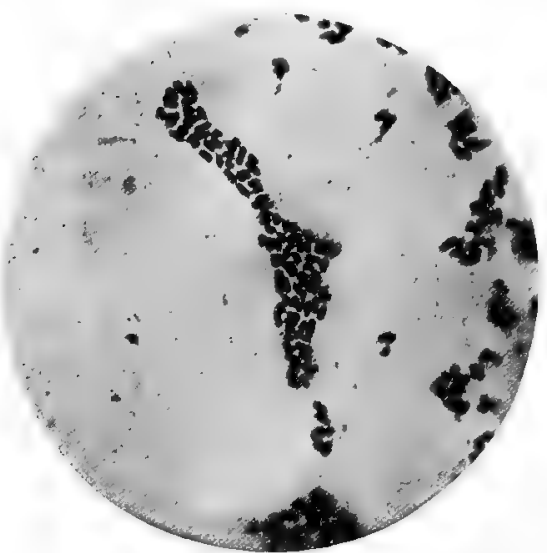

Fig. 32. B .30; $\times 1,000$. A small bacillus which cannot by itself $f x$ atmospheric nitrogen but stimulates the activities of nitrogenfixing organisms. respect. For instance, it was found by the writer that Azotobacter Vinelandii can fix much larger quantities of nitrogen than Azotobacter Beyerinckii When, however, the latter is developing in the presence of a certain small bacillus, its output of combined nitrogen may equal that of Azotobacter Vinelandii. We are, therefore, confronted here by a relation which may be designated as symbiosis. It may be assumed safely that the organisms accompanying the azotobacter are enabled to develop because of the nitrogen compounds elaborated by the former. In what manner the azotobacter are favored by the growth of the accompanying organisms is not known. It is likely, however, that the latter use up much of the nitrogen fixed by the azotobacter and that these are, therefore, compelled to increase their activities. 
There are, also, symbiotic relations between azotobacter and algæ, -one-celled, green plants. The algæ are widely distributed on land and sea and are found in cultivated and uncultivated soils, in fresh and salt water. As green plants, they are able to build their sugars and starches out of carbon dioxid and water. The azotobacter living with them use the sugars and starches thus produced as the fuel for the production of nitrogen compounds from the free nitrogen of the air. The algæ are, therefore, provided by the bacteria with nitrogen compounds, while the bacteria are provided by the algæ with sugar. It is probable that the two organisms furnish very considerable quantities of combined nitrogen to other inhabitants of the sea. At any rate both Azotobacter chroöcoccum and Clostridium Pastorianum have'been found in large numbers in seawater.

Agricultural importance of the two classes of bacteria.Very little is known as yet of the actual additions to the store of combined nitrogen in the soil by the aërobic and anaërobic nitrogen-fixing bacteria. There are a few instances on record when they were apparently responsible for marked gains of nitrogen. It is reported by Khün, for instance, that after growing non-leguminous crops on the same soil (sandy loam) for twenty years, the yields became no smaller, notwithstanding the fact that only non-nitrogenous fertilizers were added. Similarly, in a portion of the Geesecroft field, at Rothamsted, abandoned to itself between the years 1882 and 1904, and bearing no leguminous vegetation, there was an average annual 
gain of twenty-five pounds of nitrogen per acre. Azotobacter and other nitrogen-fixing bacteria must have played a prominent part in the accumulation of this nitrogen. At any rate, azotobacter has been shown to be quite abundant in the Rothamsted soils.

Gains of nitrogen have also been noted in smaller quantities of soil employed in vegetation experiments. A number of such gains are recorded in the literature of the subject. The gains found at the New Jersey Experiment Station occurred in a poor, sandy soil, and were remarkably large in those instances when horse manure was applied to the soil. It amounted, in some instances, to more than one-third of the nitrogen originally present or supplied. The experiments in question offer strong proof of the ability of these organisms to add large quantities of combined nitrogen to the soil. They also show the necessity of supplying to the bacteria an abundance of organic material that they may use as food and fuel in manufacturing nitrogen compounds.

Other nitrogen-fixing forms.-Aside from the two large groups of nitrogen-fixing bacteria discussed here, there are also a number of soil organisms that, to a limited extent, may display an ability to fix atmospheric nitrogen. They are not, strictly speaking, nitrogenfixing bacteria, and belong properly to the ammonification ol denitrification groups, or to others. Neither the conditions that stimulate their power of nitrogenfixation nor their relations to the nitrogen-fixing bacteria proper are well understood. It does not necessarily follow that their ability to utilize atmospheric nitrogen 
in artificial cultures in the laboratory finds a parallel in the soils in the field. At the same time, the possibility is not excluded that even there they may play a part not only in the transformation of nitrogen, but, also, in the addition of nitrogen to the soil.

Apart from the bacteria proper, molds and algæ have been demonstrated to possess the ability of fixing small quantities of atmospheric nitrogen. The results secured with these organisms are quite contradictory and cannot be accepted without reserve. None the less, in the case of molds, at least, there are recent investigations that indicate that they may be an important factor in the accumulation of combined nitrogen in peaty soils. 


\section{CHAPTER XXII}

\section{SYMBIOTIC FIXATION OF NITROGEN}

Jetrro Tul, who wrote a treatise on agriculture in the first half of the eighteenth century, makes some interesting statements concerning sainfoin and lucerne (alfalfa). Himself a good farmer and a careful observer, he added to his knowledge by travels in France and Italy, as well as by the study of ancient writers on the art of agriculture.

The soil-enriching qualities of legumes had been commented on by the Roman writers and Tull could confirm their observations from his own experience. He contributes excellent testimony as to the efficiency of - legumes in the restoration of depleted soils. The farmers of Europe found in these crops, and particularly in clover, a means for increasing the waning harvests. Previous to its introduction the lands were in a poor - condition.

John Christian Schubert, who introduced clover into Austria, was knighted by Emperor Joseph II for his services to agriculture. Clover rapidly replaced the bare fallow in accordance with the admonition of Schubert.

The limitations of legumes.-The farmers of Europe soon learned, however, that clover was liable to fail 
after it had been grown on the same soil a number of times. This was a matter of common knowledge in England even in Tull's day, for he was led to say that "the true cause why clover and St.-Foin do not succeed so well after their own respective species, or that of each other, as corn, etc., can, is that they take great part of their nourishment from below the plough's reach so that under-earth cannot be tilled deep enough, but the upper part may be tilled deep enough for the horizontal roots of corn, etc., towards which the rotting of the clover and St.-Foin roots, when cut off by the plough, do not a little contribute."

Legumes and fertilizers.-In the application of marl, and, subsequently, of gypsum, the farmers found a means for bringing clover back to their soils, but, in the course of time, even these ceased to be efficient. It was stated about the middle of the last century that "the application of gypsum to the soil now makes the clover only more watery, without increasing the crop; land treated with marl is more unproductive than before."

The inability of the land to grow clover decreased the resources of the farmer for producing manure, practically the only important fertilizer then known. This loss was felt keenly.

The cause of the soil-enriching qualities of legumes.It is evident that the peculiar value of clover and of other legumes was fully appreciated in the eighteenth and early in the nineteenth centuries. As to the reason for the soil-enriching qualities of crops like clover, opinions differed. It was thought by many that these qualities were due entirely to the deep-rooting habits 
of the clovers and their ability to forage for food and moisture through a much greater thickness of soil. Part of the food, it was thought, derived from the subsoil, was concentrated in the roots and stubble near the surface and was later made available to succeeding crops.

When the composition of plants was begun to be studied, it was learned that certain chemical elements are always present in them. The number of analyses increased with the improvement of the chemical methods and led to the further investigations on the origin of plant-food. The source of nitrogen, one of the constituents always found in plants, became a subject for much study and discussion, particularly in view of the fact that so large an amount of nitrogen gas is present in the air. Some of the chemists in the early years of the nineteenth century were inclined to think that the gaseous nitrogen of the air serves directly as plant-food.

Liebig's theory.-The existing uncertainty was seemingly dispelled for a time by the declaration of Liebig that plants can derive not only their carbon but also their nitrogen from the air. According to him, however, the nitrogen is not supplied to crops in the elementary state, but in the form of ammonia. Liebig thought all crops capable of securing their nitrogen from the air, but that legumes and other broad-leaved plants were particularly capable. His position was based on the fact that legumes not only benefited the succeeding cereal crops, but that they did not respond to applications of nitrogenous fertilizers.

Liebig's conclusions were not accepted by all of the 
contemporary scientists. It was soon demonstrated by investigations on the Continent and in England that the quantities of ammonia and of other nitrogen compounds in the air are very small, and that the amounts brought down in the rain and snow would account for only a small fraction of the nitrogen removed in the crops. Notwithstanding these investigations, Liebig retained his belief in the sufficiency of the nitrogen compounds in the air for supporting vegetation.

Other theories.-To Boussingault in France and to Lawes and Gilbert in England the facts then known seemed to point in one direction. They had become convinced that the nitrogen compounds of the atmosphere were sufficient only for a very meager vegetation, but there was still a possibility that the enormous quantities of the free nitrogen of the air may supply the needs of plants for this element. Accordingly a series of experiments was instituted by Boussingault in 1851, and by Lawes, Gilbert and Pugh in 1857. These experiments were carried out with great care. Determinations were made of the nitrogen in the seed and soil at the beginning of the experiments and in the plants and soil at their conclusion.

Lawes, Gilbert and Pugh took the precaution to calcine the soil employed, and to remove all the ammonia from the air before it was admitted into the glass cage where the plants were growing. Their results and those of Boussingault agreed fully, all of them indicating that the free nitrogen of the air was not available to the plants in their experiments. These results were accepted as decisive for many years, notwithstanding the ex- 
periments of others which pointed in the opposite direction.

New evidence ' was accumulated, in the course of time, which again opened the question of the utilization of atmospheric nitrogen by plants. Field and pot experiments, carried on in Germany, France, England and the United States, in the early eighties, furnished abundant proof that, under some conditions, the plants of the legume family possess the unmistakable ability to secure nitrogen from the atmosphere. The investigations of Atwater in this country, in 1883 and 1884, demonstrated the ability of legumes to acquire the nitrogen of the air. In some of his experiments with peas, the nitrogen gained was 50 per cent more of the total quantity harvested. This gain was ascribed by him to the direct utilization of the free nitrogen.

The solution of the problem.-The mystery was cleared up in 1886 by Hellriegel at a meeting of scientists in Berlin. Hellriegel, and Wilfarth, who was associated with him, noticed in their experiments that when peas were grown in artificial soil containing no combined nitrogen, but provided with mineral plant-food, they developed normally until all of the nitrogen in the seed was used up, when they turned yellow and perished. There were, however, occasional plants which passed through this critical period. Such plants again assumed a healthy green color and grew vigorously to maturity. The examination of these plants showed that their roots invariably contained nodules, whereas the plants which perished contained none, or only an occasional small nodule. 
In order to determine whether the formation of nodules was due to the infection of the roots by microörganisms, these investigators instituted an experiment with forty pots of soil. Ten of these soils received each a very small quantity of leachings from a fertile soil, while the remaining thirty soils received none. It was noticed that the plants in all of the pots that had received the soil-leachings passed through the critical period and turned dark green, whereas the plants in twenty-eight out of the remaining thirty soils showed strong evidence of nitrogen hunger. An examination of the roots showed that the vigorous plants all possessed an abundance of nodules.

In further experiments, when everything was sterilized, the peas germinated and grew vigorously for $a$. while, but finally turned yellow and died. No nodules were found on the roots of these plants, and Hellriegel and Wilfarth concluded, therefore, that the nourishment of legumes, their power of acquiring free nitrogen, the formation of nodules and the presence of microörganisms stood in intimate relation to one another. Similar experiments with crops belonging to other plant families gave negative results.

In commenting on these experiments, Gilbert, of Rothamsted, said: "It must be admitted that Hellriegel's results, taken together with those of Berthelot and others, do suggest the possibility that, although the higher plants may not possess the power of directly fixing the free nitrogen of the air, lower organisms, which abound within the soil, may have that power, and may thus bring free nitrogen into a state of com- 
bination within the soil in which it is available to the higher plants-at any rate, to members of the Papilionaceous family. At the same time, it will be granted that further confirmation is essential before such a conclusion can be accepted as fully established."

The further confirmation was not lacking, and was soon brought forward by numerous investigations, among them those begun at Rothamsted in 1888 . The failures of the earlier experiments were also explained since the artificial soils used there precluded the entrance or development of the bacteria.

Nodules on the roots of legumes.-The discovery of Hellriegel and Wilfarth demonstrated that legumes possess the power of acquiring the free nitrogen of the - air, owing to the bacteria which form the nodules on their roots. Without the bacteria and the nodules, they lack this power. However, these investigators were not the first to observe that nodules are present on the roots of leguminous plants. We have reason to think that these swell ngs or nodules had been observed centuries ago. The Italian, Malpighi, described them in 1687. They appeared to him as galls.

In 1866 it was demonstrated by the Russian botanist, Woronin, that the nodules are filled with great numbers of bacteria, and, subsequently, it was shown by others that besides the bacteria there are certain filaments or threads which appear to pass from cell to cell. These filaments are much like hollow tubes widening out to funnel-shaped forms where they come in contact with the cell-walls. It is apparently their function to create a passage through which the bacteria pass from cell to cell. 
The nature of the nodules.-For some years there existed among botanists and bacteriologists a difference of opinion as to the true nature of the nodu'es. It was held by some persons that they are the result of some disease in the roots. Others thought that they are thickened modifications of the healthy roots. Still others regarded them as storage places for reserve food materials. Among the latter was the German, Brunchorst, who saw in the bacteria-like particles only reserve protein bodies and named them "bacteroids" (which means bacteria-like). Hellriegel asserted that the nodules are due to infection from without, caused by bacteria; but, that these invading bacteria are not disease germs and inflict no injury upon the host-plant. He regarded the relation established between the hostplant and invading bacteria as advantageous to both, and, therefore, an instance of symbiosis.

A further step in advance was made by the investigations of Beyerinck and also of Prazmowski. The former demonstrated that the bacteria-like bodies in the nodules are true bacteria, by growing them artificially on various substances outside of the legume roots. Prazmowski showed that the roots of legumes could be artificially infected by such laboratory cultures and nodules produced thereby. It was thus firmly established that the nitrogen-gathering power of legumes is due to their ability to form a partnership with certain species of soil bacteria, named by Beyerinck Bacillus radicicola. This partnership is mutually profitable, the bacteria furnishing nitrogen compounds to the plants, while the latter provide sugar and various mineral salts to the 
invading germs. The nitrogen compounds manufactured in the nodules are carried to other parts of the plant where they are employed for the building of new tissue.

The bacteria of legumes.-The legume bacteria are widely distributed in the soil and are present in streams and lakes. The particles of dry soil which are carried by the wind may have adhering to them one or more
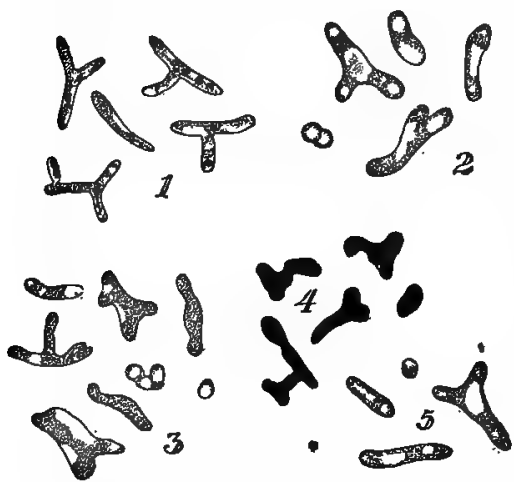

Fig. 33. Bacteroids from legume tubercles.1. From Melilotus alba; $\times 3,000$. 2,3, and 5. From Medicago sativa; $\times 3,000$. 4. From Vicia villosa; $\times 3,000$. (Harrison and Barlow.) of these organisms; hence wild legumes may be enabled to establish themselves in new places because of the occasiona! infection by bacteria brought by the wind. The formation of nodules, or tubercles, as they are frequently called, occurs only on the younger parts of the roots.

Under proper conditions, the germs that come in contact with the roothairs penetrate the latter, and, by means of the filaments already mentioned, make their way toward the interior of the root-branch. There is no regularity in the arrangement of the tubercles on the roots, since infection may occur in different places and at different times. The bacteria that enter the legume roots are very small and rod-shaped, but within the nodules they subsequently assume various shapes and sizes. In different 
plants, they may appear as irregular rods, or pear-, $\mathrm{X}-$, or $\mathrm{Y}$-shaped. These irregular forms, designated as bacteroids, are characteristic in some of the legumes.

The organisms that find their way into the legume roots multiply there rapidly and increase to enormous numbers. The small rod-shaped forms are rather abundant in the young tubercles but, as the latter grow older, the larger irregular forms, the bacteroids, become more and more numerous. Later still, the bacteroids are dissolved and absorbed by the host-plant. Not all of the organisms are thus absorbed, however, for very considerable numbers remain in the partly emptied nodules. On the decay of the latter, the surviving bacteria find their way back into the soil where they probably derive their nourishment from the humus until a new opportunity is given them to enter the roots of some legume.

It is evident that soils which frequently bear crops of legumes must. necessarily be richer in nodule-bacteria. This is so because the greater the number of such plants, the greater the number of bacteria that escape back into the soil from the decayed nodules. For example, it is a matter of common observation that when two crops of cowpeas or of soybeans are grown in succession on the same soil, the second crop is frequently superior to the first. Similarly, $\mathrm{n}$ the case of alfalfa, soils new to this crop yield but a scanty stand of inoculated plants. When, however, the latter are turned under and the field reseeded, the new stand is usually much better. It appears, therefore, that the decay of the comparatively few tubercles leads to an increase of the bac- 
terial numbers in the soil and provides for a better inoculation of the succeeding plants.

The relations between legumes and the nodule-bacteria.The exact relations between the plant and bacteria in the formation of tubercles are not yet fully explained. The information thus far in our possession indicates that the plant offers more or less resistance to the entrance of the bacteria and that the latter must be sufficiently vigorous to overcome this resistance. It is
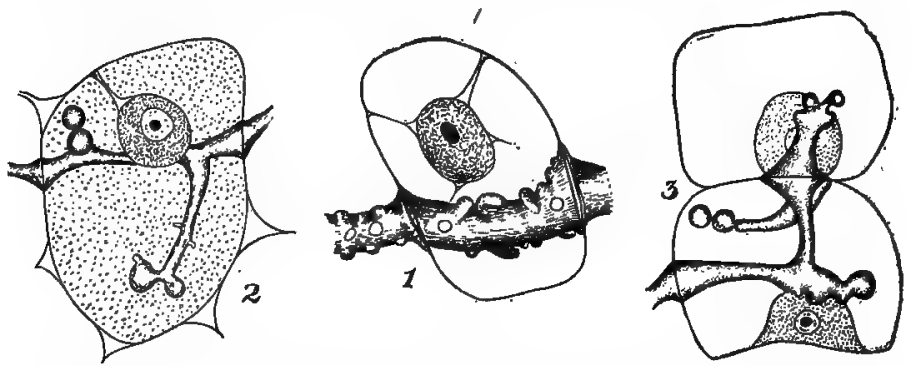

Fig. 34. Sections through root tubercles.-1. Cell from tubercle of Pisum sativum, showing bacterial filament. 2 and 3 . Cells with bacterial filaments from tubercle of Trifolium Pannonicum. (Stefan.)

well known that when an abundance of available nitrogen is present in the soil, or when nitrate is applied, the formation of tubercles is partly or wholly suppressed. The suppression of tubercle-formation is explained, in this case, by the assumption that the bacteria can enter the roots of leguminous plants only when the latter are in a weakened state, as is true, for example, of legumes growing in nitrogen-poor soils.

The young plants in such soils finding but meager quantities of combined nitrogen to supply their needs, 
soon turn yellow and pass into a state of "nitrogenhunger." In this weakened state, they have but slight power of resistance, and the nodule-bacteria find it comparatively easy to enter their roots. On the other hand, the legumes growing in soils well supplied with available nitrogen compounds remain vigorous and retain a high power of resistance, thus precluding the entrance of the bacteria. Furthermore, it is known that after some tubercles are formed on the legume plants, the formation of additional tubercles becomes more difficult. Now, since plants already possessing a few tubercles are better supplied with nitrogen, their vigor is increased and they can

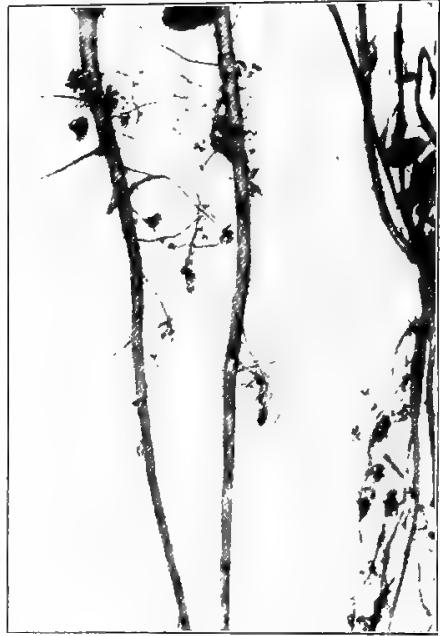

Fig. 35. Root tubercles of healthy alfalfa plants. The tubercles are small and numerous. better resist the attacks of the bacteria.

Virulence.-Another conception in the relations of legumes and their nodule bacteria should not be overlooked. In considering the greater or slighter resisting power of different plants under different conditions, it should be remembered that the bacteria, also, may display differences in their ability to penetrate the legume roots, as well as in their ability to fix atmos- 
pheric nitrogen when developing within the nodules. The term virulence has been used to designate this variable power of the bacteria. Organisms of a high degree of virulence readily penetrate the legume roots, and secure large quantities of nitrogen from the air.

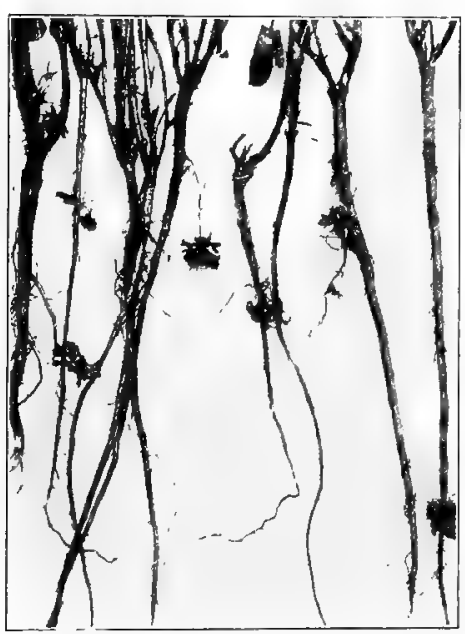

Fig. 36. Root tubercles of unhealthy alfalfa plants. The tubercles are large and few in number. Organisms of a low degree of virulence are feeble in this respect.

Under favorable soil conditions the virulence of the bacteria may be increased; under unfavorable soil conditions their virulence may be greatly diminished. Hence, soils well provided with lime and humus, soils in good tilth, well aërated and supplied with an abundance of moisture, will favor the fixation of large quantities of atmospheric nitrogen. On the other hand, ill-drained soils, or those deficient in humus, will tend to diminish the virulence of the nodule-bacteria, to the injury of the legume crops that may be grown upon them.

Balance.-The conception of resisting power of plants on the one hand and that of the virulence of bacteria on the other, introduce a third conception of a balance 
between the two. The resistance of the plants must not be too great to exclude the bacteria; the virulence of the bacteria must not be great enough to prevent the plant from securing the nitrogen fixed by them. It is only when the true balance is established that a condition of symbiosis is created. It is conceivable that the virulence of the bacteria may be augmented to such an extent as to enable them to retain all of the nitrogen fixed by them for their own purposes. In such a case, the bacteria would contribute nothing to the growth of the host-plant, but would rather constitute a drain on its starches, sugars and mineral salts. In other words, they would become parasites. It is further believed by some bacteriologists that vigorous bacteria need not necessarily be also virulent bacteria. According to them, vigorous strains of the nodule-bacteria that possess but a slight power of fixing atmospheric nitrogen may be produced. Such organisms would act as true parasites within the nodules.

The final explanation.-These theoretical considerations may help to account for the beneficial effects observed at times from light top-dressings of nitrate on new fields of alfalfa. By increasing the vigor, and, hence, the resisting power of the young plants, the nitrate excludes from the roots all but the most virulent bacteris and leads, théreby, to a greater ultimate fixation of nitrogen. Heavier applications of nitrate would prove objectionable, since they would exclude the bacteria to too great an extent. Feeble plants, on the other hand, would not only allow the entrance of bacteria of a low degree of virulence, but would be unable to force tho 
latter to give up their nitrogen as rapidly or as fully. There is scarcely a doubt that future investigations will show how to maintain this proper balance between plants and bacteria, and will make it possible to secure the highest yields of nitrogen under any given conditions of soil, climate, or crop-rotation. 


\section{CHAPTER XXIII}

\section{SOIL-INOCULATION}

THE discovery that the fixation of atmospheric nitrogen by legumes is accomplished with the aid of bacteria suggested the artificial introduction of the latter into soils liable to be deficient in them. Such artificial addition of bacteria to the soil, designated now as' soil-inoculation, was already resorted to by Hellriegel and Wilfarth, as well as by other investigators in their studies of nodule-formation. When they employed sterile soils, they were obliged to use soil-leachings in order to make possible the formation of nodules on the roots. In other words, they inoculated their soils with the bacteria present in the leachings. The principle established by them was soon applied in a practical way.

Having learned that legume-nodules are caused by bacteria, men began to wonder whether all soils are sufficiently provided with the proper numbers and kinds of bacteria. There was a possibility that the failure of leguminous crops might be due to the lack of nodulebacteria. Accordingly, some experiments to test this point were begun as early as 1887 at the Moore Experiment Station at Bremen, Germany. The conditions were particularly favorable for the success of inoculation, 
since the soils experimented with were reclaimed heath or swamp soils that had not borne leguminous vegetation. The soils in question had been burned over and. limed on their reclamation and had also received dressings of mineral fertilizers.

The inoculations were performed with soils derived from various sources, some of them noted for their power to yield abundant harvests of legumes. The inoculating material was broadcasted at the rate of about 350 pounds per acre in October, 1887, and the inoculated and uninoculated plots were seeded with various legumes in the following spring. As the season progressed, the plants on the inoculated plots were marked by their dark green color and vigorous growth, whereas the uninoculated plants remained yellow and small.

There was noticed, furthermore, a very considerable difference in the action of the different soils used for inoculation. Thus, in one instance, the inoculation with a fruitful soil from Germany gave an increase over the uninoculated of 67 per cent of grain and 87.7 per cent of straw, while the inoculation under the same conditions with a productive soil from Holland gave an increase of 90.3 per cent of grain and 117.0 per cent of straw. The first attempts at inoculation were, therefore, a distinct success in so far as the reclaimed peat soils were concerned. It became possible, thus, to grow successful crops of legumes on these humus soils and to secure large yields of forage.

The next step in the development of soil-inoculation was the application of old legume-soil not only on re- 

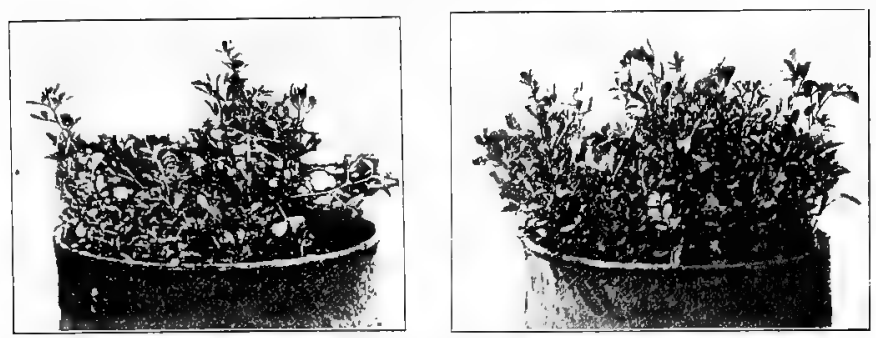

claimed heaths and marshes, but also on ordinary arable soils. It was conceivable that the introduction of bacteria into reclaimed marsh soils might prove highly beneficial. It was otherwise with clayey, loamy, or sandy soils in which legumes had grown at one time or another. Was the inoculation of such soils likely to yield increased returns? A partial answer to this question was given by experiments carried on in Germany in 1889, 1890 , and 1891.

Soils of various descriptions, including clayey, loamy and
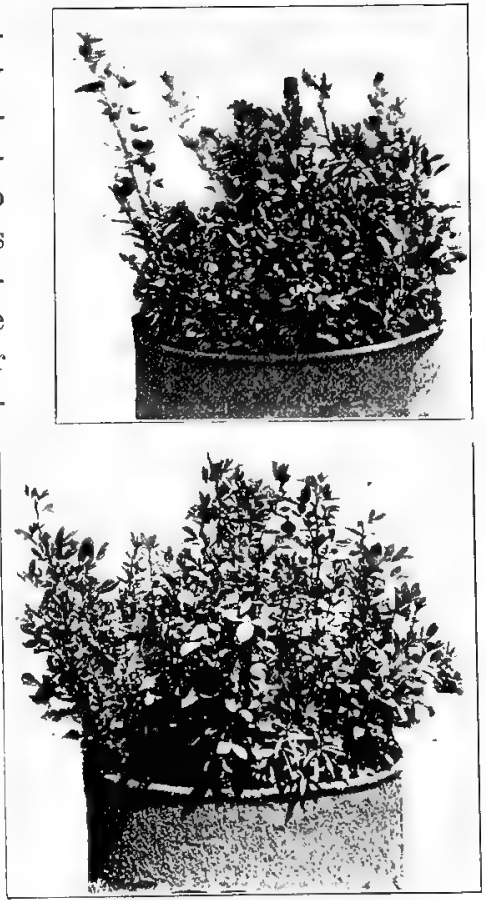

Fig. 37. The effects of a more or less thorough inoculation. 
sandy soils were inoculated, in most cases for lupins or seradella. The results were contradictory, some experimenters reporting a decided success, others complete failure. It was agreed, however, that on soils
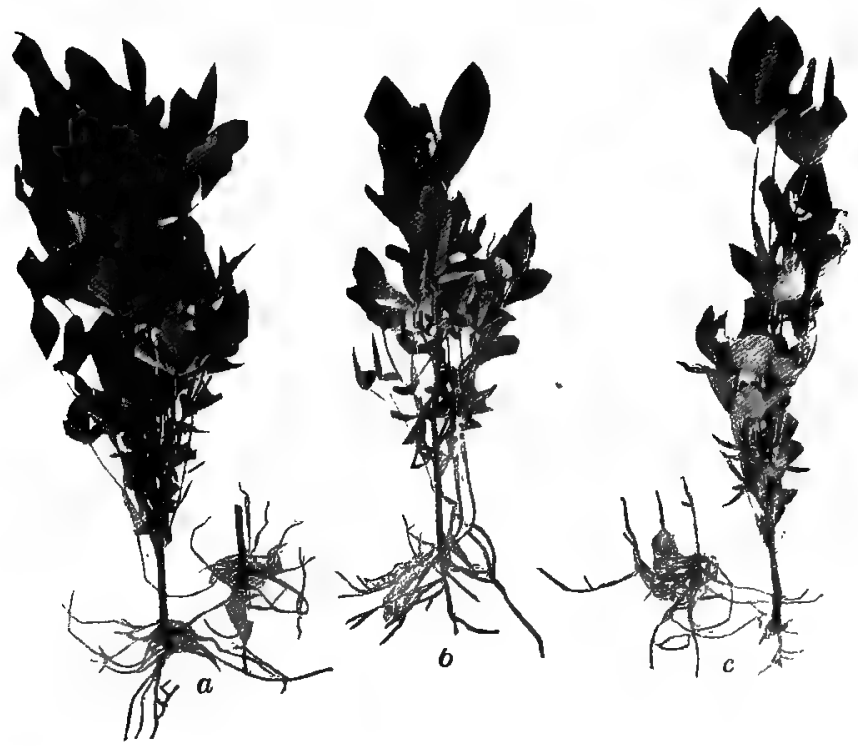

Fig. 38. A soybean plant and root, inoculated with soil, are shown at (a); $d$ soybean plant, untreated, is shown at (b), and soybean plant and root, inoculated with soybean chaff, are shown at (c).

newly placed under cultivation, on soils that had been deepened recently and had had much of the subsoil brought to the surface, and on soils that had been burned over, inoculation was likely to prove successful. Instances were also reported of light, sandy soils and of impoverished loam soils in which inoculation yielded 
very gratifying results.. Incidentally, the observation was made that in a mixture of field-peas and lupins, seeded on the same soil, the former developed numerous nodules, while the latter possessed scarcely any nodules at all, an indication that the same organism is not capable of producing nodules on both peas and lupins.

Altogether, these early experiments with old legumesoil as inoculating material demonstrated the usefulness of soil-inoculation under certain conditions. They also rendered another service to agriculture in calling attention to the need of careful preparation of the soil for the best development of legumes, of the importance in this respect of humus, lime and of phosphoric arid and potash. They helped to spread gradually the $\mathrm{kn}$ (s)ledge that leguminous plants are different from those of other families. They helped to make plain, also, that their power of gathering atmospheric nitrogen as determined by their relation with the bacteria in their nodules was capable of being modified by soil conditions. Intelligent farmers came to know that soil-inoculation meant simply the transfer of bacteria from one soil to another. They learned, also, that different soils were not equally efficient for the purpose, some of them containing, apparently, more vigorous organisms than the others.

Certain observations were made, likewise, in the use of legume-earth. Under certain conditions it was seen that its application was objectionable even where it was desired to introduce bacteria in the soil. Instances were noted in which soil-transfer from one field to another led to the introduction of weeds and to fungous troubles. Our own experience in this country in the inoculation of 
soils for alfalfa, has taught us to beware of blight, and also of dodder, which is frequently a greater scourge than blight. Thus the ground was prepared for the abandoning of legume-earth as inoculating material in favor of another method, that of pure cultures.

Pure cultures.-A pure culture is a growth of any one kind of bacteria (or of other microörganisms), uncontaminated by the presence of other kinds. A pure culture of Bacillus radicicola, the organism of the legumenodules, is the uncontaminated growth of these bacteria on any material (medium), whether it be a solution of sugar and mineral salts, gelatin, or potato. Since the nodules of legumes are formed in each case by the penetration of bacteria into the root-hairs, and since the many thousands of bacteria found in any particular nodule are the offspring of the single organism that entered the root-hair, it follows that every nodule contains a pure culture of Bacillus radicicola. To be sure, other microörganisms may find their way into the nodules after the latter are already formed. Nevertheless, it still remains true that pure cultures of the nodule organism may be secured without difficulty from legume tubercles.

After the latter are removed from the roots, they are carefully washed in sterile water to remove the particles of soil adhering to them and are thus freed from most of the soil bacteria on their outside. The nodules are then washed in a solution of corrosive sublimate, rinsed again in sterile water, cut open with a sterile knife, and the bacteria within them transferred to a nutrient solution in which they could multiply. 
Pure cultures were secured in this manner by the Dutch bacteriologist, Beyerinck, and by many others after him. The Germans, Nobbe and Hiltner, conceived the idea of preparing such cultures on a commercial scale, and induced a manufacturing concern to place them on the market under the name of nitragin in 1896. Nitragin was a pure culture of the nodule-bacteria on nutrient gelatin. It was sent out in flat, glass bottles, stoppered at first with a cork, but later with a piece of cotton.

The persons purchasing such cultures were instructed to dissolve the contents of the bottle in lukewarm water, to moisten the seed with it, and, finally, to dry the latter in a cool place and plant it. The large number of bacteria contained on the gelatin were thus distributed among the seeds and were carried by the latter into the soil. Since each legume had, if not a different variety, at least a different strain of the same variety best adapted to it, the manufacturers supplied cultures for each legume.

Nitragin.-The nitragin met with an enthusiastic reception in Germany and elsewhere. It not only promised to supply bacteria to soils lacking them, but, also, bacteria of a high degree of efficiency. The rather cumbersome method of inoculation with legume-earth could be dispensed with, and the inoculation of soils made safe and easy. The purchasers of nitragin were many. It was tried by experiment stations and private individuals in Europe and in North America and was judged according to its merits.

The results from its application in the first and second seasons included some favorable reports, but they were 
very few. By far the greatest proportion of the returns were negative. In some instances, when it was compared with earth it proved to be much inferior. Nitragin was a failure. The old method, clumsy and expensive though it was, was still more reliable than the new one. The demand for nitragin fell off rapidly and its sale was discontinued. Such was the first experience with pure cultures for soil-inoculation.

Agar as a medium for cultures.-The theoretical advantages of pure cultures failed to appear in practice, a fact that stimulated the originators of nitragin and other investigators to seek for the cause of failure. It was soon discovered that gelatin was not a proper material for the breeding of nodule-bacteria. It is of animal origin and is rich in nitrogen, discouraging thereby the tubercle-bacteria from utilizing the nitrogen of the air. The cultures grown upon it deteriorate rapidly and either die out or lose, wholly or in part, their power of fixing free nitrogen.

In order to remedy this defect, the cultures were prepared in an experimental way on agar, a substance of vegetable origin. Agar is prepared from a certain kind of sea-weed and has the property of changing into a starchy mass when boiled in water. The liquefied agar solidifies again on cooling and may thus be used for the preparation of solid cultures (cultures growing on solid media, like gelatin, potatoes, beets, or gypsum plates).

Difficulty in using pure cultures.-It was further discovered that when the seed begins to swell before germination it produces certain soluble substances 
injurious to the bacteria, which pass out from the interior of the seed to the seed-coat. The bacteria brought into contact with these poisonous secretions of the seed are destroyed or weakened and are no longer able to infect the young legumes. In order to obviate this latter difficulty, it was proposed to soak the seed in water for some hours, thus getting rid of the poisonous secretions, and then to inoculate the swelled seed. There was, however, a practical objection to this method,the inconvenience in planting partly germinated seed. Subsequent inquiry showed that the poisonous secretions produced in the seed could be made harmless to the bacteria by mixing the cultures, preparatory to inoculation, in a weak solution of salts or in skimmed milk, tnstead of water.

Artificial cultures.-A gradual improvement has thus been made in the character of artificial cultures and has led, within the last two or three years, to very gratifying returns from their use in Germany. The keen disappointment which followed the failure of nitragin in 1896, 1897 and 1898, cast discredit on artificial cultures, and the farmers in Europe went back to the cumbersome but more certain legume-earth method. The so-called New nitragin, slowly evolved by the efforts, largely, of Hiltner and his associates, is restoring the confidence in artificial cultures.

Extensive experiments with such cultures, conducted throughout Germany, and especially Bavaria, have yielded very promising results within the last three years. A positive increase from inoculation has been obtained, not only on soils that had never borne legumes, 
but, also, on cultivated soils on which these crops have been raised more or less extensively. The latter fact is of considerable significance because it shows that the introduction of artificial cultures into the soil may add to it not only a large number of organisms, but also the kind that are more vigorous and more efficient than those already present there. In other words, there is every indication that we may develop in the laboratory strains of tubercle-bacteria of a higher degree of virulence than is possessed by the bacteria in the soil. Future investigations will teach us to utilize soil-inpculation more extensively and more profitably by pointing out to us the best condition and treatment for any particular soil or crop.

Soil-inoculation in the United States.-The history of soil-inoculation efforts in the United States is, in many respects, unique. As in Germany, the first attempts at inoculation involved the application of legumeearth as inoculating material. Crops like clovers, cowpeas, field-peas, beans, and even vetches did not apparently require any inoculation. As a rule, they grew on new soils rather vigorously and produced the characteristic nodules, thus indicating that the proper bacteria are present in most soils. It was otherwise with at least two leguminous crops, soybeans and alfalfa. Soybeans, originally introduced into the United States from Japan, did not do very well. They frequently failed to develop that healthy, dark green color characteristic of vigorous leguminous plants. Careful examination showed their roots to be devoid of tubercles. Soybean earth, straw and chaff were obtained from Japan ard 
placed in the ground together with the seed. The plants thus inoculated developed normally, and produced an abundance of tubercles.

This experience demonstrated the need of soil-inoculation for soybeans. Many cases are reported in experiment station literature in which these inoculations gave positive results. For instance, in the experiments of the New Jersey Station, on light sandy soils at Hammonton, when cowpeas and soybeans were planted in the same ground, the former grew luxuriantly and gathered nitrogen from the air by means of their numerous nodules, while the soybeans remained small and yellow and produced no tubercles. It was not until the introduction of some soil from a field where these plants had been grown successfully for several years that the soybeans developed properly and grew as luxuriantly as did the cowpeas.

Similar observations were made time and again in the case of alfalfa. Soils to which this crop was new usually required inoculation, even though they had successfully produced red or crimson clover. It appeared, as in the case of soybeans, that the bacteria capable of producing nodules on alfalfa were absent, as a rule, from soils in which this crop had not been raised before. This observation has led to the rather common practice of scattering old alfalfa soil on new fields where this plant was to be established. It was found subsequently that the bacteria causing nodule-formation on alfalfa were seemingly identical with those producing tubercles on sweet clover. Inoculation was therefore superfluous on soils to which sweet clover was native, and, more- 
over, sweet clover soil could be used as inoculating material for new alfalfa fields.

In the course of time, it became apparent that the use of legume-earth for inoculating purposes in the United States has its disadvantages. The need was felt for efficient pure cultures of the legume-bacteria, and, accordingly, the Department of Agriculture in Washington turned its attention to the preparation of such cultures. A representative of the Department, who was sent to investigate the preparation of nitragin in Europe ${ }_{w}$ reported the outlook as rather unpromising. The Department undertook, therefore, to develop a new method for the distribution of pure cultures of legume-bacteria. The work was placed in charge of Dr. George T. Moore, Physiologist in the Bureau of Plant Industry.

The progress made by him was deemed satisfactory by the chiefs of the Bureau for, in the preface to Bulletin 71 of January, 1905, it is stated that "he has succeeded in perfecting the pure-culture method of distribution even beyond our expectations." It is stated further that "Doctor Moore, in the course of the investigations, soon discovered why it was that the former methods of culture and distribution were so uncertain in their results. $\mathrm{He}$ worked out improved methods of making the cultures and increasing by growth in non-nitrogenous media the nitrogen-fixing power of the organisms, and perfected a method of drying them by which their activity can be preserved indefinitely."

The method, as it was elaborated in the Bureau of Plant Industry, differed in many particulars from the 
German method of Nobbe and his associates. The German nitragin supplied to the purchaser a mass of gelatin, the surface of which was covered with a growth of nodule-bacteria. The number of the latter was so great that their mere distribution in a quantity of water and the moistening of the seed with the latter was sufficient to allow every seed to be supplied with a number of organisms.

The so-called cotton cultures of the Department of Agriculture consisted of a piece of absorbent cotton that had been moistened with a liquid culture of the nodule-bacteria, and subsequently dried. The dried cotton was, therefore, supposed to contain a comparatively small number of nodule-bacteria, capable of growing and multiplying when placed in the proper nutrient solution. In order to supply the latter, the package of inoculated cotton was accompanied by weighed quantities of cane-sugar, phosphate of potash, sulfate of magnesia, and phosphate of ammonia. These salts were to be dissolved in water, furnishing a complete food for the nodule-bacteria, and the cotton was to be placed in the solution. With conditions favorable for their development, the nodule-bacteria could thus rapidly increase in numbers, and could furnish sufficient material for the inoculation of a considerable quantity of seed.

In the cotton method, as can be seen, the preparation of the cultures was really left to the farmer. The danger was always present that the bacteria, molds, and yeasts introduced from the air, or contained in the utensils or water might prove a serious menace to the 
proper growth of the nodule-bacteria supplied on the cotton. It was subsequently found, moreover, that the method of preserving the tubercle-bacteria in a dried condition on cotton was not so satisfactory as had been supposed. Most of the organisms perish in the drying. When the temperature and moisture changes of the atmosphere are of considerable range, it is difficult to preserve any of them in a dried state.

The commercial preparation of the cotton cultures received a serious check when it was discovered in the experiments of several of our experiment stations that such cultures failed almost uniformly to produce the desired results. European tests of cotton cultures also gave negative results, thus substantiating the conclusions of the American experiment stations that no reliance can be placed on the cotton method for the distribution of efficient cultures of nodule-bacteria.

The use of pure cultures in the United States is at present subject to more or less uncertainty. "The unsatisfactory nature of the cotton cultures having been demonstrated, pure culture material is sent out now in liquid form, or as a growth on agar. The farmers are warned, however, to utilize such cultures within the space of ten days or two weeks, for the rapid deterioration of the cultures after that period renders their value doubtful. It is evident, at any rate, that further investigations of cultures and culture methods are quite necessary.

While there is reason to think that, in this country, the employment of pure cultures is destined to occupy a larger place in agricultural practice, the present uncertainty makes it advisable to place more reliance in 
the old legume-earth method. With proper care, the use of legume-earth gives us an assurance of success of which we are by no means certain from the use of artificial cultures. The careful trials certain to be made in the near future with the new nitragin of the German investigators will enable us to determine whether it is so much superior to legume earth, as the published reports lead us to suppose. It would also be desirable to compare the new nitragin with the liquid cultures as well as the agar cultures prepared in the United States.

Alinit.-Soil-inoculation has also been attempted in the case of bacteria other than those forming nodules on leguminous plants. Under the name of alinit, there was placed on the market in 1897 a material purporting to be a pure-culture Bacillus Ellenbachensis. This organism was isolated by Caron, the owner of the estate Ellenbach in Germany. It was claimed by him
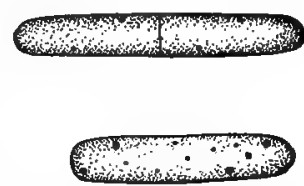

Fig. 39. Alinit bacteria (Bacterium Ellenbachensis). to be one of the non-symbiotic nitrogen-fixing bacteria. Alinit was investigated and tested by numerous investigators and was found incapable of fixing atmospheric nitrogen.

Experiments were likewise conducted with the nitrogen-fixing azotobacter species with negative results. To these might be added the records of inoculation with nitrifying and other soil organisms. All of them usually failed to yield encouraging returns. We are, therefore, forced to conclude that while the future may see grati- 
fying results from the use of pure cultures of various nitrogen-fixing, decay and nitrifying bacteria, our present state of knowledge seems to offer a greater assurance of success in stimulating the activities of soil bacteria by soil-improvement. Better moisture conditions, as well as better conditions of aëration, more and better humus, and a better supply of mineral plant-food will not only stimulate the increase of soil bacteria, but will, also, intensify their virulence. They will thus be enabled to cause more decay, more nitrification, and more nitrogenfixation in a given time. On the other hand, the mere introduction of efficient bacteria of whatever class, without previous soil-improvement, will fail to yield the desired results, since the bacteria introduced will soon deteriorate under the unfavorable soil conditions. 


\section{CHAPTER XXIV}

\section{GREEN-MANURING}

MODERN research on the nitrogen-gathering power of legumes has led to their systematic use as greenmanures. They have become, to a great extent, the present-day fallow crops, the successors of the bare fallows. Green-manuring, which is, essentially, the turning under of green crops for the benefit of succeeding crops, has been developed into a system. The crops used for green-manuring purposes need not necessarily belong to the legume family. Crops like rye, wheat, oats, buckwheat, mustard, rape, and even turnips have been used more or less extensively as green-manures. All of these may benefit the soil by preventing the loss of soluble constituents, and particularly nitrates, during a part of the year when the main crops are not occupying the land. Furthermore, they supply organic material which, when plowed under, helps to maintain the store of humus in the soil.

Green-manures and humus in the soil.-The importance of this latter function will be readily recognized when we remember that the humus combines with a part of the phosphoric acid, potash, and lime of the soil. These combinations, known as humates, are extremely . important as available sources of the mineral constitu- 
ents of plant-food. It has been shown that when various organic materials are mixed with soil and kept in the open for a year or more, the organic substances in changing to humus gain phosphoric acid from the soil. When, however, the organic materials are themselves rich in phosphorus, there may be a loss instead of a sain in the resulting humus.

Leguminous green-manures and nitrogen in the soil.All green-manures, then, may be valuable because they prevent the loss of soluble plant-food, and because they add humus to the soil. Humus in its turn may be valuable because it improves the physical properties and chemical composition of the soil. Over and above all these advantages, common to all green-manuring crops, those of the legume family possess the additional advantage of adding nitrogen to the soil. Broadly speaking, therefore, the non-leguminous crops, in so far as they are used as green-manures, affect the fertility of the land by modifying the transformation of the soilnitrogen. They take up the soluble nitrates and build them again into insoluble protein compounds. When turned under, they undergo decay and become the food of vast hosts of soil bacteria. They are resolved again into simpler substances and yield ammonia and nitrates, as well as a humus richer in phosphoric acid, potash and lime. The green-manuring crops of the legume family accomplish all this and further modify the composition of the soil by the addition to it of nitrogen.

From the bacteriological standpoint, the differences are of great moment, since there seems to be a certain relation between the crop growing on the land and the 
numbers and kinds of bacteria present in it. It has been shown in the study of our northwestern wheat soils that the continuous cultivation of wheat on the same land involves very serious losses of nitrogen and of humus. The losses are due apparently not only to the leaching out of the soluble nitrates in the late summer and early fall, but, also, to the destructive decomposition of the humus by the soil bacteria and the liberation of free nitrogen gas. On the other hand, when crops are grown in regular rotation with the inclusion of clover, the losses are greatly reduced. In fact, gains of both humus and of nitrogen may be shown under favorable conditions. These facts indicate that the bacteria that are so destructive to the nitrogen compounds of the soil, are largely suppressed when crop-rotations are practiced.

In systems of green-manuring, the use of legumes after cereal crops has the additional advantage, therefore, of diminishing the losses of humus-nitrogen. Hence, leguminous green-manures are doubly valuable in adding nitrogen to the soil and in decreasing the losses of humus-nitrogen by suppressing the activities of the injurious bacteria. It is easy to understand why leguminous cover-crops have gained in favor to so great an extent within the last two or three decades.

Historical sketch.-The practice of turning under crops for soil-improvement is not new. To the farmers of ancient Rome, lupins, vetches and beans were known as soil-renovating crops, and their use as green-manures, at least in the case of lupins, was more or less extensive. Even when these crops were not turned under, but rather removed from the land, the stubble and roots were fre- 
quently sufficient to improve the soil very materially. Unfortunately, however, much of the valuable experience of the ancients was lost in the succeeding centuries, and European agriculture of the Dark Ages, like European culture of the Dark Ages, was marked for its de-

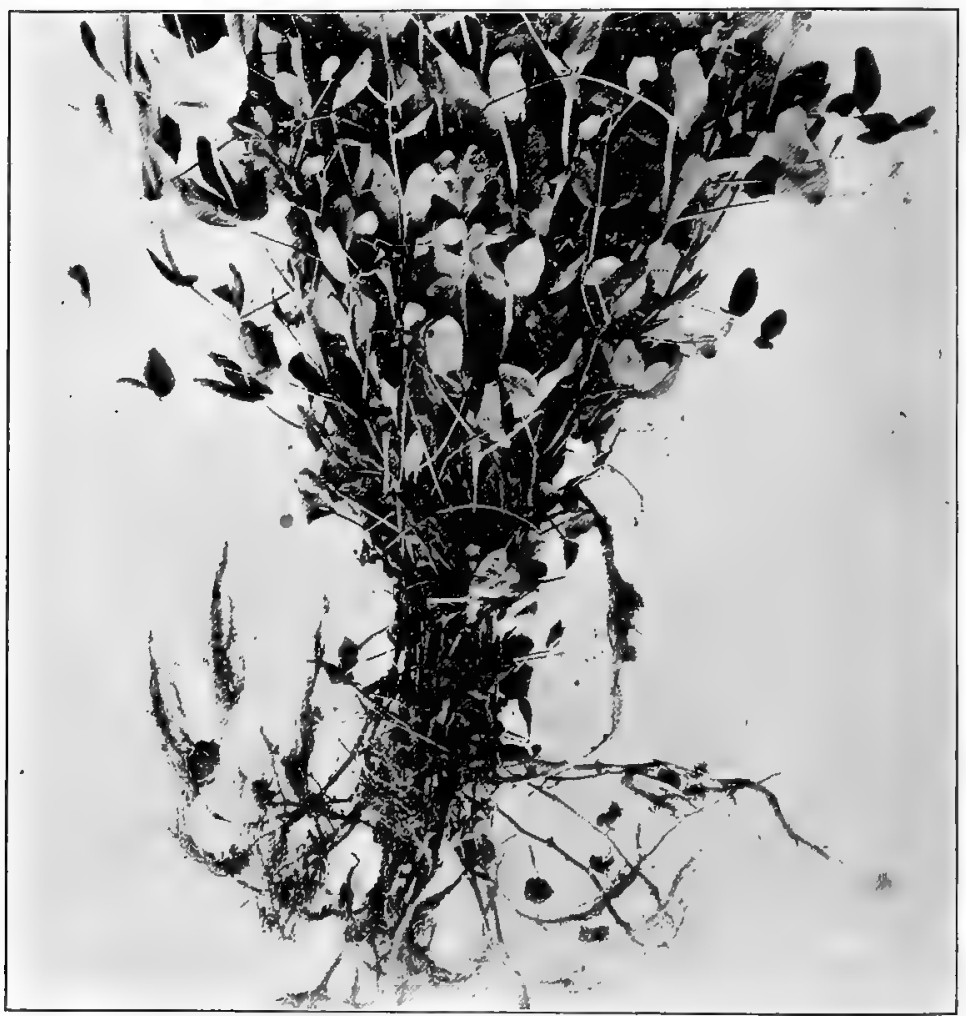

r.g. 40 field peas, lumed and well manured, showing an abundance of tubercles. 
cline. The exhaustion of lime and of available phosphoric acid in the older soils of Europe made the growth of beans and peas uncertain. Their cultivation was much reduced or entirely abandoned on thousands of farms, and the use of bare fallows greatly extended.

In the seventeenth and eighteenth centuries, there came a revival in European agriculture. Marling and liming again made possible the growth of legumes. Clover was introduced and proved a boon to the impoverished soils. Regular rotations were evolved, and hoed crops like turnips became more prominent. The time came later when clover failed more and more frequently, until gypsum and, subsequently, artificial fertilizers, were found to be a partial or complete remedy for the difficulty. Finally, the discovery of the nodule-bacteria and the explanation of their true functions led to the development of rational methods of farming, by which the nitrogen of the air is systematically utilized by means of leguminous crops and is made to supply the needs of non-legumes.

Green-manures on sandy soils.-Green-manuring has found a wider sphere of usefulness and more thorough utilization on light sandy soils. This is accounted for by the greater poverty of such soils, their openness, their inability to hold sufficient moisture for the best development of crops, and their lack of humus. Theoretically, at least, these soils could be improved by the addition of fertilizers. But, because of their very open character, the proportion of plant-food lost from them would be considerable. The addition of something that will help to hold in the soil not only the plant-food, but 
also the moisture, is needed. Hence, in the improvement of light soils, green-manures have played, in the past, and are playing today, a prominent rôle. The green-manures are made here to supply the humus, the nitrogen, and, indirectly, the moisture, to the money crops. Thousands of acres in Germany, France and Belgium, and many thousands of acres in the eastern United States have been brought to a high state of cultivation by the use of mineral fertilizers and green-manures alone without the introduction of much organic material from without.

The practice of green-manuring, as it has been developed on sandy soils, owes much to the work of Schultz, at Lupitz, Germany. Starting in 1855 on an extremely poor, coarse-grained, sandy soil, he gradually improved it by the use of lime, phosphoric acid and potash in connection with such green-manuring crops as lupins, seradella and field-peas, until he could produce three hundred to four hundred bushels of potatoes per acre. He showed that proper mixtures of several legumes may yield more nitrogen and organic matter than any single legume, because of the proportionately slighter injury from insect pests and fungous diseases. He showed that lupins and seradella, the most valuable green-manuring crops for his soil, but very readily injured by even moderate amounts of lime, could be made to grow vigorously in spite of the lime, provided, liberal amounts of kainit were added to the soil.

We owe much to him for information concerning the time and manner of seeding and harvesting the amounts of potash and phosphoric acid to be used and the manner of their application. We are also indebted to him for 
having demonstrated that slight dressings of barnyard manure, too slight in themselves to increase the yield appreciably, are highly beneficial when spread over a green-manuring crop before the latter is plowed under. It seems that two or three tons of manure per acre, thus applied, add to the soil millions of bacteria that hasten the decay of the green crop and make it more quickly available.

The peculiar value of green-manures on light, sandy soils is due chiefly to the open character of the latter. In the presence of sufficient moisture, vegetable and animal substances decay very rapidly in them. It is frequently next to impossible to accumulate any considerable quantity of humus in such soils. The various decay bacteria work very rapidly under such conditions and, in extreme cases, set free very considerable quantities of nitrogen. In order, therefore, to maintain the humus and moisture in these soils, green-manures must be plowed under frequently. With a sufficient supply of lime there is no danger of too great an accumulation of acidity. The rapid and, at times, intense decomposition of the organic matter assures the ready availability of the plant-food taken by the green crop from the soil. There is, however, one serious drawback in the use of green-manures on light soils, and that is the limited amount of moisture available in them for the growing of crops.

Loss of moisture.-Careful experiments made in this country and in Europe show that for every ton of dry matter there are removed by evaporation from the leaves and stems of the crop about three hundred tons 
of water. This means that three tons of hay will cause the loss from the soil of moisture equivalent to nine or ten inches of rainfall. Furthermore, this will not represent the entire loss, since moisture is also evaporated from the soil directly, or is lost by percolating downward into the subsoil.

Because of the drying effect of the main crop, the moisture content of the soil is frequently reduced to such an extent as to prevent the germination of the green-manure crop. But should the latter germinate properly and grow well, its drying effect on the soil may result in serious injury to the succeeding crop. It is a fact familiar to most farmers that green-manure crops, especially when they have matured too far, may, at times, remain undecomposed in the soil. There arises, then, a two-fold injury to the succeeding crop, the partial exhaustion of the soil-moisture and, therefore, its insufficient supply, and the far-reaching destruction of the soil bacteria.

As the soil dries out, the number of these latter decreases rapidly and the natural bacterial balance is destroyed. The decomposition of the green-manuring crop is then temporarily stopped. When the water contant of the soil is again increased by rainfall, the decomposition does not proceed in the same way as it would have proceeded had the soil remained sufficiently moist. It is best, therefore, not to seed a green-manuring crop in a dry soil, nor allow a green-manure to become too mature before it is turned under. When the growth is very bulky, it is always better to harvest the crop and to plow under the stubble alone. 
The cowpea, soybean, and velvet bean as green-manure crops.- On the sandy soils of the East, the cowpea, soybean, sand vetch, crimson clover, and velvet bean have been used widely for the improvement of land. In the cotton-growing states of the South, the cowpea is almost indispensable as an aid in the maintenance of the humus and the nitrogen of the soil. Because of the long growing season and abundant rainfall, two crops of cowpeas may be grown in a single season in some places. With the cheap phosphates available to the farmers of that region and the great supply of atmospheric nitrogen at the disposal of the cowpea, the growing of cotton and of corn is less difficult than formerly on poor soils. Many acres that had been depleted of their fertility and abandoned have been made highly productive. The bacterial activities in the decomposition of the cowpea vines and roots, or of the residues of other crops, are scarcely suspended during the mild winters of the South. Green-manuring must necessarily, therefore, find there a more extensive application.

In states like Alabama, Florida, and Louisiana, the velvet bean promises to become a rival to the cowpea as a green-manuring crop. It is fond of warm, moist weather and produces, under favorable conditions, immense quantities of plant substance. In experiments with the velvet bean in the three states just mentioned, the yields of green material per acre were 19,040 pounds, 22,919 pounds, and 21,132 pounds, respectively. The corresponding yields of nitrogen were 213.9 pounds, 172.9 pounds, and 141.2 pounds, respectively. In the experiments of the Alabama station, oats were seeded 


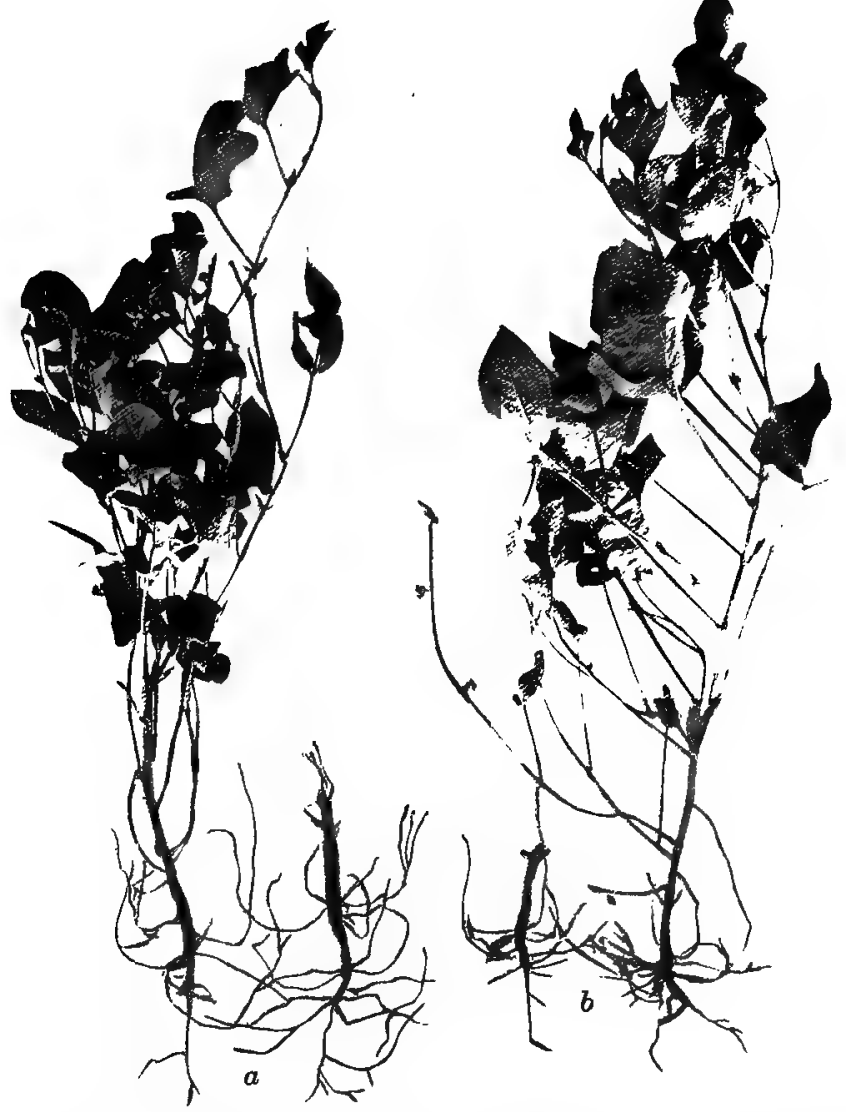

Fig. 41. A cowpea plant and root, grown in the first season, are shown at (a); while a cowpea plant and root, grown in the third season, are shown at (b). The nodule-bacteria had evidently accumulated in the soil during the interval, 
on velvet-bean stubble, on land where a crop of velvet beans had been turned under, and on land where crabgrass had been harvested.

On the first of these plots, the yield of oats was at the rate of thirty-eight bushels per acre, and on the third, at the rate of seven bushels per acre. Evidently, the preceding growth of velvet bean had benefited the oats both on the land where the stubble and where the entire crop of beans was turned under. The very large amount of green material turned under on the second plot reduced the yield of oats. Either the acidity introduced into the soil or the loosening of the soil to too great an extent, thus affecting adversely the moisture conditions, was the cause.

The great value of cowpeas as a green-manuring crop is not restricted to the southern or southwestern states proper. It has found a place in Maryland, Delaware and New Jersey and has been used in other states of the Atlantic seaboard, as well as in the Middle West. It has rendered valuable service in these states, not only in restoring worn-out soils, but, also, in the building up of vast tracts of light, shifting sands. The bacteriaproducing nodules on the roots of the cowpea seem to be widely distributed in these soils, and hence make artificial inoculation unnecessary. The soybean, which is related to the cowpea, has also been used as a greenmanure on light soils. It does well, however, also on heavier soils, provided it is properly inoculated, and is not as readily injured by cold weather.

Crimson clover.-Cowpeas and soybeans are summer crops and are serviceable for green-manuring purposes after 


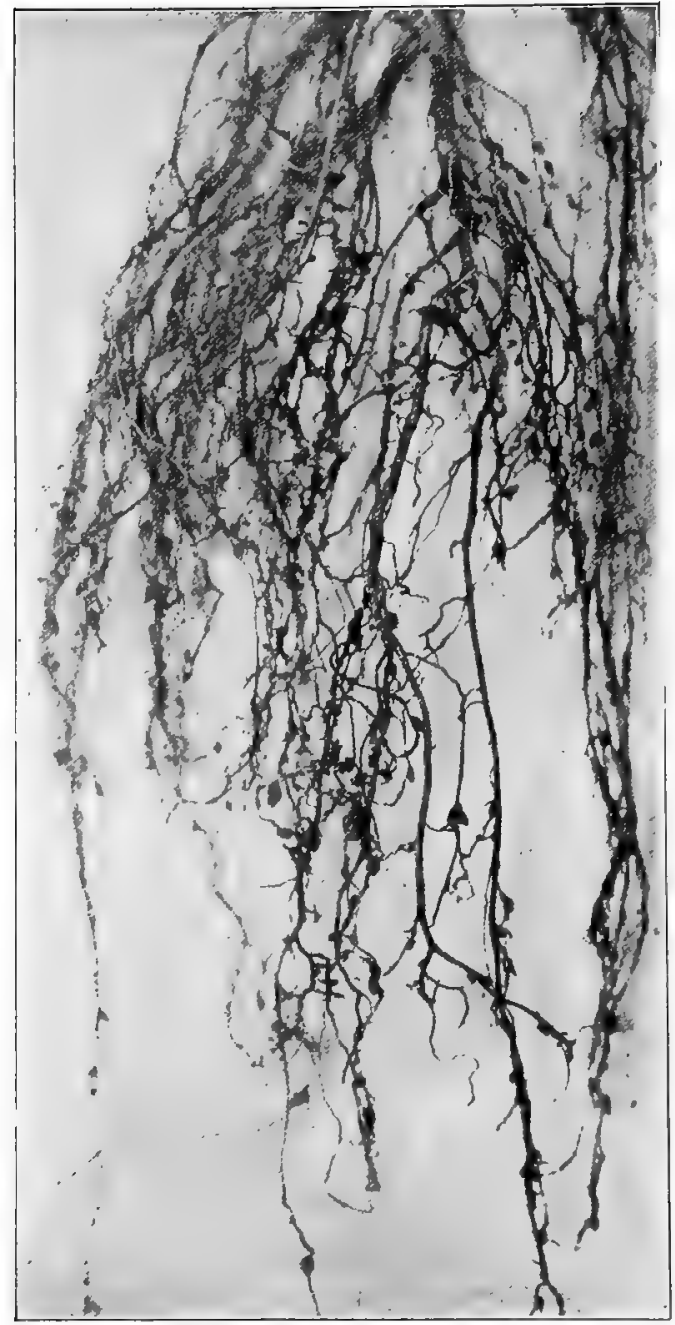

Fig. 42. Tubercles on the roots of crimson clover. 
winter wheat or rye, oats, early potatoes, or sweet corn. Crimson clover, on the other hand, has demonstrated its wide usefulness on light soils as a fall and early spring crop, and is employed extensively for seeding in corn, late potatoes, tomatoes, and the like. Seeded in the corn at the time of the last cultivation, it makes a vigorous growth in the fall and early spring and furnishes an abundant quantity of humus and nitrogen for the succeeding crop.

The light, sandy soils of New Jersey, Delaware and Maryland have derived great benefit from the cultivation of crimson clover. It was cultivated in Delaware as early as 1885 , and rapidly gained in favor in the following decade. The high esteem in which it is held

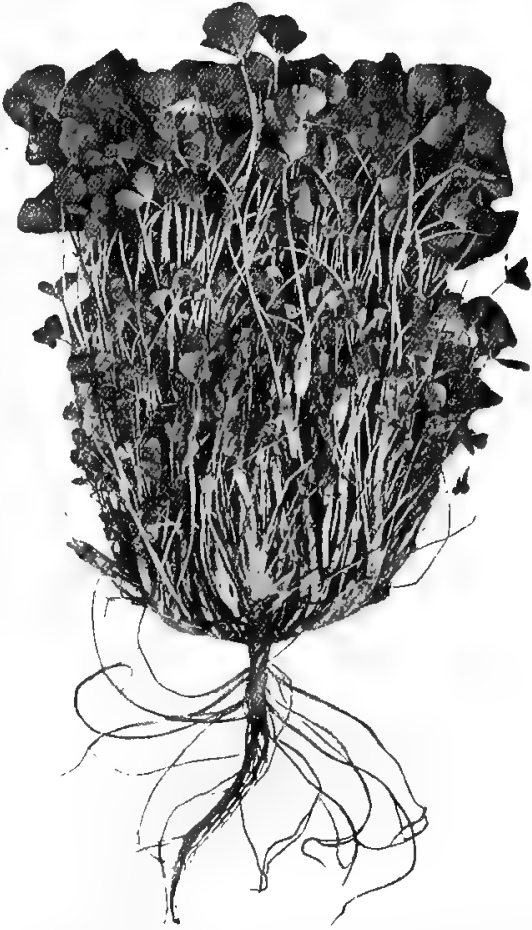

Fig. 43. This single stool of crimson clover has eighty-six branches. The height to the tips of the leaves is twelve inches; as it stood in the field it covered more than one square foot. With a generous supply of mineral plant-food, the accumulation of atmospherie nitrogen by such plants is both rapid and extensive. 
there is evidenced by its being referred to as the "mortgage lifter." Its early cultivation in New Jersey dates back to about the same time. The acreage devoted to it was greatly increased in 1891 to 1894 , owing to the investigations of the experiment station. It has been used in these states for the improvement of uncultivated unproductive soils, as a green-manuring crop in the regular rotations and as a cover-crop in orchards.

The information thus gathered concerning this crop serves to throw an interesting light on the bacterial relations.involved in the gathering of nitrogen from the air, as well as in the decomposition of the green-manure in the soil. "The experiments conducted by the Delaware station showed that crimson clover completes its work of gathering nitrogen at a much earlier date on soils that have previously borne it than on those to which it is new.

This circumstance may be explained partly by the assumption that on the older soils the crimson clover derives a larger proportion of its nitrogen from the soil itself rather than from the atmosphere. Now, since such soils contain considerable quantities of available nitrogen, the clover plants will take it up and develop rapidly in the early part of the growing season. This explanation is only partial, however, for, as a matter of fact, the older soils contain greater numbers of nodulebacteria, and possibly also more virulent modifications of these organisms. The early formation of numerous tubercles allows the plants to gather large amounts of nitrogen, in a comparatively short time, an advantage not possessed by crimson clover on new soils.

The differences thus indicated lead to variations 
in the nitrogen-gathering power of crimion clover on different soils and in different seasons. Rainfall, temperature, humus, and the supply of lime, phosphoric acid and potash, aside from many other factors, play an important rôle. In general, the amount of nitrogen in a crop of crimson clover may range from 50 pounds per acre, or less, to 200 pounds per acre or more. In the experiments of the Delaware station, already cited, the yield of nitrogen per acre was from 139 to 188 pounds.

The sand vetch (Vicia villosa) is another crop that has been employed successfully as a greenmanure on light

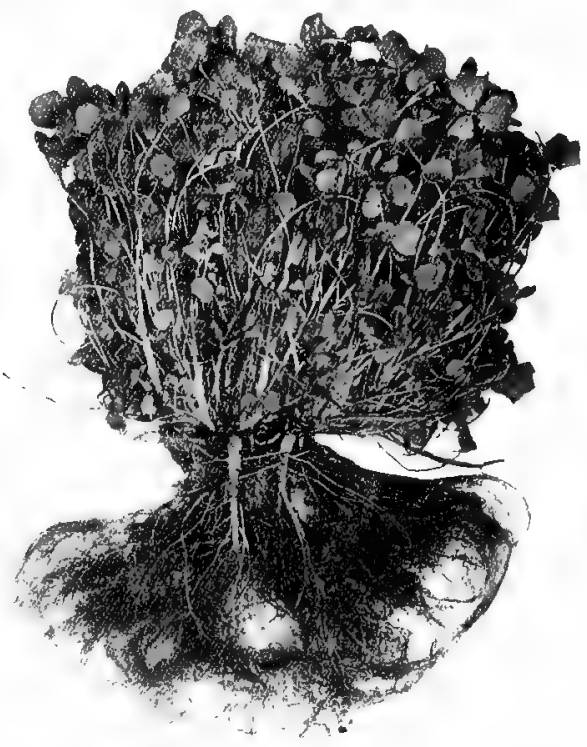

Fig. 44. A bunch of crimson clover plants. The mass of fibrous roots indicates a wonderful feeding capacity and explains its rapid and early growth.

soils. It is a hardy plant that will thrive on poor lands and will stand cold weather well. It has been recommended as a cover-crop for the tobaceo soils in the Connecticut valley. It is stated by the Connecticut station in this connection that it survived in spots where rye was completely winter-killed. "In one portion of a 
field, which was covered with ice for several weeks, the vetch survived." In the milder climate of south Jersey, the sand vetch frequently remains green all winter and shows evidences of growth in the early spring.

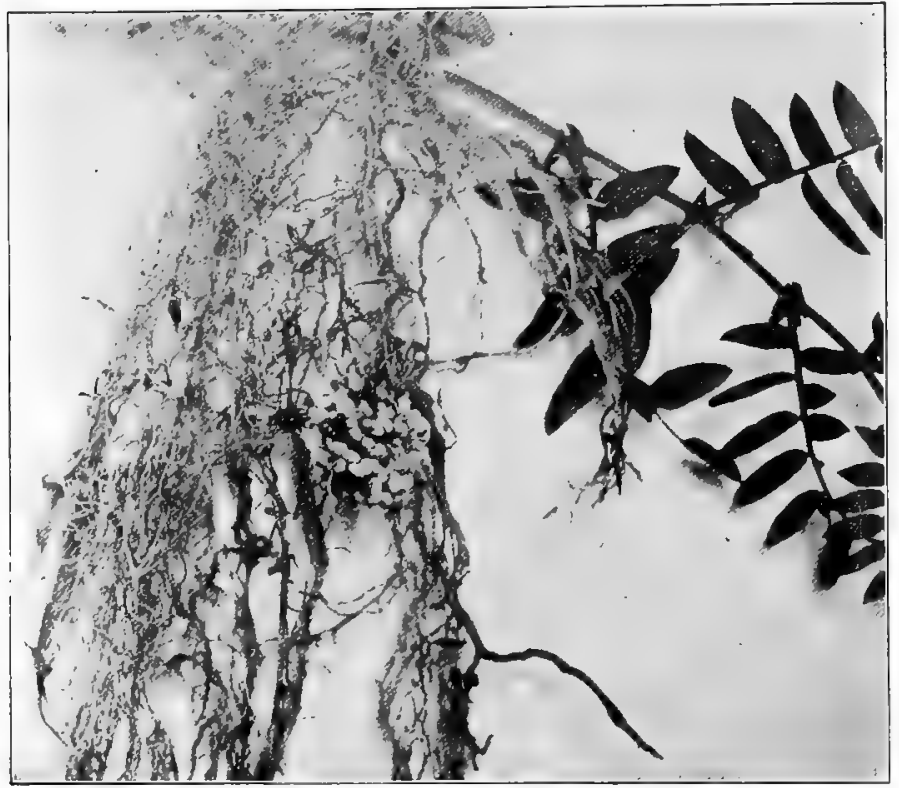

Fig. 45. Roots of sand or winter vetch, showing an unusually large tubercle.

Owing to this ability to withstand cold weather, and to make rapid growth in the fall and spring months, the sand vetch is a valuable addition to the list of covercrops. A mixture of cowpeas and vetch should prove suitable for orchards or in crop-rotations on sandy soils, since it permits a greater accumulation of nitrogen and 
of humus than would be possible when but one of these crops were grown. With an abundance of the mineral constituents the two crops may, without difficulty, add a hundred pounds or more of nitrogen to the soil per acre.

Green-manures on loams and clay soils.- While best adapted for light, sandy soils, systems of green-manuring have also been successfully followed on heavier loams or clay soils. Lupins, seradella, yellow, red and crimson clover, field - peas, horsebeans and vetches, have been employed on such soils with marked

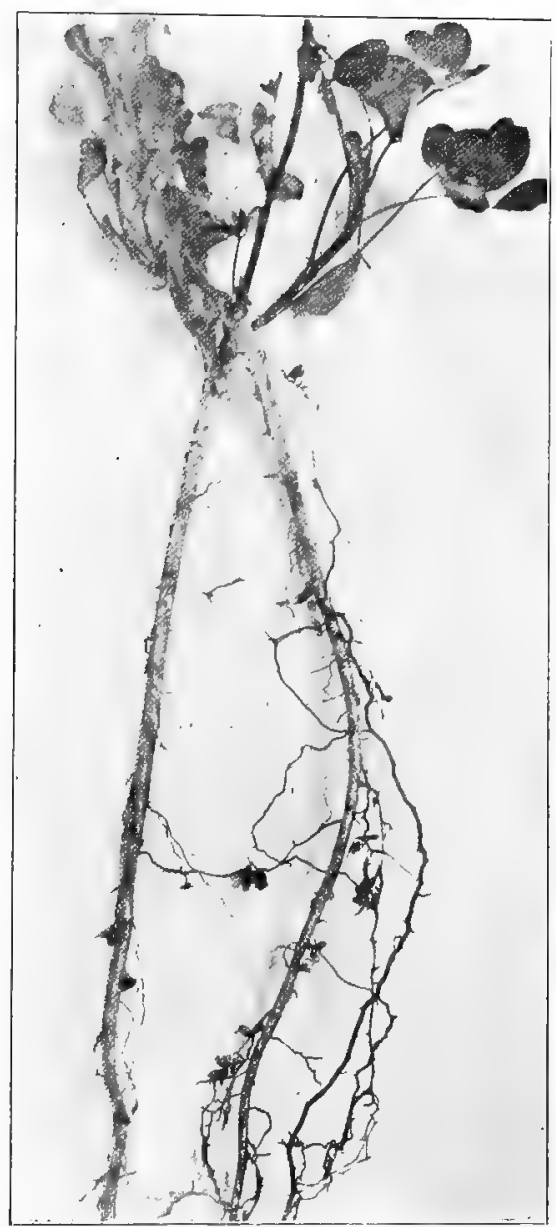

Fig. 46. Tubercles on the roots of a young alfalfa plant. 


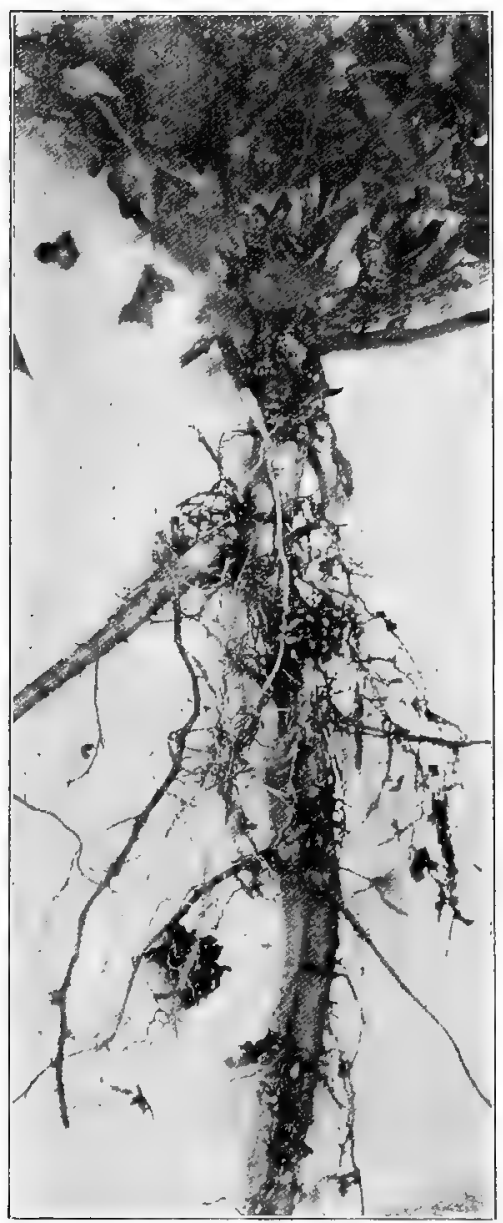

Fig. 47. Tubercles on the toots of an old alfalia plant. success. While on light soils, greenmanures serve the threefold purpose of supplying nitrogen, fermentable, organic material as an aid in dissolving the mineral plant-food in the soil, and finally humus as an aid in increasing the water-holding power of the soil. The last-named function of green-manures is not as important on the heavier soils. Furthermore, because of the greater quantities of moisture contained in them, the heavier soils do not warm up as rapidly in the spring, nor does the air circulate in them as freely.

The decay bacteria are not stimulated in their activities to such an extent as in the more open sandy soils, 
hence the decomposition processes do not run their course as rapidly here, and the green-manures and animal manures last longer. In other words, the soil-humus needs to be replenished on heavier soils less frequently than on light soils. Similarly, the losses of nitrogen are usually smaller from heavier soils than they are from light soils, because the nitrates are not as readily leached from the former, nor are the decay processes in them sufficiently intense to lead to the setting free of gaseous nitrogen. One exception is found in heavy soils that are apt to become water-logged. Under such conditions, the soil-nitrates may be reduced with the evolution of nitrogen gas.

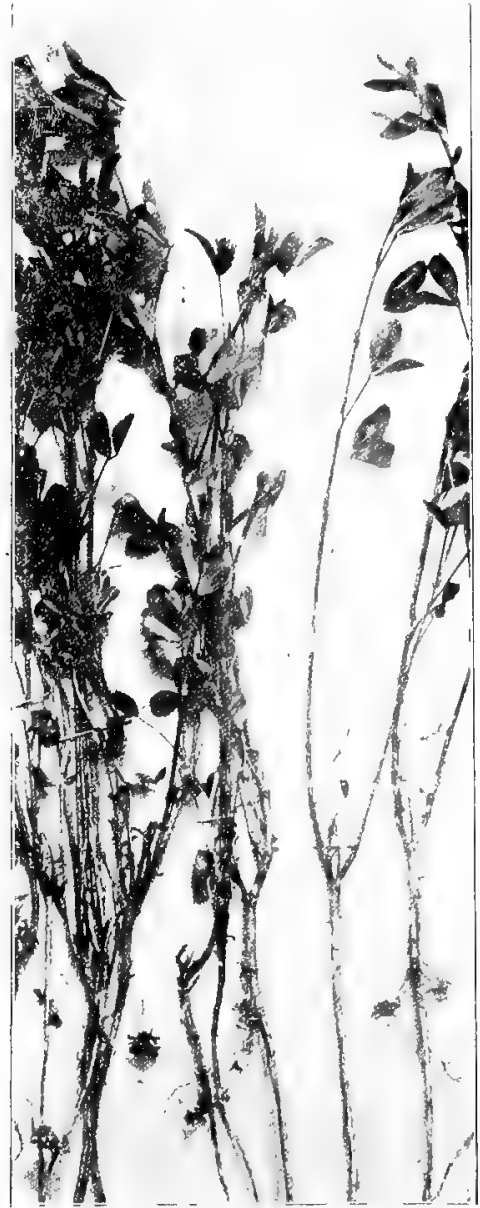

Fig. 48. Young alfalfa plants. The few tubercles are, for the most part, larga. 
It appears thus that the benefits accruing from the turning under of green crops may not be as great on heavier soils. None the less, even with these it may bring rich rewards. Numerous facts show that the phosphoric acid and potash of many heavy soils are practically inaccessible to the crops without and abundance of easily decomposable organic matter. They show, likewise, that shale, slate and clay soils are maintained in better tilth, conserve their moisture better, and allow a more uniform crop development when abundantly provided with humus. Hence, an intelligent use of cover-crops may prove highly profitable on heavier soils. However, greater care is required in the selection of the green-manuring crop, and in the manner and time of seeding.

It has been found that crops like field-peas, horsebeans and vetches are most suitable among the legumes for green-manuring purposes for heavy soils. Impoverished soils in northwestern United States and Canada have been improved by the growing of winter rye, followed by field-peas as a green-manuring crop. The latter may therefore be said to do the same work here as that performed by the cowpea in the southern states. In some of the European countries, notably. England, horse-beans and sainfoin have been employed widely as soil-renovators, while on the Continent, seradella and various clovers have been used in a similar capacity.

In comparing the development and utilization of green-manuring crops on light and heavy soils, account must be taken of the activities of the various bacteria concerned in the fixation of atmospheric nitrogen, as 


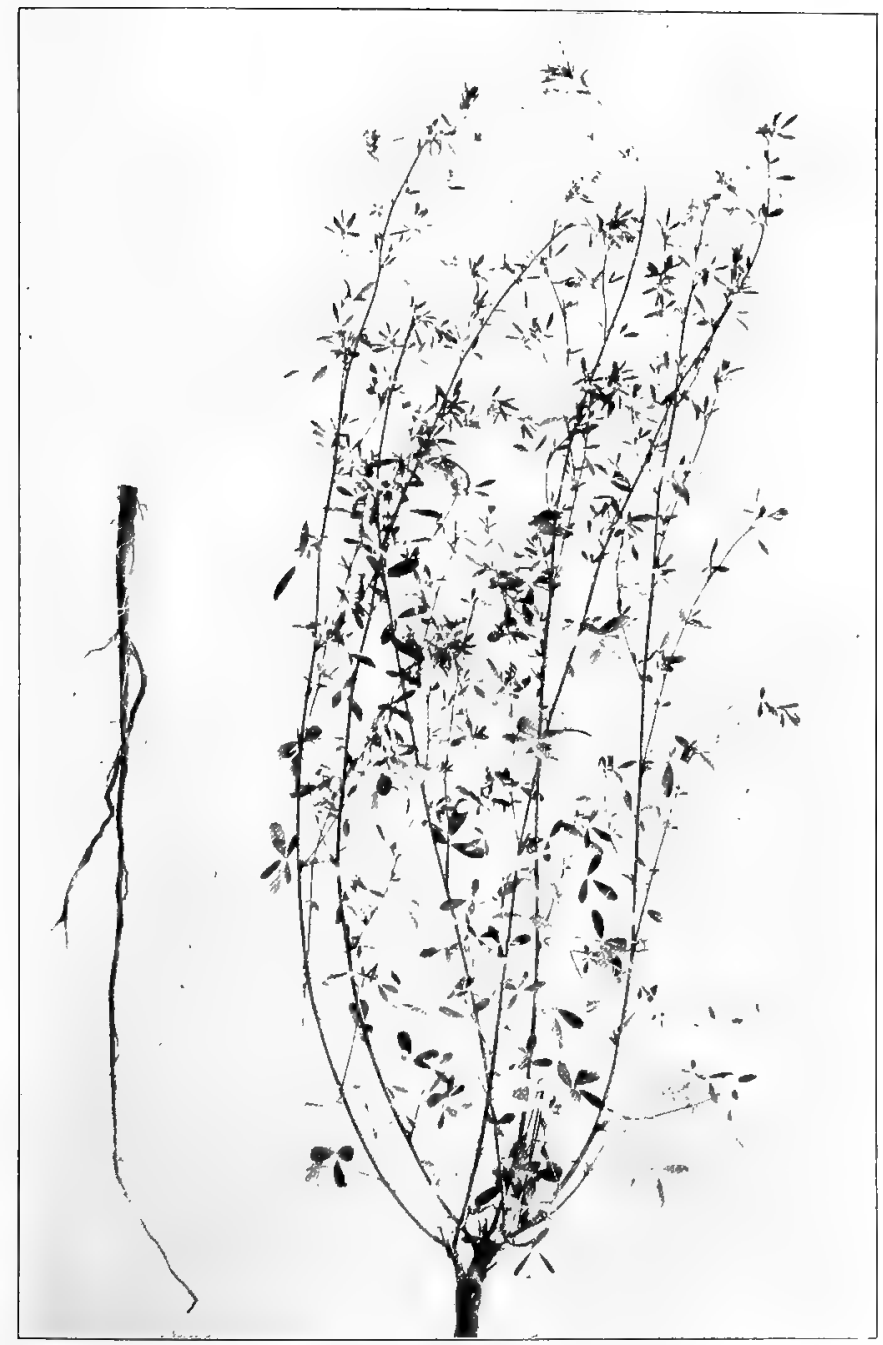

Fig. 49. An alfalfa plant and its powerful tap-root. 


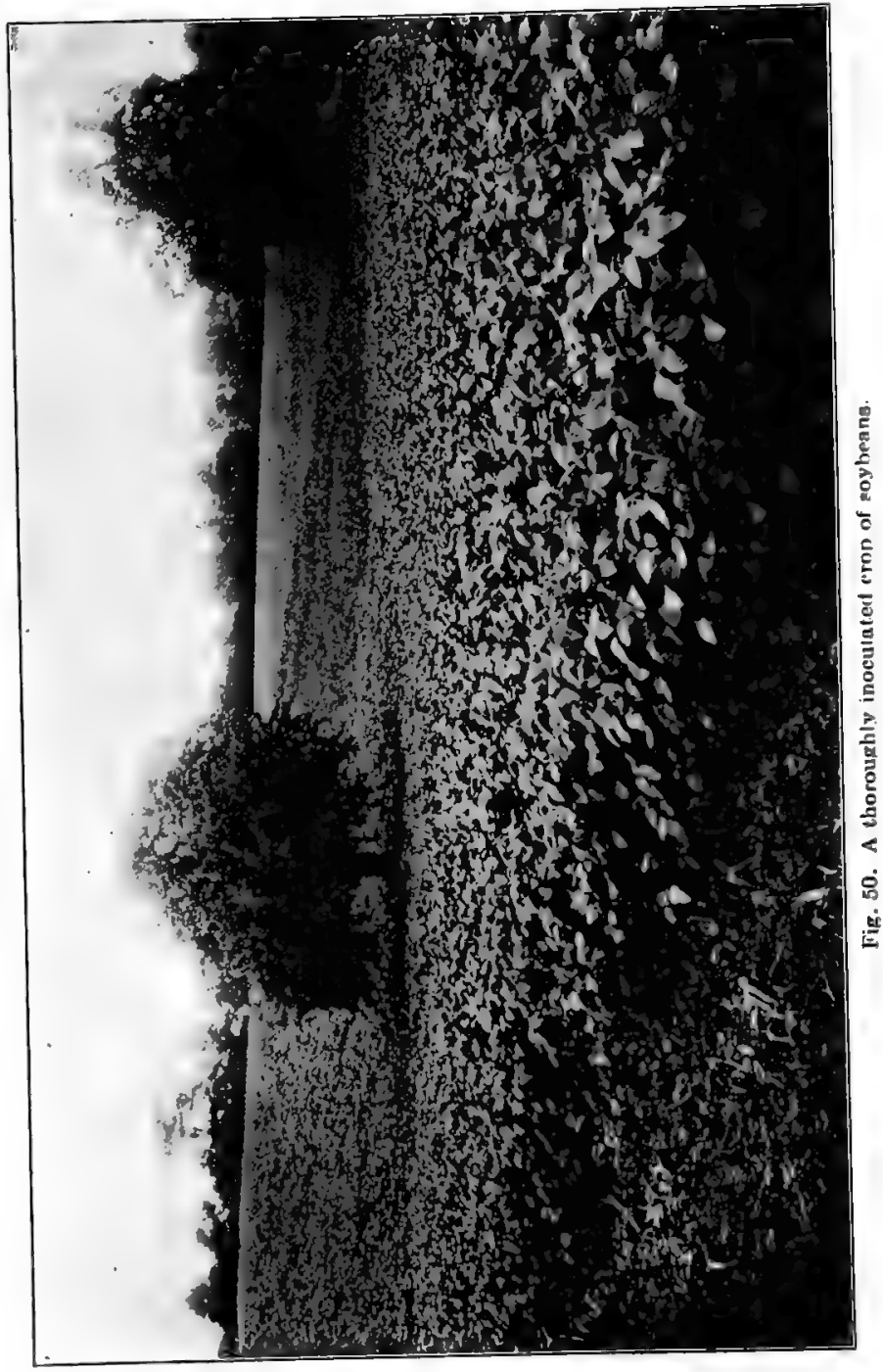


well as its subsequent transformation in the soil. The physical character of the soil determines not only the depth at which nodules may be formed on the roots of legumes, but also the usefulness of these nodules. It also determines the rate at which the vegetable matter in the soil shall decay.

In general, it should be remembered that in lighter soils a green-manure may be covered up with a deeper soil layer than in heavier soils, since in the former the processes of decay are active at greater depths. On the other hand, the deep plowing of green-manuring crops on heavy soils may not only retard the decomposition of the organic materials, but also may lead to the accumulation of acid substances by encouraging the growth of certain acid-forming bacteria. This danger exists scarcely at all in open soils. In their case, the danger lies rather in too great a degree of aëration, with the consequent drying out of the upper soil layer, the destruction of the decay bacteria and the preservation of the green-manure in an unchanged condition for a long time. In such cases, a heavy roller may be employed to advantage in overcoming this difficulty.

Leguminous green-manures and the succeeding crops.Leguminous cover-crops affect the quality as well as the quantity of the succeeding crop. It has already been noted that they may pump out of the soil so great an amount of moisture as to affect injuriously the following harvest. In countries where the rainfall does not exceed, on the average, thirty inches per annum, this is a matter of great moment. It has been found by Schultz, of Lupitz, and likewise by many others, that 


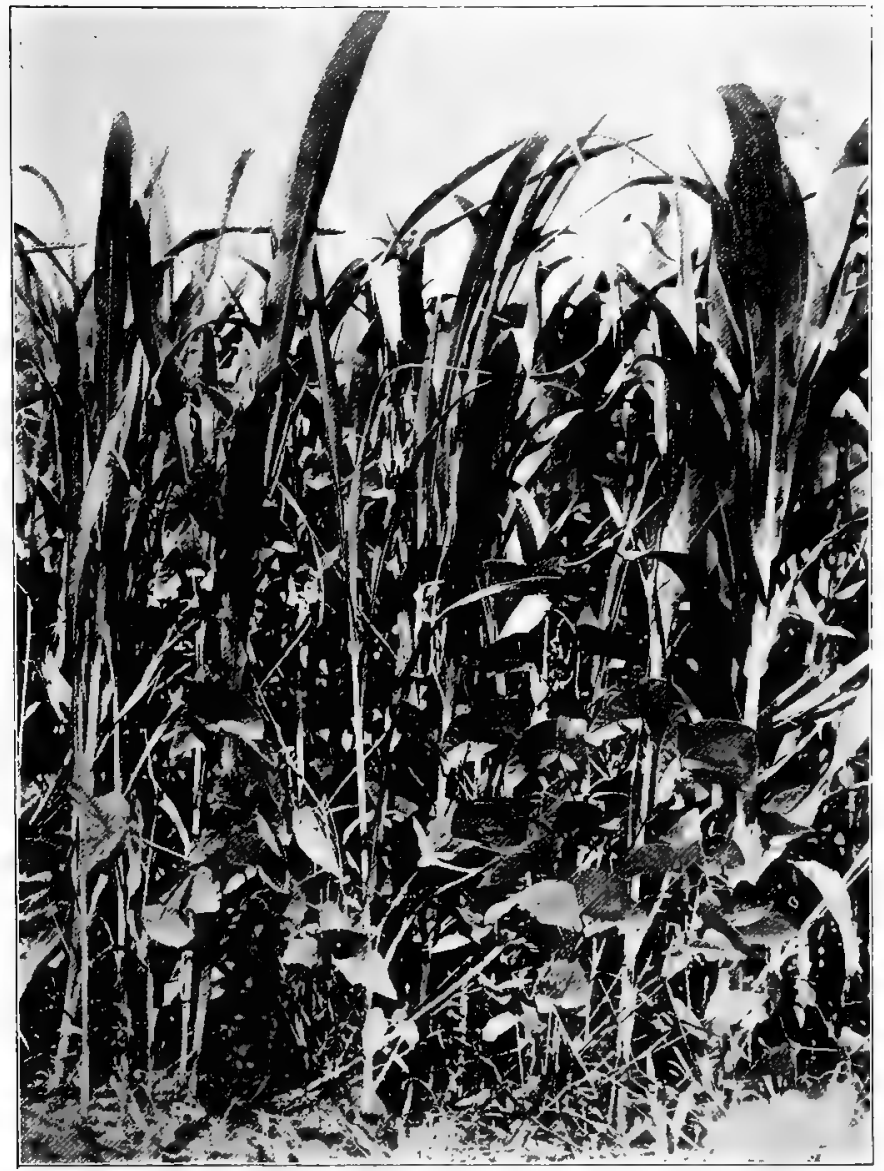

Fig. 51. Kafir and velvet beans. The dark green color and thrifty appearance of the kafir would indicate that it is receiving a benefit from association with the legume. 
this drying action of the cover-crop may seriously interfere with the germination of the winter grain. On the other hand, it has been demonstrated by Schultz that deep-rooting legumes like lupins may protect the succeeding potato crop from drought. This is accomplished by the lupin roots which, by penetrating into the subsoil and later decaying, furnish channels along which the potato roots pass downward and possess themselves of the subsoil moisture which would, otherwise, remain inaccessible to them.

When nitrogen is the controlling factor of growth, the leguminous cover-crops may further affect the succeeding non-legumes by offering to them greater or slighter amounts of this constituent. A case in point is the experience of Schultz, who succeeded, in the course of from twenty-five to thirty years, in increasing the nitrogen content of some of his soil from 0.02 to 0.03 per cent to 0.17 per cent. This is an increase equivalent to about five thousand pounds of nitrogen per acre, when only the surface soil is considered. The nitrogen store of the soil was augmented by him almost entirely at the expense of the atmosphere, for it has been his practice to buy only lime, phosphoric acid and potash, and scarcely any nitrogen at all.

In so far as the quality of succeeding crops is concerned, leguminous green-manures undoubtedly play an essential part. We have reason to believe that such cover-crops grown in orchards affect the keeping quality of the fruit. Much depends, in this case, on the activities of the soil bacteria, since intense decomposition of the green-manure and the formation of large amounts of 


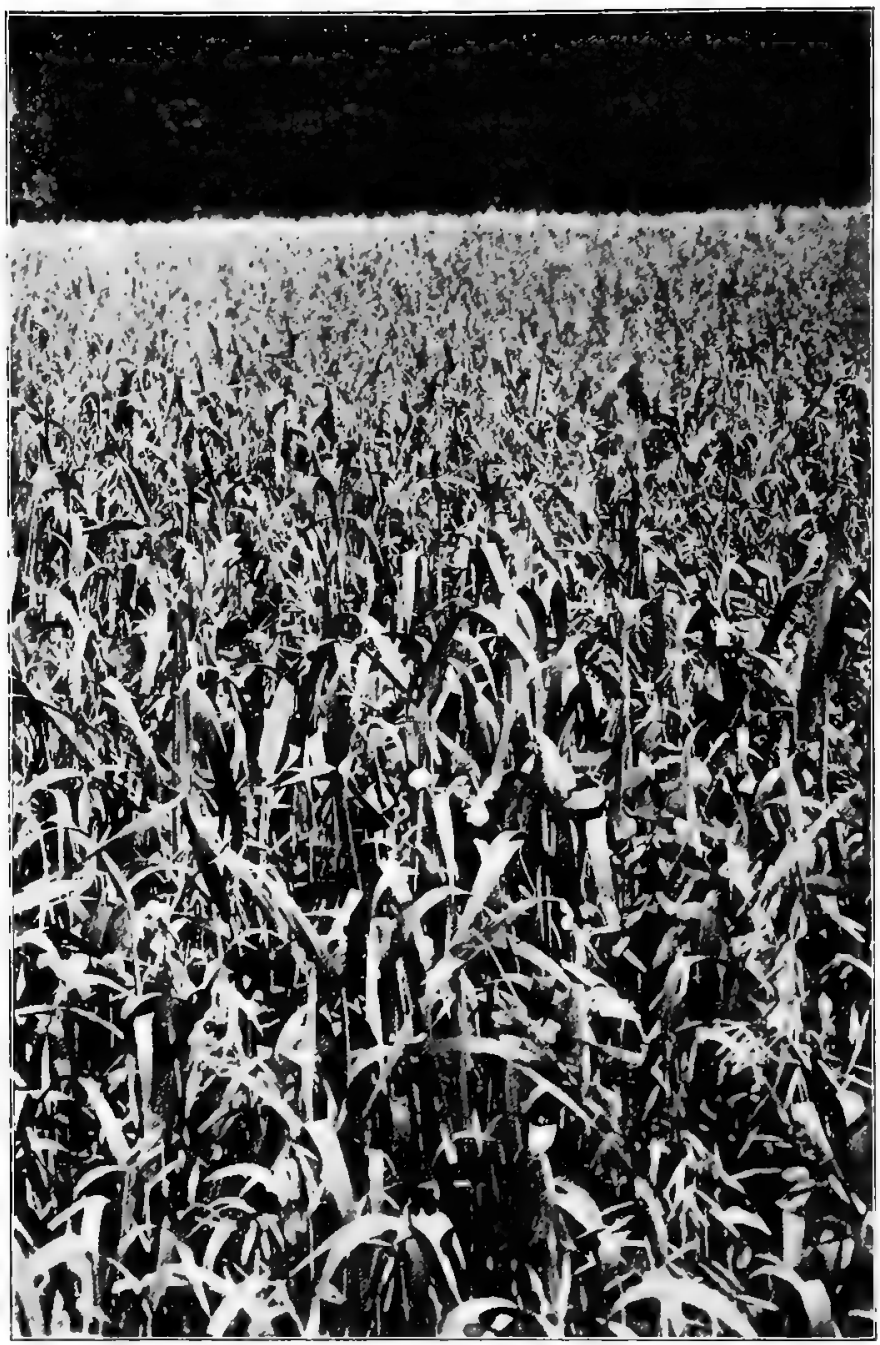

Fig. 52. Oats and peas. A profitable partnership for the oats. 
available nitrogen compounds undoubtedly retard the proper ripening of the fruit.

In the case of cereal crops, a green-manure may lead to the same result as that caused by a very heavy application of animal manure or of nitrate. The grain crop may develop the dark green color so characteristic of plants generously fed with nitrogen, and may finally lodge and prove a partial or total loss to the farmer. Again, in the case of crops like the sweet-potato, the growers are careful not to plant it immediately after the soil has been enriched by a heavy growth of some leguminous green-manure. There is always danger under such conditions that the forcing effect of the readily available green-manure nitrogen may result in the production of sweet-potato vines at the expense of the roots.

It may be safely stated that the successful utilization of green-manures must always reckon with the bacterial activities that concern their decomposition. A proper understanding of the principles involved will help the farmer to secure larger yields of superior quality. Ignorance and indifference will lead to inferior products, and, not infrequently, to smaller yields. 


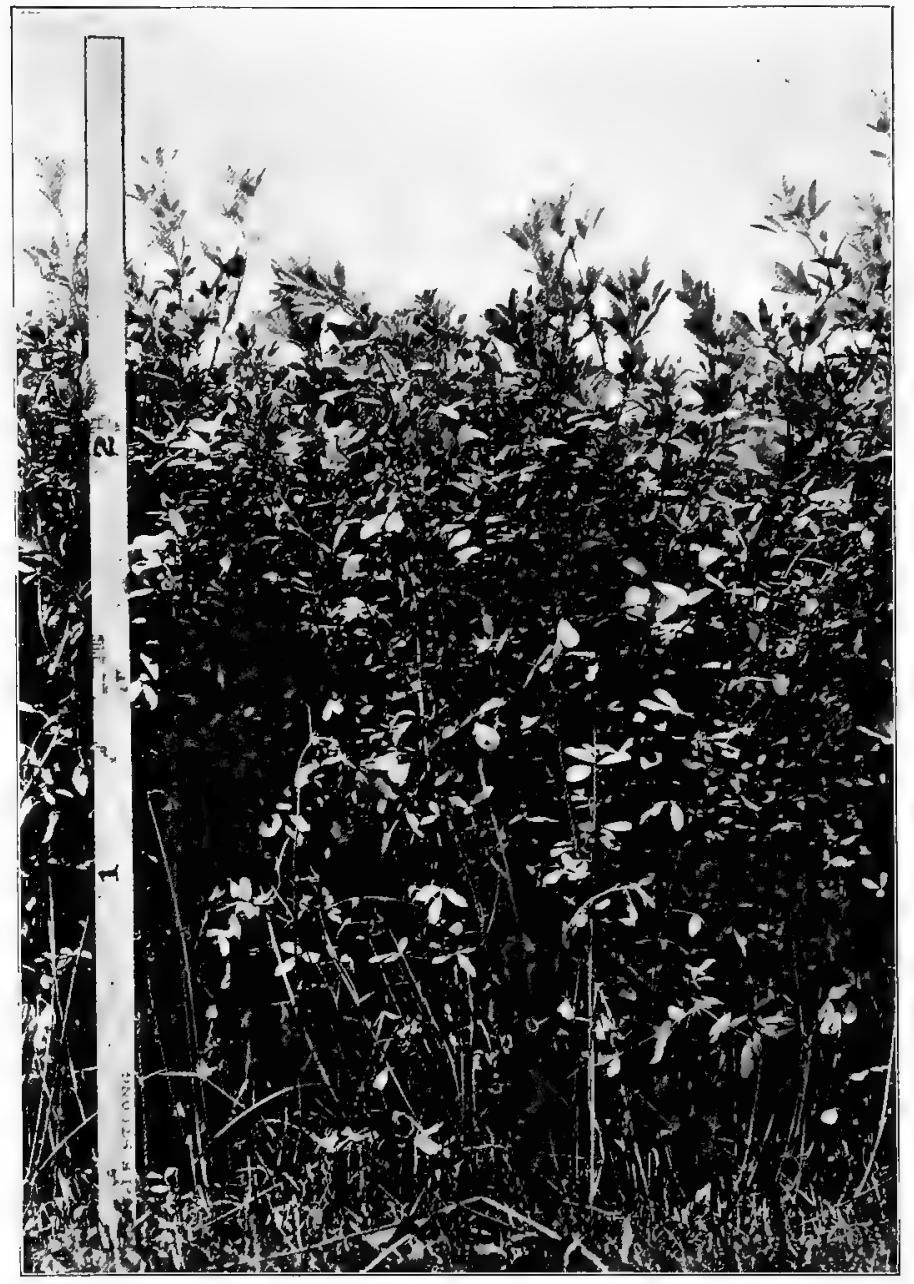

5ig. 53. Alfalfa.-The fixation of nitrogen in the root nodules is in full swing. 


\section{CHAPTER XXV}

\section{FALLOWING}

THE practice of fallowing, that is, of keeping the land for a longer or shorter period uncropped but cultivated, was once very prevalent. It was based, in part, on the belief that the soil needs an interval of rest during which to prepare itself for the future work of crop-production. Farming experience seemed to bear out this conception, for uncropped lands apparently regained a portion of the fertility of which they had been robbed by preceding harvests. Fallowing thus became indispensible in the growing of crops and was strongly recommended by Roman writers.

The check given to European civilization by the disruption of the Roman'empire extended its baneful effects to agricultural practice. This made but scant progress for centuries. The best thought and effort, whatever they may have been in those days, were devoted to anything but farming. The raising of crops became the work of an ignorant and down-trodden peasantry, who, living, as they did, in economic and political slavery, cared but little for the soil and its welfare. The noble lords were concerned more about the chase and the arts of war, and seldom hesitated to run their horses and dogs through a field of waving grain. 
Small wonder, then, that farming saw no progress, and that bare fallows and their various modifications retained a prominent place on the farm. It was customary in many places to fallow the land after two successive crops of wheat, or after a crop of beans, followed by wheat. The necessity of bare fallows was questioned, however, as early as the seventeenth century, particularly after the more extensive cultivation of clover and of turnips. The work of Jethro Tull in England gave an impetus to a more intelligent consideration of the question. The implements of tillage that he devised or improved helped to undermine the faith in the necessity of bare fallows.

Towards the middle of the eighteenth century there was much discussion and a strong division of opinion on this question. The partisans of fallowing were evidently losing ground, however, for the practice became less prominent as time went on. On many farms where bare fallows were still-retained, they were resorted to once in five, six, or seven years, instead of once in two or three years. Thaer in Germany was particularly prominent in the latter half of the eighteenth century in teaching the unwisdom of fallowing and in advocating systematic rotations and the introduction of hoed crops in such rotations.

Fallow crops.-Bare fallows were thus gradually superseded by the so-called fallow crops, that is, either hoed crops, like turnips, potatoes, or swedes, or greenmanuring crops like clovers, vetches, lupins. In the case of the hoed crops, the seed was planted in drills or rows and the land could be cleaned of weeds. The 
soil could be stirred frequently with implements of tillage so as to hasten the formation of plant-food and the conservation of moisture. In the case of the greenmanuring crops, the weeds could be also suppressed, while the subsequent turning under of a mass of green material induced certain fermentations in the soil and hastened thereby the weathering of the rock particles. The succeeding crops were thus placed in possession of larger quantities of available plant-food, the mechanical condition of the soil was improved, and, as modern investigations have shown, the store of total plant-food in the soil was increased by the addition to it of nitrogen from the air.

All of these considerations tended to eliminate bare fallows, and the fallowed areas decreased accordingly. At the same time, some farmers in Europe, not a few of them progressive in their farm methods, have persistently retained the bare fallow as a part of their system of soil management, notably on certain types of soil. More recently, bare fallows have again been given a greater degree of attention on account of various theoretical considerations, among them that of the addition of nitrogen to fallow soils by non-symbiotic nitrogenfixing bacteria.

Fallow and cropped lands.-In comparing fallow and cropped soils of the same origin, there are noticeable differences of temperature, moisture, and aëration. The investigations of Wollny have shown that fallow soils are warmer in summer and colder in winter than corresponding cropped soils. The summer temperatures may show differences between the two kinds of soil of 
from $2^{\circ}$ to $3^{\circ}$, a fact of considerable significance in so far as the bacterial activities in the soil are concerned. The modifications introduced, thereby, affect the numbers and the species relationships of the soil-organisms.

Still more important are the changed moisture conditions induced by fallowing. It was found by King that fallowed land contained in the upper four feet of soil 203 tons of water per acre in excess of that present in similar cropped land. Moreover, this effect of fallowing was felt in the second season. Similarly, in the investigations of Hiltner and Störmer in Germany it was found that an uncropped and uncultivated field contained at the end of a very dry summer only 2.77 per cent of moisture, whereas, the adjoining field worked as a bare fallow contained 9.28 per cent of moisture. In the first instance, the proportion of water was insufficient for the growth of bacteria; in the second instance, it was quite ample for this purpose. In the first instance, also, there was but little decomposition in the humus; in the second, the roots and the stubble were entirely destroyed. This is in accord with the observation of Wollny, who noted a more intense oxidation of the organic matter in fallowed soil as compared with a similar cropped soil.

Moisture and fallows.-The larger proportion of moisture in fallowed soil is due largely to the diminished evaporation effected by the stirring of the ground from time to time. In the uncropped, but undisturbed soil, on the other hand, the capillary action is not interfered with. Large amounts of water are brought from the deeper layers to the surface, where it is changed into 
vapor and carried away by the air currents. Furthermore, the undisturbed soil becomes covered with a growth of weeds which may pump out of the ground very considerable quantities of water. Adding to this the great absorptive power of fallowed land that reduces the losses of water by surface-drainage and percolation, it is easy to account for the observed differences. We become better able to appreciate the true significance of bare fallows in the conservation of moisture.

It appears, then, that in countries of slight rainfall, where moisture is the controlling factor in crop-production, bare fallows are not only necessary but frequently indispensable. Every effort is made to husband the limited store of water by frequent stirring of the surface soil and by keeping it free of vegetation for an entire season or a portion of it. Provision is made in this manner not only for supplying the succeeding crop with sufficient moisture for its growth but also for permitting the soil bacteria to accomplish this work in the production of plant-food. The growing of fallow crops is inadvisable under such conditions, for they would deplete the store of soil-moisture and leave the soil too dry for the succeeding crop. This is true of hoed crops, as well as of green-manuring crops. Altogether, the area of cultivated soils where the soil-moisture must be conserved by alternate years of fallowing, is comparatively small.

Aerration and fallows.-From the standpoint of aëration, again, bare fallows are hardly indispensable even on refractory clay soils. It was formerly thought that the proper tilth for such soils could be secured only 
by exposing the bare fields modified by implements of tillage, to the action of sun, wind, and rain. It is now known that the same purpose can be accomplished in these soils by liming and by the additions of large quantities of organic matter. Objectionable weeds may be eliminated in the careful cultivation of a hoed crop.

The use of bare fallows may result in considerable injury to the land on which the soil is rather light. The frequent stirring and more thorough aëration intensify the decomposition of the humus by stimulating the chemical and bacteriological transformations. Such intense changes, leading, as they do, to the accumulation of available plant-food in the soil, involve possible losses from leaching. They form, therefore, the strongest argument against bare fallows, not only for sandy soils or sandy loams, but also for clay and clay-loam soils.

Fallowing and plant-food.- It has been proved by experiments that fallowing is not an economical procedure from the standpoint of plant-food. The comparatively large amount of nitrates accumulated during the fallow period is apparently retained only in part for the succeeding crop, the remainder being washed into the drains. The differences would be even more striking on soils lighter than those upon which the experiments were made. This view is further supported by the fact that the benefits arising from fallowing were least apparent at these fields in seasons of abundant rainfall, when proportionately and absolutely greater amounts of nitrates were removed in the drains.

The benefits of fallowing, therefore, in so far, as they arise from the larger supply of plant-food, are secured 
at the expense of the dormant constituents. Fallowing from this standpoint is a means for hastening the spoliation of the land and is wasteful in that it allows a considerable proportion of the nitrates to escape into the drains. It is surely more rational to occupy the ground with some cover-crop during the portion of the year when the main crop is not growing.

The cover-crop secures the plant-food that becomes available and transforms it into organic material which undergoes decay more rapidly than the old humus. If the cover-crop belongs to the legume family, the additional advantage is secured of utilizing atmospheric nitrogen and storing it up in the soil in the crop residues. Provision is thus made for restoring from time to time the losses of humus and nitrogen, and for maintaining the soil in a good physical condition. Fallowing, on the other hand, hastens the burning up of the humus and the depletion of the nitrogen and, in time, makes it necessary either to abandon the soil to weeds or to seed it down to grass. After remaining in an undisturbed condition for some years its store of humus and of nitrogen becomes greater again and bare fallows seem to yield, once more, profitable returns.

This was the plan followed in olden times and it is still followed in many localities. Many of the so-called abandoned farms in the older portions of the United States are again being placed under cultivation and are yielding fair returns. The years during which they remained untilled permitted them to gather a small store of easily decomposed organic matter and made a portion of their mineral constituents more available. 
Bare fallows and nitrogen in the soil.-The partisans of bare fallows have tried, within recent years, to justify the practice by the claim that, during the period of fallowing, the nitrogen-fixing bacteria, particularly the azotobacter species, increase in numbers and add considerable quantities of nitrogen to the soil. The German estate owner, Caron, the originator of alinit, noted an increase of nitrogen in his soil and ascribed it to the influence of bare fallows. Other observations made in various localities, are in accord with this in so far as gains of nitrogen in bare soils are concerned. To what extent the activities of the non-symbiotic nitrogenfixing bacteria are intensified by the process of fallowing is still to be determined.

Bacterial changes.-There is no doubt, however, that the changes in the bacterial relations in the soil, due to fallowing, are far-reaching. It was shown by the investigations of Hiltner and Störmer that under normal conditions the various groups of soil bacteria establish a certain balance among themselves, a balance that is partly or wholly destroyed by changed soil conditions. Thus, when the soil is treated with antiseptics, like carbon bisulfide, chloroform, or ether, the bacteria are decimated in their numbers. Some of the species are injured by this treatment to a greater extent than others. After the destructive action of the antiseptic had disappeared, the bacteria increase again to enormous numbers, exceeding by many times the normal quantity in cultivated soils. Furthermore, the new development under such conditions does not show the same relations among the various groups. Similarly, the process of 
fallowing seems partly to destroy the normal group relationships.

Contrary to expectations, the number of the decay bacteria growing on gelatin is diminished in fallow soils. Others, among them the nitrifying bacteria and nonsymbiotic nitrogen-fixing bacteria, become more prominent. The influence of fallowing is felt in the second year in the decreased number of soil-organisms, a decrease that falls more heavily on some groups than on others.

The subsoil is likewise influenced in a similar manner. It is still to be determined to what extent these changes occur in the various modifications of the bare fallow. We have ample reason to believe that, beneath hoed crops subjected to frequent tillage, the bacterial transformations are not the same as those under wheat, oats, or rye. The different conditions of moisture, temperature and aëration beneath hoed crops are more akin to those in fallow land, modified by the influence of the plants themselves. For the rest, it is for future investigation to teach us how rotations, and the arrangement of the various crops in the rotation, affect the development of desirable and undesirable bacteria. It is likewise to teach us whether the gains of nitrogen in bare fallows may be sufficient to make a resort to them advisable under given conditions of soil, climate and cropping.

The prospect.-The task of systematizing our knowledge on the economy of plant nutrition, so that we may know when the waste of plant-food is legitimate, and when it is not legitimate, is still before us. This applies 
particularly to the transformations of nitrogen in the soil through the agency of various microörganisms and the effect on these transformations of different methods of soil-treatment, including cropping, tillage and fertilization. 


\section{CHAPTER XXVI}

\section{SOIL BACTERIA IN RELATION TO MINERALS IN THE SOIL}

THE mists that rise from the sea and gather into clouds travel far, at times, before they rejoin the sea. Very often, they fall on the land as rain or snow and, making their way past the soil-particles, continue their journey until the ocean is reached once more. Thence they may again start on new travels and repeat the cycle. In all cases, the sea is the point of departure as well as the final destination. And yet there is an important difference in the going and the coming of the waters.

The mists that leave the sea carry nothing with them. They come back laden with booty-treasures gathered by percolating rain, by brooks, rivulets and rivers. With every completed cycle, the sea becomes richer and the land poorer,- poorer in nitrogen, lime, magnesia, potash, soda, phosphoric acid and sulfur; poorer, likewise.in other ingredients. The gain of the sea would be slight if the land were an inert mass. As it is, the gains are large, because the weathered crust of the earth is not inert, for there are in it forces making soluble not only the remains of living things (organic matter), but also the purely mineral constituents. 
Among the forces that compel a tribute from land to sea, the soil bacteria stand out prominently as busy workers in the achievements of great results. Under their touch, the inert mass of organic remains becomes less inert, it yields copious amounts of the gas, carbon dioxid. This, in its turn, becomes the key that helps to unlock the mineral plant-food in the rock fragments.

It is necessary that in this change from the insoluble to the soluble state certain losses occur, for the reason that the growing crop cannot take up all of the soluble food. The sea claims and receives its tribute from the store of this unused plant-food. It would be unjust, however, to condemn the soil bacteria for their too intense activity. In order that the crops may have enough available food, more than enough must be produced. It is for the farmer to decide whether more or less of that excess is to be wasted from the land.

\section{SOIL BACTERIA IN RELATION TO LIME AND MAGNESIA}

Of all the rock ingredients in the soil, lime and magnesia are, perhaps, most readily affected by the activities of bacteria. The work of the latter constitutes a constant drain on the lime resources and, to a lesser extent, on the magnesia resources of the soil. Where vegetation is luxurious and bacteria are abundant, as is almost invariably the case in limestone regions, the plant remains decay rapidly and the limestone rock fades away in the presence of the carbon dioxid produced. Layers of limestone, 10,20 , or 30 feet thick, are sometimes reduced to a few inches of soil; cañons, caves and 
underground rivers are formed, and enormous amounts of lime are carried to the sea to serve there as building material for coral reefs, for the outer skeletons of shellfish, and other almost innumerable forms of marine life.

With the passing ages this lime may be given back to the land. Its life in the form of chalk cliffs, of crinoidal limestone beds, and of shell marls, may perhaps again go through the process of erosion and solution, and travel to the ocean once more. Thus the lime and magnesia of the rocks and soils migrate from land to sea and from sea to land, just as the nitrogen and carbon of the soils migrate from the land to the atmosphere, and from the atmosphere to the land.

The causes of the migration of lime and magnesia.The migrations of lime and magnesia will be understood more readily if we remember that lime carbonate by itself is very slightly soluble in water. For all practical purposes it is insoluble. When, however, the water carries in solution carbon dioxid, the lime carbonate is changed to a bicarbonate which is soluble. It follows, therefore, that, the greater the intensity of decay in the soil, the greater the amount of carbon dioxid formed and of the lime carbonate rendered soluble and removed. Every progressive farmer knows that in order to maintain his soil productive he must lime it from time to time. It is only in the case of limestone soils that liming seems usually, though not always, unnecessary. There are records of chalk soils underlaid by chalk to which the application of lime has been found profitable, so completely had the lime carbonate been dissolved and carried away. 
The liming of soils.-The periodical liming of soils is necessary because of the gradual removal of the lime from the surface layers in the manner just noted. The analysis of drainage waters shows that every soil loses its lime more or less rapidly, the amount removed being increased by the application of organic materials, especially of animal manures and of green-manures. Furthermore, the operations of tillage, which, by better aërating the soil and by conserving its moisture, stimulate the growth of decay bacteria, increase the losses of lime from the soil. The removal of lime from the soil is, therefore, not only absolutely but also proportionately greater in well-tilled lands abundantly provided with humus. The action is also reciprocal, since the addition of lime to the soil favors the growth of most soil bacteria, while the more intense growth of the latter leads to the rapid formation of products that hasten the removal of lime from the soil. In one way, therefore, it would be proper to say that the more the soil is limed the more lime it will require, provided, always, the proper porportion of organic matter is maintained.

Losses of lime.-Greater or slighter losses, then, of lime as bicarbonate occur from all soils. Lime may, however, be lost from soil in other ways. It has already been noted under nitrification that, in the change of the humus-nitrogen to nitrate, considerable quantities of lime are used to combine with the nitric acid produced by the bacteria. The nitrate of lime thus formed is soluble like other nitrates and distributes itself freely in the soilwater. When not taken up by the growing crop, the nitrate of lime or magnesia ultimately finds its way 
into the drains. The analysis of drainage waters shows the latter to contain lime as bicarbonate, nitrate, sulfate and chloride. The formation of the first two is due to bacterial activities, the formation of the third is also related to a considerable extent to the activities of certain bacteria. It will be seen, therefore, that, directly and indirectly, lime plays an important part in the life of the soil bacteria and that the latter in their activities affect the fortunes of lime in the soil.

These losses of lime become greater when commercial fertilizers are used, particularly those containing sulfate or chloride of ammonia. Large amounts of lime are used up when the latter are changed to nitrate by the nitrifying bacteria. It has been found that when muriate (chloride) of potash is applied to the soil the potash is fixed in the latter. The drainage waters show corresponding additions of chloride of lime. Similarly, when sulfate of ammonia is applied, the drainage waters will receive additions of both nitrate of lime and sulfate of lime. Investigations at Rothamsted show losses of lime amounting to 1,000 pounds per annum,losses that serve to explain the need of the periodical liming of most soils. Hilgard frequently quotes the popular saying that "a lime country is a rich country." There is very good reason for the belief expressed in this statement, for the reason that no soil is productive unless it has a vigorous bacterial flora. The latter is not possible in a soil deficient in lime.

The importance of lime.-Proper decay of the humus, proper nitrification and proper nitrogen-fixation are all dependent upon an abundant supply of lime. We 
have experimental evidence that the nitrogen-fixing azotobacter are readily found only in soils well supplied with lime; that most of the nitrogen-gathering, leguminous plants prefer soils well provided with lime; that decay and nitrification proceed more rapidly in lime soils. In a word, then, lime is essential for the wellbeing of the soil bacteria and its removal from the soil is largely dependent on their activities. The limestone strata of many countries bear witness to the far-reaching results of these activities, to the important geological changes caused by them and to the indirect effect on the life in the sea.

Bacterial activities and lime.-It should not besupposed, however, that the activities of soil bacteria tend always to decrease the amount of lime carbonate in the soil. On the contrary, certain changes caused directly or indirectly by bacteria tend to restore somewhat the losses of lime caused by other bacterial changes. It has been demonstrated that, in the decay of vegetable or animal substances containing lime, the carbonate of the latter may be formed. It has been found, likewise, that certain compounds of lime, existing in rock fragments and known as silicates, may be changed gradually to carbonate of lime under the influence of carbon dioxid produced by the soil organisms. This is in accord with the observations made on certain soils derived from trap-rock. These soils were found to contain very slight amounts of lime carbonate. Notwithstanding this, the application of lime seemed to do no good. It is believed, therefore, that, in the gradual weathering of the trap-rock with silicates of lime, sufficient amounts 
of lime carbonate are formed to answer the needs of the plants and of the bacteria.

SOIL BACTERIA IN RELATION TO PHOSPHATES AND OTHER COMPOUNDS OF PHOSPHORUS

The phosphoric acid in the soil exists there mainly as phosphate of lime, the so-called tricalcic or insoluble phosphate of lime. As a matter of fact, tricalcic phosphate is not entirely insoluble, but, rather, only very slightly soluble. It takes a very small amount of it to form a saturated solution, one which will hold no more of it under any given conditions. Extremely dilute as is this solution in soil-moisture, it is still capable of supplying all the needs of the growing crop for phosphoric acid in all productive soils.

As the plants withdraw the phosphoric acid from this solution, more is added from the undissolved reserves in the soil. In other words, there is the tendency to reëstablish a saturated solution. It happens, however, that not all soils possess the same power of replacing the phosphate withdrawn from the soil-moisture by the roots. Some soils apparently possess the ability of replacing it rapidly, others of replacing it but slowly, a fact of evident importance in the growing of crops, since it is only the soluble plant-food that serves as the immediate nourishment of crops.

Bacterial activities and phosphorus.-The variable ability of different soils to furnish soluble phosphates to the crop cannot be directly correlated with the amount of total phosphoric acid in the soil. There are soils containing fairly large amounts of phosphoric acid that yield. 
but scant amounts of it to the crop during the growing season. Others contain much smaller quantities, yet supply the needs of large harvests. There is scarcely a doubt that bacteria play an important part in determining these differences. For one thing, the carbon dioxid evolved in the decay of organic matter hastens the solution of soil phosphates, just as it hastens the solution of the lime carbonate.

In fertile soils well supplied with humus the bacterial activities are rather vigorous. Large amounts of carbon dioxid are produced and the solution of the soil-phosphates proceeds at a comparatively rapid rate. Higher plants, therefore, find in the soil bacteria powerful allies in securing an abundance of available phosphoric acid. The bacteria, in their turn, are affected not only by the amount of humus present in the soil, but, also, by its quality. A greater or slighter proportion of nitrogen in the humus influences directly not only the numbers, but, also, the kinds of bacteria that become most prominent. Our knowledge of the relations in this case is extremely limited. Future investigation will undoubtedly find this an interesting as well as a profitable field to develop.

The influence of soil bacteria in the supply of phosphoric acid to crops may be best understood by remembering that the element phosphorus exists in the soil in two general classes of compounds,-inorganic and organic. The inorganic or mineral combinations of phosphoric acid exist in the more or less weathered rock particles as phosphates of lime and magnesia; to a slight extent, also, as phosphates of iron and alumina. These 
mineral phosphates are affected in their solution by the presence of carbon dioxid produced by bacteria from the humus. They are also affected in their solubility by other substances produced by bacteria, notably organic acids.

Organic phosphorus.-The other class of phosphorus compounds - the organic-exist in the humus and have a double origin. By far the greater part of the phosphoric acid in the humus is locked up in an insoluble condition in the decaying roots and stubble. It came originally from the soil-water and was withdrawn from the latter by the plants. Another portion of the phosphoric acid in the humus is also derived from the phosphates dissolved in the soil-water, but in this case it is changed into insoluble modifications either by being used by the bacteria themselves, or by combining with some of the substances produced by bacteria. In other words, the soil bacteria help to produce soluble phosphates in the soil. They also use up some of the latter by changing them into combinations not immediately available to crops.

As the soil-humus is broken down by the attacks of various microörganisms its inert phosphorus may again become available. Indeed, there is evidence to show that the organic combinations of phosphorus in the soil probably play a more or less important part in the supply of this element to higher plants. It is clear, therefore, that bacteria bear an intimate relation to the supply of phosphoric acid for crops not only by helping to make soluble the mineral phosphates in the rock particles, but, also, by making available again the 
organic phosphorus of the humus. As to the rate at which the phosphorus of the humus may become available under different soil conditions, and as to the value of such phosphorus compounds as compared with mineral phosphates, we know practically nothing. Certain investigations seem to establish a certain relation between the reduced content of organic phosphorus and the depleted fertility of the prairie soils.

Bacterial activities and phosphate fertilizers,-Phosphate fertilizers like ground phosphate-rock (floats), ground bone, superphosphates, and Thomas slag, are likewise affected by the activities of soil bacteria. It is well known that floats may be made more effective and more available by being composted with barnyard manure. In the light of the foregoing remarks, it is not difficult to understand why this should be so. The barnyard manure with its vast numbers of bacteria, its organic matter undergoing decay, and its large amounts of carbon dioxid, must of necessity hasten the solution of the insoluble phosphate. Similarly, in the case of green-manures, particularly those rich in nitrogen, the use of floats may yield profitable returns. Conditions favorable for the rapid increase of bacteria and of bacterial products are thus created and, therefore, also for the comparatively rapid conversion of the insoluble phosphoric acid into available forms.

From the standpoint of soil fertility, in its more permanent relations, this matter is of very considerable economic significance. If, by the proper supply of organic materials and the proper encouragement of bacterial activities larger returns can be secured from the untreated 
phosphate rock, the supply of cheap phosphoric acid is assured. Under such conditions it would be possible to add much larger quantities of phosphoric acid to the soil for the same money expended, and thus provide, not only for large harvests in the near future, but, also, for large harvests in the more distant future. The value of soil-humus, well appreciated by practical men everywhere, becomes more definite when considered from this point of view, as well as in its other relations. A clearer insight into the process of plant-production is gained as an understanding of the manifold reactions in the busy laboratory of the soil is developed. Soil-humus stands revealed to us, then, not alone as the storehouse of nitrogen, but as a medium wherein countless species of microscopic life achieve a great work, as a key that unlocks the abundant treasures of the inert rock masses.

Ground bone. - The rate at which ground bone becomes available is determined, as in case of floats, by the amount and character of the soil-humus and the bacterial activities occurring in it. The fineness of division plays an important part here in so far as it concerns these activities. It is quite evident that the finer the particles, the more intimate their contact with the bacteria and their products. The phosphoric acid of fine bone becomes more quickly available than that of coarse bone because it presents a greater surface for the attack of the microörganisms. Lime seems to decrease the availability of the phosphoric acid in ground bone.

A number of experiments in which smaller returns were secured from bone on the limed portions of the field are on record. The decrease is accounted for on 
the assumption that the excess of lime not only combines with the organic acids generated in the humus, but, also, with the carbon dioxid to form bicarbonate of lime. These substances are, therefore, prevented from exerting their solvent action on the insoluble bone phosphate. On the other hand, fairly satisfactory returns are secured from bone on sour soils. Its use on the reclaimed moor (peat) soils of Europe has been found to be profitable. Since lime is known to encourage bacterial activities in the soil, it might seem that the decreased availability of the phosphoric acid in bone, consequent upon liming, is due to the more vigorous growth of the bacteria. This seeming contradiction is, however, explained by the foregoing remarks. With a plentiful supply of humus there is but slight difficulty to be apprehended from this source.

The effect of using sulfuric acid.-The practice of treating phosphate rock with sulfuric acid in the manufacture of superphosphate (acid phosphate or dissolved rock) is justified by the greater availability of the phosphoric acid in the resulting product. The tricalcic phosphate of the crude rock is changed by the acid into the water-soluble or into the reverted phosphate, both forms available to the crops. Superphosphate is, therefore, essentially a mixture of water-soluble, reverted and insoluble lime-phosphate and gypsum. The soluble phosphate is "fixed" in the soil, that is, it is changed back into an insoluble form.

It may seem rather wasteful to dissolve the crude phosphate rock in order to have its phosphoric acid return to the insoluble state in the soil. As a matter 
of fact, however, the soluble phosphate distributes itself more or less thoroughly in the soil before it is fixed. Even then it exists in so fine a state of division that it may be rapidly rendered available by the chemical and bacteriological changes in the soil. In so far as the bacteria are concerned, the action of superphosphate is somewhat different from that of floats or ground bone, for the superphosphate adds to the soil more or less gypsum, besides the mixture of phosphates, which is slightly acid. A certain effect is thereby produced on the soil bacteria. This not only affects the decomposition of the humus and the subsequent availability of the phosphoric acid of the superphosphates, but, also, that of the soil phosphates proper. In soils in which large quantities of superphosphates are applied at frequent intervals, the resulting bacteriological changes must be far-reaching, as future investigations will probably demonstrate.

Thomas slag.-In European agriculture, particularly that of Germany, France and Belgium, Thomas slag serves as an important source of phosphoric acid. Thomas slag is a by-product in the manufacture of steel from phosphatic iron ores, and contains, besides the phosphate of lime, considerable quantities of iron and lime carbonate. The material, as placed on the market, is merely the finely ground slag. The availability of the phosphoric acid in the slag depends largely on its fineness of division. The bacterial relations in this case are influenced by the iron and the lime contained in the slag, as well as by its phosphoric acid. The latter exists in combination with lime in the so-called tetra- 
calcic (four-lime) form, and shows a high rate of availability under suitable soil conditions.

The use of Thomas slag yields particularly gratifying returns on light open soils containing an abundance of humus. It seems that the open character of the soil, by encouraging the bacterial decomposition processes, makes possible the formation of large quantities of carbon dioxid and of other substances which help to make soluble the phosphate in the slag. Thomas slag has been found to be particularly acceptable on light, soils, on which green-manuring is systematically resorted to. Schultz, of Lupitz in Germany, celebrated for his systems of green-manuring, employed Thomas slag for many years and found it a suitable as well as economical source of phosphoric acid. The great masses of leguminous catch-crops turned under by him offered splendid opportunities for intense bacterial changes and for the formation of abundant amounts of available phosphoric acid.

Other sources of phosphoric acid.-In the case of greenmanures, animal manures, and of commercial fertilizers of organic origin, such as ground fish, meat meal, tankage, castor pomace, and the like, the bacterial reactions, in so far as the phosphoric acid is concerned, are of the utmost importance. The barnyard manures, so extensively employed in general and special farming, contain their phosphoric acid in insoluble combinations. The solid excreta and the litter containing nearly all of the phosphoric acid of the manure must first undergo decay in order that they may yield available plant-food to the crops. What the particular reactions through 
which the phosphoric acid of manure and of other organic materials must pass before it becomes available as plant-food are, is still to be learned. We know that in its action the phosphoric acid of manure compares favorably with that of superphosphate, the results being modified by the physical and chemical nature of the soil.

In different soils there are probably different species of decay bacteria that come to the foreground as far as the phosphoric acid is concerned. Whether any of the species of decay bacteria are particularly prominent in the processes of transformation to which the phosphoric acid of organic manures is subject, is still to be learned. However, interesting differences in this direction must exist since, in the process of evolution, species have been developed that differ in their relations to phosphoric acid, just as the soil bacteria differ in their relations to nitrogen. In one instance, at least, it is known that the nitrogen-fixing bacteria of the azotobacter group are sensitive as to the supply of phosphoric acid in the media in which they grow; also, that, with conditions otherwise favorable, their growth is but meager in soils deficient in available phosphoric acid.

ACTIVITIES OF SOIL BACTERIA IN RELATION TO POTASH

Most of the potash in the soil exists there in the rock particles. A small proportion is found in combination with the humus. Clay soils derived from the weathering of feldspar and of other minerals rich in potash, naturally contain a large amount of the latter. Sandy soils formed 
from rocks poor in potash are usually deficient in this constituent.

All soils contain their potash chiefly as silicate, an inert substance insoluble in water. Because of its insolubility, it offers scarcely anything to the growing crops in the absence of conditions favoring its decomposition. Instances are not uncommon in which clay soils containing 30,000 to 40,000 pounds of potash per acre to a depth of one foot are markedly benefited by applications of 100 or 200 pounds of muriate of potash. This may be readily understood from the fact that the insoluble silicate of potash is weathered very slowly under ordinary soil conditions.

Potash and the weathering process.-The weathering process may be naturally so slow as to furnish available potash enough only for a very meager harvest. The farmer has it in his power, however, to hasten the weathering process by the frequent stirring of the soil and by the addition to it of large quantities of organic matter. In either case, he unconsciously or consciously encourages the development of soil bacteria, the decay of humus, the formation of carbon dioxid, and the decomposition of the inert silicate of potash. As in the case of phosphoric acid, the carbon dioxid becomes the key that helps to unlock the great stores of inert plant-food,the key furnished by the busy hosts of bacteria working in the dark recesses of the soil.

What has been said of the insoluble soil-phosphates holds good also in the case of the silicates of potash. The soil-humus and the materials that go to make it, attain a striking importance when viewed in this light. 
They are the seat of desirable bacterial changes which, in their turn, like the hypothetical Philosopher's Stone of the Middle Ages transmute the valueless into the valuable.

Lime as an indirect source of potash.-The beneficial effect of lime on heavy soils is frequently ascribed to its action as an indirect source of potash. The lime crowds out the potash from its insoluble combinations and renders it available. It must not be supposed, however, that the formation of available potash in the soil is due entirely to the action of lime on the potash minerals. Bacterial life plays an important part in that it furnishes the carbon dioxid important in the weathering processes. In the presence of carbonate of lime and of carbon dioxid, the insoluble silicate of potash is gradually converted into carbonate of potash and also into other compounds of the latter. It will be seen, therefore, that applications of lime to the soil add to its available potash by direct action on the insoluble potash minerals, as well as by encouraging the growth of decay bacteria and the production of larger quantities of carbon dioxid.

Humus in relation to soil-potash.-In this relation, humus plays fully as important a part as it does in the case of phosphoric acid. Large quantities of readily decomposable organic materials are essential in the profitable utilization of the soil-potash. Indeed, the influence of humus and of decay bacteria is, in some respects, more important. From the standpoint of insoluble potash locked up in the soil, it seems legitimate for the farmer to employ every means at his command to secure larger returns from it without much fear that 
he will appreciably impoverish the potential fertility of his land.

Organic acids and decomposition of rock fragments.Aside from carbon dioxid, there are other substances generated by bacteria that play a more or less important part in accelerating the decomposition of rock fragments. Among such substances may be included the various organic acids generated in the course of decay, as well as the nitrous and nitric acids produced by the corresponding organisms. As yet but little is known of the action of organic acids and of other organic compounds on the decomposition of rock particles and in the formation of available potash. In the case of nitric acid, it is known that nitrifying organisms are met with on rock surfaces, and that they contribute to the disintegration of the rock.

Potash salts and bacteria.-Aside from aiding in the formation of available potash in the soil, the bacteria are themselves readily affected by the supply of soluble potash salts. Such salts materially aid nitrification, as is evidenced by both laboratory and field experiments. Similar experiments tend to indicate that decay bacteria proper are favorably influenced by available salts of potash. The same is true of the nitrogen-fixing bacteria, particularly those forming tubercles on the roots of legumes. The stimulating influence of carbonate and of sulfate of lime in the growth of most legumes ascribed, as was already noted, to the increase in the store of available potash, is, undoubtedly, extended also to the tubercle-bacteria.

Direct applications of potash salts, particularly of 
the carbonate of potash found in wood-ashes, exert the same effect. The carbonate of potash is doubly effective because of its potash and its ability to neutralize acid substances in the soil. In the so-called alkali soils, and, in general, in irrigated districts, the accumulation in the surface soil of salts of potash and of soda, undoubtedly produces interesting bacteriological effects.

\section{BACTERIA IN RELATION TO SULFUR}

Sulfur is one of the chemical elements that enter into the composition of protein substances; it is, therefore, essential to the life of plants and of animals. As one of the indispensable building materials for organized life, it affects the development of bacteria. It is, in its turn, affected by the growth of the latter in its relation to other elements. Locked up in the inert residues of plants and animals, it needs the transforming touch of microörganisms before it can again enter into circulation to be used once more as building material for new cells.

Sulfuretted hydrogen.-The odor of sulfuretted hydrogen, a compound of hydrogen and sulfur, is often perceptible in the decay of eggs or meat. It denotes, under such circumstances, that certain of the decay bacteria are actively multiplying in the material undergoing decomposition. More frequently, however, the sulfuretted hydrogen is formed slowly and its odor does not become perceptible. This is true of decay processes in the soil, in streams, lakes and the sea, where the organic debris is broken down by bacteria. But whether 
produced slowly or rapidly, the sulfuretted hydrogen, a gaseous substance, is not in itself available to higher plants as a source of sulfur. It must be changed further into sulfate, usually sulfate of lime (gypsum), before it can be used to advantage.

The sulfuretted hydrogen evolved in the decay of animal and vegetable materials may be changed to sulfate by purely chemical means,

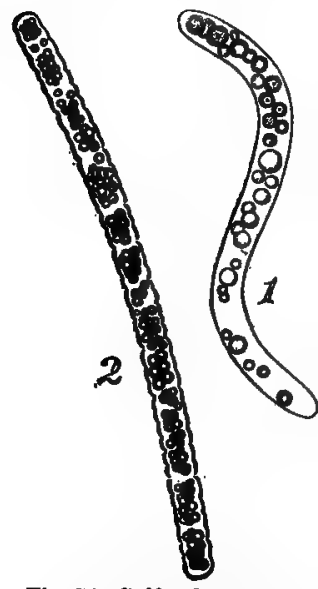

Fig. 54. Sulfur bacteria.1. Thiospirillum Winogradskiz; $\times 2,000$. (Omelianski.) 2. Beggialoa alba; $\times 2,440$. (Corsini.) or by a group of organisms designated as sulfur bacteria. The sulfur bacteria are found in ditches, canals, swamps, seas, and mineral springs,-in places where there is a more or less constant supply of sulfuretted hydrogen. These organisms possess, in a very marked degree, the power of decomposing the sulfuretted hydrogen and of depositing granules of sulfur in their cells. When grown in solutions containing sulfuretted hydrogen, the cells are seen to be filled with sulfur granules. The latter make up, at times, 80 to 95 per cent of the fresh weight of the bacteria.

When the supply of sulfuretted hydrogen is diminished or exhausted, the sulfur granules gradually disappear and the bacteria perish. Evidently, the organisms are dependent on the sulfuretted hydrogen for their energy. They secure the latter by causing the hydrogen. 
to combine with oxygen to form water and subsequently, by causing the elementary sulfur deposited in their cells to combine with oxygen to form, with water, sulfuric acid. The last named combines with lime to form sulfate of lime. The tissues of dead plants and animals are made to give up their sulfur as sulfuretted hydrogen by the common soil bacteria. The sulfuretted hydrogen serves an important purpose in the life of a special group of bacteria, and the sulfur finally reappears as sulfate of lime, sulfate of magnesia, sulfate of soda, or sulfate of iron, and is in a condition again to be utilized by green plants. The transformation is thus complete, and the sulfur is ready to pass through another cycle and to circulate between land and sea.

Sulfate of lime.-The drainage waters that pass out of the soil contain considerable quantities of sulfate of lime. The sea ultimately receives the latter as it receives all else borne to it from the land and offers it to its denizens. Enormous quantities of gypsum are thus brought to the ocean daily and are constantly being added to by the restless streams. It should not be supposed, however, that the gypsum that finds its way to the sea is doomed to stay there unchanged and inert. Other bacteria, widely distributed in nature, are capable of compelling it to pass through other transformations and to part with its sulfur. Some of the most common decay bacteria, like Bacillus mycoides and Proteus vulgaris have been found capable of producing sulfuretted hydrogen out of sulfate of lime and of thus changing once again the sulfur into a gaseous compound.

Aside from the decay bacteria, there are well-defined 


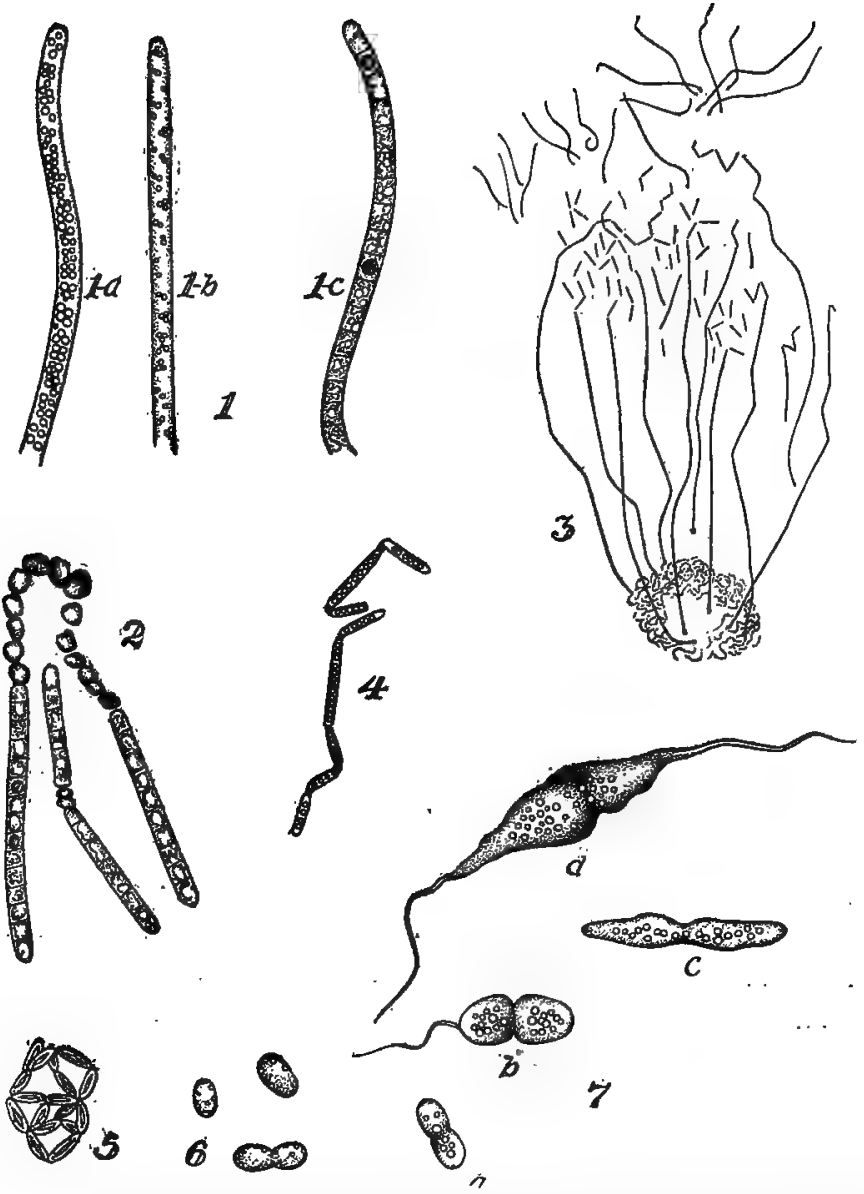

Fig. 55. Sulfur bacteria.-1. Beggiatoa alba. (a) A filament rich in sulfur granules; $(b$ and $c$ ) Filaments showing the gradual disappearance of the sulfur; $\times 900$. 2. Filaments dying for lack of sulfur; $\times 900$. 3. Thiothrix tenuis; $\times 100.4$. Motile filament of Thiothrix tenuis; $\times 900$. 5. Thiodictyon elegans; $\times 900$. 6. Thiothece gelatinosa; $\times 900$. 7. (a) Chromatium Wetssii; (b) Chromatium Okpnii; (c) Rhabdochromatium roseum; (d) Rhabdochromatium fusiforme; $\times 900$. (All after Winogradski.) 
organisms designated as sulfate-reducing bacteria. They are anaërobic organisms widely distributed in soils, lakes and streams and apparently play an important part in the purification of potable waters. By means of the oxygen that they withdraw from the sulfate, they cause the destruction of the organic materials suspended or dissolved in the water and help to make it wholesome for human use.

The sulfate of lime that accumulates on the bottom of seas, lakes and streams, is reduced by one or another of the bacterial groups just referred to. The sulfuretted hydrogen passes upward while the lime is left behind as carbonate. The sulfur bacteria at or near the surface, seize the sulfuretted hydrogen and convert it ultimately into sulfate of lime. This may be redeposited at the bottom to go through a similar cycle of transformation. It has been demonstrated that the mud baths, celebrated for their curative properties in rheumatism and similar diseases, are characterized by the presence of sulfuretted hydrogen derived from the reduction of gypsum by bacteria.

The bacterial activities. - The curative muds of the Black Sea are marked, among others, for the bacterial activities just alluded to and may serve as an illustration of the vast work performed by microörganisms in the change of mineral as well as of organic materials. The composition of the deposits of mud in land-locked waters and on the ocean bed bear an intimate relation to bacterial activities. The formation and the destruction of gypsum, the formation and the destructoin of lime carbonate are but a part of the far-reaching transforma- 
tions. Both serve to teach us that in the soils of today and in the soils of tomorrow, bacteria are an essential factor in plant-production.

Not the least interesting fact in connection with the sulfur bacteria is the ability of a portion of them to grow vigorously in bright daylight. The so-called red sulfur bacteria produce a pigment that partakes to some extent of the properties of chlorophyl. It has been asserted that with the aid of this pigment the red sulfur bacteria are able to decompose carbon dioxid and to assimilate the carbon after the manner of green plants. It has been shown that they are attracted by light. It appears, therefore, that these organisms have a two-fold source of energy, in the coloring matter and sunlight on the one hand, and in the sulfuretted hydrogen on the other.

In so far as their ability to decompose carbon dioxid with the aid of sunlight is concerned, they may be regarded as allied to the minute green plants known as algæ. In other respects, they should be classed as bacteria. As to their distribution, and that of other sulfur and sulfur-reducing bacteria, it may be said that they are distributed widely. Much remains to be learned, however, of their activities in arable soils. The study of sulfur compounds and their transformation in the soil, as related to bacteriological factors, reveals a mass of interesting facts and sheds a new light on the important problems of soil-treatment and soil fertility.

Sulfur and bacterial development.-The compounds of sulfur, particularly sulfates, exert a decided influence on bacterial development. Magnesium sulfate, çomr 
monly employed in the preparation of culture media, serves as the source of sulfur to the organisms in such cultures. In field and pot experiments, sulfates have been found to produce favorable results in encouraging the development of certain groups of soil bacteria. It has been shown that sulfates of lime, magnesia, potash and soda favor nitrification in most soils. It has also been shown that in the decomposition of manure, gypsum (sulfate of lime) exerts a retarding effect at the beginning. Carbon dioxid is evolved less rapidly, and the losses of nitrogen are smaller. When, however, the nitrification processes once set in, the change of the organic nitrogen into nitrate proceeds more economically and more rapidly. The resulting product is of better quality and yields a greater crop increase than the untreated manure.

Sulfate of iron, another compound of sulfur, has likewise been found in some instances to stimulate crop growth. The effects in this case are undoubtedly of a bacteriological character, although scarcely anything is known of the exact nature of this action. There is reason to believe that, at times, the stimulating action may be due to the iron rather than the sulfur in the iron sulfate, while at other times the sulfur plays a predominating rôle.

BACTERIA IN RELATION TO IRON

Substances capable of uniting with the element oxygen are said to possess potential energy. Such potential energy is possessed, among other elements, by nitrogen, carbon, hydrogen, and șulfur. We have seen 
the manner in which this potential energy is utilized by bacteria. The formation of nitrites and nitrates, the production of carbon dioxid, of water, and the formation of sulfur. granules and their subsequent oxidation to sulfate, are all instances of energy production by various groups of bacteria under well-defined conditions. Similarly, in the case of iron, a certain amount of energy may be set free in the addition of oxygen to this element. Iron rusts when exposed to the air, that is, it combines with the oxygen of the atmosphere to form an oxide of iron. Under ordinary conditions, the rusting (oxidation) process is so slow as not to show
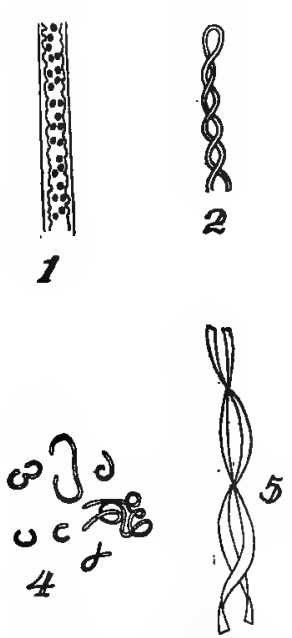

Fig. 56. Iron bacteria.-1. Leptothrix ochracea. 2. Gallionella ferruginea, typical thread. 3. Spirophyllum ferrugineum. 4. Gallionella ferruginea cell division. 5. Spirophyllum ferrungineum, twining individuals. 6. Gallionella ferruginea, conidia formation. (After Ellis.)
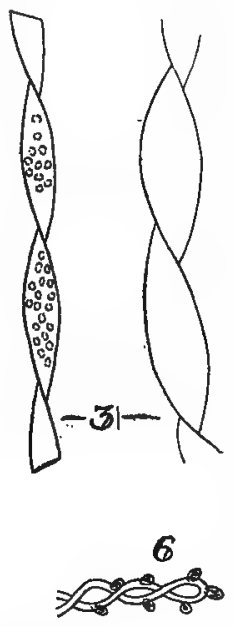

any increase in temperature. It remains true, none the less, that heat is set free in the rusting of the iroir.

Iron rust and bacteria.-Under certain conditions this rusting is caused by bacteria, and the heat produced is utilized by them for their own development. We have an analogy here to 
the oxidation of sulfuretted hydrogen by the sulfur bacteria. The sulfur is not used by the latter as a food, but only as a fuel-a source of energy. Similarly, in the case of the iron bacteria, the iron which is made to take on oxygen serves as a source of fuel. In the one case, the final product is sulfuric acid, which passes out of the bacterial cells. In the other, a soluble compound, or compounds, of iron passes into the outer sheath of the microörganisms.

The importance of iron bacteria.The iron bacteria, represented chiefly by Cladothrix dichotoma and Crenothrix Kühniana, have played in the past and are playing in the present a rôle of considerable significance in the accumulation and migration of iron compounds in certain localities. This applies particularly to swamps, meadows and marshes $n$ which deposits of bog iron are, at $t$ mes, formed. Soluble compounds of iron of a lower state of oxidation are carried to such places and are there made to combine with more oxygen, partly through the activities of iron bacteria. One of these soluble compounds of iron, known as ferrous sulfate, or copperas, is a substance quite
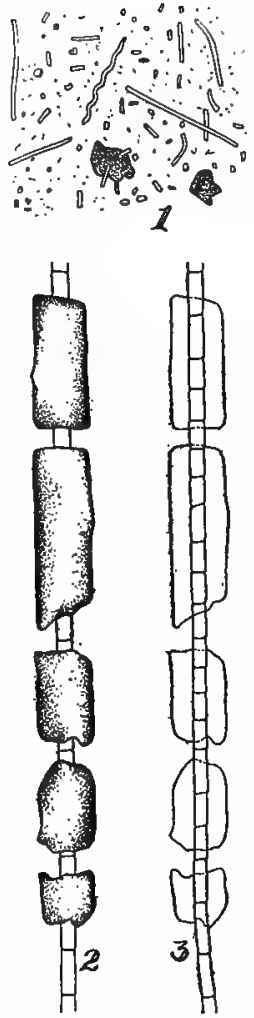

Fig. 57. Iron bacteria. i. Bog iron. 2. Psichohormium antliarium, s bowing masses of iron surrounding the cellwalls. 3. The same, after treatment with dilute acid; $\times 600$. (Mo-lish.) 
injurious to vegetation when present in any but small proportions in the soil. In the presence of lime, the ironbacteria are capable of converting the copperas into the harmless oxide of iron and gypsum.

Iron in the soil and decay bacteria.-Apart from the iron bacteria proper, the fortunes of iron in the soil are affected by the great host of decay bacteria. The soilhumus and the more recent plant residues contain more or less iron. When these substances are broken down by the soil bacteria, the iron may be changed to a ferrous carbonate which, in the presence of carbon dioxid, becomes soluble and is diffused in the soil-water. Coming in contact with sulfuretted hydrogen, formed in the decay of protein substances, the iron may be changed ultimately to copperas, and, finally, to iron oxide and gypsum.

It has been demonstrated in the study of pure cultures of common decay bacteria, that such reactions play an important part in the formation of black sand in seas, bays, and lakes. The iron bacteria and the decay bacteria, widely distributed on land and sea, may, therefore, be regarded as geological agents of some moment, as well as direct factors in providing to crops the iron compounds essential to their growth.

Influence of iron on bacteria.-In so far as the influence of iron on the bacteria themselves is concerned, our knowledge is meager. It is now known that salts of iron exert a stimulating effect on the development of the nitrogen-fixing bacteria of the azotobacter group, and probably also on other soil-organisms, as shown by applications of ferrous sulfate. 


\section{PART V}

\section{Bacteria in Barnyard Manure}

\section{CHAPTER XXVII}

\section{MANURE: ITS COMPOSITION AND LOSSES}

BARNYARD manure is rich in bacteria because it offers conditions favorable for their rapid development. The organic matter which serves as food for the microorganisms is not only present in much larger proportion than it is in the soil, but its composition is such as to be readily available to them. As the bacteria multiply the manure begins to undergo a change. Its bulk becomes smaller; it assumes a darker color, develops a higher temperature, and finally shrinks more and more in volume until, in the course of time, it contains but a small fraction of its original bulk. The change in the appearance in the manure is followed by a corresponding change in its composition. A portion of its plantfood is lost entirely by being changed into gaseous products which pass out into the surrounding air. The rest is affected in its availability.

Bacterial change in manure.--The nature of the bacterial change which manure undergoes bears a direct relation to the composition of the latter. The proportion 
of water, of soluble and insoluble nitrogen compounds, and likewise of phosphoric acid, potash and lime, exerts in each case a decided influence. The following table, given by Beal, shows the average composition of manure from different animals and may be taken as an illustration of the natural differences affecting the bacterial processes:

\begin{tabular}{|c|c|c|c|c|}
\hline & $\begin{array}{l}\text { Water } \\
\text { Per cent }\end{array}$ & Nitrogen & $\begin{array}{c}\text { Phosphoric acid } \\
\text { Per cent }\end{array}$ & Potash \\
\hline ". & 5 & 0.768 & 0.391 & 0. \\
\hline & 77.73 & 0.497 & 0.172 & 0.532 \\
\hline Hog & 74 & 0.840 & 0. & 0.320 \\
\hline & 75 & 0.4 & 0. & 0. \\
\hline es. & 48.69 & 0.490 & 0.260 & 0.480 \\
\hline
\end{tabular}

As is indicated by the analyses, the horse manure contains much less water than the cow manure. In consequence of this, it is more permeable to air and favoris the rapid growth of aërobic bacteria. The cow manure, on the other hand, not only contains more water, but, also, mucilagenous substances derived from the digestive tract of the animal. These substances help to form an impervious crust over the solid excreta and contribute, thereby, to a more effective exclusion of air from the interior of the mass.

Mechanical constitution and bacterial change.-The mechanical constitution of manure in so far as it is determined by its content of water, becomes thus an important factor in the bacterial changes that subsequently take place. The reference to horse and sheep manure as being dry and hot, in contradistinction to cow and pig manure may, therefore, be regarded from the bacterial standpoint as indicating susceptibility to decomposition processes. 
Chemical composition and bacteria change.-The chemical composition, like the mechanical constitution of manure, exerts a direct influence on the rapidity and extent of the bacterial changes. It is to be remembered that the solid excreta represent the undigested portion of the food. They are largely insoluble in water and not readily attacked by most of the manure bacteria. The materials used as litter, such as straw, sawdust, leaves, and peat, are, likewise, somewhat resistant to the attacks of the microörganisms. On the other hand, the liquid excreta represent the food materials that have been broken down into simpler substances in the process of digestion and have passed through the kidneys in a soluble state. On account of their comparatively simple composition and their solubility, these substances are readily accessible to bacterial changes. Their proportion in the manure intimately affects the rate of the decomposition of the latter.

The following table, also given by Beal, shows the composition of the solid and liquid excreta of different farm animals:

\begin{tabular}{|c|c|c|c|c|c|c|c|c|}
\hline \multirow[b]{3}{*}{ Hor } & \multirow{2}{*}{\multicolumn{2}{|c|}{$\begin{array}{c}\text { Water } \\
\text { Per cent }\end{array}$}} & \multirow{2}{*}{\multicolumn{2}{|c|}{$\begin{array}{c}\text { Nitrogen } \\
\text { Per cent } \\
\text { Solid Liquid }\end{array}$}} & \multicolumn{2}{|c|}{$\begin{array}{l}\text { Phosphoric acid } \\
\text { Per cent }\end{array}$} & \multicolumn{2}{|c|}{$\begin{array}{l}\text { Potash and soda } \\
\text { Per cent }\end{array}$} \\
\hline & & Liquid & & & & & & \\
\hline & 76 & & .50 & & & & .30 & 1.5 \\
\hline & 4 & 92 & .30 & .80 & .2 & & .10 & 1.4 \\
\hline & 8 & 97 & .6 & & .4 & .1 & .50 & .2 \\
\hline & & 86 & .7 & 1.4 & .6 & .050 & .30 & 2.0 \\
\hline
\end{tabular}

The most noteworthy facts brought out by the table are the comparatively large proportion of nitrogen and of potash in the liquid excreta and the presence of almost all of the phosphoric acid in the solid excreta. Notwithstanding the great dilution of the liquid excreta, they 
contain about one-half of the total nitrogen and about three-fourths of the total potash originally present in the food of milch cows. In the case of sheep, it has been found that the liquid excreta contained nearly one-half of the potash and from one-half to three-quarters of the nitrogen voided by the animals.

These figures show that a large proportion of the nitrogen compounds in animal excreta are soluble and subject to rapid decomposition. Severin, who isolated a number of bacteria from manure, found that certain species which grew readily in the liquid excreta refused to develop in the solid excreta. When, however, both the solid and liquid excreta were present, the organisms developed readily and attacked the former as well as the latter.

This indicates that, in manure properly protected from the leaching action of rain, the decomposition of the comparatively inert substances in the solid excreta land the litter proceeds more rapidly on account of the soluble nitrogen compounds which enable the bacteria to grow vigorously and to attack also the insoluble materials.

\section{LOSSES FROM FARMYARD MANURE}

The value of farmyard manure in stimulating crop growth is due to its organic matter, to its plant-food constituents, and to some extent, also, to its bacteria. A ton of farmyard manure of average composition adds to the soil 425 pounds of organic matter, 10 pounds of nitrogen, 7 pounds of phosphoric acid, 9 pounds of potash and a countless number of bacteria. The organic matter 
is gradually changed into humus by the activities of the latter. In this change, a portion of the inert plantfood in the manure, as well as of that in the soil, is rendered available to the crops.

Animal manures, green-manures, and other organic fertilizers possess, therefore, a value over and above that possessed by purely mineral carriers of plant-food. In measuring the utility of organic materials, allowances should be made for the quantity of bacterial food contained in them.

Losses of elements in the animal.-In animal manures the organic matter is derived from the food and the litter. However, much of it never reappears in the manure. A large part of it is burned up in the body in order to provide the animal with the necessary energy. It is also exhaled from the lungs as carbon dioxid and water. It was found by Henneberg that a steer thus exhaled in one day fifty pounds of carbon dioxid and water. Another portion of the organic matter in the food is changed into gaseous products by bacteria in the intestinal tract, respiration calorimeter experiments showing the presence of considerable quantities of marshgas in the gaseous excreta of herbivorous animals. The total amount of organic matter burned up in the animal body may thus amount to more than half of that in the food consumed.

In passing through the animal body, the food suffers a loss, not of carbon and hydrogen alone, but, also, of nitrogen, phosphoric acid and potash. In fattening steers, as much as 5 to 10 per cent of the food nitrogen may be retained, while in milch cows the amount se- 
creted in the milk and retained in the body may amount to about one-sixth of the food-nitrogen. A portion of the phosphoric acid and of the potash are also retained in the body or secreted in the milk, although, in the case of the potash, the portion retained is quite slight. Because of this destruction or retention of the food constituents in the animal body, the amount of plant-food in the manure is less than that in the food from which it is produced.

Other causes for losses. - The loss of plant-food constituents does not stop here, however. Further losses occur in the manure itself. These are brought about, on the one hand, by the leaching of the soluble compounds of nitrogen and potash, and to a slight extent, also, of phosphoric acid from the manure pile, and on the other, by various fermentations that lead to the breaking down of the organic matter and the setting free of nitrogen either in an uncombined state or as ammonia.

The monetary value of the plant-food leached out from improperly stored manure is truly. enormous. The losses thus incurred are not directly due to bacterial activities. However, the losses occasioned in the decomposition of manure by bacteria are considerable, but they concern only the organic matter and the nitrogen. The phosphoric acid and the potash are not changed into gaseous products in the course of decay and cannot, therefore, be lost when the manure is properly protected from the leaching action of rain.

Importance of proper storing.-The quality of organic matter lost from the manure pile in the course of fer- 
mentation is variable and is influenced by the composition of the manure as well as by the manner of storing. When the manure is stored loosely, the aërobic bacteria are favored in their growth. Their activities may become so intense as to cause a rapid oxidation, that is, a rapid burning up of the organic matter. Under such circumstances, the temperature of the manure is raised to a perceptible extent, frequently giving rise to firefanging. Oxidation is more intense in the upper layers of the manure on account of the more ready access of oxygen to them. It has been demonstrated by actual measurements that the temperature is highest near the surface and lowest near the bottom of the pile.

By compacting the manure and by largely excluding thereby the access of air, the aërobic bacteria are suppressed, and the anaërobic favored in their growth. The decomposition then proceeds more slowly, the character of the chemical products is modified to a considerable extent, and the losses diminished. Under different conditions of storing, the losses of organic matter from the manure pile in three or four months may range from 15 or 20 per cent to 40 or 50 per cent of the initial quantity. Obviously, then, the value of manure as humusforming material is greater when it is kept well compacted than it is when stored loosely.

On light, sandy soils, in which the quantity of humus is so important a factor in the maintenance of proper moisture conditions, this difference is significant. To take a concrete example, ten tons of fresh manure and litter, containing 4,250 pounds of organic matter, may be made to contain at the end of four months about 
3,600 pounds by proper storing, or about 2,100 pounds by improper storing. The differences do not end here, however, for the quality of the residual organic matter is not the same in the two instances, and the effect produced by their application to the soil must necessarily show corresponding differences in their rate of decomposition there.

The loss of nitrogen.-Apart from the loss of organic matter in the manure, the activities of the bacteria involve also a loss of nitrogen. This may be evolved either as a free gas or as ammonia. Beyond a certain point this loss cannot be avoided even when the greatest care is observed in the conservation of the manurial constituents. In the experiments conducted at Woburn in England in 1899, 1900, and 1901, the manure was kept under the feet of the animals in box stalls having cemented sides and a cemented bottom. Enough litter was used to absorb all of the liquid excreta, no loss could have occurred through drainage, and the compacted condition of the manure largely excluded aërobic fermentation. Notwithstanding all this, there was an average loss for the three years of more than 15 per cent of nitrogen.

The manure thus made in the early winter was kept under cover until early spring, care being taken to prevent losses by drainage. Samples of the well-rotted manure were taken in the spring and analyzed. A further loss of 15 to 18 per cent of nitrogen was discovered. Similarly, in the experiments made by Goodwin and Russel in England, the manure was kept in a covered box-stall and well compacted. Rapid fermentation was 
excluded as far as possible. Nevertheless, there was a loss of nearly 15 per cent of nitrogen.

In Maercker's experiments in Germany, twenty-four steers were kept in box stalls for a period of 136 days. Twelve of the steers were tied in deep stalls whose floor and sides were cemented. Sufficient litter was employed and the manure was allowed to accumulate under the feet of the animals. The manure from the other steers was removed daily and kept partly under cover, and partly in an open yard. The compacted manure from under the animals showed a loss of more than 13 per cent of nitrogen, the manure in the covered heap showed a loss of 36.9 per cent and the manure from the open heap a loss of 37.4 per cent.

In a subsequent experiment, the animals were removed from the box stalls after a certain length of time and the compacted manure kept untrampled for another month. It was found that the untrampled manure showed a loss of 35.5 per cent as against 13.2 per cent in the manure taken directly from under the feet of the animals. In a similar experiment at the Pennsylvania station, the compacted manure in the stalls with cemented floors showed a loss of 5.73 per cent of nitrogen, while the untrampled manure showed a loss of 34.12 per cent.

In view of the facts just presented, Voelcker and Hall are quite right when they state that "If there be this loss in the case of dung made under such conditions, with all the precautions that are practicable under the best conditions of farm management, and if we also allow for what is retained by the animal, it may be 
concluded that an estimated loss of 50 per cent of the total nitrogen contained in the foods is not too high for manure made under average conditions of farming."

The losses of nitrogen that occur in decomposing manure, fall most heavily on the soluble portion. Wagner calculates that to every 100 parts of insoluble or inactive nitrogen there should be voided by the animals 100 parts of soluble or active nitrogen. As a matter of fact, however, we find only 25 to 35 parts of the latter to 100 parts of the former in fresh manure. The discrepancy is evidently due to the greater susceptibility of the soluble nitrogen compounds to attacks by bacteria.

On the other hand, the solid excreta and litter suffer comparatively little from the destructive bacterial changes. This fact has suggested the separate collection and preservation of the liquid and solid excreta. It is claimed that the inert nitrogen compounds in the latter will resist decomposition more effectively in the absence of the former. The liquid excreta drained into a cemented pit will be but little accessible to aërobic bacteria on account of the anaërobic conditions in the interior of the liquid.

Aërobic and anaërobic decomposition.-The smaller losses of nitrogen in compacted manure, as compared with those in loosely stored manure, are readily accounted for by the different conditions as to bacterial development prevailing in one and in the other. As previously noted, aërobic processes prevail in the loosely stored manure or in its upper layers, and the organic matter, containing nitrogen, undergoes a correspondingly rapid decomposition. The carbon and the hydrogen find an 
abundance of oxygen to combine with and give rise to the formation of carbon dioxid and of water. The nitrogen thus detached from its combinations may be evolved as a free gas, or may still remain united to hydrogen as ammonia. In either case, the losses are considerable.

When anaërobic processes prevail, as in compacted manure, the oxygen needed by the bacteria is withdrawn from the organic matter itself. It thus happens that the gases evolved in anaërobic fermentation also contain carbon dioxid. However, the limited supply of oxygen greatly retards decomposition. Some of the hydrogen passes off in an uncombined state, or unites with carbon to form marsh-gas. The nitrogen is changed into more simple organic substances or into ammonia. The remaining mass becomes poorer in oxygen and proportionately richer in carbon; also in nitrogen, when the decomposition is properly controlled. The darker color of old manure, like the dark color of fertile soils, is due, therefore, to humus substances comparatively rich in carbon, and more resistant to decay than the substances from which they were derived.

The differences in aërobic and anaërobic decomposition of manure from the standpoint of losses involved, is well illustrated by an experiment of Hansen's as cited by Stutzer. The manure from ten cows, fed and"bedded alike, was removed twice a week and placed in two cemented pits. In one of these it was stored loosely, and the excess of liquid excreta allowed to drain away into a smaller pit. In the other, it was carefully trampled. down and the liquid excreta retained. 
Considerable differences in the temperature of the two lots of manure soon became apparent as is shown by the record of observations through the months of February, March, and April. The temperature on the different dates in degrees centigrade is showing in the following table:

\begin{tabular}{|c|c|c|}
\hline Date & $\begin{array}{l}\text { oosely stored } \\
\text { manure }\end{array}$ & $\begin{array}{c}\text { Compacted } \\
\text { manure }\end{array}$ \\
\hline February $2 \ldots \ldots \ldots \ldots \ldots \ldots$ & .. 45 & 7 \\
\hline February $9 \ldots \ldots \ldots \ldots \ldots$ & .. 60 & 4 \\
\hline February $16 \ldots \ldots \ldots \ldots \ldots$ & .. 57 & 3 \\
\hline February $23 \ldots \ldots \ldots \ldots$ & 44 & 8 \\
\hline March $2 \ldots \ldots \ldots \ldots$ & .. 41 & $\mathbf{1 1}$ \\
\hline March 16 & 29 & 11 \\
\hline March $30 \ldots \ldots \ldots \ldots . .$. & .. 29 & 19 \\
\hline April $6 \ldots \ldots \ldots \ldots \ldots$ & .. 25 & 18 \\
\hline April $13 \ldots \ldots \ldots \ldots \ldots$ & .. 26 & 21 \\
\hline April $20 \ldots \ldots \ldots \ldots \ldots \ldots$ & .25 & 20 \\
\hline April $27 \ldots \ldots \ldots \ldots \ldots \ldots \ldots$ & $\ldots 25$ & 19 \\
\hline
\end{tabular}

The maximum temperature of $60^{\circ}$, it will be seen, was reached in the loosely stored manure on February $9 \mathrm{th}$, and gradually declined after that during the rest of the period. In the compacted manure, on the other hand, the maximum temperature was not attained until April. Even then it was lower than the minimum temperature recorded for the loosely stored manure. Now, the higher temperature is merely an indication of more rapid combustion, just as the radiation of unequal quantities of heat from two similar stoves is an indication that more fuel is being consumed in one than in the other.

Careful analyses of samples of manure from the two heaps at the end of twenty-one weeks showed that the 
loosely stored manure had lost 53 per cent of its organic matter and 34 per cent of its nitrogen; whereas, the compacted manure had lost only 28 per cent of its organic matter and 15 per cent of its nitrogen. The anaërobic prosesses in the compacted manure were, therefore, less wasteful of the nitrogen and of the organic matter than were the predominatingly aërobic processes in the loosely stored manure.

Bacterial activities and money losses.-The extent of the monetary losses involved in the improper control of the bacterial activities in manure may be appreciated from the following considerations. Taking the amount of manure and litter for each cow at 15 tons annually and for each horse and mule at 5 tons annually, we find, in round numbers, 130 pounds and 50 pounds of nitrogen respectively to be credited to each animal. With a value of only 8 cents per pound, this nitrogen would be worth $\$ 10.40$ and $\$ 4$ respectively. With, say, $60,000,000$ of cattle and 20,000,000 horses and mules in the United States, the value of the manurial nitrogen would be greater than $\$ 700,000,000$. Assuming that the difference between economical and wasteful transformation of this nitrogen in the manure pile by bacteria would represent 20 per cent, the monetary loss would amount to $\$ 140,000,000$.

Similar losses would also occur in the storing of manure from sheep, swine, and domestic fowls. Of course, these figures should be taken only as an illustration of the possible or probable magnitude of the interests involved. They will serve very well, however, to demonstrate that, entirely apart from the vast losses 
of manurial constituents by leaching, there may be enormous losses brought about by the countless number of microörganisms developing in manure. Some of these losses cannot be avoided, even by most careful management. A large portion of them can, however, be prevented and, from the standpoint of national economy, they are deserving of intelligent consideration at the hands of the farmer.

The unnecessary losses of the humus-forming organic matter in animal manures represent smaller, though none the less important, material values. For instance, market-gardeners in New Jersey and other eastern states pay as much as $\$ 2$ or $\$ 2.25$ for a ton of horse manure, the value of whose nitrogen, phosphoric acid and potash does not exceed $\$ 1.50$ at best. They are, therefore, paying at least 50 cents for the organic matter in a ton of manure. Evidently, they are willing to go to the expense and trouble of securing this organic matter, since it is absolutely necessary to incorporate, from time to time, sufficient quantities of humus-forming material into their open soils. The organic matter of manure has, therefore, a more or less definite value. Wasteful bacterial decomposition may lead here, as in the case of nitrogen, to losses of great magnitude.

The importance of this matter is frequently overlooked, even by persons otherwise well informed. There are many thousands of acres of arable land thin and defective in their physical properties and poor in bacteria on account of their deficient supply of humus. Long years of improvident treatment of the manure produced on the farm gradually robbed the land of the 
organic matter that should have been returned to it. The soluble organic compounds were allowed to be leached out or destroyed in the unprotected, loosely stored manure. The residual portion, poorer in available nitrogen and in readily decomposable organic substances, added to the soil something that was very inert and not easily decomposed by the soil bacteria. 


\section{CHAPTER XXVIII}

\section{THE BACTERIA IN MANURE-AMMONIFICATION}

ANIMAL excreta are extremely rich in microörganisms. Most of these organisms are typical inhabitants of the intestinal tract. The others are derived from the food eaten by the animals and are not apparently destroyed by passing through the animal system. Among the latter should be included certain spore-forming bacteria which occur in large numbers on substances of vegetable origin. For example, Wuthrich and Freudenreich found in hay 7,500,000 bacteria per gram of substance. Twenty five per cent of these belonged to the spore-bearing Bacillus subtilis (hay bacillus) group. In sour potatoes, on the other hand, with about 5,000,000 bacteria per gram, the proportion of hay bacilli was comparatively slight. When fed to animals, the bacterial content of these materials apparently affected that in the manure. It was noted, for instance, that the manure of animals fed on grass contained $1,800,000$ to $12,250,000$ bacteria per gram, consisting largely of the colon bacillus and the hay bacillus. When the animals were fed on hay, the manure contained $20,674,000$ to $375,000,000$ bacteria, also consisting, for the most part, of the two organisms just named.

Changes in manure bacteria.-In his examinations of (318) 
horse manure, Severin observed that in fresh samples there was a predominance of rod-shaped organisms, but that the spherical forms began to predominate as the manure grew older. A further change occurred in the character and numbers of the bacteria in manure when the latter was plowed into the soil. The rod-shaped organisms then became proportionately fewer and the spherical forms proportionately more numerous.

It would seem, therefore, that some of the bacteria prominent in the intestinal tract of domestic animals are rapidly reduced in numbers in the manure pile. Others hold out for a while, but are ultimately suppressed. The colon bacillus is thus rapidly reduced in numbers, while the members of the hay bacillus group, the socalled proteus group, and of the cellulose-fermenting group, increase in numbers to a greater or less extent.

As the decomposition processes proceed and the soluble organic substances disappear, the nitrous and nitric ferments multiply more rapidly. Many of the rod-shaped forms no longer find the conditions favorable for their growth and are gradually crowded out.

Three stages of change,-There are, thus, three stages in the bacterial characteristics of manure. During the first, the intestinal bacteria are most prominent in numbers. During the second, the decay and putrefaction bacteria come to the foreground. During the third stage, when the organic matter is already partly mineralized, the nitrous and nitric ferments become numerous and lead to the accumulation of nitrates. The transition periods from one state to another are gradual and their length is determined by the composition of the excreta 
and the litter, by the season of the year, and by the manner of storing.

Bacteria and conditions affecting decomposition.In manure rich in soluble nitrogen compounds, certain species of ammonifying bacteria appear in greater numbers, and remain active for a longer time, than in manure less rich in such substances. Similarly, in the summer months, the decay and putrefaction-bacteria complete their work sooner and allow the appearance of the nitrifying bacteria. The daily losses of organic matter and of nitrogen from cow manure are much greater in the months of May, June, July, August, and September, than they are in the months of February, March and April. The length of the transition period is affected by the amount of oxygen that gains access to the manure pile. When the material is kept moist and compact, and the decomposition thereby retarded, the nitrifying bacteria do not appear so soon nor are their activities so prominent at the beginning. Gradually, however, the structure of the manure becomes more crumbly, the amount of moisture is diminished and the air finds more ready access to the interior of the heap.

\section{AMMONIFICATION IN MANURES}

Ammonia is one of the first products formed in the decomposition of protein substances. The undigested nitrogenous materials in the solid excreta, as well as the soluble compounds in the liquid excreta, both furnish ammonia as they begin to undergo decay. Still another source of ammonia in the manure pile may be 
found in the nitrate that is formed in the course of time in the surface layers. It happens, at times, that the nitrate thus formed is diffused downward and is reduced there to nitrite and to ammonia.

Hippuric acid.-The liquid excreta of herbivorous animals contain their nitrogen for the most part in a substance called hippuric acid which is derived from the protein substances in the food. Hippuric acid is readily decomposed with the formation of a simpler substance, glycocoll, which, in turn, is changed by bacteria into carbonate of ammonia.

Uric acid.-In a similar manner, the nitrogenous substances in the liquid excreta of carnivorous animals consist largely of urea and uric acid. These also are changed by bacteria into carbonate of ammonia. The ammoniacal odors in stables are due to this formation of carbonate of ammonia from liquid manure. The carbonate is a substance that is readily vaporized at ordinary temperatures and is used for this reason, in the preparation of smelling salts.

The formation of ammonia in liquid excreta.-The conversion of the nitrogenous substances in liquid excreta into carbonate of ammonia proceeds very rapidly. Wagner observed that a quantity of cow urine containing thirty-nine parts of nitrogen included only one part of ammonia nitrogen in a fresh condition. At the end of two days, there were twenty-three parts of ammonia nitrogen in the liquid and at the end of four days, thirtyfive parts. Thus in four days all but four parts of the initial nitrogen had been converted into ammonia. He observed, also, that when the urine was mixed with 
solid excreta, the formation of ammonia occurred even more rapidly, since all but five parts of the nitrogen were converted into ammonia at the end of four days.

It has been found that liquid excreta undergoes ammoniacal fermentation more readily when the material is more concentrated. This fact partly explains the greater readiness of horse manure, as compared with cow manure, to undergo this change.

The transformation of urea and of hippuric acid into ammonium carbonate is due to a number of bacterial
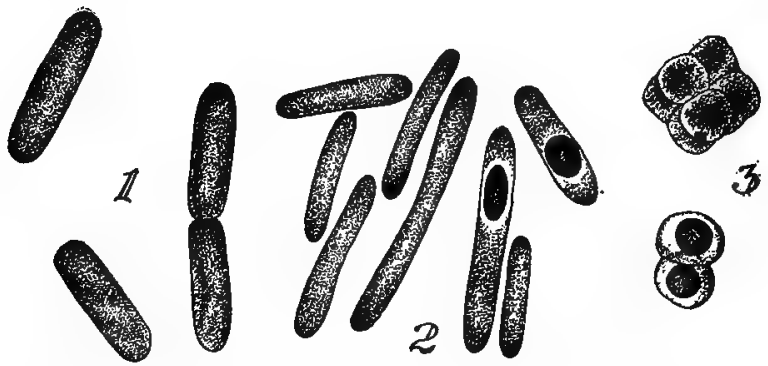

Fig. 58. Urea bacteria.-1. Urobacillus miguelii; $\times 9,000$. Urobacillus leubii; $\times 9,000$. Planosarcina urea; $\times 9,000$. (After Beyerinck.)

species known as uro-bacteria. These may include rodshaped forms (uro-bacilli) and spherical forms (urococci). Uro-bacteria occur universally in nature and may be readily isolated from soil, water, manure and air. Ammonium carbonate is a volatile substance and easily passes out of the manure and is lost. The danger of loss is greatest in the summer months for the two-fold reason that the bacteria work more rapidly at the higher temperatures, and, also, because liquids evaporate more rapidly under such conditions. 
Loss of ammonium carbonate.--It is evident, therefore, that, as the liquid manure is concentrated by evaporation, the proportion of ammonium carbonate in the liquid is increased and is more readily volatilized. For this reason, the application of fresh manure to the soil without immediate plowing under may lead to very considerable losses of valuable ammonia nitrogen by the rapid drying of the manure. In rainy weather, the danger of such loss is slight, for the soluble ammonium carbonate is then washed into the soil.

The ready volatility of ammonium carbonate also accounts for the diminished losses of nitrogen from manure piles that are kept moist. It is a common practice in France to keep the manure in compact heaps and to moisten it from time to time with the liquid manure which drains away from it into cemented pits. In dry weather, when the evaporation is intense, liquid manure may become too concentrated and insufficient in amount to keep the solid excreta and litter in proper moisture condition. Water is then added to the manure.

Urease.-A number of the uro-bacteria have been found to produce an enzyme, urease, by means of which the transformation of the urea into ammonium carbonate is accomplished. This may be readily demonstrated by subjecting cultures of uro-bacteria to chloroform vapor, when the organisms themselves are destroyed, but not the enzyme. It will be found that the cultures thus treated still retain the power of changing urea into ammonium carbonate. As in the case of other species, the urea- or uro-bacteria differ in their ability to produce the enzyme. Varieties of the same species that 
show very marked differences in their physiological efficiency may be isolated.

Not all of the organisms capable of changing urea into ammonium carbonate produce urease. Some of them seem to perform the work directly without the intervention of an enzyme, and are not capable, for this reason, of accomplishing as much change in a given time as some of the others. It should be added here, also, that some of the uro-bacteria produce spores and are capable of resisting unfavorable changes of temperature and concentration. Quantities of ammonium carbonate that would prove destructive to other organisms do not appear to injure them at all. They survive when the concentration of the liquid excreta is very marked.

Other ammonia-forming bacteria.-Apart from the uro-bacteria proper, ammonia may be produced from the nitrogenous substances in manure by other species of microörganisms. As in the case of the protein substances in the soil-humus, the corresponding compounds in the manure are gradually broken down with the formation of ammonia as one of the cleavage products. The inertness of the solid excreta and of the litter does not allow as extensive a formation of ammonia as takes place in the liquid excreta. Nevertheless, the inert nitrogenous substances in the manures do undergo decay slowly and may lead to appreciable losses of ammonia.

Importance of ammonification.-Generally speaking, therefore, ammonification, whether occasioned by the rapid transformation of urea and hippuric acid by urobacteria, or by the more gradual change of undigested 
protein substances by decay and putrefaction-bacteria, is an important process in the preparation of waste organic materials into food available to higher plants. The formation of ammonia is accompanied by other changes in the composition of the manure. The starches, sugars, organic acids and cellulose, as well as the protein substances, all undergo modifications through bacterial activities. The resulting product is ready for further transformations when incorporated into the soil. Other nitrogen relations.-In this chapter we have discussed the nitrogen losses in manures through the ammonifying processes. In the two following chapters we shall consider the nitrogen content of manures in reference to denitrification and nitrification. 


\section{CHAPTER XXIX}

\section{DENITRIFICATION IN MANURES}

REFERENCE is occasionally made to losses of nitrogen from the manure pile as due to denitrification. In the proper definition of the term, namely, the destruction of nitrates with the evolution of gaseous nitrogen, denitrification processes in manure are by no means as extensive as is commonly supposed.

Nitrates in manure. - No nitrates are present in fresh manure, since the large quantities of soluble organic matter are unfavorable to the development of the nitrifying bacteria. Subsequently, however, when changes more or less deep-seated had occurred in the organic matter, the nitrifying bacteria make their appearance in the upper layers of the manure pile where the supply of air is more abundant.

The nitrates thus formed may be diffused downward or washed down by rain and reduced to nitrogen gas. It is doubtful, however, whether, under actual conditions, the reduction of nitrates in the interior of the manure pile is as far reaching as that. More frequently, the reduction is only partial and no escape of nitrogen gas occurs as a result of denitrification. Losses of elementary nitrogen do occur in the manure pile, but are brought about by different bacterial processes. 
Denitrifying bacteria.-These are abundant in the excreta of herbivorous animals and in the straw used as litter. They may, therefore, when added to the soil, cause the destruction of nitrates produced there by nitrifying bacteria or added in fertilizers. Yet, even in the soil, denitrification takes place only when large quantities of organic matter are present. In other words, denitrification in the soil or in the manure pile is not brought about by the mere presence of denitrifying bacteria.

The destruction of nitrates by these bacteria may be accomplished only when the three essential conditions are supplied, namely, organic matter, nitrates and bacteria. In the manure pile, nitrates do not make their appearance until the decomposition of the organic matter has advanced considerably; hence only two of the conditions are supplied,- -bacteria and organic matter. In the soil, on the contrary, the nitrates and bacteria are present, but not an abundant supply of readily decomposable organic matter. This will account for the very occasional denitrification in the soil occurring only after excessive applications of strawy manure, as pointed out in a preceding chapter.

Experiments in denitrification.-It has been noted in numerous experiments carried out in Germany and elsewhere, that the denitrifying effects of manure grow less significant as its decomposition goes forward. Wagner found in his experiments that manure two weeks old when added in weighed quantities to a given amount of nitrate solution, destroyed the nitrate completely in 14 days. When the same quantities of manure 
42 days old were added to the solution, half of the nitrate was reduced in 14 days, and 30 days were required for the complete reduction.

When the manure employed in the experiments was thoroughly stirred at frequent intervals, its nitratereducing power decreased more rapidly than that of the unstirred manure.

Similarly, portions of manure whose decomposition had been retarded by additions of gypsum, superphosphate, and kainit, retained their denitrifying power to a more marked degree. Lime, which hastened the decomposition of the manure, caused, in some of the experiments, a more rapid decline of its denitrifying power. The various samples of treated or untreated manure which had been thus kept for 112 days, reduced at the end of that period the following amounts of nitrate out of every 100 parts present in the solution:

Manure without addition of conserving materials, reduced.. 8 parts Manure with gypsum, reduced ...................39 parts Manure with gypsum and phosphate, reduced ..........40 parts Manure with kainit, reduced....................66 parts Manure with lime, reduced $. \ldots \ldots \ldots \ldots \ldots \ldots \ldots . .9$ parts

In another experiment, in which samples of manure 70 days old were added to the nitrate solutions, all of the nitrate was destroyed in 64 days when the untreated manure was employed. When, however, manure treated. with lime was used, it required 83 days to complete the destruction of the nitrate. The conservation of the organic matter in the manure by means of chemicals, or by merely compacting the heap and excluding the air, is equivalent, therefore, to the conservation of its de- 
nitrifying power. The more rapid decomposition of the manure brought about by loose storing or by additions of substances like lime is equivalent to a more rapid decline of the denitrifying power.

The danger from denitrification.-Since nitrates do not appear in the manure until the organic matter is largely decomposed and its denitrifying power greatly reduced, it follows that the danger from denitrification in the manure cannot be great. Moreover, the claim of some of the German investigators that denitrification in the soil, following the application of large quantities of manure, is brought about by the addition of large numbers of denitrifying bacteria, is hardly in accord with the facts just noted. The soil itself possesses an abundance of these organisms and it is only the supply of much easily decomposable organic matter that enables them to destroy the nitrates in the soil.

Further light is thrown on this question by other experiments performed by Wagner and his associates. They found that, when manure was exposed to the action of carbon bisulfide and later incorporated into the soil, the return from the nitrate used with it was smaller than that when untreated manure was applied. This result was contrary to the expectations of Wagner, for he had believed that the manure treated with carbon bisulfide, and deprived thus of its denitrifying bacteria, would prove less injurious than the untreated manure. In still other experiments, when the carbon bisulfide was applied directly to the soil, the returns from nitrate were increased instead of diminished.

These conflicting returns, that appeared very 
puzzling to Wagner, may be interpreted more readily with the aid of recent investigations. The carbon bisulfide destroyed the existing bacterial equilibrium in the soil and allowed the enormous increase of new species combinations, with the result that the humus-nitrogen was made available at a more rapid rate. On the other hand, when the manure itself was treated with carbon bisulfide, the bacteria were, to a great extent, destroyed. The surviving spore-forming organisms and others derived from the soil, freed from the competition of the non-spore-forming species, soon made up for lost time. The decomposition of the manure proceeded more rapidly, greater quantities of available organic substances were placed at the disposal of denitrifying bacteria in the soil, and greater quantities of soil-nitrates were destroyed.

\section{LOSSES OF ELEMENTARY NITROGEN}

It is generally conceded that the loss of nitrogen from decomposing manure may be decreased by compacting it, and increased by facilitating in it the circulation of air. However, there is still serious difference of opinion as to the manner in which the nitrogen is lost, or, at any rate, as to the manner in which most of the nitrogen is lost. The loss may be due to the change of the organic nitrogen into ammonia and the volatilization of the latter. There is no doubt that the rapid transformation of the nitrogen compounds in liquid manure into ammonium carbonate, and the concentration of the liquid, lead to losses of ammonia. 
The problem of the loss of nitrogen.-Numerous experiments besides those already named may be cited to show that such losses actually occur in liquid manure when kept by itself in shallow vessels. Similar losses are known to occur in culture solutions in the laboratory, containing gelatin, peptone, or other nitrogenous organic substances. In the manure pile, however, where the liquid manure is intimately mixed with the litter and the solid excreta, the losses of ammonia are by no means so extensive. The frequently large decrease in the quantity of combined nitrogen must be attributed to other causes.

There are a considerable number of experiments on record to indicate that, in many instances, the losses of nitrogen from manure should be attributed largely to the formation of free nitrogen gas in the course of decay. We have already noted how the formation of free nitrogen may occur in denitrification processes. It has been pointed out, likewise, that in the manure pile the losses of free nitrogen through denitrification cannot be very large.

There is, however, still another process through which free nitrogen gas may be formed in the decomposition of organic matter. It is the burning up of ammonia with the formation of water, on the one hand, and of elementary nitrogen on the other. Such burning up of ammonia can take place only when the access of air is very abundant, in other words, under pronounced aërobic conditions. This process is contrary to denitrification, the process whereby nitrates are destroyed under conditions that are, for the most part, anaërobic. 
Nitrogen may, therefore, be lost from fermenting manure as ammonia (and, to a slight extent, in the form of other gaseous compounds of nitrogen), or as free nitrogen gas. The latter, in its turn, may be produced by the destruction of nitrates by denitrifying bacteria, or by the oxidation of ammonia by another class of bacteria, at present but imperfectly known.

Since the numbers and kinds of bacteria are affected by the composition of the manure and the conditions under which it is kept, the transformation and losses of nitrogen are, of necessity, variable. No better proof of this is required than the conflicting results secured by different investigators, some of whom claim that the losses of nitrogen from manure are slight; others, that they are large.

Again, some investigators assert that the losses that occur are due almost entirely to the volatilization of ammonia. Others assert that they are due to the escape of free nitrogen gas produced in the processes of denitrification, or in the oxidation of ammonia. Wagner found, for instance, that in some of his experiments only 1 per cent of nitrogen was lost in four months when the manure was kept compacted, and 2 to 6 per cent when the manure was kept loose and frequently stirred. On the other hand, some of the experiments by Pfeiffer and his associates show losses of more than 42 per cent of nitrogen in ten months. Small amounts of ammonia escaped from the manure. The loss must be attributed to the evolution of nitrogen gas. It seems, also, that vigorous aëration of the material intensified the loss of nitrogen. 
Recent information on the problem.-In the light of recent bacteriological studies by Kaserer, in Austria, the contradictory results of different investigators are fairly intelligible. We now know that there occur in manure, as in the soil, certain organisms capable of causing the oxidation of ammonia. Much still remains to be learned concerning their habits and their relation to other bacteria concerned with the transformation of nitrogen compounds. There is reason to believe, at the same time, that they attain their fullest development under conditions most favorable to the rapid oxidation of organic matter.

In the system of earth-closets by which the excreta and paper are destroyed in an incredibly short time without any marked accumulation of nitrogenous substances, the work of destruction must be accomplished by just such organisms. Similarly, in open, sandy soils, in which the humus and the organic manures applied disappear rapidly, the same organisms must be active.

These facts indicate that apart from a plentiful supply of oxygen, these bacteria are favored in their development. Furthermore, they are able to meet the competition of other organisms when the prevailing temperatures are fairly high and when the proportion of moisture in the medium is rather low. High temperatures are found both in loosely stored manure and in light-colored, porous soils. The same may be said, also, of the moisture content in the manure and soil in question. The study of these bacteria offers an attractive field for the discovery of new and interesting facts. such studies may teach us, besides, how to suppress 
more effectively these undesirable activities in the soil and the manure heap. They may also teach us how to encourage them on occasions when it is desired to hasten as far as possible the decomposition of offensive waste materials.

SOLUBLE NITROGENOUS SUBSTANCES MADE INSOLUBLE

Soils kept bare during a part of the summer rapidly accumulate a store of nitrates that are liable to be leached into the subsoil and lost to succeeding crops. In order to obviate this loss, it has been proposed to grow crops like mustard, buckwheat, or millet to take up the nitrates. The nitrogen, it was thought, could be subsequently recovered by the turning under of these crops as green-manures.

In practice, this has often been found unsatisfactory, because the nitrogen thus laid fast in the green-manure did not again become available rapidly enough to satisfy the demands of the succeeding crop. A somewhat analogous condition is found in the manure pile. The nitrogen of the liquid excreta is one of the most valuable constituents of manure, because of its almost immediate availability to growing crops. Hence, manure rich in liquid excreta, in other words, manure rich in available nitrogen, is more desirable than similar manure poor in available nitrogen.

It happens, however, that in the storing of manure, the proportion of insoluble nitrogen compounds is increased, while the proportion of the soluble nitrogen compounds is decreased. Mention has already been made 
of Wagner's statement that freshly voided manure should contain equal portions of available and unavailable nitrogen. However, samples a few days old actually contain 25 to 35 parts of available nitrogen to 100 parts of unavailable nitrogen. It was similarly observed by Maerker that fresh manure which contained 40 parts of available in 100 parts of total nitrogen was sufficiently changed in $2 \frac{1}{2}$ months to contain only 11 parts of available nitrogen.

The change of available into unavailable nitrogen.The decreased proportion of available nitrogen is unquestionably due in part to the volatilization of ammonia. It is likewise due to the actual increase in the quantity of insoluble nitrogen compounds. It has been demonstrated that the bacteria and molds that develop in the manure appropriate the soluble nitrogen compounds for their growth and convert them into comparatively inert protein substances. These protein substances, like those in the green-manures, must again undergo decay before they may become available as a source of nitrogen to higher plants.

Conditions affecting the change.-Under favorable conditions, the conversion of the soluble nitrogenous substances in manure into insoluble compounds. may proceed very rapidly, as may be demonstrated by simple laboratory experiments. The insoluble nitrogen compounds thus formed consist, for the most part, of the bodies of the microörganisms. Because of their small size, these undergo decay rather rapidly when incorporated into the soil. None the less, an appreciable amount of time is required for the decomposition and, 
as in the case of other nitrogenous substances, losses of nitrogen are thereby incurred. It is evident, therefore, that, aside from actual losses of nitrogen, manure may deteriorate on account of the changes just noted.

In well-compacted manure, the conditions for the conversion of soluble into insoluble nitrogen seem to be more favorable than in loosely stored manure. This may be accounted for by better moisture conditions and, perhaps, also, by the different combinations of bacteria developing in the interior of the heap. As is to be expected, large variations occur in the quantity of nitrogenous material rendered insoluble under different conditions. In some experiments, the amount of insoluble nitrogenous substance was increased by 120 per cent, as reported by Maercker and Schneidewind, in others, only by 5 or 10 per cent.

\section{CONCLUSION}

It may thus be seen that, from the nitrogen standpoint, there may be a more or less serious deterioration in the quality of stored manure. This deterioration is conditioned upon direct losses of nitrogen as ammonia or as free nitrogen gas, and, also, upon the change of available into unavailable compounds. It will be shown later how these undesirable losses and transformations may be controlled by chemical and mechanical means. 


\section{CHAPTER XXX}

\section{NITRIFICATION IN MANURES}

THE formation of nitrates in the manure heap is brought about by the same influences that lead to their formation in the soil. In either case, the presence of nitrogenous organic substance, and the presence of sufficient moisture, warmth, and air is necessary. The presence, also, of some base like lime, to combine with the nitric acid formed by the bacteria, is required. Besides, there must not be too great an excess of soluble or easily decomposable organic matter, lest the nitrifying organisms be injured thereby.

These conditions are usually fulfilled in all cultivated soils. They are not fulfilled in the manure pile until after the decay bacteria have partly accomplished the decomposition of the manure. For this reason, the formation of nitrates does not take place in fresh manure, notwithstanding the presence of nitrifying bacteria in the air and in the soil. Moreover, conditions may be created favorable to the nitrification in the upper layers of the heap, but unfavorable to it in the lower layers. Under such circumstances, the nitrates may be washed downward and reduced in the interior of the heap.

Nitrification in manure.--The early experience gained 
in the production of niter in artificial niter-beds serves to throw much light on the processes of nitrification in manure. It was found by niter-refiners that certain rules had to be observed for the profitable production of niter. Provision had to be made for the proper circulation of air in the niter-bed. This was accomplished by separating the layers of earth mixed with organic matter, by means of faggots or twigs. Nitrifiable organic matter was to be furnished, and was supplied best by moistening the niter-bed with liquid excreta.

Effect of liquid.-It was learned here that there is a limit to the quantity of liquid excreta that may be added with safety. When that point was passed, nitrification not only stopped, but there was an actual diminution in the amount of nitrate that had already formed. Moisture was needed in just the right proportion. With too much, nitrification was suspended and reducing processes set in. When nitrification was well under way, the proportion of moisture that could be advantageously retained in the niter-bed was still further reduced.

In view of the foregoing facts, we can readily understand that, everything being equal, a quantity of manure rich in liquid excreta would begin to nitrify at a later date than a similar quantity of manure poor in liquid excreta. Similarly, a manure pile frequently drenched by rain would not only lose its nitrates by leaching, but, also, by reduction on account of the replacement of the air in the interior of the heap by water. A small proportion of carbonate of lime would favor the nitrification processes in the manure by preventing the accumulation of acid substances injurious to the organisms. 
The compost heap, which is really an imperfectly constructed niter-bed, derives much of its value from the same nitrification processes. The various waste materials of organic origin that enter into its composition, have their inert nitrogen gradually transformed into nitrate. The application of material from an old compost bed, or the application of well-rotted manure is, therefore, equivalent to the application of nitrate.

There is an important difference, however, between the compost heap and the manure pile. The former may be legitimately employed for the decomposition of waste substances like brush, weeds, dead animals, rags, leaves, and household refuse. The bacterial activities in it may be encouraged until the organic matter has lost its structure, and until its nitrogen has been changed into nitrate.

The loss of humus-forming material, and the accompanying losses of greater or slighter quantities of nitrogen are not of great significance. On the other hand, the organic matter in the manure must be considered more or less of an asset in the maintenance of the soil in proper mechanical condition. Its destruction in the manure pile is, therefore, not to be encouraged.

The statement made by Jethro Tull applies here. "For every sort of dung," he said, "the longer time it ferments without the ground, the less time it has to ferment in it, and the weaker its ferment will be." When the soil is properly supplied with moisture, the decay of organic matter will proceed rapidly enough. Moreover, nitrification in the soil will, as a rule, be less wasteful of the nitrogen than in the manure pile. When the manure 
is stored in well-compacted heaps, the initial fermentations may be useful in preparing the organic matter for more rapid decomposition in the soil. This will not involve extensive and, at the same time, costly losses of nitrogen.

The same cannot be said of more prolonged and more thorough decay of the stored manure when the latter is to be employed in general farming. The reduction of a very large heap of fresh manure to a very small heap of well-rotted manure, for the purpose of accumulating a material rich in nitrates, is scarcely an economical procedure. When at all advisable, it should find favor with the market-gardener rather than the general farmer.

Now and then conditions may arise such as to make it expedient, even in general farming, (i. e., in connection with very light, dry soils), to allow the decomposition of the organic matter and the nitrification of the organic nitrogen to go on in the manure heap rather than in the soil. Practical farmers have long been aware of this fact. From what has been said in a preceding chapter, it is evident that in the open, dry soils, the organic matter may be burned up, just as it is burned up in the earth closet, without the formation of nitrates and with the evolution of nitrogen gas.

Under such conditions, it is surely better to let the manure decay in the yard, and to apply to the soil the well-rotted material rich in nitrate. We may be certain, then, that at least a portion of the nitrogen in the manure is thus placed at the disposal of the crops in a readily available form. On the other hand, in the case of more 
compact soils, the latter may be made to act as compost heaps, and to transform both the organic matter and the nitrogen with the greatest degree of economy. It should be remembered, however, that this transformation in the soil itself may be unsatisfactory when acid conditions prevail, either on account of imperfect drainage or the use of ammonium sulfate in large quantities. A generous use of lime may be depended upon, in such cases, to correct the existing defects. 


\section{CHAPTER XXXI}

\section{CELLULOSE FERMENTATION}

Cellulose is a substance closely related to starch and sugar. It enters into the composition of the cellwalls of all plants and is familiar to us as a material resistant to decay. Wood, paper and straw are all rich in cellulose, while cotton and flax fiber, and, particularly, Swedish filter paper, contain it in almost pure form. When plant substances undergo decay, the cellulose usually resists the attacks of bacteria for a longer time than do the starches, sugars and proteids. However, under certain conditions, it máy be dissolved by microorganisms and converted into a mixture of gaseous and solid products.

Because of its inert nature, cellulose is not readily digested by animals. Foods rich in "crude fiber" possess, therefore, a lower degree of digestibility than foods with a small proportion of it. At the same time, herbivorous animals are, to a greater or less extent, endowed with the ability to digest cellulose, as was already observed by Haubner in 1855 . In 1875, it was announced by Popov that the marsh gas observed to issue from cesspools and swamps was derived from the fermentation of cellulose. This led to the suggestion that the marsh gas known to form a portion of the gases in the intestinal 
tract of herbivorous animals might also have its origin in the cellulose of the food.

Not long afterward it was demonstrated that the production of marsh gas in the animal system is due to certain microörganisms present in very large numbers in the large intestine and capable of setting up cellulose fermentation. This fermentation is accompanied by the formation of soluble substances assimilated by the animals, and also of gaseous products, including carbon dioxid and marsh gas. The cellulose ferments in the animal intestine may be thus regarded as a distinct aid in the digestive processes of their host.

The cellulose in the solid excreta and the litter undergoes further fermentation in the manure pile. Indeed, it has been pointed out that cellulose fermentation in the latter may be regarded as a continuation of the same process in the intestinal tract. In the interior of the heap, these processes proceed very rapidly, leading to the familiar crumbling of the woody material and the entire disappearance, under favorable conditions, of the coarse portions of the uneaten food and of the litter.

Gases in the manure pile.-The analysis of the gases in the manure pile shows that the destruction of the cellulose takes place largely in the deeper layers where the air is almost entirely excluded. Gases taken by Dehérain from different parts of the heap showed the following composition:

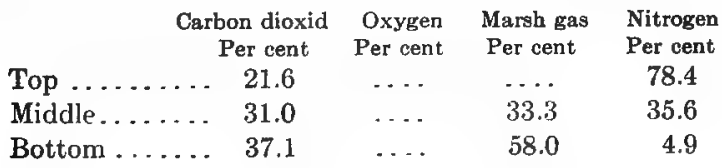


The greater proportion of carbon dioxid found toward the bottom of the heap may generally be readily accounted for by its comparatively high specific gravity and its tendency to sink down, but, more especially, by the greater amount of cellulose fermentation in the lower part of the heap. Similarly, the increase of marsh gas toward the bottom of the heap may be taken as a certain indication of the more intense cellulose fermentation taking place there. The accompanying decrease in the proportion of nitrogen indicates the more or less complete exclusion of atmospheric air.

The ferments.-From these facts it may be seen that the cellulose ferments are anaërobic. Confirmation of this is furnished by a series of observations extending throughout the latter half of the last century and crowned by the investigations of Omelianski, begun in the spring of 1894. Omelianski isolated in pure culture two distinct species of rod-shaped anaërobic ferments capable of gradually dissolving strips of Swedish filter paper. The two species, while closely resembling one another in appearance, were found to differ in their physiological activities. In the gaseous products formed by one of them, marsh-gas was present in large proportion, while, in the gaseous products of the other, hydrogen took the place of the marsh gas.

The two organisms.-the marsh gas (methane) ferment and the hydrogen ferment are widely scattered in nature and are met with in all soils, and at the bottom of ponds, lakes, rivers and canals. There they are concerned with the destruction of woody tissues under anaërobic conditions. Their work in the manure pile is 
important, for, by destroying the resistant cell-walls, they make accessible to other bacteria the nitrogenous and non-nitrogenous substances enclosed within the cell.

The anaërobic changes in the manure pile do not involve large losses of nitrogen, and the intense activity of the cellulose ferments cannot be regarded, therefore, as prejudicial to the economical transformation of the nitrogen compounds. For this reason, the manure, when kept moist and well compacted, goes through the initial stages of decomposition with large losses of organic matter, but with comparatively small losses of nitrogen.

Aërobic.-The decomposition of cellulose may also occur under aërobic conditions. Thus the destruction of fallen trees and twigs in the forest is accompanied by the initial softening of the wood, and its gradual crumbling to a fine powder. In this case, the work is done not by bacteria but by fungi. Later on, the work of the fungi is supplemented by that of bacteria until the woody tissue is completely destroyed. Besides the fungi, there are also a number of different species of aërobic bacteria that can attack and dissolve cellulose. Certain denitrifying bacteria are credited with this ability, and it is safe to assume that other cellulosedestroying aërobic organisms will be discovered in time. These organisms will be found, most likely, in dry, open soils, in which the humus disappears rapidly, or in the soil used in earth closets and in which the destruction of the organic matter is so rapid as to resemble purely chemical rather than physiological processes. 
LITTER, AND THE DEVELOPMENT OF BACTERIA IN MANURE

Materials like straw, wood-shavings, sawdust, peatmoss and dead leaves, used as litter, are not so readily decomposable as the solid and liquid excreta. Some of them, like peat and peat-moss, contain substances more or less injurious to the bacteria, and when present in large proportion may, for a time, check their growth. In consequence of this, the addition of litter to the animal excreta must necessarily affect the bacterial activities in the latter.

The influence thus produced is modified by both the chemical and the mechanical nature of the materials employed. For instance, finely cut straw is superior to coarse straw because it presents a larger surface and, therefore, absorbs more liquid and, at the same time, allows a better circulation of air in the manure pile. Again, dead leaves and pine needles make a poorer manure than straw. They are inferior in their ability to absorb liquids, do not favor the circulation of air in the manure pile to as great an extent, and do not decompose as readily in the soil.

Peat and peat-moss have a very high absorptive power and are, in this respect, superior to straw. On the other hand, they are quite resistant to decay on account of the acid substances and other products contained in them. When left to themselves they decompose very slowly, but when mixed with manure, their decay is hastened. In certain districts in Europe, they are held in high esteem, not only on account of their absorptive power, but, also, on account of their ability 
to hold fast the ammonia formed in the decomposition of the manure. They thus protect the manure from loss. It is customary in some localities to fill the gutters in the stables with fresh peat-moss and to allow'it to remain there until it had absorbed as much liquid as it will hold. Under the influence of the peat-moss, the urea and hippuric acid are not changed so rapidly into ammonium carbonate, nor does the latter escape so readily into the air:

Wood-shavings and sawdust are not readily decomposed by bacteria and, therefore, retard the decay of the manure to which they are added. Even in their case, no injurious effects are noted when they are applied in moderate amounts on clay and loam soils. Larger applications, especially on the lighter soils, seem to react unfavorably on the mechanical and bacteriological properties of the land. Under such conditions, it is better to allow more of the preliminary decomposition to occur in the manure pile than in the soil.

The activities of the cellulose ferments are thus intensified and the woody material sufficiently broken up to assure its more rapid and uniform decomposition in the soil without injury to the texture of the latter. A longer preliminary decomposition period has been found advantageous also in the case of peat and peatmoss. The more so, since peat is comparatively rich in nitrogen, which is rather inert in itself. However, when the peat is mixed with fermenting manure, the bacteria in the latter attack the inert nitrogen compounds and change them into forms more readily available to the crops. 


\section{CHAPTER XXXII}

\section{THE CONSERVATION OF MANURIAL CONSTITUENTS}

VARIOUS chemicals have been tried as a means to check the losses of nitrogen, and, to some extent, also, of the organic matter in manure.

\section{CHEMICAL METHODS}

Gypsum was thus employed almost a half a century ago, its probable usefulness having been indicated by purely theoretical considerations. It was thought that gypsum, which is a sulfate of lime, would react with the volatile ammonium carbonate in the manure and give rise to the more stable ammonium sulfate. Laboratory experiments on a small scale seemed to bear out this view, and gypsum, in a powdered state, was recommended for strewing in the manure.

Gypsum.-Subsequent experiments by several investigators proved, however, that the efficiency of gypsum as a conserver of nitrogen had been over-estimated. To be sure, small amounts of ammonia are really held back by the gypsum. It may also be said in its favor that it stimulates the growth of the nitrifying bacteria and leads, therefore, to a greater accumulation of nitrates in the manure. For all that, it should be remembered that the loss of nitrogen from manure is frequently 
due almost entirely to the escape of nitrogen gas, which gypsum is incapable of holding back.

Everything considered, therefore, it would scarcely be advisable to recommend the purchase and use of gypsum as a conserver of nitrogen. The value of the nitrogen saved would usually be smaller than the value of the material employed. Occasions may arise, of course, when the use of gypsum will prove profitable, as, for instance, in the vicinity of potteries, where broken gypsum molds may be had for the asking.

Burned lime, shell-lime and limestone.-Burned lime and finely ground shell-lime and limestone have also been tried as to their ability to conserve the nitrogen in manure. As to the first of these, it could hardly be expected to prove efficient in this direction. It is well known that quick lime has the ability to expel ammonia from its combinations, and in the manure it acts in a similar manner and intensifies the escape of this substance. Ground shell-lime, ground limestone, and calcareous marl are more mild in their action. They encourage decay and subsequently, also, nitrification, but they do not appear to decrease the loss of nitrogen. There is an indication, none the less, that further inquiry may enable us to utilize mild lime with more or less advantage if not in the conservation at least in the more rapid transformation of nitrogen in manure.

Superphosphate.-Superphosphate, like gypsum, has received much attention in experiments on the conservation of manure nitrogen. Superphosphate is made from phosphate rock or bone by treatment with sulfuric acid, the resulting products being gypsum, insoluble lime 
phosphate, reverted lime phosphate and water-soluble lime phosphate. The latter is the efficient material that unites with the ammonia formed in decay and prevents its escape. Under practical conditions, the use of superphosphate has not been found to be entirely satisfactory.

In order to save a large portion of the ammonia it becomes necessary to use considerable quantities of superphosphate so as to render the manure distinctly acid. Stutzer states that Pfeiffer used, in some of his experiments, a low-grade supherposphate at the rate of about one pound for each 1,000 pounds of live weight, and effected a considerable saving of ammonia in the fresh manure. But, after three months of storage, the manure that had received additions of superphosphate had lost more nitrogen than the untreated manure. In the long run, therefore, the application of acid phosphate did not prove of any advantage in the conservation of the manure nitrogen.

Kainit.-The superphosphate, when it proves efficacious at first, owes its conserving power to its acid reaction. The latter enables it not only to unite with the ammonia, but, also, to create conditions unfavorable to the rapid multiplication of the bacteria. More or less of the latter effect is also brought about by kainit and other crude potash salts that have been employed in the conservation of manure. When sufficiently large quantities of these salts are used, the bacteria in the manure are hindered in their development, or perhaps entirely suppressed for a time. They act, therefore, in the manner of preservatives, and, by retarding the bacterial activities, they diminish the losses of ammonia. 
Very large quantities of kainit are required to conserve the ammonia, for, even with 1 or 2 per cent of it in the manure, the losses are hardly reduced. Besides, when used in such proportion, the kainit is apt to injure the feet of the animals. To sum up, therefore, kainit and other crude potash salts, as well as common salt, cannot be regarded as efficient, within economical limits, in the conservation of manure nitrogen.

Sulfuric acid.-There is another substance which, among the many recommended for the purpose, has stood out rather prominently as a possible remedy against the undesirable bacterial activities in manure.

Sulfuric acid appears suitable for the purpose, sjince it is capable, not only of combining with the ammonia, but, also, of destroying the denitrifying bacteria. Yet there are evident objections to its use. It is a very corrosive substance, dangerous alike to the attendants and to the cattle, and injurious to the walls and floors of the building. Moreover, while the sulfuric acid destroys the undesirable bacteria in the manure, it also destroys those whose activities can not be dispensed with in the proper transformation of the manure and its constituents. It acts, in this case, as a preservative just as salicylic acid, formaldehyde, or benzoate of soda act in the preservation of food products.

When a sufficiently large quantity of the acid is employed, all of the ammonia already present in the manure is held fast, and the further development of the various bacteria that cause losses of ammonia or of nitrogen is either retarded or entirely stopped. Furthermore, the influence of the sulfuric acid is felt, not only in the 
manure heap, but also in the soil. The sour manure, even though thoroughly incorporated with the soil, does not decay as rapidly as similar manure not treated with acid. Its nitrogen becomes available more slowly, and the maturing of the crop is delayed.

When smaller quantities of sulfuric acid are employed, the losses of nitrogen from the manure pile are not materially reduced. The denitrifying bacteria in the manure itself may be injured to some extent, yet the manure scarcely loses any of its denitrifying power. This is not difficult to understand, in view of the fact already noted, that denitrification in the soil is caused by manure in virtue of the organic matter it supplies. In other words, in virtue of the food it provides for the denitrifying bacteria. The soil itself contains an abundance of the latter and the destruction of nitrates can be accomplished by them in the presence of excessive quantities of organic matter, such as is supplied in the manure.

Value of chemical methods.-The use of chemicals for the conservation of the organic matter, of the nitrogen, and of other constituents in the manure, has not given, on the whole, satisfactory results. The chemicals that are mild in their action, as gypsum, or small amounts of superphosphate, prevent, to some extent, the loss of ammonia by changing it to more stable combinations. They do not prevent, on the other hand, the loss of nitrogen in the free state. These losses are more serious than those due to the volatilization of ammonia. The chemicals more or less injurious to the bacteria, for example, large quantities of superphosphate, kainit, 
common salt, caustic lime, sulfuric acid, and hydrochloric acid, reduce the losses, but are found to be too costly when used in effective amounts. Frequently, they change the properties of the manure so as to interfere with its proper decomposition in the soil. After all, it should be remembered in this connection, that manure and other substances of organic origin are valuable to crops only in so far as they are susceptible to decay.

Manure that has been treated with large amounts of preservatives has been called pickled manure. It resists the activities of the decay bacteria. The plant-food locked up in it becomes inaccessible, for a time at least, to the crops growing in the field and garden. It should be remembered, further, that the bacterial activities are more intense in the manure than in the soil. These activities, when properly controlled, can be utilized to advantage in preparing the manure for more rapid and more uniform decomposition in the soil. When the manure is protected from leaching and kept moist and well compacted, the bacteria may be entrusted with the task of subjecting it to desirable preliminary transformations with a minimum loss of valuable manurial constituents.

\section{MECHANICAL METHODS}

Air, moisture, and temperature determine the extent and the nature of decay in manure. By the intelligent control of these factors, the wasteful changes may be largely eliminated without resort to chemical treatment. As has been stated before, well-compacted manure loses less nitrogen than loosely stored manure, a fact properly 
attributed to the exclusion of atmospheric oxygen. The surface of the manure pile is in contact with the atmosphere, even when the air is effectively excluded from the interior of the heap. It follows, then, that the larger the surface exposed to the atmosphere, the better the opportunities for aerrobic transformations in a portion of the manure. It follows, also, that a tall, conical heap of manure, or a flat heap with a rough, ridged surface, will offer better conditions for aerobic changes than a flat, heap with a smooth surface.

In the conservation of manure, therefore, advantage is taken of this circumstance in that the material is not only kept compacted, but its surface is kept smuoth. In order to make the exclusion of the air from the interior of the heap effective, trampling by heavy animals is more desirable than that by lighter animals. In some places, the process of compacting is accomplished by means of heavy rollers passed over the surface of the heap.

Effect of moisture.-The exclusion of air is further facilitated and the desirable bacterial changes favored by controlling the amount of moisture. An excess of water is to be avoided lest unlooked-for putrefactive processes come to predominate and the accumulation of sour substances take place. Careful observation will soon show the farmer the right proportion of moisture to be maintained in the manure. When the quantity of moisture in the manure becomes insufficient, it should be replenished either by the application of liquid manure or water. Liquid manure should not be applied in a thin stream, for the losses of ammonia may be markedly 
increased thereby. Similarly, the liquid manure should not be applied in very warm weather, since the rapid evaporation, under such circumstances, may lead to appreciable losses of nitrogen.

The temperature of the manure may be taken as a convenient indication of the extent of oxidation processes taking place in the heap. When the temperature of the manure pile does not rise appreciably, the aërobic processes are probably excluded, and the anaërobic processes predominate. On the other hand, a marked rise in temperature denotes active oxidation and corresponding development of the aërobic bacteria. A measurement of the temperature in the different portions of the manure pile may serve as a simple and convenient means for gauging the treatment the manure is to receive. Should the temperature be found to rise beyond a given limit, the necessity of compacting and of further additions of moisture will be indicated.

Preventing loss of ammonia.-Recent investigations have shown that the loss of ammonia from decomposing manure may be greatly reduced by spreading the fresh manure on a layer of older manure undergoing active decomposition. It seems that the carbon dioxid generated in large quantities in the older manure prevents the escape of the ammonia from the fresh portions without inhibiting, at the same time, the development of the bacteria. By proceeding in this way, the loss of nitrogen was reduced in the experiments at Lauchstädt, Germany, from 30.31 per cent to 16.94 per cent. The losses of organic matter were nearly. the same.

On the strength of these and other experiments, 
Schneidewind recommends that the manure produced on the farm be kept in pits or cellars, with cemented floors, and that the fresh manure have as a foundation a layer of older manure undergoing active decomposition. In a word, therefore, exclusion of air by composting, a proper proportion of moisture, and a supply of partly rotted manure as a foundation for the fresh manure may enable the farmer to control the decomposition processes, and to accomplish his end with a minimum loss of valuable constituents.

Such mechanical methods appear to be, at present, more efficient and more economical than the chemical methods already considered. It may be further said in their favor that they do not attempt to eliminate bacterial changes, but, rather, to control them so as to achieve the desired transformation with the least loss of plant-food. 


\section{PART VI}

\section{Bacteria in Milk and Related Products}

\section{CHAPTER XXXIII}

\section{MILK AS A FOOD}

At some remote period in the history of mankind, the shepherd made his appearance among the hunters and the fishermen. He was richer than his neighbors, for he possessed tame animals that followed him over the plains. He was more certain than were his brethren of an abundant supply of food. His possessions came to include, in time, sheep, goats, horned cattle, and other animals. Their flesh, their wool, their hides, and their bones furnished him food and materials for his garments, his tents, and his various implements. Many years must have passed, however, after the domestication of these animals, before the shepherd realized more fully that he could secure food from them without destroying them. The time came at last when he learned to know that the milk of these animals was an important food for him as well as for his children. Still later, his widening knowledge taught him that certain milk products are not as perishable as the milk itself. So cheese and butter were added to his list of foods. 
As modern times are approached, a steady improvement in the art of milk-production and treatment is noticeable. Progress in dairy husbandry was most marked in the production of different varieties of cheese, and some of the dairy industries then established still retain their prominence. But while there was undoubted progress in more than one direction in the seventeenth and eighteenth centuries, it was not until the nineteenth century that the true nature of the changes in milk was understood. The teachings of bacteriology revealed to us the relation of bacteria to the keeping quality of milk and made possible, thereby, a wonderful development of dairy methods. Sanitary production of milk, the significance of cleanliness in the barn and dairy, pasteurization and sterilization, the use of pure cultures in the ripening of cream, are well appreciated today, but were scarcely known a generation ago.

Milk a medium for bacterial development.-Because of its composition, milk offers an excellent medium for the development of all sorts of microörganisms. It contains sugar, a food constituent suitable for many bacteria; protein substances capable of serving as nourishment for a great number of species; and fats especially acceptable to various molds. Because of these substances, the bacteria that gain access to the milk multiply with extreme rapidity and cause chemical changes in its composition. Souring is but one of these changes. There are many others that may destroy its value as food, or may even lead to the accumulation in it of substances injurious to health.

Without bacteria or other microörganisms milk under- 
goes practically no change at all, and may be kept sweet and wholesome for almost an indefinite length of time. Similarly, under the same circumstances, milk with few bacteria will pass through undesirable changes less quickly than will milk with many bacteria. It was the recognition of these facts that has made possible the striking improvement in the methods of milk-production and distribution. It is the aim now of every progressive dairyman to secure milk that is as free from bacteria as is consistent with its economical production, and to treat it so as to suppress the multiplication of those that gain entrance in spite of his care. It is clear, thus, that it is highly important for the dairyman to know how bacteria may find their way into his milk. 


\section{CHAPTER XXXIV}

\section{SOURCE OF BACTERIA IN MILK}

THE milk secreted by the milk-glands of healthy cows contains no bacteria. But that drawn from the cow's udder is seldom entirely free from them.

Bacteria in the udder.-It has been demonstrated that bacteria from the outside may enter the opening of the teat and spread gradually in the milk-ducts. Once present in the latter, the invaders multiply rapidly under the favorable conditions as to food and temperature. In the process of milking, the organisms in the udder are largely removed with the milk. For this reason, the fore-milk contains a much greater proportion of bacteria than the strippings, even though the latter are not always sterile.

In a practical way, attempts are frequently made to improve the keeping quality of milk by removing the first portion into a separate vessel. The milk subsequently drawn is found to remain sweet for days,- sometimes for weeks. However, such milk is not always free from bacteria. Species other than those that cause the souring of milk may be present, and may cause, in time, undesirable changes.

Bacteria in the air.-The air above the earth always contains germs. The proximity and activities of human 
beings and of domestic animals increase the germ content of the atmosphere of barns and stables. Germ-free, or nearly germ-free milk can be secured more readily by milking the cows in the open. The milk drawn in the barn is almost always contaminated.

These facts are extremely instructive in showing, not only that the number of germs that may fall into the open milk pail or into the open can may be very large, but that they may prove of considerable significance in determining the keeping quality of the milk. It follows, therefore, that clean floors, clean walls, clean ceilings, and clean cows are essential for a small proportion of dirt and bacteria in the air in the barn. The cows should not be brushed or fed shortly before milking, nor should the barns be swept and bedding placed in the stalls at that time. Intelligent precaution thus taken will well repay the dairyman and will enable him to keep his milk sweet and pure for a longer time. Many thousands of bacteria that would otherwise fall into the milk pails and into the milk can, while the milk is being strained, may thus be kept out and undesirable decompositions and flavors excluded. Much of the subsequent value of the milk will depend on the proper observance of these precautions, for, once in the milk, the bacteria will multiply there very rapidly when the temperature is at all favorable.

Bacteria on the cow's body.-Many of the germs found in freshly drawn milk are derived from the cow's body. Minute particles of dried manure or bedding, hairs, and scales from the skin, as they fall into the milk pail, may each contribute various numbers and kinds 
of bacteria. Fraser has shown that the weight of dirt collected from under unwashed udders, while the milker went through the motions of milking for four and onehalf minutes, was three and one-half times as great as that collected under the same circumstance; from under the same udders that had been previously washed. The 158 exposures under unwashed udders showed, on the average, 578 colonies, while the same udders, previously. washed, led to the development of only about a third of that number.

These results are not at all surprising when we remember that a single gram of dirt collected on the cow's body may contain as many as $80,000,000$ germs. A single hair may contain hundreds of thousands of bacteria and, not infrequently, much greater numbers. Milk produced even in sanitary dairies is not always free from appreciable quantities of dirt which collects as sediment in the bottles. In the milk and cream contest held in Cleveland, Ohio, in March, 1907, only about one-third of the samples showed no sediment whatever. Yet there is reason to think that more than ordinary care was taken by the dairymen in the contest to produce clean milk. A large proportion of the sediment in milk is undoubtedly derived from the air; nevertheless, the body of the cow and the hands and garments of the milker contribute largely to it. This is particularly true of dairies where the cows are not kept clean and where the milkers pay scarcely any attention to personal cleanliness.

A microscopical examination by Grotenfelt of the dirt particles in unstrained, freshly drawn milk revealed the presence of the following substances: 
1. Manure-partieles (numerous).

2. Fodder-particles (had not passed through the alimentary canal of the animals).

3. Molds and other fungi.

4. Cow hair (numerous).

5. Particles of the skin.

6. Human hair.

7. Parts of insects.

8. Down from birds.

9. Small wooden pieces, snavings, and pleces of tir leaves.

10. Woolen threads.

11. Linen threads.

12. Soil particles (rather frequent) and moss particles.

13. Fine threads (most likely cobwebs).

The miscellaneous solid impurities that fall into the milk pail or milk can act as carriers of germs. Everything being equal, the greater the amount of dirt in the milk, the greater the numbers of bacteria present, and the less satisfactory the keeping quality of the milk. Sanitary dairies make proper allowance for this fact in that the animals are frequently cleaned, the floors and walls are not permitted to accumulate filth, and the udder of the cow is wiped with a moist cloth or sponge shortly before milking. By these means, the number of germs that may be detached from the cow's body during milking is reduced to a minimum.

The milker.-The hands and garments of the milker may add materially to the contamination of milk by bacteria. The human skin is naturally inhabited by large numbers of microörganisms. 'Those on the hands of the milker become detached in the process of milking and fall into the pail. The practice of milking with wet hands intensifies the contamination from this source 
to a very marked extent, for the germs are more readily washed off thereby from the hands as well as from the cow's udder.

Similarly, the garments of the milker may serve as a serious source of contamination, especially in ill-kept dairies where the milkers take no pains to keep their clothing clean. In fact, the garments set aside for the work in the barn are frequently indescribably filthy and weighed down by dried manure and other dirt. Moreover, the milker may occasionally contaminate the milk not only with lactic acid or other harmless bacteria, but, also, with disease germs, among them those of tuberculosis, typhoid and diphtheria.

Progressive dairies attempt to eliminate the milker as a source of contamination by compelling him to wash his hands, not only at the beginning of each milking, but, also, after the milking of individual cows. Clean milking-suits are supplied daily, and all care is taken to exclude those men from the barn who are suffering from any contagious disease. There is no doubt that the greater care for the health and appearance of the milkers in high-grade dairies is partly instrumental in enabling them to produce milk of high quality and to secure a high price for their products.

The utensils.-The thorough cleaning of milk pails is not a simple matter. Mere rinsing in luke-warm or even hot water is not sufficient to destroy the microörganisms in the creases of the pail, or even on the exposed portions. Investigations have shown that the slimy substances that accumulate in the creases of the pail may contain 500,000 to $50,000,000$ microörganisms per gram of 
material. These organisms survive readily in the moist crevices of improperly cleaned milk pails and are ready to multiply rapidly when fresh milk is poured into them.

It is quite certain that the so-called "milk faults," or "milk diseases," that occasionally prevail in dairies, may be traced directly to the survival of undesirable species in milk pails or other utensils. It is suggested, therefore, that in all sanitary dairies the milk pails, cans, and strainers be washed first with lukewarm water to avoid coagulating the albuminoid substances, thoroughly scrubbed with a good stiff brush, and then exposed to live steam. Such treatment will permit of very satisfactory cleansing, and the effective elimination of various germs.

Milking-machines.-With the introduction of the milking-machine, it was expected that the closed vessels employed would permit the reduction of the number. of bacteria in the freshly drawn milk. However, the comparative studies made by Stocking on machinedrawn and hand-drawn milk showed these expectations to be unjustified when no more than ordinary care was taken to clean the milking-machines. In one series of experiments, carried out in a dairy of average grade, the machine-drawn milk contained, on the average, 2,790,100 bacteria per cubic centimeter, while the hand-drawn milk contained, under the same conditions, an average of only 768,382 bacteria per cubic centimeter. Similar experiments in a high-grade dairy showed the machinedrawn milk to contain 172,958 bacteria per cubic centimeter, and the hand-drawn milk only 9,400 bacteria per cubic centimeter. 
It was thus evident that, while in the milk of the high-grade dairy the total number of bacteria was smaller, the hand-drawn milk was bacteriologically superior to the machine-drawn milk in both cases.

It was clear, also, that the method employed in cleaning the milking-machines-namely, rinsing with water containing some sal soda, and then washing with hot water,-was not adequate for eliminating the bacteria from the rubber tubes of the machines. On taking the rubber tubes and teat-cups apart, Stocking found the interior of the long tube to be coated with decaying milk. These tubes had become, therefore, nurseries for various germs, particularly the more resistant forms. The milk drawn through them naturally. became filled with bacteria.

Scalding the machines by means of boiling water pumped through them failed to achieve satisfactory results. Steaming at atmospheric pressure for a halfhour, or boiling the tubes in clean water for three quarters of an hour, was insufficient for their sterilization. On the other hand, the boiling of the tubes in a weak solution of borax, or their immersion in brine solutions for several hours, proved effective. After the brine treatment, the machine-drawn milk in Dairy 1 contained 327,412 and 153,629 bacteria per cubic centimeter, respectively, for the night and morning milking. 'The corresponding samples of hand-drawn milk contained 693,488 and 240,054 bacteria per cubic centimeter, respectively. In Dairy 2 , treatment with brine reduced the bacterial content of the machine-drawn milk to 2,444 per cubic centimeter, while the corresponding 
number of bacteria in the hand-drawn milk was 11,712 per cubic centimeter. Similarly, when the tubes had been boiled in a borax solution, the machine-drawn milk contained 506 bacteria per cubic centimeter, and the corresponding hand-drawn milk 1,090 per cubic centimeter.

These interesting experiments show strikingly that with the exercise of extreme care the milking-machines may prove an adequate means for the production of sanitary milk with good keeping quality. They demonstrate no less strikingly that in the ordinary dairy, and, for that matter, in the best of dairies, the milkingmachine may prove a detriment rather than an advantage to the production of high-grade milk. They again emphasize the fact that the elimination of bacteria from dairy utensils is a matter of some difficulty, calling for patience and intelligence on the part of the dairyman.

Milk-strainer.-The milk-strainer is often another prolific source of bacteria in milk. Apart from the dust particles that fall on the strainer from the air of the barn or dairy room, the dirt that gains access to the milk during milking may itself be retained by the strainer, while the germs adhering to it are washed into the milk. Grotenfelt states that by spreading soil on the strainer cloth and filtering milk through it, he found that the microörganisms originally present in the soil were washed off the soil particles and carried down into the milk. Similarly, hairs or particles of manure, carrying on their surface large numbers of bacteria, would be rinsed free of microörganisms by the milk poured upon them. The germ content of the milk is thereby materially increased, 
since a better distribution of the organisms is thus assured and their subsequent multiplication favored. It is desirable, therefore, to change the strainer cloth frequently, and to clean the strainer thoroughly.

Of the various strainers or strainer materials placed on the market, few can be said to be effective. On the whole, a strainer with four thicknesses of cheese-cloth will be found satisfactory enough; as will also cotton placed between two layers of cheese-cloth. Such strainers, intelligently cared for, will hold back a more or less considerable proportion of the bacteria in the milk, as well as the grosser particles of the various insoluble impurities. They will thus contribute to the improvement, not only in the general appearance of the milk, but, also, to the keeping quality of the latter. 


\section{CHAPTER XXXV}

\section{KINDS OF BACTERIA IN MILK}

MiLK may be contaminated by bacteria from the cow's udder, as well as by organisms from the soil, manure, bedding, air, water, milk utensils and the milker. Owing to these various sources of infection, the number of species found in milk, at one time or another, is large. However, the bacterial flora of freshly drawn milk soon begins to undergo a change. The struggle for existence that sets in, ends disastrously for many of the species originally present, and they either disappear entirely, or are crowded back so as to play but an insignificant rôle in the subsequent changes in the milk. The elimination or suppression of these species leaves the entire field to a comparatively few organisms,organisms that may be regarded as normal milk-bacteria.

Species of bacteria in milk.-The bacteria commonly occurring in milk may be conveniently divided into three groups.

The first of these includes the important lactic ferments, organisms capable of fermenting milk-sugar with the formation of lactic acid. The spontaneous souring of milk, with the characteristic curd formation, is due to these bacteria. They are prominently represented by 
Bacterium lactis acidi (B. Güntheri), a universally distributed organism which, more than any other, is responsible for the souring of milk at ordinary temperatures.

In all, the number of lactic-acid bacteria is considerable, some of them producing large quantities of other products besides the lactic acid. Mention may be made here of Bacillus coli communis, a common inhabitant of the intestinal tract of animals, and Bacillus aërogenes (B. lactis aërogenes), another organism widely distributed in nature. Bacillus coli communis most readily gains entrance into the milk with particles of manure; while Bacillus aërogenes may come from the manure, bedding, and food. The two organisms may prove a source of great annoyance in the dairy, especially Bacillus aërogenes, which occasionally causes much loss in cheesemaking.

The second group includes organisms that cannot cause the souring of milk, but possess the ability to curdle it by means of a rennet-like enzyme secreted by them. Many of these possess the ability, likewise, of digesting the coagulated casein by means of another pepsin-like enzyme, and of transforming the milk into a clear transparent fluid. This group includes, also, organisms that do not curdle the milk, but digest its casein slowly until the liquid becomes clear and transparent. We see, therefore, that the organisms of this group produce either one or both of the two enzymes. When the curdling is caused by them, the milk does not become sour, but shows an alkaline reaction, the process being designated as sweet curdling.

The members of this group are rather numerous and 
may find their way into the milk from various sources. The soil harbors not a few of them, and others are found in manure, in decaying vegetable and animal substances, in the water of streams and wells, and on the roots and stems of plants. They frequently gain access to the milk and multiply in it to a greater or slighter extent. Yet, under normal conditions, they seldom gain the upper hand and are forced by the lactic-acid bacteria to assume a secondary place.

The third group is composed of bacteria that cause neither the acid nor sweet curdling of milk, nor do they produce casein-digesting enzymes. Under certain conditions, they may apparently multiply in the milk to very considerable numbers without producing any marked change in its taste or appearance. Occasionally, some of these species find lodgment in the cow's udder, and occur thus in large numbers in freshly drawn milk. However, like the members of the preceding group, they are rapidly crowded back by the lacticacid bacteria and do not play a prominent part in the subsequent changes which the milk undergoes.

Lactic-acid bacteria.-The composition of the milk is peculiarly favorable for the rapid growth of the lacticacid bacteria. No matter what the initial contamination may be, the latter are almost always certain to make their appearance and to cause those changes that lead to the suppression of the organisms of the second and third groups, as well as of others not included in them.

The powerful weapon possessed by the lactic-acid bacteria for the crowding back of other species consists 
of their ability to form lactic acid which rapidly accumulates in the milk and thereby creates conditions unfavorable for the development of the other organisms. The acid thus accumulated causes the precipitation of the casein; in other words, the curdling of the milk. The same may be accomplished by the addition of vinegar (acetic acid), or of other mineral or organic acids.

It was formerly thought that the lactic-acid bacteria did not produce rennet-like or pepsin-like enzymes, and that the curdling of milk caused by them was accomplished merely by the presence of the lactic acid. Boekhout and de Vries have shown, however, that lacticacid organisms exist which can secrete the two enzymes. They described an interesting organism isolated by them from a sample of cheddar cheese made in New York state, and demonstrated that while producing lactic acid it secretes a milk-coagulating enzyme as well as a casein-digesting enzyme. This fact is of particular interest in its possible bearing on the rôle of lactic-acid bacteria in the ripening of cheese.

The normal changes in milk are dependent upon the rapid development of the acid-forming species which continue to increase until their predominance is clearly established. Considerable variations exist even among different strains of the same species of lactic-acid bacteria in so far as their power of souring milk is concerned. For instance, $B$. lactis acidi from different sources has been found to show very considerable variations, moreover, the power of producing acid in milk could be increased or decreased by cultivation in different media and under different conditions. Aside from the vigor 
of the bacteria, the rate of souring is also affected by the temperature at which the milk is kept.

These facts show, then, that different lactic-acid organisms may be prominent at different temperatures. It may be likewise noted in this connection that the supply of air also helps to determine the predominance of one or another of the lactic-acid species. For example, $B$. lactis acidi will grow where air is freely supplied, whereas Bacillus casei $E$ will grow best where the air is excluded.

Notwithstanding the crowding out of the non-acid species by the lactic-acid bacteria in milk undergoing a normal transformation, the former are of some importance in influencing the rate of souring. It has been shown by Marshall that certain of these organisms, though themselves incapable of producing acid, encourage, to a very marked degree, its formation by the lacticacid bacteria. Moreover, when such non-acid bacteria are allowed to grow in the milk for some time, and the latter is then sterilized and again inoculated with a pure culture of a lactic-acid bacterium, the formation of lactic acid will proceed more rapialy than in a similar portion of milk in which the non-acid bacteria have not been allowed to grow previously.

The spontaneous souring of milk is not, therefore, as simple a process as is commonly supposed. Prominent as are the lactic-acid bacteria in such transformations, still they are encouraged in their development by the numerically unimportant non-acid species that probably prove serviceable in splitting the complex nitrogenous substances of the milk. It is likely that the 
activities of the lactic-acid organisms are enhanced by the accompanying non-acid species in other ways. It has been found for Bacillus casei $E$, that aërobic bacteria promote its development and hasten the souring of milk by using up the oxygen in the liquid. Anaërobic conditions suitable for this organism are thus produced.

\section{MILK FAULTS}

When organisms other than the lactic-acid bacteria, or even certain of the less common lactic-acid bacteria, gain the upper hand in the milk, changes may occur that render the milk unattractive in appearance, unpleasant to the taste or smell, or even dangerous to health when consumed in larger quantities. Such abnormal changes in milk are known as milk faults, or milk diseases. Milk faults, well known in olden times, were then more common than they are today because of the less adequate means for cleaning and disinfection. Blue milk, bitter milk, slimy or ropy milk, red milk, and many other kinds, frequently caused much annoyance in dairies. Unfortunately, some of them occur, but too frequently at present.

Blue milk.-This was the first of the milk diseases to be studied carefully. Its bacterial origin was suspected before the middle of the last century. It is manifested usually in warm weather, within one to three days after the milk is drawn, by the appearance of bluish spots on the surface and their gradual spread until the entire surface assumes a blue color varying in intensity. The organism producing this fault has been isolated 
in pure culture and is designated as Bacillus cyanogenus. It is a rod-shaped organism, a pronounced aërobe, and is entirely harmless to human beings. It. grows readily in milk as well as on potatoes, boiled rice, and vegetable casein. Being susceptible to acid conditions, this organism will not develop in sour milk. The pigment produced by it is readily soluble and diffusible, so that, notwithstanding
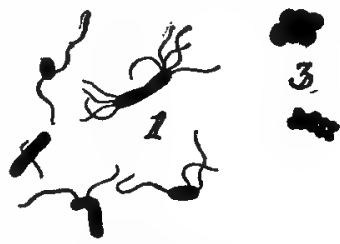

Fig. 59. Bacteria producing milk faults.-1. Bacillus cyanogenus (bacillus of blue milk); $\times 2,600$. (Hinterberger.) 2. Bacillus lactorubefaciens (red milk); $\times 2,000$. (Gruber.) 3. Coccuslactis viscosi (ropy milk); $\times 2,600$. (Gruber.)

the restriction of the bacterial growth to the surface, the coloring matter may become diffused throughout the liquid.

In the presence of other organisms, the characteristic blue pigment may be partly or entirely obscured, although the other changes produced by Bacillus cyanogenus may still remain prominent. Instances are recorded in which the milk fault caused by this organism persisted for years in certain localities. Its elimination was finally effected either by the thorough cleaning of the utensils and premises, or by the inoculation of the fresh milk with sour milk containing vast numbers of the normal lactic-acid bacteria.

Red milk.-The red coloration that gradually develops after milk is drawn may be produced by one of several microörganisms. Bacterium prodigiosum and Bacillus lactis erythrogenes are more prominent than 
the others in this connection. Bacterium prodigiosum grows best at about $75^{\circ}$ Fahr., and develops readily on bread, boiled vegetables and boiled meat. The red coloration of milk, as due to these organisms, is of minor significance, for it occurs only on milk that is some days old, and then very rarely. The same may be said of other bacterial colorations, such as various shades of yellow and green.

Bitter milk.-So-called bitter milk is another of the milk faults occasionally forced upon the attention of the dairyman. It may develop in pasteurized or sterilized milk, and is due then to spore-forming anaërobic ferments. At other times, it may be due to aërobic organisms developing in either raw or boiled milk. The bitter taste thus produced is probably caused by certain decomposition products of the casein.

Ropy milk.-Slimy or ropy milk, as produced by the activities of bacteria, is quite distinct from the ropy or stringy milk that has its origin in diseased udders. When of bacterial origin, the milk fault develops gradually in milk that is in every way normal when freshly drawn. In twelve to thirty hours, the milk becomes viscid and may be drawn out in long threads.

The list of organisms capable of producing sliminess or ropiness in milk is fairly long. One of them, first isolated by Adametz and called by him Bacillus, lactis viscosus, is peculiar in that it can grow well at temperatures of $45^{\circ}$ to $50^{\circ} \mathrm{Fahr}$, when the common milk bacteria are dormant. After ropy milk has once appeared in a vessel of milk, a fruitful source of future trouble is occasioned by careless scalding of the vessel when it is 
washed. The organism of ropy milk is frequently present in water, and the latter may, therefore, become the source of this milk fault.

Ropy milk is harmless to those who consume it. In some localities, the ropy-milk bacteria are even encouraged in their development, and the products of their activities prized for their palatability. It is stated that ropy whey is successfully utilized in Holland in the preparation of Edam cheese. In Scandinavia, ropy milk is artificially prepared by the rubbing of the interior of milk vessels with the leaves of butter-wort, a plant that harbors large numbers of ropy-milk bacteria.

The cause of the ropiness is apparently not the same for the different species producing this milk fault. It is believed that some of the organisms make the viscous substances out of the milk-sugar. This view is borne out by experiments in which pure cultures of such bacteria were found capable of producing viscosity in solutions of various sugars. Other species undoubtedly bring about a ropy condition of the milk by causing the decomposition of its nitrogenous substances, while still others, by means of the mucilaginous sheaths surrounding the bacterial cells, produce the same effect. 


\section{CHAPTER XXXVI}

\section{MILK BEVERAGES}

ThE preparation of alcoholic beverages is dependent upon the fermentation of sugar by yeasts. It follows, therefore, that if the sugar in milk could be attacked by yeasts, the milk would be transformed into an alcoholic beverage. As a matter, of fact, milk-sugar is not readily fermented by yeasts as is cane-sugar. Besides, the milkbacteria, and, particularly, the lactic-acid bacteria, seem to exclude the yeasts to a great extent, so that no alcoholic fermentation takes place in it. Nevertheless, there are conditions under which lactic acid and other bacteria seem to work in harmony with yeasts and lead to the accumulation in milk of both lactic acid and of alcohol. A number of different beverages, namely, kefir, kumiss and matzoon, that are thus prepared from milk, are highly esteemed in some countries and are even recommended for invalids.

Kefir.-This beverage, which first became known in Asia, is made now in Europe and America also. It is prepared from cow's milk by means of so-called kefir grains, yellowish, hard, rather irregular masses that have been used from time immemorial in the Caucasus, and whose origin is shrouded in mystery. The kefir grains are first immersed in lukewarm water and after- 
wards, when softened, they are placed in a small quantity of milk. The milk is occasionally stirred, poured into bottles at the end of twenty-four hours, and in two or three days is ready for use. The kefir thus prepared has a pleasant acid taste and contains, also, small quantities of alcohol.
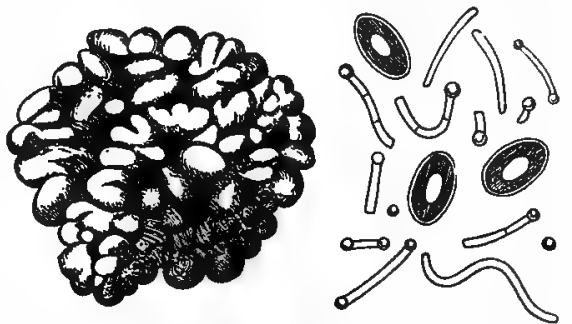

Fig. 60. Kefir grains, and microörganisms of kefir. (After Freudenreich.)

Microscopical examination shows the kefir grains to consist of yeasts and bacteria. There is in them, besides ordinary beer yeast, a bacterial species at one time called Diaspora caucasica. It is thought that the yeast found in kefir is not capable of fermenting the milksugar directly, but that the alcohol is made by it out of the milk-sugar, with the aid of the lactic-acid bacteria. We must conclude, therefore, that the microörganisms of the kefir grains represent another instance of associative action.

Kumiss.-Kumiss is another milk beverage very popular among the Mongolian peoples of Siberia and Central Asia. It is prepared by the addition of yeast to mare's or camel's milk kept in wooden vessels. Both lactic acid and alcohol are formed in the milk, the beverage being ready for consumption in two or three days. The exact nature of the changes occurring in the making of kumiss is not known. It is likely, however, that, as in the case of kefir, lactic-acid bacteria are prominent, 
not only in the formation of lactic acid, but, also, in changing the milk-sugar so that it may become fermentable to the yeast cells. In this country, kumiss is readily prepared by the addition to cow's milk of a quantity of cane-sugar and of ordinary beer yeast. The cane-sugar is then caused by the yeast to undergo fermentation, while the milk-sugar is changed into lactic acid by bacteria.

Matzoon.-Matzoon is a milk beverage of Armenian

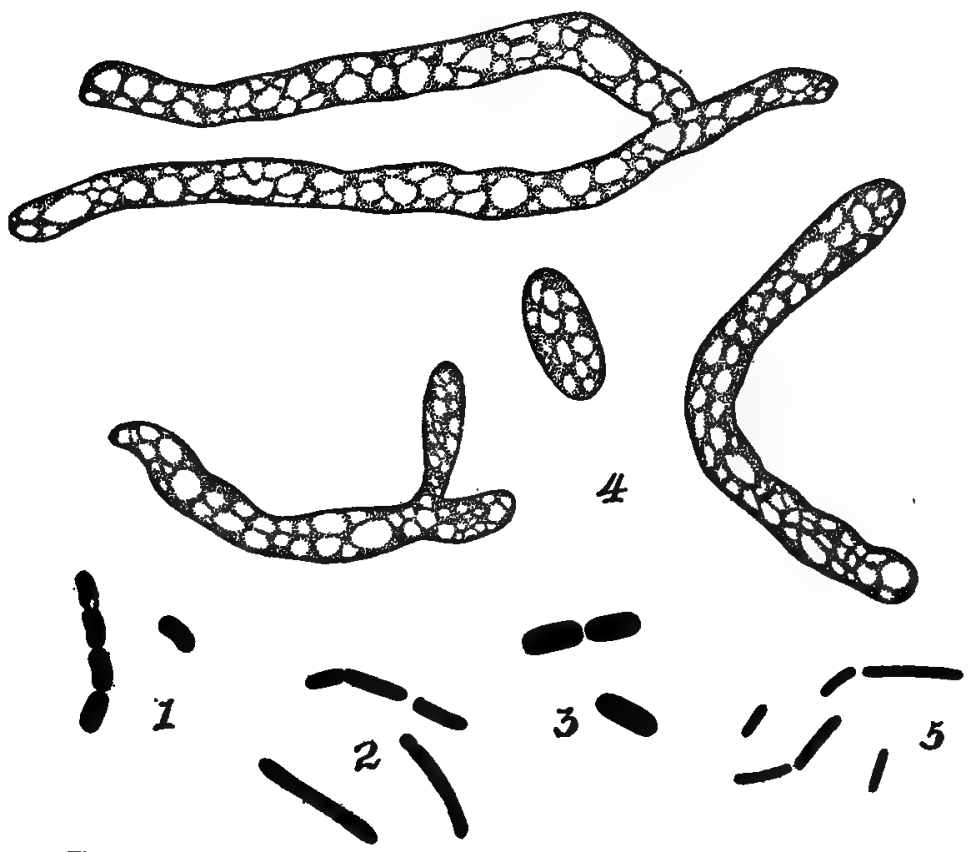

Fig. 61. Microörganisms of Armenian matzoon. (After Weigmann, Gruber and Huss.) 
origin. Both the fermented milk and the curd made from it are used as foods. The microörganisms of matzoon were investigated by Emmerling and Kalantarjanz, who found them to consist of a mixture of yeast and bacteria. Other investigators found that Saccharomyces Pastorianus, one of the yeasts present in matzoon, when inoculated into sterile skim-milk, caused the fermentation of the milk-sugar and the formation of alcohol. It produced, likewise, an agreeable fruit-like aroma that persisted even when the yeast grew together with the other microörganisms isolated from matzoon. Another organism prominent in the preparation of matzoon is Bacterium mazun, a pronounced lactic-acid ferment capable of producing such large quantities of acid as to make the milk too sour for use. Bacterium mazun was found to be accompanied by other lactic bacteria, among them, $B$. lactis acidi.

It is stated that, on account of the vigorous flora of matzoon and the desirable aroma produced by it in milk, it is utilized by the natives of Armenia for the preparation of butter. Laboratory experiments, carried out in Europe with the microörganisms isolated from matzoon, do not indicate, however, that they can be employed to advantage in the making of starters for cream ripening. This is true, particularly, of Bacterium mazun, noted for its acid-producing power. 


\section{CHAPTER XXXYII}

\section{THE KEEPING QUALITY OF MILK}

A count of the bacteria in fresh milk, compared with one made a few hours later, will frequently show that the organisms have decreased in number. The decrease is most pronounced at $70^{\circ} \mathrm{Fahr}$., although the subsequent multiplication of the bacteria at this temperature is more rapid than that at lower temperatures. The examination of fifteen samples of milk from different cows gave the following results:

Number of Bacteria in $1 \mathrm{cc}$. OF Milk

\begin{tabular}{|c|c|c|c|}
\hline Freshly drawn & $\begin{array}{c}40^{\circ} \text { Fahr. } \\
6,759\end{array}$ & $\begin{array}{c}55^{\circ} \text { Fahr. } \\
6,759\end{array}$ & $\begin{array}{c}70^{\circ} \text { Fahr. } \\
6,759\end{array}$ \\
\hline After three hours.... & 5,988 & 5,241 & 4,200 \\
\hline After six hours......... & 5,417 & 5,143 & 3,411 \\
\hline After nine hours... & 5,929 & 5,311 & 3,947 \\
\hline After twelve hours....... & 5,188 & 5,370 & 6,341 \\
\hline After fifteen hours...... & 5,531 & 5,052 & 23,495 \\
\hline After twenty-four hours.. & 5,174 & 4,872 & 589,980 \\
\hline After thirty-two hours. & 5,067 & 5,399 & \\
\hline After forty-eight hours ... & 4,917 & 18,663 & \\
\hline
\end{tabular}

The so-called germicidal power.-A decrease in numbers evidently occurred in every case. The diminished number of bacteria in the fresh milk may be accounted for by assuming that milk, as it is drawn from the cow's udder, possesses a germicidal property that is 
most intense at $70^{\circ}$, but which endures longer at lower temperatures.

The decrease may also be assigned to the dropping out of the bacteria unsuited to their surroundings rather than to any germicidal property in the milk. Although the total number of bacteria suffers a decrease, the latter falls on the non-acid bacteria, rather than on the lactic-acid bacteria.

Whatever explanation we accept for the decrease in the numbers of bacteria in fresh milk for some hours after it is drawn, the fact is indubitable that the decrease does occur. On the whole, however, the decrease is not uniform, and of comparatively short duration. No reliance, therefore, can be placed on it as a natural means for increasing the keeping quality of milk. It is rather the low temperatures on which we must depend for retaining the milk wholesome for more or less considerable lengths of time. Since some of the organisms begin to multiply as soon as they enter the milk, and since a single hour of this initial multiplication may mean much in determining the keeping quality of the milk, it follows that milk should be cooled at once rather than allowed to cool gradually.

Temperature.-In some, experiments reported by Conn, the influence of temperature is shown to be paramount in determining the keeping quality of milk. In a portion of milk kept at $50^{\circ} \mathrm{Fahr}$., the bacteria multiplied only fivefold in twenty-four hours, whereas, in a similar portion of milk kept at $70^{\circ} \mathrm{Fahr}$, the increase was seven hundred and fifty fold.

"Sometimes it is found possible to keep the milk 
much longer by the simple precaution of cooling it quickly and keeping it at a temperature below $50^{\circ}$. Milk has been kept for two weeks and over without curdling and without becoming noticeably injured by the action of bacteria. If a temperature lower than this-in the vicinity of $40^{\circ}$, or below-be maintained, the milk can be kept for an even longer period. The value of these facts to dairymen is clear. They show that, in the keeping of milk, the maintenance of a low temperature is a factor of more significance than any other factor connected with dairying."

Different species of bacteria may become prominent in milk at different temperatures. At $95^{\circ}, B$. lactis aërogenes develops more vigorously than any of the other lactic-acid bacteria. At $70^{\circ}$, the lactic-acid organism that is most prominent is $B$. lactis acidi, an organism that, unlike the other, causes the gradual souring of milk, without the formation of gas and without the production of unpleasant tastes. At $50^{\circ}$, neither of the two lactic-acid organisms develops. Instead, there appear various kinds of bacteria that produce undesirable changes, some of them partaking of the nature of putrefaction. At this temperature, therefore, the milk may outwardly remain sweet and wholesome, and yet be filled with millions of bacteria and the unwholesome or even dangerous products of their activity. The cooling of the milk at once, and the constant maintenance of temperatures of $50^{\circ}$ Fahr., or less, will safeguard the dairyman against loss, and will permit him to supply to the consumer milk of superior keeping quality. 
MEANS FOR IMPROVING THE KEEPING QUALITY OF MILK

Any precautions that will facilitate the exclusion of dirt from fresh milk will necessarily contribute also to its keeping quality. Such precautions will include the frequent removal of the manure from the barn, the daily cleaning of the floors, the whitewashing of the walls and ceilings, the currying of the animals, personal cleanliness on the part of the milkers, and thorough cleaning of the milk pails and other utensils. Mere washing with hot water and soap is not sufficient for the removal of the bacteria from the pails, cans, strainers and milk tubes. Live steam is the cheapest and most efficient means for the destruction of the milk bacteria. When live steam is objectionable on account of injury: to the rubber tubes and other parts, antiseptics, like borax, or concentrated brine solutions should be employed.

Careful attention should be given, likewise, to the reduction of the number of bacteria in the air of the barn. It is evident that the fewer the number of microorganisms in the atmosphere surrounding the milker, the fewer will be the number that will fall into the milk during the process of milking. Hay, feed, and bedding should not be distributed in the barn shortly before milking, nor should any unnecessary commotion be allowed. Good ventilation in the barns should be provided for, since the more frequent the admission of germ-poor air from the outside, the more effective the crowding out of the germ-rich barn air. But with all the reasonable care for maintaining the atmosphere of the 
barn comparatively free from bacteria, more or less considerable numbers of them will still remain suspended in the air, and will fall into the milk at the first favorable opportunity. It will be seen that much will depend on the character of the farm.

It is self-evident that the larger the surface of the milk exposed, the greater will be the number of bacteria to fall into it in a given time. This circumstance has therefore, stimulated attempts to eliminate, as far as possible, the exposure of the milk to the air. With thorough care in the cleaning of the various parts of the milking-machine, the germ content of freshly drawn milk may be materially diminished. Not only is it necessary to clean the parts of the machine very thoroughly, but, also, to free the air entering it from bacteria by means of cotton placed in the tubes. With such precautions observed, the milk drawn by the machine is much superior to that drawn by hand; in fact, in some instances, it is almost germ-free. It will be seen, therefore, how much depends on the operator.

These excellent results cannot be secured, however, until all the rubber tubes are placed, after thorough washing, in a 3.5 per cent solution of formalin, and the air entering the machine drawn through a layer of cotton. When these precautions are not observed, the germ content of the machine-drawn milk is generally higher than that of the hand-drawn milk. In fact, it has been demonstrated that the thorough sterilization of the rubber tubes by formalin is not sufficient for making the germ content of the machine-drawn milk lower than that of the hand-drawn milk. The cotton 
filters are evidently indispensable for retaining most of the bacteria present in the stable air.

In milk drawn by hand, the germ content may be materially diminished and the keeping quality increased by the use of pails with small openings. In clean stables and with clean cows, the improvement in the keeping quality of the milk is not proportionately as marked as it is in filthy stables. This, of course, is what one would expect.

It becomes important to determine how a comparatively slight initial contamination of the milk produced in clean dairies may be made to interfere as little as possible with the keeping quality of the product. There are methods now by means of which milk may be freed from all, or a part, of its living bacteria. These have all been tested practically or experimentally. They include the subjecting of milk to centrifugal force; its pasteurization or sterilization by means of heat; and its partial or eomplete sterilization by means of chemicals.

Pressure.-Pressures of one to four tons to the square inch have failed to improve materially the keeping quality of milk. Pressures of ten to fifteen tons exerted through a period of several days, have given much better results, although the disease germs introduced into the samples were not all destroyed. The effect of pressure has been studied throughout a range of 200,000 pounds to the square inch. It has been found that some of the germs survived them all.

Milk kept under pressure in an atmosphere of carbon dioxid has been found to remain sweet for weeks, in 
some instances, while other samples from the same lot, kept under ordinary conditions, turned sour in a few days. While carbon dioxid, under pressure, retards the development of the bacteria, and particularly of the lacticacid bacteria, it does not destroy them. In one series of experiments, milk was kept for some hours under a pressure of fifty atmospheres of carbon dioxid, at the end of which time the organisms were found capable of growth when the pressure was removed.

Centrifugal force.-When subjected to centrifugal force, milk may be deprived of the heavier particles of dirt and, to some extent, also, of the smaller particles including the bacteria. It has been suggested, therefore, that cream separators, run at a low speed might prove useful for removing bacteria from milk, and for improving its keeping quality.

The investigations made in this connection have demonstrated that a portion of the solid impurities in milk can be thus removed. They have shown, at the same time, that the number of bacteria in milk is either slightly or not at all diminished by this treatment, and that the keeping quality is scarcely improved. The expense and labor involved, as well as the partial separation of the cream when excessive speed is used, together with the slight benefits derived, may, therefore, be urged as serious objections against the use of the centrifuge for this purpose.

Sterilization by heat.- Theoretically, the most effective means for the destruction of bacteria in milk would be its boiling for some time. It is well known that all bacteria that do not produce spores are readily killed 
by temperatures of from $150^{\circ}$ to $160^{\circ}$ Fahr. On the other hand, the spore-bearing organisms are not thus destroyed, even at higher temperatures, and prolonged boiling becomes necessary for their destruction. When pressure and high temperatures are combined, the most resistant spores can be killed in a comparatively short time, as is done, for instance, in the autoclave at 1.5 to 2.0 atmospheres of pressure. Milk sterilized in this manner, and protected against fresh infection, will remain unchanged for an indefinite length of time. But a very serious objection is raised against such treatment in that milk thus sterilized is really boiled milk and, as such, is not likely to be acceptable to the consumer.

Pasteurization.-In order to meet this objection, it becomes necessary to heat the milk to a point below that at which the cooked taste becomes perceptible. Such heating possesses no value if inadequate for the destruction of the objectionable bacteria. Extensive experiments have been carried on, therefore, to determine, on one hand, the limit to which milk may be safely heated without producing a distinctly cooked taste, and, on the other, the effect of different temperatures on the various organisms frequently or occasionally occurring in milk.

The results secured by investigators in different countries show that temperatures of $155^{\circ}$ to $160^{\circ}$ Fahr. should not be exceeded in the heating of milk. They show, also, that the bacillus of tuberculosis, regarded as the most resistant of the non-spore-forming disease bacteria, may be killed by exposure to a temperature of 
$140^{\circ} \mathrm{Fahr}$., for fifteen to twenty minutes, or in a shorter time at higher temperatures; occasionally a few of the tubercle-bacteria survive this treatment, but even these are rendered less virulent.

In view of these facts, the heating of milk at $150^{\circ}$ to $160^{\circ} \mathrm{Fahr}$., is extensively resorted to as effective for the destruction of the germs of diphtheria, typhoid and tuberculosis. The process is known as pasteurization, after the eminent French chemist and biologist, Pasteur, who first recommended the method for ridding wine of certain germs that multiplied in it and injured its quality.

When properly carried out, pasteurization reduces the germ content of milk from many thousands or even millions, to a few hundreds or less. Herein lie the advantages and disadvantages of pasteurization, as will be seen from the following considerations: Under normal conditions, milk gradually turns sour on account of the rapid development in it of the lactic-acid bacteria, and the accumulation of lactic acid. The lactic-acid bacteria find no difficulty in crowding out the other forms, and, while the souring of milk is, in itself, objectionable to the dairyman and the consumer, it is, none the less, a protection against the growth of other germs whose products may not be as harmless.

The lactic-acid bacteria do not produce spores, and are all destroyed in the process of pasteurization. The spore-bearing decay bacteria are now given a free field, and, when the temperature conditions are favorable, they multiply rapidly and produce unpleasant tastes and odors in the milk. The substances thus produced 
from the casein and albumin may prove more or less harmful, and, at times, decidedly poisonous.

Although pasteurized milk cannot always be regarded as wholesome, it can be made a valuable aid in the supply of good milk to the city populations. The disease bacteria are destroyed in the process and the intestinal diseases among children are materially reduced in consequence. Moreover, the keeping quality of the milk is improved, a point of vast significance in the great cities where the milk is frequently twenty-four to thirtysix hours old when it reaches the dealer.

The conclusion to be drawn from this and similar experiments is that pasteurization is effective for the destruction. of disease bacteria in milk and for the improvement of its keeping quality. It is agreed that city children fed on pasteurized milk, properly heated and properly cooled, are less subject to intestinal disturbances than children fed on raw milk. At the same time it must be admitted that the pasteurization of milk already filled with bacteria, and the products of their activities, will not remedy its defects. The undesirable substances formed by the bacteria are not entirely destroyed by the heating and may still cause injury to the person consuming the milk.

By resorting to pasteurization, a dealer may be able to dispose of milk that would otherwise quickly become unsalable. Similarly, the failure to cool the pasteurized milk quickly, and to keep it at a temperature of $50^{\circ}$, or below that, may lead to the rapid multiplication in the milk of germs producing injurious or poisonous substances. Hence, pasteurized milk should be consumed 
within twelve hours, or should be immediately cooled down to between $45^{\circ}$ and $50^{\circ}$. The intelligent use of pasteurizing apparatus, and the intelligent treatment of the milk subsequent to pasteurization, can not but prove a decided benefit to all city populations, and, particularly to those whose sources of supply are distant.

Treatment with chemicals.-Substances like borax, boric acid, hydrogen peroxide, salicylic acid, benzoate of soda, sodium sulfite, common salt, saltpeter and formalin have been used for retarding the decomposition of foods. It was believed that, unlike the more violent poisons, such as corrosive sublimate and carbolic acid, these materials could be used in small amounts without marked injury to the health of the people consuming the food thus treated. The use of common salt and of saltpeter for pickling vegetables, fish, or meat products, is of ancient origin. These substances are not generally regarded as particularly injurious, even when they are consumed in comparatively large quantities.

State and féderal regulations prohibit, however, the use of antiseptics and preservatives in food products except under certain specified limitations. The usse of preservatives in milk is not allowed at all, it being reconnized thatt, whatever difference of opinion may exist concerning their use in small quantities in other foods, their presence in milk would be a source of grave dănger to chíldren.

Recent investigations indicate that hydrogen peroxide and formaldehyde can be employed in quantities small 
enough not to interfere with the digestive processes, yet large enough to hinder the multiplication of bacteria in milk. It has been found that market milk that will ordinarily sour in twenty-four to twenty-eight hours, will remain uncurdled at the same temperature for fortyeight to seventy-two hours when treated with formaldehyde at the rate of one part to 40,000 parts of milk.

Since the experimental evidence at present available gives us no reason to think that formaldehyde in this proportion will prove injurious even to young children, it follows that, under certain conditions, its use may be found justifiable. A number of authorities state that formaldehyde, employed in the proportion of one to 40,000 , or even in somewhat larger proportion, does not affect the action of the digestive ferments, nor does it decrease the digestibility of the food used.

They show, likewise, that the addition of formaldehyde, in the proportion indicated, to milk, retards the growth of the bacteria, but that the retarding effect is not the same in the case of the different species. It appears that the harmless lactic-acid bacteria are comparatively resistant to the action of the formaldehyde, as was evidenced in the samples in which the proportion of formaldehyde was one to 5,000 , or one to 10,000. The law should not allow the use of formaldehyde, of hydrogen peroxide, or of other preservatives in milk even within supposedly safe limits, lest some one be tempted to employ larger amounts. Then, too, the addition of preservatives, even in quantities otherwise permissible, would tend to encourage slovenly methods in the production and handling of milk. 
The milk-producer in the country is bound by ties of common interest to the milk-consumer in the city. In proportion as the milk sold in the city is clean and wholesome, the demand for it is increasing. The intelligent consumer is willing to pay a higher price for high-grade milk. It is in the interest of the milk-producer, therefore, to supply milk of good quality.

The campaign in the interest of sanitation that is now conducted in every progressive city, and the higher standard of education and intelligence among the dairy farmers, have been responsible for a clearer understanding of the problems of milk-transportation and milkdistribution. The farmers of the East, of the Middle West and of the West, appreciate, much better than do the farmers of the South and of the Southwest, that the keeping quality of milk, and its wholesomeness, are determined largely by the rapidity with which milk is cooled after its removal from the barn.

Milk-producers have been taught that, aside from cleanliness in production, it is essential that the milk be cooled at once to $50^{\circ} \mathrm{Fahr}$., or below that if practicable. Hence, we see that some of the milk sold in New York City, and carried for 350 to 400 miles before it reaches its destination, is as good or better than much of the milk sold in southern cities, and carried but three or four miles before it reaches its destination.

The milk-dealers and sanitarians constantly emphasize the fact that milk must not only be cooled, but that it must be kept cool until it is delivered to the consumer. 
Hence, we see that, in the hills of Pennsylvania and of New York, the spring-water, once considered ample for keeping the milk cool, is reinforced by ice. On the level plains, still larger quantities of ice are employed. The farmer cools his milk quickly and places it on his wagon after it is cooled. Not only does he cover the cans with a blanket, but, also, places a cake of ice in the wagon if the distance to the milk-station or creamery is considerable. At the shipping stations, or creameries as they are commonly called, the milk is cooled again, placed in refrigerator cars, and forwarded to the city. No refrigerator cars are used when the haul is short; the milk is cooled when it reaches its destination. In the case of New York City, a large portion of the supply is bottled at the creameries; in the case of Philadelphia, Boston, and other cities, the bottling is done in the city itself. Some of the dealers also pasteurize a portion or all of the milk sold by them.

Notwithstanding this undoubted advancement in the methods of handling milk, the number of bacteria in the city milk is still very large. Much is yet to be accomplished to insure to the consumer in the city wholesome milk with a low bacterial content.

As far as the producer is concerned, further improvement in securing milk with a relatively small initial bacterial content is not only possible, but, also, practicable. He can be instrumental, also, in improving the conditions of transportation so that the multiplication of the bacteria in milk during transit may be reduced to a minimum. The handling of milk subsequent to its arrival in the city is beyond his direct control. In justice 
to him, the city authorities and the milk dealers should see to it that the number of bacteria in the milk does not increase rapidly through carelessness in distribution. Much is being done, and more will be done in this direction by enlightening public sentiment, by the publicspirited attitude of medical organizations, and by the liberality of the consumer. 


\section{CHAPTER XXXVIII}

\section{DISEASE BACTERIA IN MILK}

MILK may servel as a carrier of disease germs, and may become the cause of sickness for single individuals or for large numbers of people. Tuberculosis, typhoid, diphtheria, scarlet fever, and various intestinal disturbances are more or less frequently produced by infected milk. The subject is one of vast significance to public hygiene, and is receiving the attention of sanitarians in all progressive communities.

Tuberculosis.-In some of our dairy states, tuberculosis is very prevalent among milch cows. Apart from the enormous losses sustained by the dairy interests in the gradual wasting away and final death of these cattle, the question as to the relation of bovine and human tuberculosis is becoming more and more insistent. How many of the thousands of adults and children carried off annually by this dread disease are infected from milk? Unfortunately, the facts in our possession do not permit us to give a definite answer as yet to this question. We know only that market milk frequently contains living tubercle bacilli, which, in some instances at least, find lodgment in the human system and produce the characteristic disease.

The milk secreted by tuberculous cows does not (397) 
necessarily contain tubercle bacilli. They may be detected with certainty only when the animal is suffering from generalized tuberculosis, or has tuberculous lesions in the udder. Nevertheless, even though the milk as it is secreted may be free from these germs, they may find their way into it during the process of milking.

The feces of tuberculous cattle, even when the disease is not advanced, may contain millions of living tubercle bacilli. The animals do not expectorate and the tubercular matter thrown off from their lungs passes through the alimentary canal and is excreted without involving thereby the destruction of the organisms. It is estimated that the thirty pounds of moist feces produced daily by the average cow would contain, in the case of diseased animals, 37,000,000 microscopically demonstrable tubercle bacilli.

Considering the ease with which particles of such feces find their way into the milk from the body of the cow, from the air, from the bedding, and from the walls and floor of the stable, it is not at all surprising that the germs of bovine tuberculosis are so frequently found in market milk and in market butter. Further proof as to the infectiousness of the feces from the tubercular herds may be found in the alarming increase of tuberculosis among hogs that are allowed access to such feces, or are fed on skimmed milk. Experimentally, also, the disease may be readily imparted to hogs by adding quantities of feces from tubercular cows to the milk or other food given to them.

The claim has been advanced that bovine tubercle bacilli cannot produce tuberculosis in human beings. 
It is asserted that, if they could, pulmonary tuberculosis would show an increase instead of a decrease, and that, if infection were due to milk, intestinal tuberculosis would be quite common, instead of being comparatively rare. As to the decrease of pulmonary tuberculosis among men, as indicated by recent statistics, this cannot be accepted as a proof against the infectiousness of milk containing germs of bovine tuberculosis. Better hygienic conditions, and perhaps a greater degree of acquired immunity, may go far toward accounting for this decrease. The statistics available at present do not indicate that intestinal tuberculosis among children has suffered a decrease within the last generation.

There are numerous facts on record that indicate that tuberculosis among human beings has been caused by the drinking of milk from tuberculous cows, or by accidental inoculation with bovine tubercle bacilli. It has been demonstrated, moreover, that these germs when swallowed with the food, may pass readily through the intestinal walls, lodge finally in the lungs and produce pulmonary tuberculosis. Hence, whatever difference of opinion there may prevail as to the extent of human tuberculosis caused by the consumption of milk and milk products, it is conceded by sanitarians that persistent efforts should be made to eradicate bovine tuberculosis.

Municipal and state regulations, reinforced both by an intelligent use of the tuberculin test and by methods of immunization, will make possible the more or less complete extinction of this disease. These regulations will not only increase the value of milk for the human 
family, but, also, will add to the profits of the dairyman and will relieve him from constant anxiety as to the health of his cattle. Meanwhile, the consumer of milk must seek safety in the pasteurization or boiling of the milk, or at any rate, must patronize the dairyman who honestly endeavors to keep tuberculosis out of his herd.

Typhoid.-Unlike the tubercle bacilli, the germs of typhoid multiply readily when they once find their way into milk. Under favorable temperature conditions, their increase may be very rapid and the milk may then become the cause of a more or less serious outbreak of typhoid fever. Many an epidemic of typhoid has been traced to milk. Too much cannot be said against the carelessness that makes such epidemics possible.

A few typhoid germs derived from polluted water soon multiply to thousands in the warm milk, and, when distributed along the milk route, bring disease and perhaps death to many families. The dairyman should remember that a few drops of water from his well or brook, left in the milk can, is sufficient to bring about this result. He should be careful, therefore, to sterilize his milk cans and other utensils in live steam, and to employ only boiled water for washing them when cases of typhoid exist in his family or his immediate neighborhood.

He should be careful, also, to exclude from his dairyhouse and his barn all persons who come in intimate contact with typhoid patients. Above all, he should remember that convalescents from typhoid continue to pass off living typhoid bacilli in the solid and liquid 
excreta for weeks or months. Such persons continue to be a source of possible infection for a long time. This fact, if carefully remembered, may save much sorrow to himself and his customers. It may be added that the germ of cholera, which is related to the typhoid bacillus, may, on rare occasions, be distributed in infected milk. The precautions indicated in connection with typhoid are applicable also in this case.

Diphtheria and scarlet fever.-Diphtheria is caused by a specific germ. This has been isolated and studied in pure culture. Scarlet fever is probably, also, caused by a microörganism whose true nature is not yet fully understood. It has been definitely established that milk may become the carrier of the germs of these diseases.
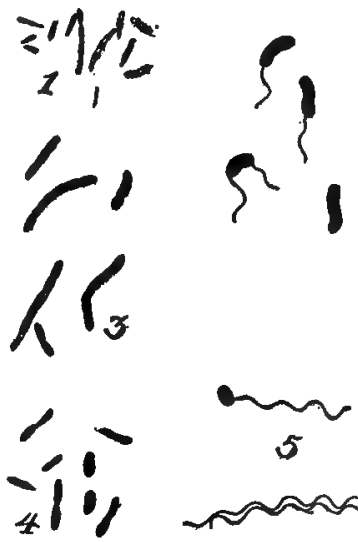

Fig. 62. Disease bacteria known to have occurred in milk.- 1:. Diphtheria bacillus; $\times 3,000$. (Hewlett.) 2 . Cholera vibric); $\times 2,000$. (Hinterberger.) 3 . Tubercle bacillus; $\times 3,000$. (Hewlett.) 4. Typhoid bacillus: $\times 3,000$. (Hewlett.) 5 . Typhoid bacillus; $\times 2,000$. (Hinterberger.)

The rules of sanitation require that the utmost care be exercised in assuring the exclusion of these germs from milk. Persons coming in contact with diphtheria or scarlet fever patients. should not be allowed to enter the dairy, nor should convalescents from these diseases be permitted to become a source of infection. Other disease bacteria may likewise be distributed in milk. 


\section{CHAPTER XXXIX}

\section{BACTERIA IN CREAM, AND CREAM-RIPENING}

THE numbers and kinds of bacteria found in cream are determined to a great extent by the method of its production. Cream secured by separating sweet milk will differ bacteriologically from cream prepared by the shallow or deep-setting systems, at low or at comparatively high temperatures. Separator cream made from fresh milk, with a low bacterial content, will contain frequently but a few thousands of bacteria per cubic centimeter. For instance, one of the cream samples at the milk and cream contest at Cleveland, in 1907, contained only 1,100 bacteria per cubic centimeter, while three others contained from 20,700 to 29,200 per cubic centimeter. In two samples, on the other hand, the numbers were 392,000 and 402,500 per cubic centimeter, respectively. These differences were undoubtedly due to the care observed in the production of the milk and its subsequent treatment. It is generally true that, everything else being equal, milk of good keeping quality will furnish cream of good keeping quality. In the production of good cream, therefore, the same precautions as to cleanliness and temperature should be observed as were already noted in the discussion of milk. 
But, aside from the use of sweet cream for direct consumption or for the making of ice-cream, we must consider it in its important relation as the raw material for the manufacture of butter. The vast significance of the latter as an article of diet will be readily realized from the fact that the product of more than one-half of all the cows in the United States (there were 18,000,000 of them in 1900) is turned over to the butter-maker. The important material interests involved in this agricultural industry have stimulated extensive inquiry into the economy of butter-making and have thus brought to light a long array of interesting facts. The dairy bacteriologist has played a prominent part in discovering and explaining these facts and the butter-maker owes to him much of his ability to produce a uniform and high-grade product.

Sweet-cream butter is made from cream immediately or soon after it is separated. In some of the European countries the demand for such butter is very large. In the United States the demand for it is almost wholly confined to the cities with large foreign populations. The success in the making of sweet-cream butter depends essentially on the checking of bacterial growth in the cream. As far as possible, the latter must remain unchanged in flavor and composition; hence, in its preparation, the milk is quickly removed from the barn, passed through the centrifuge, and the cream at once cooled to a low temperature. The operation of churning is hastened as far as possible, and is performed so as to exclude bacterial contamination. 
But, even when the most scrupulous care is observed in excluding dirt and bacteria from the milk and cream, the keeping quality of sweet-cream butter is poor at best, and the butter must be, therefore, consumed within a short time after its production. Some grades of sweet-cream butter are made out of pasteurized cream and possess, then, fairly good keeping quality, besides being freed, incidentally, from any disease bacteria that may have been present in the milk or cream.

Ripened cream, butter.-By far the greatest proportion of butter made in the United States, and, for that matter, in foreign countries, is prepared from cream that has undergone bacterial change. The ripening process involves changes that affect the yield of butter from any given quantity of cream, the keeping quality of the butter produced, as well as the flavor of the latter. It is well known that ripened cream produced by the gravity system will yield a larger quantity of butter than the same amount of unripened cream. In the case of separator cream, the difference is not so apparent.

The greater yield of butter from ripened cream is accounted for by the assumption that the fat globules in milk are separated by or perhaps coated with protein substances, that in the course of ripening the peptonizing bacteria attack these substances, and gradually decompose them. This change is hastened by the lactic acid formed by the lactic-acid bacteria. The digestion of the protein substances by the bacteria becomes, therefore, an aid to the rapid coalescing of the fat globules in the subsequent churning. That the bacteria must necessarily 
play an important part in the ripening process is evidenced by their presence in such truly enormous numbers. According to Conn, normally ripened cream contains $100,000,000$ to $1,500,000,000$ of bacteria per cubic centimeter, the average number being about $500,000,000$. The organisms grow rapidly at the temperature of ripening cream and produce the changes that subsequently modify the flavor and probably also the keeping quality of the butter.

In cream, as in milk, the various kinds of bacteria must compete for their food. Only those best adapted to their environment finally emerge victorious from the struggle. We have already seen that in milk the lacticacid bacteria, largely on account of the lactic-acid produced by them, usually gain the upper hand and prevent the growth of the other species. We have seen, also, that there is more or less associative action in the bacterial decomposition of milk, for the lactic-acid germs are evidently stimulated in their development by the changes caused by some of the other species.

Similar conditions prevail in cream. While it is still sweet, the peptonizing bacteria grow freely, decompose the protein substances and prepare the ground for the lactic-acid germs. These, in their turn, become more and more prominent, and, finally, crowd out the other species. As a result of the activities of the two groups of organisms, we have an accumulation of protein decomposition products on the one hand, and of lactic acid on the other. These substances impart distinct tastes and flavors to the cream and to the butter made from the cream. 
We see, therefore, that the ripening of cream is equivalent to the accumulation in it of certain products. Under properly controlled conditions, the quantity and quality of these products are satisfactory to the buttermaker, for they impart to his butter the desired properties. Experience has taught him, at the same time, that it is not safe to depend on the spontaneous bacterial changes in the ripening cream for the production of high-grade butter. The method is not only slow, but uncertain. Occasionally the lactic-acid bacteria do not gain the ascendancy in the ripening cream. Other species become prominent and produce substances that impart to the butter objectionable flavors, or injuriously affect its keeping quality. The butter-maker must attempt, therefore, to control the ripening process by adding to the cream large quantities of desirable bacteria, such additions being known as "starters."

Starters.-If a quantity of cream sours normally and produces butter of superior quality, it must contain bacteria capable of bringing about this result. A starter is a quantity of inoculating material and is valuable only when it contains the proper kinds of bacteria, that is, bacteria capable, not merely of producing certain chemical changes, but, also, of growing with sufficient rapidity to overcome the other organisms present in the cream.

A pure culture of some germ capable of carrying forward the ripening process in a satisfactory manner may be added to the cream. This is actually done on a more or less extensive scale in the dairy districts of northern Europe, notably in Denmark. A limited use 
of pure cultures is made also in the United States and Canada.

The method itself is fairly simple. A laboratory culture of some lactic-acid germ is added to a small quantity of sterilized or pasteurized milk, or to skimmed milk, and is allowed to grow at a suitable temperature for a day or two. This milk, with its bacteria multiplied to vast numbers, is added to a still larger quantity of pasteurized milk or cream. After a similar period of increase, the latter is ready to be added to the mass of cream that is to be ripened. The starter is thus gradually built up, and added to the sweet cream in the proportion of about one to ten. The building-up process is almost indispensable. It is depended on to furnish numbers of bacteria great enough to permit the suppression of the organisms in the cream, as well as to allow the ripening process to run to completion rapidly. The direct addition of such laboratory cultures to the body of cream has, for these reasons, proved unsatisfactory in most instances.

Starters may be built up in a similar manner out of samples of milk, skim-milk, or cream, that have been allowed to sour spontaneously. They are known as natural starters, in contradistinction to the pure-culture starters just described. A natural starter may frequently happen to be practically a pure culture of some lacticacid bacterium, since such organisms readily become prominent in milk or cream. In order to secure a natural starter, the butter-maker obtains, with every precaution as to cleanliness; a quantity of milk from a healthy cow. This milk is set aside, partly skimmed, warmed, and 
allowed to turn sour naturally. Separator skim-milk may be used instead of whole milk or partly skimmed milk. The following steps are much like those noted in connection with the building up of pure-culture starters. It is not necessary to build up a new starter for each churning, for a quantity of ripened cream or of buttermilk reserved from the preceding lot may be used for the preparation of the starter. From time to time, however, the building up of a new starter becomes essential.

Pure-culture starters possess certain advantages which render their use acceptable to the butter-maker. Experience soon teaches him how to control his ripening process within narrow time limits, and he can, therefore, carry on his work with a precision not attainable in the use of natural starters. He is more certain of uniformity in his product, and finds himself, therefore, able to place a standard article on the market.

The natural starters, on the other hand, cannot always be relied on. In spite of the care observed in their preparation, they are apt, at times, to yield an unsatisfactory product, both as to flavor and keeping quality. With that much admitted, however, the skilled buttermaker who uses natural starters believes that he can, with their aid, produce a better-flavored product than he could with the use of pure-culture starters. This is not difficult to understand, since no single species has yet been discovered that is capable of producing all of the substances found in properly ripened and highly flavored cream. According to Grotenfelt, Jensen characterizes the ideal lactic-acid bacterium as possessing 
the following properties: (1) "That it will sour the cream rather strongly in a comparativly short time, so that it can compete with other bacteria present; (2) that it will thrive at a relatively low temperature $\left(60^{\circ}\right.$ to $72^{\circ}$ Fahr.); (3) that it will coagulate the cream and milk to a uniform homogenous mixture, and give it a slightly sour taste and odor; (4) that it will produce an agreeable aromatic taste and flavor."

Since no single organism thus far known is capable of meeting all these requirements, the cream ripened by means of pure cultures must necessarily, be inferior to good cream ripened under the best conditions by natural starters. It should be remembered, however, that the average sample of cream ripened under the average conditions by means of natural starters will probably be inferior to the same cream ripened under average conditions by means of pure-culture starters. The more general introduction of the separator adds, in some respects, to the superiority of the pure-culture starters, since the proportionate amount of cream brought by farmers to the creameries, is increasing, while that of whole milk is decreasing. By separating the milk on the place, the farmer not only simplifies the problem of transportation, but he also has the skim-milk at his immediate disposal, and, moreover, reduces the danger of infecting his cattle and his pigs with tubercle bacilli, brought from the creamery in skimmed milk.

Advantages and disadvantages.-These advantages to the farmer involve certain disadvantages to the creamery manager; for the cream is accumulated at the farm and is delivered in a condition frequently far 
from satisfactory. Under the older system of delivering whole milk, the farmer found procrastination less practicable. This state of affairs is not only unjust to the farmer whose dairy is clean, and whose cream is of good quality, but, also, complicates the work of the buttermaker and, at times, reduces him to despair. He cannot make good butter out of inferior cream, however careful he may be in the preparation and use of his starters. When confronted by this situation, his chances for turning out a fairly uniform product are improved by the use of pure-culture starters and the pasteurization of his cream.

The best results from pure-culture starters are to be expected, theoretically, when the latter are used with pasteurized cream. The bacteria present in the fresh cream are either destroyed or weakened by pasteurization, and the organisms supplied in the starter are permitted to develop unhindered. As already noted, a uniform product is thus assured. When two or three different species are furnished in the culture, the flavor, as well as the keeping quality of the butter are, on the whole, satisfactory.

In some localities in Europe, and particularly in Denmark, the pasteurization of cream and its ripening by means of culture starters is the common practice. In this country, a more strongly flavored butter is preferred, and unpasteurized cream is found, therefore, to yield a more satisfactory product. Either artificial or natural starters are employed, and are added in proportions sufficiently large (usually about 10 per cent) to assure a preponderance of the desirable lactic-acid bacteria. 


\section{CHAPTER XL}

\section{BACTERIA IN BUTTER}

Butter, as it grows older, usually deteriorates in quality. It loses its flavor and begins to undergo decomposition. This proceeds slowly at low temperatures, but very noticeably at higher temperatures. Ultimately it assumes the rancid character of old butter. The changes thus occurring are partly chemical and partly bacteriological.

The loss of flavor is accounted for readily enough by the escape of the small amounts of the volatile compounds present in fresh butter. On the other hand, the development of rancidity, accompanied by the accumulation of acid substances, is not so simple. There is scarcely a doubt that bacteria are intimately concerned with the development of rancidity. For one thing, butter kept at, low temperatures not only retains its good qualities, but, also, for some time after it is removed from cold storage. Moreover, butter made from cream delivered sweet at the creamery, has a better keeping quality than butter made from cream that was sour. The differences are not apparent while the butter is in cold storage, but subsequently become noticeable.

It has been likewise demonstrated experimentally that butter made from pasteurized cream does not become 
rancid so readily as butter made from unpasteurized cream. In fact, butter made from sterilized cream does not seem to become rancid at all as long as it remains sterile. In preventing butter from becoming rancid, antiseptics are as effective as sterilization by heat. Butter made from pasteurized or sterilized cream may be made to become rancid by the addition to it of a small quantity of old butter. Furthermore, butter containing a large proportion of casein or milk-sugar becomes rancid more readily than butter poor in these substances. When air and light are excluded, the butter does not deteriorate so rapidly. In hermetically sealed cans, it keeps best when the latter are full, that is, when the air is excluded.

Numbers and kinds.-Bacteriological examinations of fresh butter show large numbers of organisms, frequently many millions per gram. The number is intimately affected by the source and character of the cream. Cream from the milk of clean cows and in a clean dairyhouse will yield butter with a much smaller number of bacteria than filthy cream. Clean cream contains, for the most part, only lactic-acid bacteria that rapidly decrease in numbers in the butter, whereas filthy cream contains other species that do not decrease as rapidly, and, in some instances, actually multiply in the butter.

A study of the various microörganisms found in butter will show that different species are prominent in the same sample at different times. Fresh butter necessarily contains lactic-acid bacteria in predominating numbers. There are usually present, also, Bacillus fuorescens liquefaciens, derived from the wash-water, 
Oidium lactis and other molds, and various yeasts. In stored butter, the lactic-acid species decrease rapidly, while Bacillus fluorescens liquefaciens may increase for a time. Oidium lactis is always prominent, but is finally suppressed by another common butter mold, Cladosporium butyri. Certain yeasts also persist in stored butter, and become so prominent at times as to constitute nearly the entire flora. There is still a difference of opinion as to the part played by these various organisms in the development of rancidity in butter. It has been found that samples of butter prepared under aseptic conditions become rancid when inoculated with a culture of Bacillus fluorescens liquefaciens, or of Bacterium prodigiosum. On the other hand, the mold, Oidium lactis, while capable of developing strong acidity in butter and of decomposing the butter-fats, does not cause rancidity when present alone. Neither does Cladosporium butyri; yet, when the two are growing together, rancidity is produced. We note thus associative action in the production of rancidity by two prominent butter molds, and, in general, it may be said that bacteria, molds and yeasts contribute to the development of rancidity and to other changes that occur in butter.

Disease bacteria in butter.-The spread of infectious diseases by means of butter has been made the subject of considerable discussion. The wide prevalence of bovine tuberculosis, and the frequent presence of tubercle bacilli in milk, are the cause of the presence of the bacilli of tuberculosis in butter. An examination of forty samples of market butter in Posen revealed the presence of tubercle bacilli in 22 per cent of these sam- 
ples. In another instance, an examination of one hundred samples of butter selected in Stuttgart showed that living tubercle bacilli were present in nearly one out of every ten samples. There is, therefore, more or less danger of transmission of tuberculosis by means of butter, and the pasteurization of cream in buttermaking, whenever practicable, must be regarded as a commendable practice from the standpoint of public hygiene. In the case of typhoid and diphtheria, on the other hand, the danger of transmission in butter, if it exists at all, can be only slight. The germs of these diseases do not seem to occur in market butter. Typhoid bacilli, purposely added, disappeared gradually and could not be detected at the end of ten days. Tubercle bacilli also gradually disappear in stored butter, although they are hardier than the typhoid germs and may persist for weeks, perhaps for months.

Butter faults.-Occasionally butter acquires undesirable characteristics, quite different from the ordinary development of rancidity. The objectionable changes known as butter faults or butter diseases may affect the appearance and taste of the butter, giving rise to mottled, putrid, bitter or tallowy butter. Such faults have been traced to microörganisms that may be derived from the cream or from other sources. Samples of inferior cream produced in a filthy environment often contain species of bacteria that later develop in the butter and destroy its value as a food product. The pasteurization of such cream undoubtedly improves the keeping quality of the butter made from it.

Not infrequently, butter faults have their origin not 
in the cream supplied by the patron but in the water used at the creamery. Certain bacteria present in wells, brooks, or springs, are introduced into the butter with the wash-water, and bring about undesirable changes. Even creameries with an established reputation for excellent butter are now and then confronted by the sudden deterioration of their product on account of microörganisms causing butter faults. In such cases, normal conditions are reëstablished only after the most thorough cleaning of the premises, and, when this is insufficient, by the boiling of the water used in the creamery. 


\section{CHAPTER XLI}

\section{BACTERIA IN CHEESE}

Fresh cheese curd consists of rather tough, elastic material, which, according to popular belief, is not easily digestible. Ripened cheese is soft and waxy, in some varieties nearly semi-liquid, and rich in water-soluble nitrogenous nutrients. The transformation of the fresh curd into ripened cheese may be accomplished in four or five weeks in the soft varieties. It may require several. months for its completion in the hard varieties.

The ripening process.-The three important constituents of the curd-the fat, milk-sugar and casein-are affected by this process of transformation and undergo more or less deep-seated changes. The fat, while frequently modified to a very slight extent, contributes none the less to the pungent taste and smell of the ripened cheese. The milk-sugar is changed into lactic acid, which, in its turn, plays an important rôle in the reaction that subsequently occurs in the ripening mass. But, more important than these are the changes that occur in the casein, or paracasein, as the chemists call the rennet coagulated mass.

The proteid in the insoluble curd (Calcium paracasein) is rapidly modified so as to become soluble in a 5 per cent salt solution at $50^{\circ}$ to $55^{\circ} \mathrm{C}$. $\left(122^{\circ}\right.$ to $131^{\circ} \mathrm{Fahr}$.). 
After this reaction is completed, the curd proteid is again changed into an insoluble form. The latter is in turn gradually transformed in the ripening process into water-soluble compounds. This last series of changes, which are intimately associated with the final digestibility and flavor of the cheese, involve the gradual breaking down of the proteid substances, and the formation of the so-called amides (amido compounds). It has been found that a properly ripened Cheddar or Swiss cheese may contain about a third of its total nitrogen in the amid form, and that 3 to 5 per cent may be present as ammonia. It is to these various amides and the ammonia that the cheese flavors are largely due, at least, in the case of the hard cheeses. The wellknown influence of temperature on the rate of ripening and the flavor may be explained by the differences in the proportionate amounts of the various amides formed.

We see, thus, that the ripening of cheese is not unlike the putrefaction of other protein bodies. However, some of the characteristic putrefaction products are absent from normally ripened cheese. It is only in exceptional cases that such putrefaction products appear. They may give rise, then, to ptomaine poisoning. While the changes leading to the formation of poisonous substances in cheese have not yet been made clear, it is assumed that these compounds are most likely to appear in over-ripe or improperly ripened cheese.

Enzymes and bacteria in the ripening of cheese.-When modern methods of investigation were first brought to bear on the problem of cheese-ripening, it was believed that bacteria and other microörganisms were the sole 
cause of the changes observed. It was thought that the organisms themselves or the enzymes produced by them, accomplished the digestion of the curd. There was a strong difference of opinion, however, as to the kinds of bacteria responsible for the important transformations. Some bacteriologists asserted that the digestion was performed by peptonizing bacteria, while others maintained that it was effected by the lactic-acid bac-
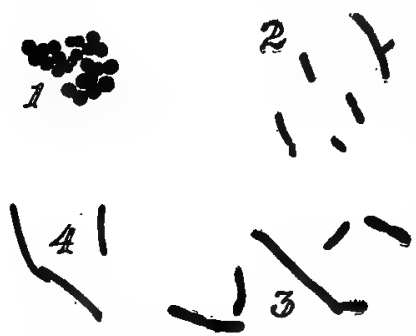

Fig. 63. Lactic acid ferments in cheese-ripening.-1. Bacterium lactis acidi; $\times 3,000$, 2, Bacillus $A ; \times 3,000$. 3. Bacillus casei $\Gamma$; $\times 3,000$. 4. Bacillus casei $\Delta$; $\times 3,000$. Thöni.) teria. In order to decide the point at issue, various organisms occurring in cheese were isolated in pure culture and were employed for the ripening of sterile curd. Large numbers of such experimental cheeses were prepared and studied, and it was found that in most instances they failed to ripen normally. To be sure, Freudenreich, in Switzerland, was able to secure a partial ripening of cheese made out of pasteurized milk and inoculated with pure cultures of lactic-acid bacteria, yet the results were not fully satisfactory. Moreover, cheese made from boiled milk and similarly inoculated failed to show any appreciable ripening. Other investigators were believed to have secured more or less satisfactory ripening, with the aid of peptonizing bacteria, but their results were, in no case, above criticism.

Meanwhile, the investigations of Babcock and Rus- 
sel, and the studies conducted independently by Jensen, in Europe, demonstrated that there is another important factor in cheese-ripening, that has hitherto been overlooked. Babcock and Russell, and, likewise, Jensen, showed that the rennet employed in cheese-making contains pepsin. The latter, as is well known, is capable of causing the digestion of protein substances. By using increased quantities of rennet in the preparation of cheese, the experimenters found that there was a corresponding increase in the amounts of total soluble nitrogen, and of albumoses and peptones formed in the course of six months. Furthermore, they found that still another enzyme, galactase, plays a prominent rôle in cheese-ripening. This enzyme has its origin apparently in the cow's body, for it is secreted with the milk. It resembles some of the bacterial enzymes in its action on protein substances and in the end products formed. Unquestionably, the two enzymes are prominent in cheese-ripening and are instrumental in the breaking down of the complex protein substances into more simple compounds.

Additional investigations carried out in Europe, and, more particularly, at the New York Experiment Station, make it practically certain that the pepsin and galactase are by themselves insufficient for the complete ripening of cheese. In the investigations at the New York station, a lot of Cheddar cheese was divided into two portions, one of which was allowed to ripen under normal conditions, while the other was treated with chloroform so as to exclude the action of microörganisms but not of the two enzymes. When examined at dif- 
ferent intervals for a period of nine months, the normal cheese showed a fairly small variation in the content of albumoses and peptones and a gradual and constant increase of amides and' of ammonia. On the other hand, the chloroform cheese showed a much larger accumulation of albumoses and peptones, a much smaller accumulation of amides and no accumulation at all of ammonia. It would seem, thus, that the pepsin and galactase are incapable of carrying the ripening process to completion and that the normal changes in cheese are dependent on still another factor or factors.

Bacteriological studies of cheese by different investigators, at different times, agree in showing that the bacteria multiply rapidly in freshly prepared cheese. In the hard varieties, the increase may continue for a month or for a few days, depending largely on the temperature at which the cheese is kept. The organisms consist almost entirely of the lactic acid species for the other bacteria, initially present, do not seem to be able to maintain their ground and are rapidly crowded out. In experiments in which large numbers of peptonizing bacteria were purposely introduced, their disappearance was fully as marked. Evidently, then, organisms, other than the lactic-acid species, do not play, numerically, a significant part in the ripening of cheese.

Since the lactic-acid bacteria constitute nearly the entire flora of fresh cheese, and since, furthermore, normal ripening of hard cheese does not occur when they are excluded, the thought naturally suggests itself that these organisms are intimately concerned with the ripen- 
ing process. Indeed, numerous attempts have not been wanting to prove that they are thus directly concerned. Howaver, the adherents of this theory have a serious difficulty to overcome in proving that the lactic-acid bacteria are capable of causing the digestion of protein substances and the formation of amides and of ammonia. In some instances, it was undoubtedly demonstrated
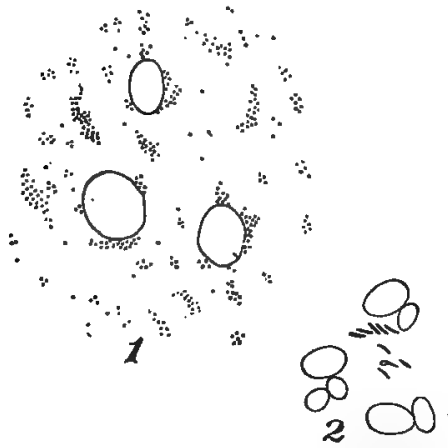

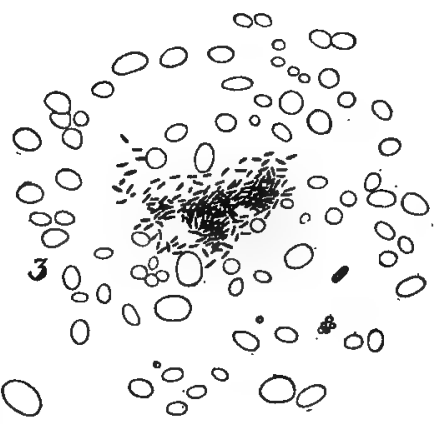

Fig. 64. Bacteria in cheese-ripening.-1 and 2. Sections through Emmentaler (Swiss) cheese, showing enclosed bacteria. 3. Section through Gorgonaola cheese. (Rodella.)

that there are species of lactic-acid bacteria that produce proteolytic, that is, protein-digesting, enzymes. Most investigators, however, have been unable to discover the production of such enzymes by the lactic-acid bacteria. The question as to the direct influence of these organisms in the ripening of cheese is, therefore, still an open one.

On the other hand, it is generally agreed that the lactic-acid bacteria are indirectly of great moment for the ripening process. Their rapid increase in the fresh 
cheese and the production of lactic acid by them excludes the predominance of other species. Moreover, it would seem that the lactic acid thus produced unites with the casein (paracasein), forming thereby a compound, which, there is reason to think, behaves differently towards the galactase and pepsin than does the casein (paracasein) itself. In some of the experiments on cheese-ripening the curd was prepared from pasteurized or sterilized milk in which the galactase and pepsin had been destroyed by heating. The enzymes being thus excluded, the subsequent inoculation with lacticacid bacteria did not reëstablish normal conditions. In other experiments, on the contrary, the bacteria, but not the galactase and pepsin, were excluded, lactic acid was not formed, chemical reaction between the casein (paracasein) and lactic acid did not occur, and enzyme action was unquestionably modified thereby. It will be seen, therefore, that the question is still far from being settled. The indirect importance of the lactic-acid bacteria in cheese-ripening having been established, it remains for future experiments either to confirm the belief as to their direct action, held by many, or to prove it untenable.

Soft cheeses.-The soft cheeses include Roquefort, Camembert, Limburger, Stilton, Brie, Gorgonzola, Backstein, Gammelost, Port de Salut, and others with reputations more or less local. They differ from the hard cheeses both in their method of preparation and their appearance, taste and flavor. They are not subjected to pressure, the whey is not as completely removed, and they contain, in consequence, more moisture. Air 
and moisture being present in greater amounts, they allow a more rapid development of microörganisms, and ripen more rapidly than the hard cheeses. The bacteria and molds concerned are not the same in the different varieties of cheese, some containing characteristic species of molds, others of bacteria.

The soft cheeses have their origin in Europe. They have been manufactured in some localities for many generations. The different conditions of moisture and temperature in the different localities, and the differences in the composition of the milk itself, have led, to the establishment of combinations of microörganisms that may be characteristic of one locality but not of another. For this reason, brands of the same variety of cheese from different localities may show a very marked divergence in taste and flavor. The soft cheeses do not keep so well as the hard cheeses, and are not so adapted for export trade.

Because of the high prices commanded by the best grades of soft cheeses, and, likewise, because of the growing demand for some of the brands in the United States, attempts are being made here to develop the soft cheese industry. Considerable progress has been made in this direction by commercial concerns employing imported cheese-makers, and much has been contributed by the investigations at the Storrs (Connecticut) Experiment Station.

The work of microörganisms in the ripening of some of the soft cheeses has been made clearer by the experiments at the Storrs station on the manufacture of Camembert cheese. The milk is heated to about $85^{\circ}$ 
Fahr., and a pure-culture starter of lactic-acid bacteria is added. After the desired degree of acidity is developed by the bacteria, the casein is coagulated by means of rennet, the curd is cut, stirred and dipped into forms. It is then allowed to drain, without artificial pressure, for four or five hours, and is inoculated with spores of the proper mold. After being salted, the cheese is ready to go through the ripening process, which requires about four weeks for its completion, and which involves the gradual change of the hard curd into a soft, waxy substance.

The softening begins near the surface and slowly spreads towards the center of the mass. "When in prime condition, the cheese is soft enough to spread upon bread or crackers, but not soft enough to run. An over-ripened cheese, however, becomes still softer, until, in time, the whole interior of the cheese below the rind is converted into a nearly liquid consistency, which will run out of the cheese readily, if the rind is broken. On the other hand, an under-ripened cheese will show more or less of the sour curd in the center, which has not been affected by the softening agents. The cheeses purchased in the market are, very frequently, in one of these two conditions, either over-ripe or under-ripe."

The lactic-acid bacteria of the milk and the starter soon become predominant in the cheese, almost entirely excluding the other species. In some of the experiments, the lactic-acid bacteria reached a maximum number of about $900,000,000$ per cubic centimeter in two days, constituting then practically a pure culture. This number was maintained throughout most of the ripening 
period, but declined towards the end. Peptonizing bacteria were found in considerable numbers only occasionally, such cheeses manifesting a somewhat abnormal ripening, but yielding fairly satisfactory final results.

The sour curd formed by the lactic-acid bacteria is a favorable medium for the development of molds. Two of these appear to play a predominant rôle in the ripening of Camembert cheese, namely, Penicillium camemberti and Oidium lactis. The molds gradually reduce the acidity of the curd until its reaction is markedly modified. Enzymes are produced which gradually diffuse towards the center of the cheese, the curd is digested and becomes, to a marked extent, soluble in water, and the transformation thus proceeds until the ripening process is complete. Experiments with pure cultures of the molds showed definitely that they are capable of causing these digestive changes when not associated with bacteria.

A number of cheeses that were prepared by means of a pure-culture starter and inoculated with Penicillium camemberti ripened properly, but showed no distinct flavor. But when Oidium lactis was also introduced in the cheese, there was developed the characteristic flavor. "Bacteria or other molds," says Thom, "in many cases modify the flavor of Camembert cheese, but do not seem to produce it independently of the mold. There thus arise characteristic secondary flavors which are associated with the output of certain factories and which command special markets. These varieties are usually more highly flavored than what we have regarded as typical. The essential relation of the Camem- 
bert Penicillium and Oidium lactis to the production of Camembert cheese is, therefore, well established."

The ripening of Camembert cheese is, therefore, due to lactic-acid bacteria and molds, the former bringing about the initial changes, the latter modifying the reaction, digesting the curd and developing the flavors. Lactic-acid bacteria, with Penicillium camemberti alone, were sufficient for the ripening and the proper texture but were not adequate for the production of the typical flavor. The latter appeared only when Oidium lactis was also present. As to actual conditions in the manufacture of Camembert cheese, it still remains to be determined whether the miscellaneous bacteria that appear in large numbers in the later stages of ripening are of decided significance. Similarly, in the case of other soft cheeses, molds are almost invariably present.

In Roquefort cheese, made out of goat's or sheep's milk, lactic-acid bacteria and a characteristic Penicillium, different from Penicillium camemberti, seem to be the principal organisms concerned. In Stilton and Gorgonzola, made out of cow's milk, a green Penicillium resembling that of Roquefort is prominent; and the same may be said of Hungarian Brinse, prepared from sheep's milk. The differences in flavor which these cheeses exhibit must be sought, therefore, in differences of quality and treatment of the materials employed, as well as in the varying predominance of the several groups of microörganisms more or less common to them all. It may be added that the American Brie and Isigny cheeses examined by Thom, contained no trace of Penicillium camemberti, but always bore a growth of Oidium 
lactis. He concludes that there is in this case associative action between Oidium lactis and various species of bacteria. The function of these organisms, as well as of the yeasts that are frequently present, on the ripening of American Brie and Isigny is still a matter of uncertainty.

Hard cheeses. - The growth of molds is excluded in hard cheeses by the strong salt content and the hardness and compactness of the rind. Hence, these cheeses, prominently represented by the Swiss Emmenthaler, the English and American Cheddar, and the Dutch Edam, in so far as they are at all affected by microorganisms, must depend for their ripening, apart from the enzymes pepsin and galactase, on the action of bacteria.

At high temperatures, the numbers of bacteria in hard cheeses evidently decrease more rapidly than they do at lower temperatures, a difference coincident with the rate of ripening. The cheeses kept at the higher temperatures not only ripen more rapidly, and develop a stronger flavor, but soon become over-ripe. It seems, furthermore, that the accumulation of amides and of ammonia goes on for some time after the bacteria had become greatly reduced in numbers. This fact indicates, therefore, that if the latter stages of ripening are due to bacteria, they must be carried out by means of enzymes secreted by the organisms.

It follows, likewise, that at the higher temperatures the bacterial enzymes are produced early in the ripening process in larger amounts, and are, therefore, enabled to accomplish their work more quickly than it is ac- 
complished at the lower temperatures. Practical studies on the ripening of American Cheddar cheese at different temperatures have shown conclusively that at the lower temperatures the ripening is more uniform, and the keeping quality of the cheese much better. In fact, ripening was shown to be experimentally practicable at temperatures but little above freezing. Commercially,

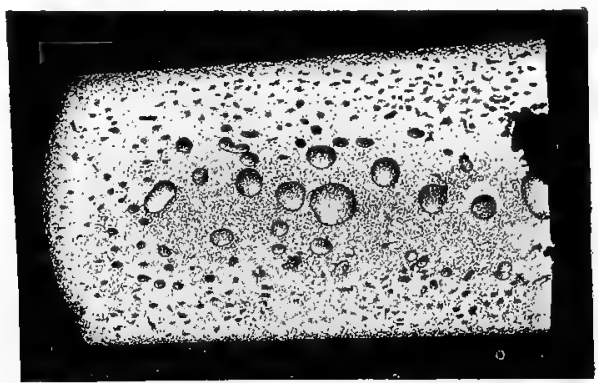

Fig. 65. Section through inflated and partly collapsed Emmenthaler cheese. (1/5 natural size. Freudenreich.)

however, this extension of the period of ripening has its limitations.

Cheese faults.-Abnormal ripening and the consequent production of cheese that is not marketable, occasion, at times, large monetary losses to the cheesemaker. Among such faults, the most common is that which leads to the formation of gassy curd. In this case, large quantities of gas are generated by certain gas-producing bacteria and the curd becomes filled with cavities of various shapes and sizes. The surface of the cheese bulges out, and, in extreme cases, the rind is split open. Other abnormal characteristics, particularly 
as to taste, accompany this phenomenon and deduct from the value of the cheese. The trouble is due most frequently to one or two lactic-acid species, notably $B$. lactis aërogenes, and can be partly overcome by the use of larger amounts of a good lactic-acid starter.

Other faults that, as a rule, are less troublesome than the preceding, involve the development of objectionable

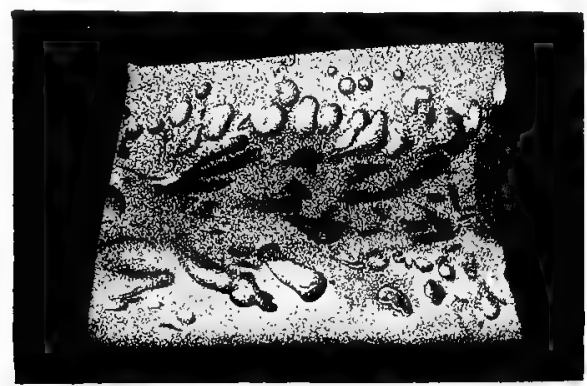

Fig. 66. Section through an inflated Emmenthaler cheese. (Freudenreich.)

tastes and odors. In soft cheeses considerable loss is now and then occasioned by yeasts which develop on the surface. The cheese becomes slimy, adheres to the board, and is liable to lose part of its surface containing the mold, thereby interfering with the proper ripening. In still other instances, the soft cheese may be invaded by putrefaction bacteria which change it into an offensive slimy mass. More or less loss to the cheese-maker is likewise occasioned by discolorations of the hard cheeses, that is, the formation of black, red, blue, or rusty spots. These are due to molds or bacteria. In all these instances, the remedy must be sought in thor- 
ough cleanliness. When objectionable bacteria, molds, or yeasts, have invaded the premises, it may become necessary, therefore, to resort to sterilization of the utensils and disinfection of the rooms. Again, certain faults occurring in the output of the cheese factory may not be due to microörganisms, but to faulty manipulation. An instance of this is found in the manufacture of soft cheeses, when some of the products become too dry on account of the lack of sufficient moisture in the atmosphere of the drying room. 


\section{PART VII}

\section{Bacteria in Relation to Preservation OF FOOD}

\section{CHAPTER XLII}

\section{BACTERIA IN RELATION TO CANNING}

THE perishable products of the farm have but a brief existence. The succulent fruits and vegetables decay and vanish; milk turns sour; butter becones rancid; wine, juices and cider are changed into acid liquids; and meat and eggs undergo putrefaction. Decay and putrefaction, as natural phenomena, were forced upon the attention of man as he emerged from savagery. When he realized that food-preservation and his own wellbeing were so intimately related, he endeavored to devise means for arresting the course of dissolution. The passing centuries taught him that moisture and warmth furnish suitable conditions for the rapid decay of vegetable and animal materials. They taught him that, for a short time at least, boiling will arrest the decomposition of food. They taught him that the addition of substances like salt or saltpeter, or the natural processes of souring, may be utilized in the preservation of food products. 
With this knowledge came its application. There came the drying or salting of fish and meat; the storing of grain in cool, dry chambers; the pickling of vegetables in tight receptacles. The seasons of plenty were made to contribute to seasons of scarcity, and these contributions were made effective largely by the natural resistance to decay of dry grains and grasses.

Modern research has made clear to us the nature of decay, putrefaction and fermentation, and has helped us to account for the instability of vegetable and animal substances. Knowing, as we do, of the universal presence of microörganisms, and of the conditions suitable for their growth and survival, we have gradually perfected the means for excluding them from our food products. We have thus developed important agricultural industries.

The principles of canning.-The successful canning of fruits, vegetables, meat and fish depends upon the destruction of all of the bacteria present in these materials, and the sealing of the cans so that no new invasion by bacteria or other microörganisms can occur. This is readily accomplished by heating the cans and their contents to a temperature that kills not only the bacteria themselves, but, also, the most resistant spores. The complete sealing of the cans previous to heating is inadvisable, for the steam pressure inside of the can might lead to the formation of leaks that would encourage subsequent infection. Hence, a small hole is punched in the cover, through which the air and steam escape during the heating process. After the sterilization, the hole is closed with a drop of solder and, if the 
work is effectively performed, the contents of the can will remain unchanged for an indefinite period.

Development of the canning industry.-An application of the principle involved in canning was suggested as early as 1782 by the Swedish chemist, Scheele, when he advised the exposure of vinegar to the temperature of boiling water, in order to assure its conservation. Some time after this, the Parisian confectioner, Appert, demonstrated that meats, vegetables and other perishable products enclosed in sealed vessels could be preserved by placing them for a short time in boiling water.

The practice of canning was thus established prior to the development of modern bacteriology, for Appert's book, recounting the results of his experience, first appeared in 1810. Gradually, the methods of canning were improved; the open tanks, in which the cans were heated to $212^{\circ} \mathrm{Fahr}$., gave way to closed vessels, in which steam under pressure made possible the use of temperatures ranging up to $250^{\circ} \mathrm{Fahr}$. The higher temperatures are convenient, not merely because they are more effective in destroying the bacteria, but also because they shorten the period of heating.

The constant improvement of the mechanical appliances and the growing demand for canned goods have both contributed to the wonderful development of the canning industries. Tomatoes, corn, peas, beans, asparagus, okra, succotash, squash, pumpkins, and other products of the garden and orchard are now placed before the consumer in a palatable and succulent state at a time of the year when, a generation ago, they were merely the subject of pleasant reminiscence. 
The canning industries have been responsible for the growth of skill and intelligence in many farming communities, and have, thereby, contributed much toward the development of American agriculture. They have benefited both the producer and the consumer and have indirectly affected the growth and prosperity of other important industries, notably the manufacture of tincans, of glassware, and of fertilizers.

Losses through imperfect canning.-Occasionally, the elimination of the bacteria from the canned goods is not complete. Spores of resistant species survive the heating process, develop later, and spoil the contents of the package. Such spoiled packages frequently burst on account of the accumulation of gas in the cans, or merely bulge outward. They are designated as "swells" at the canneries, and their contents, on opening, are found to be decomposed and offensive to the smell. In other instances, the imperfectly sterilized cans do not swell, but the bacteria within them cause the souring of the material. The losses thus occasioned to the canneries are, at times, considerable. Entire shipments are now and then rendered worthless. This involves not only a direct monetary loss, but, also, that of reputation, since the swelling does not become apparent, at times, until after the goods are in the hands of the jobber or of the retailer.

Temperatures required for sterilization.-Some fruits or vegetables require higher temperatures than others. For instance, pie-plant will keep with less heating than is required for asparagus, a difference ascribed to the acid in pie-plant. Again, the heat does not pass so readily 
through a given weight of one vegetable as it does through that of another. With a temperature of $236^{\circ}$ Fahr., the center of a two-pound can of peas has been known to attain the maximum in ten minutes, whereas, in the case of corn, this temperature was not attained at the center until after the can had been exposed to $250^{\circ} \mathrm{Fahr}$. for forty minutes. Hence, the sterilization of canned corn requires higher temperatures and longer exposure than are required for the sterilization of canned peas.

"The bacteria capable of destroying canned goods are not only of different species, but, what is of more importance to the canners, the spores of different species are capable of withstanding different amounts of heating. As a result of this, canners who have been processing successfully at a low temperature for a number of seasons suddenly find themselves in trouble when a more resistant species gets into the cans." In an outbreak of swelling, two-pound cans of peas were processed at $230^{\circ} \mathrm{Fahr}$. for thirty minutes, and the swelling of the cans was noticed in the stock-room in twenty days. The peas in most of the swelled cans emitted a disagreeable odor, "the bodies of the peas were mushy and the skins inflated with gas, like miniature balloons. The liquor was darkened and of a greenish tinge, due to the small particles of the ruptured peas." Large numbers of bacteria were present in the spoiled cans, while similar unspoiled cans proved to be sterile.

The organism that caused this trouble was an anaërobic, rod-shaped, spore-forming bacillus, that produced the characteristic swelling when inoculated into cans of sterile peas. Such cans, when kept at blood-heat, 
swelled within twenty-four hours, and, in some instances, the internal pressure was great enough to burst the can. In order to determine its resistance to heat, a number of inoculated cans were heated at $230^{\circ}$ for varying lengths of time, sealed in the usual manner, and kept under observation. Nearly all of the cans heated for twenty or twenty-five minutes swelled within ten days. Of the cans heated for thirty minutes only 16 per cent swelled in the same length of time, while none of the cans heated for thirty-five or forty minutes showed any evidence of swelling.

Further tests with a temperature of $240^{\circ}$ Fahr. demonstrated that at least thirty minutes were necessary for the efficient sterilization of the cans, although even with this treatment, a very few showed signs of swelling. An examination of the spoiled cans showed that those that had been heated for ten minutes contained a mixture of several organisms, while those heated for a longer time contained only the characteristic resistant species.

A less resistant form that caused the souring of the peas without the production of marked quantities of gas was also found. This form, when inoculated into sterile peas, produced the characteristic souring of the liquid, which assumed a milky appearance. We are taught, thus, that there are organisms in canned goods capable of withstanding temperatures of $230^{\circ}$ or $240^{\circ}$ Fahr. for varying lengths of time, and that there may be others not yet studied whose resistance to heat is even greater. These organisms constitute, at times, a serious problem for the canner, since he cannot afford 
to ruin his goods by excessive heating. A circular letter, sent out to canners in New York State, brought replies from twenty-nine, of whom eleven were of the opinion that a temperature of $240^{\circ}$ Fahr. is liable to injure the quality of the peas. The others had observed no bad effects. We must conclude, however, that exposures of more than thirty minutes at $240^{\circ}$, or shorter exposures at higher temperatures, are apt to diminish the commercial value of canned vegetables.
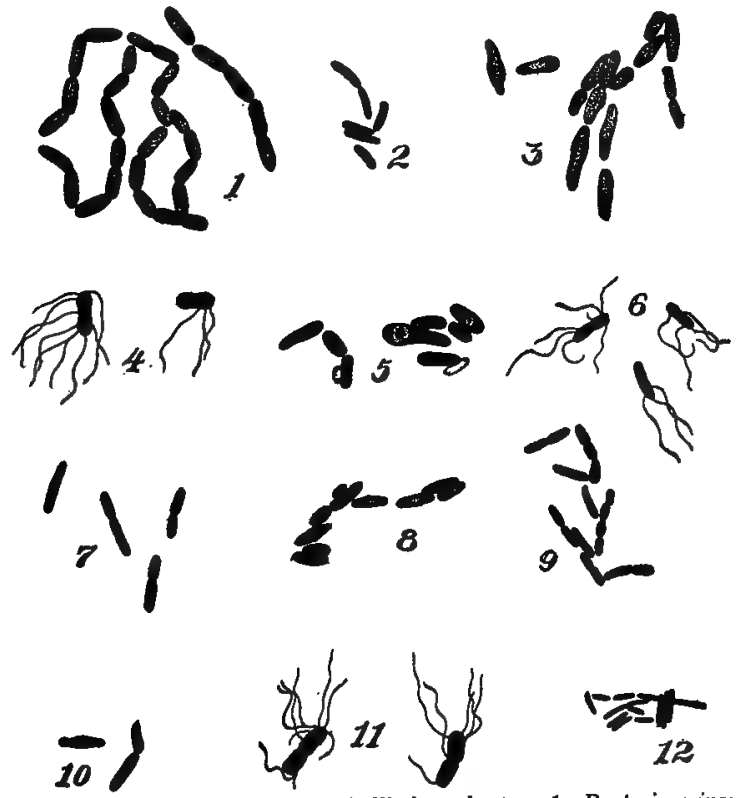

Fig. 67. Bacteria in meat extracts and allied products. -1 . Bacterium insulosum. 2. Bacillus carniphilus. 3. Bacterium rusticum. 4. Bacillus carniphilus. 5. Bacillus micans. 6. Bacillus glaciformis. 7. Bacillus carnis. 8. Bacillus intermittans. 9. Bacillus lavis. 10. Bacillus Kaleidoscopicus. 11. Bacillus levis. 12. Bacillus vegetus. (All after Wilhelmy; $\times 2,000$.) 
Canned meat.-Canned sardines, salmon, or meat, are similarly liable to be spoiled by bacteria in imperfectly sterilized goods. In the case of canned fish, the organisms develop, at times, in the liquid rather than on the fish itself. Various objectionable tastes and odors are developed, rendering the product unfit for consumption. Among the organisms found in spoiled meat or fish, spore-forming species as well as members of the coli group may be noted.

Canned milk.-In the case of canned milk, commonly known as condensed milk, complete sterilization of the material is not necessary. The milk is pasteurized and concentrated in vacuum pans after the addition of about 12 per cent of cane-sugar. Condensed milk contains, therefore, about 25 per cent of moisture and 50 per cent of sugar, the remainder being composed of fat, protein and ash. This comparatively small amount of moisture and high content of sugar make conditions unfavorable for the growth of those bacteria still present in the sealed cans.

The use of preservatives. - Since the enactment of the National Pure Food law, the canneries are no longer permitted to use antiseptics or preservatives in their canned goods without making a direct statement to this effect. They must largely depend, therefore, on heat alone for the proper conservation of their products. They must exercise greater care as to cleanliness, in order that fewer bacteria be present in the cans before heating. They must also determine carefully the safe limit of heating, so that efficiency of sterilization be combined with the greatest economy of time and fuel, 


\section{CHAPTER XLIII}

\section{OTHER MEANS OF PRESERVING FOOD PRODUCTS.-PICKLING}

Food preservation in the canning industries is made practicable and efficient by the destruction of the microorganisms by heat and their subsequent exclusion from the sealed can. On a smaller scale, the housewife makes use of the same principle in preserving fruits, berries, and vegetables. She may also eliminate bacterial growth by the addition of larger quantities of sugar. There are, however, still other important methods for the preservation of perishable foods from destruction by bacteria.

Low temperatures.-Reference should be made to the extensive employment of low temperatures, particularly for the preservation of meat and dairy products. At times, such materials are kept and transported in a frozen state. This is true of meats exported from Australia and of fish exported from Scandinavia. The efficiency of the method is determined, in this case, not by the destruction of the bacteria, but by the more or less complete checking of their activities.

Drying.-Another method, more or less efficient, for the preservation of food products, is that of drying. When the moisture content of food products is reduced below 25 to 30 per cent, the bacteria no longer find con.- 
ditions favorable for their development. Hence, by drying vegetable and animal substances, we can prevent the multiplication of bacteria in them. The preservation by cold and by drying ceases to be effective when, on the one hand, the temperature rises above $50^{\circ} \mathrm{Fahr}$, as was already noted in the discussion of milk, or when, on the other hand, enough moisture gains access to the dry material to allow bacterial growth.

Salting, pickling and smoking.- Still another method of food preservation is based on the salting or pickling of animal and vegetable substances. It is well known that meat or fish, immersed in very strong brine, is more or less effectively protected from bacterial decomposition. Similarly, meat of healthy animals may be preserved by smoking, as is actually done on a large scale at the meat-packing establishments.

All these methods are effective and desirable in so far as they permit the exclusion of the destructive bacteria, or, better still, if they allow the preservation of foods with the retention of the desirable tastes and flavors. Hence, canning, refrigeration, drying, salting and smoking each have a distinct value. From the bacterial standpoint, however, they aim only at the exclusion of microörganisms, or the suppression of their activities. In some of the pickling industries, more than mere suppression of bacterial growth is aimed at. The value of certain fish products and of dill-pickles and sauerkraut is directly dependent upon certain bacterial changes, which impart to the materials distinct tastes and flavors.

Pickled fish.-Bacteriological and chemical studies 
of herring brine have shown the latter to contain large numbers of bacteria. The maximum number is attained in fresh herring brine, the organisms ranging from several hundred thousands to a million or more per cubic centimeter. With the increasing age of the brine, this number gradually diminishes to a few thousands or a few hundreds per cubic centimeter. Not all of the bacteria disappear, even in several years, for brines five years old have been found to contain several hundreds of living bacteria per cubic centimeter.

It appears, therefore, that there is at first, a rapid increase of bacteria in the fresh brine, and, subsequently, a gradual dying off of the organisms. The bacteria are undoubtedly retarded in their activities by the large proportion of salt in the brine, yet it is certain that they are not entirely suspended, and that the changes produced by them affect the taste and flavor of the fish immersed in the brine. Some of the bacteria commonly occurring in herring brine have been isolated and studied in pure culture, and it has been observed that they can still grow in media containing as much as, 20 per cent of salt. It is interesting to note in this connection that, notwithstanding the large numbers of bacteria in the brine, the fish itself is not penetrated by the organisms. It is only when the saturated brine is diluted with water that the bacteria begin to multiply again rapidly and, with sufficient dilution, may attack the fish and induce various putrefactive changes.

Sauerkraut.-In the preparation of sauerkraut, the bacterial activities serve a twofold purpose. In the first place, the bacteria and other microörganisms 
produce certain changes that impart the characteristic taste and flavor to the material. In the second place, the substances thus formed by them inhibit the growth of the common putrefactive germs. Owing to the bacterial activities in question, the preparation of sauerkraut has grown into an industry of considerable magnitude. On the continent of Europe, there are single establishlishments whose yearly output amounts to thousands of tons, while in the United States the production of sauerkraut is undoubtedly of growing importance among the minor agricultural industries.

Briefly stated, the process of sauerkraut-making is as follows: The cabbage as it arrives at the factory is washed, the outer, green leaves and stem are removed, and the residue washed and shredded. The shredded cabbage is packed tightly into casks, salted and weighted to facilitate the expression of the juice. In this manner, considerably more than half of the 90 per cent of juice present in fresh cabbage is squeezed out. The significance of this will be appreciated from the fact that the bacterial changes take place in the juice and not in the particles of the shredded cabbage. The tight packing and compression of the latter drives out the air, and the living cells of the cabbage die the more rapidly and part with the soluble substances contained in them, a process that is further hastened by the salt that is added. The changes that occur after the cabbage is packed into the casks may be classified as follows: (1) Juiceformation; (2) the evolution of gas; (3) souring; membrane-formation on the surface. The changes do not stop here, however, for, if the sauerkraut is kept long 
enough, the acid gradually disappears again, and finally the entire mass undergoes decomposition.

As the juice passes out of the shredded material, the volume of the latter diminishes until it occupies twothirds of the former space, and, at times, only one-half or even less. In the juice itself, which contains sugar and other carbohydrates, proteins, amides, organic acids, and the like, bacteria and yeasts multiply rapidly. The bacteria that belong to the lactic-acid species, prominent among them being Bacterium lactis acidi (B. Güntheri), change the sugar into lactic acid, while the yeasts change it into alcohol and carbon dioxid. The latter accumulates in considerable quantities and leads to the characteristic foam-formation in freshly pickled cabbage.

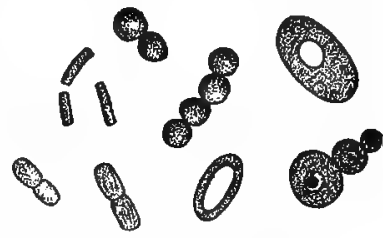

Fig. 68. Microörganisms of saverkraut. (Wehmer.)

The bacteria and yeasts apparently present, in this case, another instance of associative action, for both seem to derive a benefit from their partnership. With the increasing amount of bacterial change, the lactic acid accumulates in the juice until it reaches a maximum of about 1 per cent and imparts the familiar sour taste to the material. Under commercial conditions, sufficient souring may occur to permit the placing of the sauerkraut on the market within two weeks. In most instances, however, it is not marketed in such a short time. The manufacturer knows that there is but little danger of his goods spoiling under the prevailing conditions, namely, the acidity of the juice and the 
comparatively low temperatures of the late fall and winter.

In the course of time, a membrane or skin is formed on the surface of the sauerkraut. It is found to consist largely of Oidium lactis, and of certain yeasts. These organisms begin to consume the lactic acid formed by the bacteria, finally reducing its amount to such an extent as to permit the growth of decay and putrefaction bacteria and the decomposition of the sauerkraut. It has been observed that at a certain point in this change the juice may be alkaline, while the sauerkraut itself is still acid. Higher temperatures encourage membraneformation and the destruction of the acid, hence, the sauerkraut may be kept in condition for a longer time when stored in cold cellars. Under the best of conditions, however, the acid will gradually disappear and the sauerkraut will then spoil. It should be noted at the same time that properly prepared and stored sauerkraut will keep for a year, and can undoubtedly be made to keep longer when the growth of Oidium lactis is more or less completely suppressed.

The fermentation in the different casks of the same factory is remarkably uniform. Bacterium lactis acidi and Bacillus coli communis appear with great regularity in the early stages of the process, as do certain yeasts. Similarly, in the later stages, Oidium lactis always becomes prominent. It would seem, therefore, that the organisms present on the cabbages, as well as the composition of the juice and the prevailing temperatures in the pickling establishments, are, on the whole, fairly constant. 
Dill-pickles.-The art of preparing dill-pickles was probably unknown in western Europe until late in the Middle Ages. It was introduced there by the Slavs, with whom dill-pickles have long been a favorite food and condiment. The art itself is based on the same principles as that of sauerkraut-making. The sugars and other soluble organic substances in the cucumbers are made to pass out into the liquid in which they are immersed. The juice thus formed undergoes spontaneous fermentation through the activities of lactic-acid ferments, principally Bacterium lactis acidi and Bacillus coli communis. In its turn, the lactic acid produced serves to keep out the various putrefactive bacteria that would otherwise destroy the pickles. As in the case of sauerkraut, the acid ultimately decreases in quantity through the activities of Oidium lactis and of other molds and yeasts. The conditions finally become favorable for the growth of the decay bacteria and the pickles are attacked and decomposed.

In the case of sauerkraut, the juice in which the microörganisms multiply is pressed out of the cabbage itself, in the preparation of dill-pickles, it is supplied by the addition of water. After the washed cucumbers are placed in the cask, they are covered with clean water (in some cases with boiled water). Aside from the small quantity of salt that is added there are placed in the casks various other substances like dill, laurel leaves, oak leaves or paprica, the one used depending largely upon local preferences.

It is important to add enough water to cover the cucumbers entirely and to exclude the air from the 
souring mass. It is also important that the formation of lactic acid by the bacteria take place rapidly, since, the more rapid the accumulation of acid at the beginning of the process, the better the keeping quality of the pickles. Hence, various expedients are employed or have been suggested for hastening the initial souring, such as the maintaining of higher temperatures in the cellar for a day or two; the pricking of the pickles with needles to facilitate the penetration of the juice and the more rapid diffusion outward of the sugar; the addition of sugar that will be transformed by the bacteria into acid; the addition directly of small quantities of lactic acid; or the addition of pure cultures of lactic acid ferments.

There is no doubt that some of these expedients may be employed to advantage in assuring a more uniform product and in improving its keeping quality. This is especially true of the addition of large numbers of vigorously growing lactic-acid ferments. Lactic-acid starters can be prepared in this case by allowing pure cultures of Bacterium lactis acidi to develop in pasteurized milk which is to be added subsequently to the pickle casks.

On the whole, a better understanding of the microorganic processes underlying the pickling of cucumbers, and, similarly, the pickling of tomatoes, apples, melons, and the like, as is practiced on the continent of Europe, will allow a greater uniformity and palatability of product. Among the Slav peoples of eastern Europe, the lactic fermentation of vegetable substances is also extensively employed in the preparation of borsch from beets. 


\section{PART VIII}

\section{Bacteria and Fermentation}

\section{CHAPTER XLIV}

\section{BACTERIA IN BREAD-MAKING}

IN the making of ordinary bread, bacteria play a subordinate part. The work of fermentation is accomplished by yeasts which change the sugar derived from the starch into alcohol and carbon dioxid. On the other hand, in the making of bread from sour dough, bacteria are associated with the yeasts and produce the flavors characteristic of such bread. Large quantities of sourdough bread are made in certain parts of Europe, where rye flour is used almost exclusively in the baking of bread. It has been found that the bacteria of the lacticacid group are prominently represented in sour dough. Among the acids formed by them, acetic and lactic acid are present in large proportion, particularly the latter, which is not driven off in the process of baking and imparts a sour taste to the bread.

Bread faults.-Apart from the rôle played by bacteria in the making of bread, as just noted, microörganisms bear, under certain conditions, a direct relation to what may be termed its keeping quality. It has been observed 
that, in the summer months especially, the interior of bread loaves may become soft and slimy. When the decomposition is sufficiently advanced, the crust sinks, the bread gives off a rather sharp, unpleasant odor, the crumb being then sufficiently viscous to allow its being

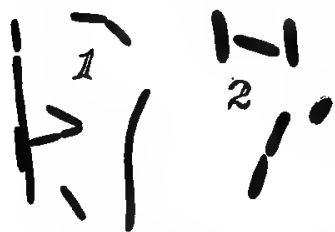

Fig. 69. Bacteria producing stringy or slimy dough. 1. Bacterium panis; $\times$ 3,000. (Fuhrmann.) 2. Bacillus mesentericus pr nis viscosi; $\times 3,000$. (Emmerling.) drawn out into long threads. Such viscosity in bread is more apt to occur when the dough has not been previously soured. One or two bacteria to which the formation of viscous bread is usually due have been isolated, and it has been demonstrated that viscosity may be developed in sound bread by inoculation with these organisms.

The occurrence of this bread fault is favored by moist, warm weather, and is most common in damp, dark bakeries. The corresponding organisms are rarely absent from commercial flours, but may be prevented from becoming prominent and injurious to the baker, by storing the fresh bread in cold closets, or by adding to the dough small quantities of lactic acid or of sour skim-milk. The latter makes the bread sufficiently sour to prevent the growth of the organisms producing viscosity. 


\section{CHAPTER XLV}

\section{BACTERIA IN THE SUGAR INDUSTRY}

THE proportion of crystallizable sugar secured from the juices of sugar-beets, sugar-cane, sorghum and other plants used for the manufacture of cane-sugar, is often reduced by the activities of certain microörganisms. Sugar refiners realized many years ago that the gelatinous masses that appear in the juice are a hindrance to its profitable utilization. They knew, also, that these gelatinous masses increase in amount, and that they may, in aggravated cases, convert the entire juice into a gelatinous mucus.

The true nature of this substance was not recognized, however, until 1875, when the opinion was expressed by Jubert that it is due to a "ferment," - that it is, in other words, of bacterial origin. A few years later, it was shown that the gelatinous substances consist of swollen and gelatinized cell-walls of bacteria, and the organism was named Ascococcus mesenterioides, renamed Leuconostoc mesenterioides, and, finally, Streptococcus mesenterioides.

Streptococcus mesenteroides.-This organism does not always enclose itself in a gelatinous sheath. On media like potato, meat-broth, gelatin and milk-gelatin, it is an ordinary spherical bacterium arranged in chains of cc 
two or more. However, when growing in media containing cane-sugar or grape-sugar, it produces the characteristic gelatinous mucus. The gelatinous envelope serves as a protection to the organism against unfavorable conditions. It enables it to withstand drying for a long time and makes it resistant to heat. For this reason, it survives in the heated juice, when other bacteria are destroyed, and retains its ability to cause mischief.

The injury caused by Streptococcus mesenteroides is twofold. It destroys a certain amount of sugar by converting it into mucus, and it produces an enzyme, invertin, which changes cane-sugar into grape-sugar, increasing, thereby, the proportion of molasses. It probably finds its way into the sugar refinery with the raw materials employed, for it may be assumed to occur in the soil.

Clostridium gelatinosum.-Another organism that is frequently a troublesome pest in the sugar industry is Clostridium gelatinosum. This organism forms resistant spores and is not destroyed when the sugar is heated to from $122^{\circ}$ to $158^{\circ} \mathrm{Fahr}$. It destroys the sugar with the production of butyric acid and of other substances.

Similarly, among the large variety of other bacteria found in the raw juice and derived from the air, water, and soil, there are species that produce organic acids and, likewise, large amounts of gaseous products. It is not at all surprising, of course, that bacteria are numerous in the raw juice, for the latter offers an abundant supply of food to most species. The manufacturer of sugar must, therefore, be constantly on his guard against the invasion of the raw juice by microörganisms. 


\section{CHAPTER XLVI}

\section{BACTERIA IN THE PREPARATION OF HAY AND OTHER FODDERS}

THE preservation of animal foods on the farm is made effective by the removal of water from plant substances until the amount of moisture left in them is no longer sufficient for the growth of bacteria. Hay, straw and corn fodder are thus preserved for the future needs of the animals by drying. However, even with these substances, the water may not be removed rapidly enough to check bacterial decompositions.

Freshly cut grass gathered in heaps shows a rise in temperature that may be high enough at times to cause serious deterioration in its value as an animal food. As the temperature of the grass in the interior of the heap gradually rises, the number of bacteria increases until the heat is too great for all except the most resistant forms. Later, even these are destroyed and the material becomes practically sterile. The question at once arises whether the organisms have anything to do with the heating of the grass or of other vegetable materials placed in heaps. Bacteriologists are not yet fully agreed as to the part played by microörganisms in this process. Some even go so far as to assert that the elevation of temperature may be accomplished without 
microörganisms, and that the phenomenon is due to the activities of the cells of the dying grass, or of the enzymes contained in them.

On the other hand, it has been shown that unwashed, moist cotton, when stored in large heaps, undergoes a rise in temperature. The latter rose to $155^{\circ} \mathrm{Fahr}$. within twenty-four to thirty hours and after a few days gradually declined. No elevation of temperature occurred in sterilized cotton, but this was induced by moistening the sterilized material with a small quantity of water pressed out of moist, unsterilized cotton. The process is analogous here to that occurring in the heating of hay, and the experiments just referred to would indicate that it is of bacterial origin. More recently, experiments have been made on the heating of hay in specially constructed vessels that would allow a thorough sterilization of the material, and its subsequent inoculation when necessary. As in the case of cotton, no heating occurred in the sterilized samples, yet these manifested a rise in temperature soon after they were moistened with a little infusion from unsterilized hay, from soil and the like.

A large number of species have been isolated and studied as to their ability to cause the heating of hay. Sterile material inoculated with such pure cultures failed, in most instances, to undergo the characteristic rise in temperature. In one instance, positive results were secured from inoculation with a certain species of mold. Resistant organisms belonging to the group of thermophile bacteria have also been found in large numbers in hay heated to $122^{\circ}$ to $140^{\circ}$ Fahr. It is not at 
all unlikely, therefore, that these organisms, capable of growing at comparatively high temperatures; play a direct rôle in the changes that occur at elevated temperatures in large masses of vegetable materials.

The process of heating, as it occurs in moist hay, may, therefore, be described as follows: The soluble substances that pass out of the moist material serve as food for a host of bacteria. The chemical changes thus occasioned, and perhaps also the respiration of the vegetable cells that are still living, lead to temperature elevation. The heat accumulated in the mass of hay destroys the less resistant forms, and, as the temperature rises higher and higher, even the most resistant species are killed off. Hay infusions, inoculated with particles of hay so heated, at times remain sterile, a fact that tends to prove that the process may amount to self-sterilization.

Brown hay.-Bacterial activities, in so far as they are at all concerned in the temperature changes that occur in the curing of hay, are utilized in some localities for the preparation of so-called brown hay. In this instance, the wilted grass is arranged in large, well-compacted piles, and is protected from the rain. The development of heat becomes manifest at the end of two or three days, when the mass begins to steam. It retains its high temperature for from eight to fourteen days, as may be readily shown by placing a thermometer in a metal pipe driven into the heated material.

After the steaming subsides, the hay is allowed to remain undisturbed for several weeks longer. It is then of a pale to a dark brown color, rather firm and dry, and somewhat aromatic. As chemical analyses have 
shown, marked losses of dry matter occur in the process of making brown hay. The losses fall most heavily on the carbohydrates and on the amides and soluble protein compounds. The making of brown hay, cannot therefore, be regarded as economical, and the practice is justifiable only in locations where rains are very frequent and interfere with the ordinary process of curing. Under such conditions, the farmer finds the preparation of brown hay a guarantee against spontaneous combustion.

Corn silage.-This substance is one of great economic importance in the United States. Vast quantities of corn are annually stored away in silos and form, later, a palatable and nutritious food for dairy cattle. The process of ensiling corn involves the cutting of the immature plants into small pieces which are then carried into square or circular structures known as silos. The material thus placed in the silos is compacted to exclude the air and is allowed to undergo fermentation. A rise of temperature occurs, large quantities of gas are evolved, and acids are produced which impart a characteristic taste to the material.

Careful experiments indicate that for the first two or three days the cells of the corn plants still have life in them. Their vital activities induce chemical changes that are evidently of moment in the making of silage. A part of the starch and sugar is thus transformed into gaseous products, some of the soluble substances are transformed into insoluble modifications, and slight losses of amides, of protein and of fat undoubtedly occur. The changes, in so far as they are of a purely chemical 
nature, may be attributed to the dying cells themselves or to the enzymes produced within them.

It is well known that large numbers of bacteria are present on the corn plants and that they are carried with the latter into the silo. What part do these bacteria play in the process? Do they contribute to the digestibility, the taste, or the flavor of the silage? or are they of no significance in silage-making? The data thus far available are not sufficient for a definite answer to these questions. In the investigations conducted at the Wisconsin station, it was demonstrated that the changes that take place in the ordinary silo may occur also when the corn is kept in an atmosphere of ether or chloroform. The product secured in the presence of these antiseptics was much like normal silage except that it contained a smaller proportion of acid.

It would seem then that silage may be produced even when the bacteria and other microörganisms are excluded, and that the changes occurring in the silo are independent of bacterial activities. However, it still remains to be demonstrated whether, under practical conditions of silage-making, the activities of the large numbers of microörganisms present are really of no significance in determining the digestibility, taste and aroma of the resulting product. 


\section{CHAPTER XLVII}

BACTERIA IN MISCELLANEOUS AGRICULTURAL INDUSTRIES

ThE fibers of flax and hemp which serve as raw material in the textile industries are held together in the plant by means of certain pectin compounds. These must be removed in order to render the fiber suitable for spinning.

The retting of flax and hemp.-The removal of the pectin substances is accomplished in practice by means of bacteria, which dissolve all of the organic compounds except the resistant fibers. The organisms in question have been isolated in pure cultures and proved capable of accomplishing the work unaided by other bacteria. Since the germs concerned in the retting of flax and hemp are anaërobic, they do their work when these materials are covered with water, as is done in the actual operations of retting.

The preparation of natto. - Natto is a vegetable cheese made in Japan by fermenting boiled soybeans. The fermenting mass is kept in a warm place for one or two days, at the end of which time it has become filled with vast numbers of bacteria. The material is then found to contain a large proportion of a mucilaginous, viscous substance, which is highly esteemed by the Japanese; 
The bacterial flora of natto consists at first largely of bacilli, but subsequently spherical forms become prominent.

Two rod-shaped organisms, isolated by Sawamura, were found to change boiled soybeans into a product similar to natto. One of these produced the characteristics taste and aroma, but did not develop a strong viscosity in the beans. The other organism was found to possess a more pronounced ability to form mucilaginous materials, but did not develop as desirable a taste and aroma. The changes produced by these organisms in the preparation of natto were shown to be due to enzymes secreted by them.

Bacteria and agricultural products.-Bacteria are also concerned more or less intimately in the preparation of other products of more or less remote agricultural origin. Among these may be included tanned hides and leather, and the various grades of fermented tobacco. In case of the latter, the exact significance of the bacterial activities has not yet been definitely established. 


\section{CHAPTER XLVIII}

\section{BACTERIAL DISEASES OF FERMENTED LIQUORS}

THE transformation of sugar into alcohol is a phenomenon that was well known to the ancients. From time immemorial, advantage has been taken of this knowledge for the preparation of a great many fermented liquors. The organisms chiefly concerned in the alcoholic fermentation of sugar are yeasts, and not bacteria, although the ability to produce alcohol is more or less common, also, to bacteria and molds. It is beyond the scope of the present work, therefore, to treat of alcoholic fermentations, even though they be of considerable interest to agriculture in their relation to grapes, grain, potatoes, and other raw materials of the fermentation industries.

The "turning" of wine and beer.-There are some changes, so-called diseases, to which wine, beer, cider, and other alcoholic beverages, are subject. The manufacture of vinegar, like these, is due to, or dependent upon, bacterial activities. The turning of wine and beer may be occasioned by acetic ferments, or by lactic ferments. The lactic taint appears most frequently in wine that is still young. The wine becomes turbid, acquires an irritating taste or flavor, and may subsequently be changed to a brown or black liquid. A slimy precipitate is formed and gradually accumulates at the bottom 
of the container. Wine thus turned always contains considerable quantities of lactic acid produced by certain lactic-acid ferments. The disease is most liable to occur in wine made from musts that are not, in all respects, normal, particularly from those whose acidity is below the average.

The turning of beer is characterized by a gradually increasing turbidity and the development of unpleasant tastes and odors. A deposit is also formed in the course of time. An organism isolated from samples of turned beer and named Saccharobacillus pasteurianus has been found to cause the disease when inoculated into sound beer. The alcohol in the beer does not prevent the development of the organism except when present in amounts greater than 7 per cent. It seems, also, that it is affected by the composition of the wort, since a larger proportion of hop extract either pre-

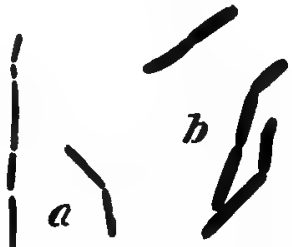

4. $\mathrm{gg}$. 70. Lactic-acid bac. teria, used for tbe souring of distillery yeast mash. $(a)$ $\times 2,000 ;(b) \times 2,700$ (Emmerling.) vents or retards its growth in the beer. The brewers guard against the turning of their product by careful refrigeration and resort to pasteurization when the beer is intended for export to warm countries. For certain varieties of beer, the lactic fermentation in beer wort is encouraged, as is done, for instance, in the brewing of "Weissbier" (white beer).

Ropiness in wine.-Another disease that leads to the development of ropiness in wine was investigated by Pasteur in 1861. He and other investigator's after him 
found bacteria in ropy wine, to which they attributed the disease, and showed that sound wine may be made to become ropy by the addition of some diseased wine. It is not yet known whether this malady is caused by a single organism, or whether there are several species capable of producing the same result.

Wine affected by this disease becomes turbid and gradually more viscid until, like ropy milk, it can be drawn out into threads. The phenomenon is attributed to the transformation of the sugar into mucilaginous substances by the bacteria. Besides this bacterial mucilage or gum, the ropy wine is found to contain a white, sweetish substance called mannite. Wines that contain more than 10 per cent of alcohol are not subject to this disease. Beer wort and beer are similarly subject to ropiness.

A number of organisms that may cause such ropiness have been isolated; some of them capable of growing only in unhopped wort, others developing in hopped worts and in beers. Worts rich in nitrogenous matter are most subject to this disease, while a high degree of acidity is inimical to the bacteria. The same or similar organisms cause ropiness in cider.

Sarcina sickness.-There is still another malady of beer, "sarcina sickness," caused by spherical bacteria. Additions of hops to the beer, or additions of salicylic acid in small quantities, may be employed for the suppression of this disease.

Loss of color in wine.-Among the common diseases of wine, of bacterial origin, may be included that which causes the loss of color. The color of red wine is changed to brown. The alcohol is changed into acetic acid, and 
the entire liquid finaliy undergoes putrefactive decomposition. The disease is more frequent in southern than' in northern countries and often involves extensive pecuniary losses. The bacterial nature of the disease is proved, not only by the presence of large numbers of bacteria in diseased wine, but, also, by direct inoculation of sound wine with a minute quantity of diseased wine. The presence of large amounts of protein favors the development of the disease, while the presence of any but minute quantities of acid retards it. It has been recommended, therefore, that citric acid be added to young wine as a preventive against the loss of color.

Mannitic fermentation.-This disease of wine is familiar to wine-growers. It is most prevalent in warm countries, largely because the bacteria causing the disease will develop best at higher temperatures. The disease is characterized by the conversion of the sugar into mannite. Still another common disease, the bittering of wine, has also been traced to bacteria. This disease, which usually affects only red wines, is manifested by a reduction of acidity, the loss of color, and the deposition of a sediment on the bottom and walls of the container. Objectionable tastes and odors are likewise developed in the wine and finally render it worthless.

The diseases of fermented liquors already enumerated by no means exhaust the list. There are others that are similarly responsible for serious injury to stored wine. Climatic conditions, locality, and the methods of manufacture employed, are factors of importance in influencing the character and prevalence of such maladies. Much bacteriological and chemical work has already 
been performed in the attempt to determine the nature ' and origin of these diseases. Much still remains to be done for their complete elucidation. All of them are of interest to agriculture in that they bear a certain relation to the value of vineyards and their crops. 


\section{CHAPTER XLIX}

\section{VINEGAR-.IAKING}

THE transformation of sugar into alcohol by yeasts and other microörganisms opens the way for still other changes. Apart from the various bacteriological diseases of alcoholic beverages already noted, the alcohol itself is the raw material for the preparation of acetic acid. It is well known that when wine, beer, or cider are left to themselves, they are likely to turn sour in the course of time; that is, they are likely to change into vinegar. Vinegar is, therefore, a sour liquid containing variable quantities of acetic acid made out of alcohol.

History of the art.-Old as is the art of vinegar-making, the true nature of the processes involved was not even suspected in the early days of the last century. In 1837, Kützing expressed the belief that the change of alcohol into vinegar is accomplished by living organisms. His statement was not accepted, however, as the true explanation of the phenomenon. The chemists, led by Liebig, carried the day, and it came to be believed for a time that the formation of acetic acid is a purely chemical process.

This claim was supported by the discovery made by Davy in 1821, that when alcohol is poured on platinumblack the latter becomes very hot and transforms the 
alcohol into acetic acid. Similarly, the spontaneous souring of wine and beer was thought to be accomplished by the condensation of oxygen in the pores of the membrane formed on the surface of the liquid. The membrane itself was regarded by the chemists as a lifeless mass of albuminous matter.

This purely chemical explanation of acetic fermentation fell to the ground, however, when Pasteur, in 1864, upheld the contention of Kützing in 1837. Pasteur demonstrated that the "mother of vinegar," the membrane on the surface of souring alcoholic liquids, was composed of minute living cells, to whose activities the formation of vinegar was due. He was not willing to admit, however, that the bacteria were directly concerned with the change of alcohol into acetic acid, but thought that they helped merely to condense the oxygen in the membrane and facilitated thus the oxidation of the alcohol.

Subsequent investigations showed that the microorganisms must play a direct part in the production of acetic acid. It was found that the transformation was accomplished best at certain temperatures. When the latter was too low, acetic acid was formed very slowly or not at all. When it exceeded $104^{\circ}$ Fahr., the formation of acetic acid stopped. Liquids containing more than 14 per cent of alcohol did not undergo acetic fermentation. On the other hand, the oxidation of alcohol by platinum-black was favored by high temperatures, and concentrated alcohol was changed as readily as was dilute alcohol. A further step in advance was made when the acetic ferments were isolated in pure culture 
and were shown to have the ability to change alcohol into acetic acid. When the organisms were kept out, this change did not take place.

Modern knowledge --Within the last fifteen or twenty years, our knowledge concerning acetic-acid fermentation has been enriched by many interesting facts. New species have been gradually added to the two acetic ferments, Mycoderma aceti and Mycoderma Pastorianum, described by Hansen in 1878, until the list includes now at least fifteen distinct organisms. The different organisms show characteristic variations as to the temperatures at which they will grow best; as to development in liquids of different concentration and composition, and as to the amount of vinegar produced in a given time. Henneberg found, for instance, that
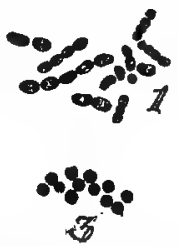

Fig. 71. Acetic-acid bacteria. -1 and 2. Bacteria from sour beer; $\times 1,600$. (Emmerling.) 3. Bacterium acetosum; $\times 2,000$. (Emmerling.)

Bacterium vini acetati showed a moderate growth at $97^{\circ}$ Fahr., while Bacterium xylinioides and Bacterium orleanense developed to a very slight extent at this temperature. Similarly, some of the species grew best at $77^{\circ} \mathrm{Fahr}$., and others at $86^{\circ} \mathrm{Fahr}$.

It may be concluded, therefore, that the different temperatures prevailing in different vinegar factories will, among other conditions, help to determine which of of the acetic ferments shall predominate. In the same way, it has been found that the various species will be unequally affected by the proportion of alcohol in the 
liquid, although they may become accustomed slowly to gradually increasing concentrations until an alcohol content of 10 per cent is reached. Even then, however, the growth is markedly retarded. Thus, it was found by Henneberg, that in the case of Bacterium xylinoides, growth occurred in five days with 0.2 per cent of alcohol; in thirty-two days, with 3 to 5 per cent of alcohol; and in forty-five days with 6 to 8 per cent of alcohol. The different species are unequally affected, likewise, by the concentration of acetic acid. According to Henneberg, the greatest amount of acid that would still allow bacterial development under certain laboratory conditions was 9.3 per cent for Bacterium xylinoides; 9 per cent for Bacterium orleanense; 8 per cent for Bacterium vini acetati, and 10.9 per cent for Bacterium Schüzenbachi.

The "mother of vinegar."-An examination of the "mother of vinegar," or "mycoderma," as it was called by Persoon as early as 1822 , will show it to consist of small, usually cylindrical cells imbedded in a mucilaginous substance. The latter causes the entire mass to form a continuous skin or membrane of variable thickness. The organisms imbedded in the membrane may occur singly, in twos, or in chains, and may also undergo more or less striking modifications in shape and size, as the temperature falls below or rises above certain limits. At temperatures below $60^{\circ} \mathrm{Fahr}$, the cells become long and exhibit pear-shaped swellings, while at $104^{\circ}$ Fahr. they not only undergo variations in shape, but may attain an extraordinary length, occasionally one hundred times that of normal cells.

As the temperature is again lowered to approximate 
the optimum, the long chains break up into the short rods. Apart from temperature, the age of the inoculating material and the composition of the liquid are of considerable influence in the formation of the extremely long or of the thickened cells. The proportion of acid in the liquid is of importance here, for with inereasing acidity the degeneration forms become prominent even at optimum temperatures, and a point is finally reached when most of the cells die off on account of the unfavorable conditions.

Acetic-acid bacteria.-These bacteria are distinguished for their ability to oxidize not only alcohol, but a whole series of other compounds. The products formed depend entirely on the nature of the original substance. For instance, oxalic acid is made by them out of grapesugar, cane-sugar, milk-sugar, and the like, the different species showing marked variations as to preference for certain compounds. Other compounds made by acetic-acid ferments include glycerine, mannite, butyric acid, gluconic acid, levulose, and various other substances. Moreover, the acetic acid itself made by the ferments out of grain alcohol may be burned up further to carbon dioxid and water.

This accounts for the fact that in sour wine, cider, and similar compounds, the acid accumulates up to a certain point and then begins to decrease in amount until, in some extreme cases, all of it has been used. Under such conditions, the ordinary decay bacteria are no longer kept out by the acid and the liquid undergoes putrefaction. The disappearance of the acetic acid in vinegar is favored by its dilution, for, having changed 
the alcohol into acetic acid, the bacteria proceed to oxidize it further. On the other hand, when the vinegar is quite strong, the bacteria and certain yeasts no longer find conditions suitable for their growth, and the acid is not burned up to water and carbon dioxid.

Methods of using acetic ferments.-In the commercial preparation of vinegar, the acetic ferments may be utilized either according to the Orleans method, or to the so-called "quick vinegar" (German, Schnellessig) method. In the first of these, named after the locality in France where it has long been employed, wine is allowed to turn sour in barrels. The latter have a capacity of about fifty-five gallons, and are provided with two holes near the top, one for the introduction of the wine and the removal of the vinegar, the other for the proper supply of air. The casks used in the process are thoroughly scalded with hot water, and then with hot vinegar. When thus made ready for use, they receive about twenty-two gallons of good, strong vinegar and about one-half gallon of wine.

At the end of eight days, a further quantity of wine (somewhat more than one-half gallon) is added, and in eight days more a somewhat larger amount; the additions being continued at similar intervals until the cask contains forty to forty-four gallons. The vinegar is then drawn off to leave about twenty-two gallons in the cask, and about two and one-fifth gallons of fresh wine added. After this, two and one-half gallons of vinegar are removed every week and are replaced by the same quantity of wine. When once properly started, the casks may be suitable for a continuous use of six to eight years, at 
the end of which time they require emptying and cleaning.

In the "quick vinegar" method, the change of alcohol into acetic acid is accomplished in vats filled with beech shavings. Grain alcohol diluted with the vinegar is allowed to trickle slowly through the shavings which, on account of the enormous surface exposed, present extremely favorable conditions for the development of the air-loving acetic ferments. We see, therefore, that while in the Orleans method the bacteria multiply at the surface of the liquid, in the "quick vinegar" method they multiply throughout the body of the shavings. When once thoroughly established on the surface of the shavings, the ferments of the "quick vinegar" method work with intense rapidity and accomplish the transformation of large quantities of alcohol in a comparatively short time. Under actual conditions in the factory, various species may come to predominate, among them yeasts and bacteria which oxidize the acetic acid to water and carbon dioxids.

The uncertainty as to the prevailing species is well illustrated by some investigations of Henneberg. In his studies of the acetic ferments in two vinegar factories in Berlin, where the Orleans method was employed, he found in casks standing close to one another Bacterium xylinum, Bacterium xylinoides, and Bacterium vini acetati. In the other factory, the differences were even more striking. Now, since the different species differ not only in the amount of acetic acid produced by them in a given time, but, also, in the quality, that is, the aroma, taste, and appearance of the product, it is 
not to be wondered that a uniform product is so hard to secure. Moreover, the manufacture of vinegar in accordance with the old methods not only makes it difficult to secure a uniform and high-grade product, but is also very wasteful of alcohol. In many instances, the liquid becomes infested with certain yeasts that burn up the acetic acid, and also with vinegar eels which, besides destroying large numbers of bacteria, also detract from the appearance of the vinegar.

Pure cultures in vinegar-making.-In order to make vinegar manufacture more certain as to results, it has been proposed that pure cultures be employed. Vinegar eels and injurious yeasts and bacteria would be thus eliminated, and the product would be uniform in character. The species that give the largest yields and produce the best-flavored vinegar could be selected, and the vinegar industry thus placed on a more firm basis.

Years ago an attempt was made to render vinegarmaking more certain in its results by the employment of a method somewhat analogous to that of natural starters used in cream-ripening. Quantities of wine were allowed to sour in small vessels, and the skin formed on the surface was carefully lifted off and placed on the surface of larger quantities of wine which was to be soured. Of course, care was taken to employ only such skin for inoculation as was, to all appearances, healthy and free from "vinegar eels." In practice, this method failed to yield satisfactory results, for the simple reason that the spontaneous skin formation in the small vessels was, at times, due to one kind of organisms, and at other times to entirely different organisms. 
Apart from the possible elimination of the vinegar eels, all of the old uncertainty as to results accompanied this method, and led to its abandonment. On the other hand, the use of pure cultures proper promises to gain favor with vinegar-makers. The difficulties involved are not at all insurmountable, and, as laboratory experiments have shown, pasteurization at comparatively low temperatures may be employed to assure the establishment of the desirable ferments.

The storing of vinegar.-The vinegar itself, like souring wine or cider, is liable to deteriorate on standing. Stored vinegar, as is well known, may lose its flavor, or may become turbid or slimy. The same undesirable organisms that become prominent in the process of vinegar-making may become prominent also in the manufactured vinegar, especially in the home-made product. Practical experience teaches us that the deterioration of stored vinegar is most marked when the proportion of acetic acid in the liquid is least.

Careful investigations have demonstrated that the vinegar eel multiplies only when the proportion of acid falls below 6 per cent. When more than this quantity is present, the growth of vinegar eels is suppressed. Similarly, the acid-consuming yeasts are not allowed to multiply when the proportion of acid exceeds 3 per cent; frequently their growth stops even when the quantity of acid is only 2 per cent of the entire volume. On the contrary, the acetic-acid bacteria are much more resistant to large accumulations of acid, some of them continuing to grow when the acid content reaches 11 per cent. Losses of acetic acid may occur under these 
conditions on account of the oxidizing activities of the bacteria.

It has been suggested, therefore, that the pasteurization of vinegar will prevent the loss of acid by the destruction of the non-spore-forming acetic ferments. . Since spore-forming. species are excluded by the acid, the heating of the vinegar need not exceed a comparatively low temperature, say $120^{\circ} \mathrm{Fahr}$. The presence of the acid hastens the destruction of the bacteria in the heating process, hence, in stronger vinegar, the organisms will be killed more quickly than in dilute vinegar. Moreover, the low temperature of pasteurization will not cause the escape of the volatile substances that impart the aroma to vinegar, nor of the acid itself.

The introduction of pure cultures in the manufacturing of vinegar promises to place the entire industry on a more certain and economical basis, while the resort to pasteurization for both the raw material and the finished vinegar will prove a boo for the manufacturer, farmer and dealer. The farmer, especially, should remember that the method of making cider vinegar, as employed by him at present, is too uncertain as to the quality of the product secured, and too wasteful of the alcohol. There is no reason why pasteurization and inoculation with pure cultures of desirable acetic ferments should not be accessible also for him. 


\section{INDEX AND GLOSSARY}

Aberson, 184.

Acetic acid, 465 .

Acetic-acid bacteria, 44, 466, 467, 468

Acid media, 44.

Acids, organic, 292.

Adametz, 376.

Aërobic bacteria (bacteria requiring an abundant supply of air), 38,40 , $117,139,309,312,345$.

Air, bacteria in, 45-54.

Albumoses (compounds formed in the decomposition of proteids), 420 .

Alfalfa, 131, 230, 231.

Algæ (minute green plants), 30, 88, 203.

Alinit (a commercial culture of bacteria at one time sold in Germany, and supposedly capable of fixing atmospheric nitrogen), 235.

Alkali salts, 78 .

Alkalinity, 44.

Altitude, effect of, on soil bacteria, 139.

Alum method, 84.

American Brie, 427.

Amide (Amides, or Amido-compounds substances formed in the decomposition of proteids and more simple in composition than albumoses), $417,420$.

Amino-compounds, 33 .

Armonia, 192, 193, 321, 331. 333; salts of, 172.

Ammonification, 161, 162, 320, 324 .

Ammonifying bacteria (bacteria capable of decomposing nitrogenous substances of animal or vegetable origin, with the formation of ammonia) 162.
Ammonium carbonate, 322-324.

Ammonium nitrate, 193.

Anaërobic bacteria, 40 .

Aniline dyes, 9.

Animalcules, (a name formerly employed to designate all very small living organisms), 71 .

Animal excreta, tubercle bacilli in, 399.

Anthrax (a bacterial disease usually fatal to cattle and sheep and due to a specific germ, Bacillus anthracis), 8.

Antitoxins (substances that can counteract the effect of toxins, or poisons, produced by bacteria), 10 .

Appert, 433

Artesian wells, 95.

Ascococcus mesenteroides, 449.

Attenuated (a term employed to designate cultures of bacteria that have been weakened by unfavorable conditions of growth), 37,38 .

Atwater, 210.

Automatic scavenger, 113.

Available substances, 182.

Azotobacter (a group of aërobic bacteria possessing a very pronounced power of fixing atmospheric nitrogen), 200-204, 235, 272, 289, 302.

Babcock, 419.

Bacilli (rod-shaped bacteria possessing the power of motion), 15.

Bacillus aerrogenes, 370, 384, 429; casei $E, 373,374$; coli communis $74,370,444,445$; cyanogenus, 375 ; Ellenbachensis, 235; fluorescens lique- 
faciens, 412, 413; lactis acidi, 372, $373,381,384,443-445$; lactis erythrogenes, 375; lactis viscosus, 376; mycoides, 295; radicicola, 213, 226, 227; subtilis, 319 .

Backstein cheese, 422 .

Bacteria (rod-shaped organisms not capable of moving about in the culture solutions. In a broader sense, all microseopical organisms of a certain character) 17; aërobic, 38; ammonifying, 162; and disease, 6; and respiration, 55; carbon compounds in, 32; carbon source of, 33; conditions affecting growth of, 36; cylindrical, 13; denitrifying, 166; digestion of food by, 164; discovery of, 2; effect of cold on, 37, - of concentration of medium on, $42,-$ of electricity on, 41, - of germicides on, 42 , - of preservatives on, 42 , of pressure on, 41,42 , - of reaction of medium on, 43, - of sugar on, 43, - of sunlight on, 40,41; food requirements of, 30 ; form and structure of, 13; in air currents, 46 ; in air, determination of, $47,-$ influence of altitude on, 55, - influence of climate on, 53, - influence of dry weather on, $52,-$ influence of season on, 52, - numbers and kinds of, 48 , - of cities, 49, - country, 51, - of Paris hospitals, 53, - of polar regions, 51; in atmosphere, 45; in bread, 447; in butter, 411-415, - numbers and kinds of, 412; in canning industries, 431-438; in cheese, 416-430; in cisterns and tanks, 95, 96; in cream, 402-410; in dust, 50; in fermented liquors, 458-461; in filter beds, 121; in hay, 451-453; in herring brine, 441 ; in ice, 97, 98; in legume nodules, 212, 214; in manure, 303-306, $309,312,318-345$; in mountain air, 54 ; in peat, 146; in pickles, 445; in rivers and lakes, 77 ; in sauer- kraut, 442-444; in sea air, 51; in sewage, 103, 108; in silage, 454,455 ; in soil, 275, 276, - decomposition of humus by, 146, - distribution of, 142, - effect of altitude, lime, manure and tillage on, 139-142, numbers of at surface, 143, phy aiological efficiency of, 160, relation of, to humus, 144 , - transformation of nitrogen by, 155, variations in vigor of, 159; in the sugar industry, 449,450; in vinegarmaking, 463-472; in water, 61-96, - character of, 62, - competition among, 69, - increase and decrease of, 64; influence of, on one another, 166; iron, 299, 302; lactic acid, $370-373,390,405,406,412,418$, 420-424, 459; nitrate-consuming, 187; nitrifying, $170,171,177,181$; nitrogen-fixing, 196-206; nitrogen, source of, 33; nitrogen-transforming, 196; numbers and kinds of in butter, 412; numbers of in soil, 137; peptonizing, 164, 418, 425; relation of nitrifying to ammonifying, 181; spherical, 13; sulfate-reducing, 297; sulfur, 294-298; thermophile, 36; tubercle, 217-219, - forms of, 215; tuberculosis, in butter, 413, - in manure, 398, - in milk, 397.

Bacterial activities, influence of lime on, $28,-$ of phosphate on, 282, 284.

Bacterial cell, chemistry of, 26.

Bacterial flora (the various species of bacteria characteristic of the soil or other natural media), 165.

Bacteroids (that is, bacteria-like, small bodies found in the nodules on the roots of leguminous plants), 213.

Bacteriology and agriculture, 11.

Bacterium mazun, 381; orleanense, 465; prodigiosum, 375, 376, 413; Schutzenbachi, 466; vini acetati, 465 . 469; xylinoides, 465, 466, 469; xylinum, 469.

Bare fallows, 266, 270. 
Barns, bacteria in atmosphere of, $\mathbf{3 6 1}$. Bassi, 6.

Beal, 309.

Berthelot, 211.

Beyerinck, 197, 199, 202, 213.

Boeckhout, 372.

Bone, phosphoric acid in, 285.

Bonnet, 4.

Boussingault, 169, 193, 209.

Bread, faults, 447; sour dough, 447 ; viscous, 448.

Brie cheese, 422, 426, 427.

Broad irrigation, 128-130.

Brown hay, 453.

Brunchorst, 213.

Butter, bacteria in, 411-415; changes occurring in, 411; disease bacteria in, 413; faults, 414, 415; lactic-acid bacteria in, 412; numbers and kinds of bacteria in, 412; rancidity of, 412,413 .

\section{Cameron, 114.}

Camembert cheese, 422.

Canning industry, bacteria in, 436; development of, 433; principles of, 432; temperatures required in, 434 , 435; use of preservatives in, 438 .

Cans, swelling of, 434, 436 .

Carbon, amount of in plants, 147; bisulfide, 272, 329; compounds of, in bacteria, 32; dioxid, $30,147,148$, 388; disappearance of, from humus, 154; monoxid, 31 ; restoration of, to air. 147; sources of, to bacteria, $31,33$.

Caron, 235, 272.

Cell, bacterial, chemistry of, 26; wall, 27.

Cellulose, 27; digestibility of, 342; fermentation, 342; fermentation of, in manures, 342; ferments, 342-345.

Cess-pools, 105; as sources of pollution, 92; origin of, 104.

Cheddar cheese, 427, 428.

Cheese, bacteria in, 416-430; lacticacid bacteria in, 418 ; multiplication of bacteria in, 420; peptonizing bacteria in, 418; ptomaine poisons in, 417.

Cheese-ripening, 416, 417; effect of chloroform on, 420; enzymes in, $419,421,422$.

Cheeses, hard, 428-430; soft, 423-427; lactic-acid bacteria in, 424; molds presence of, in ripening, 425; peptonizing bacteria in, 425 ; ripening of, 424 .

Chemical methods of sewage-disposal, 107.

Chili saltpeter, source of, 174 .

Chloroform, 272.

Chlorophyl (a green coloring matter found in the leaves or stems of plants, which is indispensable for the assimilation of their food under normal conditions), 30 .

Cholera, 58.

Cisterns, 96.

City air, bacteria in, 51 .

Cladosporium butyricus, 413.

Cladothrix dichotoma, 301.

Clark process, 84; efficiency of, 85 .

Climate, influence of, on bacteria, 53 .

Clostridia (boat-shaped cells of certain spore-forming bacteria), 15.

Clostridium gelatinosum, 450; pastorianum, 197-203.

Clover, failure of, 206.

Coal, anthracite and bituminous, 146.

Cocci (spherical bacteria), 15.

Cold, effect of, on bacteria, 37 .

Colon bacillus in soils, 75 .

Colonies (little heaps of bacteria of one kind, visible to the naked eye), 9.

Color, loss of, in wine, 460 .

Compost heap, nitrate formation in, 339.

Conditions affecting bacterial growth, 20,36 .

Contact beds (pits filled with cokebreeze, burnt clay ballast, and simi lar substances; sewage is here 
periodically admitted and withdrawn), 117.

Contagion, 2.

Corn, 383; silage, 454, 455 .

Cotton cultures, 233; commercial preparation of, 234; defects of, 234; tests of, 234.

Cotton, moist, heating of, 452 .

Country air, bacteria in, 51 .

Cowpeas, 245 ; and vetch, 252; wide usefulness of, 247.

Cream, bacteria in, 402-410; lacticacid, bacteria in, 406; pasteurized, use of, with pure cultures, 410; ripened, number of bacteria in, 405 ; ripening, 402, 404; separating of, on farms, 409.

Crenothrix Kuhniana, 301.

Crimson clover, 245; amount of nitrogen in, 251; nitrogen-gathering, power of, 250; value of, on sandy soils, 249.

Crops, fallow, 237; green-manuring, 237; relation of, to soil bacteria, 141; rotations of, $239,241$.

Culture medium (any substance or combination of substances that offers suitable conditions for the growth of bacteria), concentration of, 42; moisture in, 38; new methods for preparation of, 43 ; reaction of, 43.

Culture (a growth of any species of bacteria on suitable media), liquid, 234; pure, 9.

Dark Ages, condition of agriculture in, 240.

Deep wells, bacteria in, 93 .

Dehérain, 343.

Denitrification (the decomposition of nitrates by bacteria with the evolution, usually, of nitrogen gas), $161,183-185,188,189,326-320$.

Denitrifying bacteria, 166, 187, 188, $3: 7$.

Diarthœe, 58.
Diaspora caucasica, 379.

Digby, 176.

Digestion, losses of elements in, 307.

Dill-pickles, $445,446$.

Disease bacteria in milk, 397; butter. 413.

Diseases of fermented liquors, 458 .

Domestic filters, 87 .

Drying of food products, 439.

Dupetit, 184.

Dust, bacteria in, 50 .

Dust particles in air, $45,46,50$.

Dysentery, 59, 60 .

Eberth, 58.

Economy of fallowing, 270.

Edam cheese, 427.

Effluent (purified, or partly purified, sewage, running out of filter beds, contact beds, etc.), treatment, 119 .

Electricity, infuence of, on bacteria, 41.

Elementary nitrogen, losses of, from manure, 331.

Emmenthaler cheese, 427.

Emmerling, 381.

Enzymes (chemical compounds elaborated by animals, plants and bacteria, or other microörganisms, and indispensable to them for the proper digestion and assimilation of food), $34,35,164,419,421,422$.

Eremakausis (the decay of vegetable or animal substances with a plentiful supply of air), 150.

Ether, 272.

European agriculture, revival in, 241. Evelyn, 176.

Facultative aërobes (bacteria preferring to develop in the absence of air, but capable, also, of growing when air is admitted), 40; anaërobes (bacteria preferring to develop in the presence of air, but capable, also, of growing when air is excluded.) 40 , 
Fallow crops, 237, 266.

Fallowing (the cultivation of land which is allowed to remain bare for an entire growing season), definition of, 265; cconomy of, 270; in ancient times, 265; objections to, on sandy soils, 270; wastefulness of, 271.

Fallow soils, 267, 268; bacteria in, 273.

Fallows and aëration, 269; bare, 266, 270,272 ; characteristics of, 267; conservation of moisture in, 269; elimination of, 267.

Farms, abandoned, 271; sewage, 131.

Farmyard manure, losses from, 306 .

Fats, 28.

Fermented liquors, bacteria in, 458 .

Ferments (substances or organisms capable of causing fermentation, that is, chemical change in organic materials, which is rather intense in character), nitric, 171.

Filter beds (masses of coke, broken stone, clinkers, sand, and the like, arranged in layers of varying degree of fineness and employed for the filtration of water or sewage), $82,83$.

Filters, domestic, $86,87,121,122$; efficiency and temperature, 120; working capacity of, 124.

Filtration of sewage, 116; of water, $81,82,83$.

Finishers (chemicals that may be used to purify still further the filtered sewage), 134.

Fish, 440.

Fisher, 50.

Flagella (long, thread-like appendages on the bodies of bacteria employed as organs of locomotion), 17.

Flax, bacteria in the preparation of, 456.

Floats (finely ground raw phosphate rock), $284,285$.

Flora, bacterial, 165.

lood, absorption of, by bacteria, 164; digestion of, by bacteria, 164; products, pickling of, 439 ; requirements of bacteria, 30 .

Foods, exclusion of preservatives from, 440; preservation of, and bacteria, 431 .

Fore-milk, bacteria in, 360 .

Form and structure of bacteria, 13 .

Formaldehyde, use of, in milk, 393.

Forcing effects of green-manures, 263.

Forests, influence of, on bacteria in gir, 51.

Fraser, 362.

Freudenreich, 318, 418.

Fruit, keeping quality of, and greenmanures, 261.

Galactase (an enzyme found in cow's milk, and of considerable imporance in the ripening of cheese), $419,422$.

Gammelost, 422.

Gayon, 184.

Gelatine, use of, in plate methods, 9

Germicidal power of milk, 382, 383 .

Germicides (chemical substances destructive to bacteria even when used in comparatively small amounts), 42.

Gilbert, 193, 209, 211.

Giltay, 184.

Glycogen (a kind of sugar found in the liver, and, also, in some species of bacteria), 27 .

Goodwin, 310.

Gorgonzola, 422, 426.

Granluose (a starch-like substance found in some species of bacteria). 28.

Green-manuring, 237; practice of, 242.

Green-manures, 237; accumulation of nitrogen by, 261; decomposition of in the soil, 255; depth of covering of, 259; draught on soil-moisture, 244; effect of on keeping quality of fruits, 261; - on soil bacteria, 244, - succeeding crops, 247, 259; 
forcing effect of, 263; for loam and clay soils, 253; functions of, on light soils, 254; legumes suitable for heavy soils, 259; leguminous, value of, origin of, 239; nitrogen content of, 245; on sandy soils, 241, 243; relation to soil-humus, 237; smaller returns from on heavy soils, 259; value of, for soil-improvement 242.

Grotenfelt, 362, 367, 408.

Gypsum (sulfate of lime), 295, 297, 348 .

Hall, 312.

Haubner, 342.

Hauser, 465.

Hay, bacteria in, 451; brown, bacteriological activities in, 453 ; freshly cut, rise of temperature in, 451 ; beating of, 452, 453; preparation of, 451 ; relation of bacteria to, 452 .

Health and disease, relation of water to, 58 .

Hell riegel, 195, 210, 212, 213, 221.

Hemp, bacteria in the preparation of, 456.

Henneberg, 307, 465, 466, 469.

Herring brine, bacteria in, 441.

Henle, 6.

Higgs, 106.

Hilgard, 279.

Hiltner, 227, 229, 268, 272.

Hippocrates, 57.

Hippuric acid (a nitrogenous substance found in considerable proportion in the urine of herbivorous animals), 321.

Hoffmann, 5 .

Hospitals, bacteria in the air of, 53 .

Humic acids (sour substances found in humus), 151.

Humus, decomposition of by bacteria, 146; disappearance of carbon from, 154; exhaustion of in cultivated soils, 152; formation of in moor and heath soils, 152; in sandy soils, 153; nitrogen compounds in, 156; phos- phoric acid in, 283, 284; proportion of in acid soils, 145; rate of decay of, 149; raw, 145; relation of crop-rotations to, 239, - bacteria to, 144, - green-manuring to, 238, potash to, 291, - to water-holding power of soil, 144 .

Hydrolysis (chemical change prominent among others in the decomposition of proteids by bacteria, 118 .

Ice, bacteria in, 97, 98 .

Ice, use of, in the transportation of milk, 395.

Immunity (ability to resist infection), 11.

Impermeable, 29.

Inoculation (the introduction of definite species of bacteria, or other microörganisms, into animals, plants, or any media presumably suitable for their development), on various soils, 224; soil, cotton cultures, 233,234 , - history of, in U. S., 230, - liquid cul tures, 234, Moore's method, 232, - with alinit, 235, - with pure cultures, 226, method of securing, 226; soil 222, defects of, 225, - diseases introduced by, 225, - lessons taught by, 225.

Intermittent filtration (that is, not continuous filtration), 116.

Intermittent sterilization, 24.

Involution forms (bacterial cells of irregular or abnormal shape, and size, usually due to unfavorable conditions of growth), 15.

Iron bacteria, 301 ; as geological agents, 302; importance of, 301; influence of, on azotobacter, 302; potential energy in, 300; production of nitrates by, 195; relation of bacteria to, 299, 300; relation of decay bacteria to, 302 ; rust, 300 ; soluble compounds of, 301 ; sulfate of, 299 . 
Irrigation, broad, 128-130; intermittent, 128, 130; kinds, 128; mixed, 128, 130.

Isigny cheese, 426 .

Jensen, 408, 419.

Jubert, 449 .

Kainit, 350.

Kalantarjanz, 381.

Kaserer, 172, 333.

Keeping quality of milk, 382-385, $387,388$.

Kefir (cow's milk, fermented by means of Kefir grains, which are composed of a mixture of certain yeasts and bacteria), 378, 379; grains, 378 .

Khün, 204.

King, 268.

Klebs, 7.

Koch, 8, 9, 58.

Kohn, 8, 9.

Kumiss, (originally prepared by fermenting mare's milk by means of a mixture of yeasts and bacteria), 379,380 .

Kublmann, 169.

Kützing, 463.

Lactic-acid bacteria (organisms capable of transforming milk-sugar, or other sugars, into lactic acid), 370$373,390,405,406,412,418,420-$ $422,424,459$.

Lactic acid, formation of, in dillpickles, 445, 446.

Lakes and ponds, circulation of water in, 88 ; pollution of, 89 ; sedimentation in, 88 .

Lakes, bacteria in, 77 .

Lawes, 193, 209.

Leëuwenhoek, 2.

Legumes. as green-manures, 239-259; cause of soil-enriching qualities of, 207; entrance by nodule bacteria, 217; limitations of, 206; nodules, bacteria in, 212; tubercles, arrange- ment, of on roots, 214; value of, 206.

Lemaire, 7 .

Liebig, 192, 208, 209, 460.

Limburger, 422.

Lime, bicarbonate, 277; causes of migration of, 277; effect of, on soil bacteria, 142; importance of, 279; influence of, on azotobacter, 201, 280 ; - on bacterial activities, 280 ; in manure, conservation of, 349; losses of, from soil, 278,279 ; phosphate, 281,286 ; relation of bacteria to, 276,- - of potash to, 291, to nitrifying power of soil, 179; removal of, to the sea, 277; required for nitrification, 179 ; restoration of, by bacterial activities, 280; solubility of, 277; sulfate, 196, 295.

Limestone, decomposition of, 276 ; soils, 201.

Liming of soils, 278.

Liquid cultures, 234 .

Liquid manure, ammoniacal fermentation of, 322 .

Lister, 7, 11.

Litter, relation of bacteria to, 346 ; resistance to decay, 305 .

Lockjaw bacillus, 40.

Losses from farmyard manure, 306.

Loss of colar in wine, 460 .

Maercker, 311, 335.

Magnesia, relation of, to bacteria, $276,277$.

Malaria, 58.

Malpighi, 212.

Mannitic ( fermentation of wine undesirable changes in wine, caused by bacteria and accompanied by the formation of a white crystalline substance, mannite), 461.

Manure, aërobic bacteria in, 309 ; ammonification in, 320,324 ; bacterial changes in, 303, 304; barnyard, bacteria in, 303; cellulose fermentation in, $342-344$; changes of 
bacterial species in, 3i9; character of bacteria in, 319; compacting of, 309 ; composition of, 304, 305; conditions affecting bacterial decomposition of, 320; conservation of, 349-356; cost of organic matter in, 316; danger of denitrification from, 329; decomposition of, 313; denitrification in, 326, 327; denitrifying bacteria, carried by, 188; denitrifying, power of, 328, 329; depressing effect of, on nitrification, 186; farmyard, losses from, $306,308,309$; formation of ammonium carbonate in, 322; formation of gases in, 344; growth of bacteria in, 306; importance of proper storing of, 308; increase of insoluble nitrogen in, 334, 335; influence of, on soil bccteria, 141; liquid, ammoniacal fermentation of, 322, formation of ammonia in, 321, separate collection of, 312; losses of ammonium carbonate from, 323 , - of elementary nitrogen from, 330-332, - of nitrogen from, 310 , 311,312 , - of organic matter from, 309; measurement of temperature of, 355; mechanicai constitution of, 304; nitrates in, 326; nitrification in, $337,338,340$; numbers of bacteria in, 318; organic matter in, 307; temperature of, 314 ; value of, 307 ; of lost portions from, 315, - of organic matter in, 316.

Marshall, 373.

Marsh gas, 151, 343, 344.

Matzoon (fermented milk, originally prepared in Armenia by means of a mixture of certain yeasts and bacteria), $381,382$.

Meat, canned, 438.

Mechanical methods for conservation of manure, 30 , 356.

Membrane-formation, 19.

Methane (or marsh gas, an inflammable gas occurring in swamps, petrol- eum wells, volcanoes and cual mines), 31, 344 .

Michel, 58.

Milk, as a food, 357; beverages, 378; bitter, 376; blue, 374; canned, 438; cooling of, importance of, 384; curdling of, 370; diphtheria and scarlet fever in, 401; dirt in, 362, 363 ; disease bacteria in, 397 ; elimination of bacteria from, 386,387 ; faults, 374; germicidal power of, 382 , 383; keeping quality of, 382$384,387,388$; kinds of bacteria in, 369; machine-drawn, bacteria in, 365,366 ; numbers of bacteria in, $366,382,395$; pails, $361,365,387$; pasteurization of, 389,391 ; preservatives, 392; progress in production of, 358; red, 375; ropy, 376, 377 suitability for bacterial growth, $\mathbf{3 5 8}$; source of bacteria in, 360 ; spontaneous souring of, 373; sterilization of, by heat, 388, 389; strainers, 367 . 368; transportation and distribution of, 394, 395; treatment of, with chemicals, 392; tuberculosis, bacteria in, 397; typhoid bacilli in, 400; typhoid infection of, 59 ; utensils, 385 .

Miquel, 49, 51, 52.

Mixed irrigation, 128, 130.

Moisture in fallow soils, 268.

Molds in Camembert cheese, 425; Roquefort cheese, 426 .

Moore's method, 232.

Moors, formation of humus in, 152.

Mother of vinegar (a heavy membrane formed on the surface of alcoholic liquids which are being changed into vinegar-acetic fermentation), 464. 466.

Motile bacteria (bacteria that possess the power of motion), 19.

Motility, 17.

Mountain air, bacteria in, 5,54 .

Mouras, Autornatic Scavenger, 113.

Müller, 115. 
Muntz, 11j, 116, 169, $19 b$.

Mycoderma aceti, 465; pastorianum, 465.

Natto (a vegetable cheese made in Japan out of soy beans), bacteria in, 456,457 .

Natural starters (impure cultures of lactic-acid bacteria secured by allowing milk to turn sour spontaneously), 407 ,

Needham, 2.

Nitragin, cause of failure of, 228 ; failure of, 228; further studies with, 228; gratifying returns from, 229; improvement of, 228; new, 235; preparation of, 227; recent experience with, 229 .

Nitrate (or nitrite, a salt resulting from the union of nitric acid with a base. Nitric acid has three equivalents of oxygen, $\mathrm{HNO}_{3}$. Nitrous acid has only two equivalents of nitrogen, $\mathrm{HNO}_{2}$, and the union of this with a base produces a nitrite. Nitrate of soda is $\mathrm{NaNO}_{3},-\mathrm{Na}$ standing for sodium, $\mathrm{N}$ for nitrogen, $O$ for oxygen. Nitrite of soda is $\mathrm{NaNO}_{2}$.), accumulation of, in manures, 340; formation of, 176 , 178 , - in compost heaps, 339, in electrical discharges, 195; in gunpowder-making, 168; leaching of, from soil, 158, 194; loss of, in soils, 174; of ammonia, 193; of potash, 175; of soda, consumption of, in 1903, 175; production of, by iron, ozone, and sulfate of lime, 195, - by organic matter, 184; relation of, to plant growth, 175; removal of, in drainage, 177; utilization of, by plants, 194.

Nitric ferments, 171.

Nitrifying bacteria, 170, 181; culture media for, 171; development of, in deeper soil layers, 177; in sand filters, 83.
Nitrification (the gradual change of nitrogenous yegetable or animal substances into nitrate), 160 ; bacteriological nature of, 195; character of, 169; conditions, affected by, 173; definition of, 168; depressing effect on, of manures, 186; effect of crop on, 182; importance of, 172; in different soils, 173; in manure, $337,338,340$; lime required for, 179 ; study of, at Rothamsted, 176.

Nitrites, 171.

Nitrobacter, 171 .

Nitrogen, accumulation of, in the soil, 261; addition of, to soil, by azotobacter, 204; amount of, in atmosphere, 155, - - in crimson clover, 251; and bare fallows, 272; available and unavailable, 335,336 ; conditions affecting availability of, 160; content of, in productive soil, 191; elementary, losses of from manure, 330-332; fixation, 199 , 205, 209, 211; fixing bacteria (organisms capable of causing the nitrogen gas of the air to combine with other elements. This property enables them to enrich the soil in nitrogenous substances), 196, 199 , $200,202,-$ in filter beds, 122; gas, utilization of, by plants, 195: hunger, 217; increase of, in manure, 334 ; insoluble, 334; in soil-humus, 156 ; in subsoil, 156; loss of, in continuous growing of wheat, 179; loss of, in-soil, 157; losses of, in filter beds, 122; proportion of, in soil, 155; soil, 190, - bacteriological efficiency in transformation of, 161; soil, increase of, 190; source of, for bacteria, 35; source of, in soil, 155; theory of source of, to plants, 208 ; transformation of, by bacteria, 155; transforming bacteria, 196, 197; utilization of, by bacteria, 190 . Nitrogenous materials, availability of, 181: 
Nitrosococcus, 171.

Nitrosomonas, 171.

Nobbe, 227, 233.

Nodules (little swellings that are formed on the roots of legumes through the ageney of a certain species of bacteria), depth of formation, 259; nature of, 213; on roots of legumes, 210, 212, 217.

Non-motile bacteria, 19 .

Oidium lactis, 413, 425-427, 444.

Omelianski, 344.

Organic acids (sour substances containing the element carbon. Carbonic acid is usually not included among these.), effect of, on rock decomposition, 292.

Organic matter, destruction of, in water, 67,81 ; oxidation of, in animal body, 307; production of nitrates by, 184; quality of, in water, 78: relation of, to denitrification, 189.

Orleans method, 469.

Oxidation of ammonia, 331, 334.

Oxygen, relation of bacteria to, 38 .

Ozone (a modification of oxygen, found in minute quantities in the atmosphere, and produced artificially by chemical or electrical methods), 86, 195.

Pasteur, 5, 11, 49, 115, 169, 390, 459.

Pasteurization (the heating of materials, usually to $140^{\circ}$ to $165^{\circ} \mathrm{Fahr}$., g temperature sufficient to kill the bacteria themselves, but not their resistant spores), 23, 24, 389-391, 472.

Pathogenic bacteria (capable of causing disease), 23.

Peat, number of bacteria in, 146.

Penicillium camemberti, 425, 426.

Pepsin, 34, 422.

Peptones (substances akin to al- bumoses, derived from the decomposition of proteids), 420 .

Peptonizing bacteria (organisms producing enzymes that lead to the breaking down of proteids and the formation of albumoses, peptone, amides and ammonia), 418, 425 .

Permeable, 29.

Persoon, 466.

Pfeiffer, 332, 350.

Phosphate, fertilizers and bacterial activities, 284; lime, 281, 286.

Phosphates, influence of, on humus, 282; relation of, to soil bacteria, 281; soil, relation of, to carbon dioxid, 282; soluble, production of, by bacteria, 282 .

Phosphorescence, 35.

Phosphoric acid, action of, 289; availability of, in bone, 286 ; availability of, in Thomas slag, 287; in bone, 285; in humus, 283; in manure 289; relation of, to soil bacteria, 289; solution of, in soil, 281.

Phosphorus, in humus, 284; inorganic, and organic, 282; relation of, to soil bacteria, 282.

Photobacteria (bacteria that cause phosphorescence in the media in which they are growing), 35.

Physiology of bacteria (the ehemical changes effected by bacteria in their life processes), 5.

Pickles, 445, 446.

Pigments, 35.

Plant-food, loss of in drainage, 126.

Plant-food, removal of, to the sea, 276.

Plate methods (the isolation of bacteria from colonies on gelatin, agar, and similar materials that can be spread out and solidified by cooling on glass plates, or shallow glass dishes), 9.

Plenciz, 6.

Popov, 342.

Port de Salut, 422, 
Potash, carbonate of, 253; chararter of, in soil, 290; influence of carbon dioxid on, 290; relation of humus to, 291; relation of lime to, 291 ; relation to soil bacteria, 292, 293; relation to weathering, 290; salts, influence of, on soil bacteria, 292.

Prazmowski, 213.

Preservatives, 42, 438.

Pressure, influence of, on bacteria, 41, 42.

Proteins (complex organic substances containing about 16 per cent of nitrogen), 32.

Protoplasm, (the active substance of living cells in which the chemical reactions necessary for organized life take place), 17, 27, 29 .

Protozoa (minute, one-celled animals), 72

Pseudomonas, 19.

Ptomaines, 417.

Pugh, 193.

Pure cultures (the growth of any single species of microörganisms in suitable media), in vinegar-making, 472.

Quick vinegar method, 468, 469 .

Rancidity of butter, 412,413 .

Reaction of soils, 44 .

Rennet, 419.

Resistance, 11.

Respiration and bacteria, 54, 55 .

Ripening of cheese, $416,417,419-422$; cream, 402, 404.

Rivers and sewage, 105; bacteria in, 77; Pollution Act, 106; self-purification, of 79 .

Rod-shaped forms, 15.

Ropy wine, 460 .

Roquefort cheese, 422, 426.

Rotation of crops, 239, 241.

Rothamsted soils, azotobacter in, 204.

Ruysel, $310,419$.
Rye grass, 131.

Rye straw, 30 .

Saccharobacillus pastorianus, 459.

Saccharomyces pastorianus, 381.

Salting of foods, 440 .

Saltpeter, origin of, 168.

Sand filters, $82,83$.

Sand vetch, 251.

Sarcina, sickness of wine, 460 .

Sauerkraut, bacteria in, $4 \pm 1,443$; preparation of, 442; presence of lactic acid in, 443.

Scarlet fever and milk, 401 .

Schloësing, 115, 116, 168, 195.

Schneidewind, 355 .

Schoenbein, 184, 193.

Schroeder and Dush, 5 .

Schroeter, 7.

Schubert, 206.

Schultz, 242, 259, 261, 288.

Schultze, 4.

Schwann, 6 .

Sea-air, bacteria in, 51 .

Sedimentation (the gradual settling out of solids suspended in water), $72,73,88$.

Self-purification (the natural tendency for the decomposition and disappearance of organic substances in streams or other bodies of water'), of streams, 66,79 .

Septic tank, 114, 11 $7,118,122$.

Septic tanks (covered or uncovered pits in which a large portion of the organic matter in sewage is decomposed by anaërobic bacteria), inoculation of, 121; kinds of bacteria in, 121 .

Settling basins (tanks, pits, or depressions in the ground, in which suspended solids in sewage or water gradually settle out), 81 .

Severin, 306.

Sewage, and rivers, 105; bacteria in, 103,108 ; bacterial purification of, 112,122 ; clogging of soil with, 129; 
composition of, 110; decomposition, aërobic and anaërobic action in, 117; disposal, bacteriological methods of, 107, - chemical methods of, 106, 107, importance of, 110, - problem of, 103, 109; examination of, 111; factory wastes in, 123; farming, objections to, 133; farms, 112, 127, 131; intermittent filtration of, 115; irrigation, value of, 125, 127; preliminary treatment of, 132; purifieation, relation of temperature to, 118 ; purification, sanitary efficiency of, 134; source of, 110; spent liquors in, 124; sterilization of, 108; value of, per ton, 127.

Shape of bacteria, 15.

Silage corn, 454.

Size of bacteria, 17.

Sludge (the material that settles out of sewage, or is precipitated out by means of ehemicals), 126,132 .

Smoking of foods, 440 .

Soft cheeses, 422; lactic-acid bacteria in, 424; peptonizing bacteria in, 425; production of, in the U. S. 423 .

Soil, aërobic species in, 139; air, composition of, 150; anaërobic species in, 139; bacteria, effect of lime on, 142, - influence of tillage on, 141, - numbers of, at surface, $143,-$ physiological efficiency of, 160, relation of crops to, 139 , - variations in vigor of, 159; clogging of, by sewage, 129; colon bacillus in, 75; distribution of nitrogen in, 199; fertility and bacteria, 135; formation of nitrates in, 178; gases, 151 ; humus, decomposition of, by bacteria, 146, - nitrogen compounds in, 156; improvement, 242; inoculation, 221-226, 230, 236; leaching of nitrates from, 158, 174; loss of nitrogen in, 157; nitrifying power of, 179, 180; nitrogen, in- crease of, 190; numbers of bacteria in, 137; proportion of nitrogen in, 155; removal of nitrogen from, 191; source of nitrogen in, 155 .

Soils, ammonifying power of, 167; arid, proportion of humus in, 145; cultivated, exhaustion 'of humus in, 152; fallow, 267, 273; greenhouse and market-garden, denitrification in, 188 ; liming of, 278 ; sandy, greenmanures in, 241,243 , - humus in, 153, - value of crimson clover on, 249; sterilized, carbon dioxid in, 148.

Souring of canned vegetables, 436 .

Soybeans, 230, 245.

Spherical bacteria, 13, 14.

Spiral bacteria, 13, 14.

Spirilla (spiral-shaped bacteria), 17.

Spontaneous generation (the formation of living organisms out of dead matter), 3, 4.

Spore-formation, 22.

Spore-forming bacteria, 23.

Spores (certain cells, formed in some species of bacteria, and capable of withstanding adverse conditions much better than the bacteria themselves), 22; discovery of, 5; vitality of, 23 .

Starters, building up of, 407 .

Starters (pure or impure cultures of lactic-acid bacteria added in considerable proportion to cream that is to be ripened), definition of, 406 ; natural, 407, 409; preparation of, 407,408 ; pure culture, 407-410.

Sterilization (the complete destruetion of bacteria and other microorganisms in any material), 23, 24; by superheated steam, 25; of milk, 388,389 ; under increased pressure, 25.

Stilton cheese, 422,426 .

Stocking, 365 .

Stored water, bacteria in, 82

Storer, 127. 
Störmer, 268, 272.

Straw, denitrifying bacteria in, 187.

Streptococcus mesenteroides, 449, 450.

Strippings, bacteria in, 360 .

Stutzer, 313, 350.

Subsoil, nitrogen in, 156 .

Sugar, 32, 43.

Sulfate of iron, 299; -reducing bacteria, 297.

Sulfates, influence of soil bacteria, 299.

Sulfur, 28, 293; bacteria, 294, 298; relation of, to bacterial development, 298; transformation of, by bacteria, 295.

Sulfuretted hydrogen (a gaseous substance composed of the elements, hydrogen and sulfur), 293, 297; production by Proteus vulgaris, 295.

Sulfuric acid, in manure conservation, 349.

Sunlight, influence of, on bacteria, 41,71 .

Superphosphates (fertilizers made out of ground phosphate, rock, or bone, by treatment with sulfuric acid), 287; in manure conservation, 349 .

Swelling of canned vegetables, 436 .

Sweet-cream butter, 403.

Sweet clover, 231.

Symbiosis (the living together of two distinct organisms with benefit to both, as, for instance, in the case of legumes and their nodule bacteria), 197.

Symbiotic nitrogen-fixing bacteria, $2 \mathrm{C6}$.

Tanks, 95.

Tanning industry, bacteria in, 457 .

Temperature, relation of bacteria to, 36.

Thaer, 266.

Thermophile bacteria (organisms developing only at comparatively high temperatures), 36 .
Thom, 425, 426.

Thomas slag (a by-product in the refining of iron ore, containing phosphorus. The slag, when finely ground, is a valuable source of phosphoric acid), 287, 288.

Tillage, influence of, on soil bacteria, 141; relation to denitrification, 189.

Toxins (poisons produced by bacteria, or other living organisms), 10.

Transportation of milk, 394, 395 .

Tubercle bacteria (the organisms in the nodules on the roots of leguminous plants), forms of, 215; return of, to the soil, 215.

Tubercle-formation, suppression of, 216.

Tubercles, arrangement of, on roots, 214.

Tuberculosis bacteria in animal excreta, 398; in butter, 413 ; in milk, $397,399$.

Tull, 206, 207, 266, 339.

Typhoid, 58; bacteria in butter, 414 , - in ice, 97, - in milk, $400,-$ in sterilized and unsterilized water, 70; epidemics, cost of, 102; infection and milk, 59 .

Udder, bacteria in, 360 .

Urease (an enzyme produced by certain bacteria, and capable of transforming the substance urea into ammonium carbonate), 323,324 .

Uric acid (a nitrogenous compound found in the urine of animals), 321. Uro-bacilli, 322 .

Uro-bacteria (organisms prominent in the decomposition of urine), 322 , 324.

Utensils as a source of bacteria in milk, 364.

Vegetables, use of, in canning industries, 433.

Vetch, 251, 252.

Vinegar, eels, 470; formation, chemi- 
cal explanation of, 464; making, $463,470,472$; pasteurization of, 472 ; storing of, 471 .

de Vries, 372.

Virulence (the pronounced power of bacteria to produce severe attacks of disease. The term is also employed in the case of tubercle bacteria to denote a pronounced power of tubercle-formation.), increase of, 218,219 ; influence of nitration, 219.

Voẹlcker, 311 .

Wagner, 185, 312, 321, 329, 330, 332, 335.

Warrington, 116, 170.

Water, alkali salts in, 78; alkaline, 78; as a source of disease, 57 ; bacteria, competition among, 69; bacteria, in winter and summer, 69; character of bacteria in, 62, 65; cisterns, 95, 96; composition of, 77; colon bacillus in, 76; destruction of organic matter in, 67, 81; dilution of, 73 ; increase or decrease of bacteria in, 64; in lakes and ponds, 88; number of bacteria in, 68 ; peaty, 78 ; proportion of organic matter in, 66; purification of, 84,85 , - by ozone, 86, - by the Woolf method, 86; quality of organic matter in, 78; relation of, to health and disease, 56; self-purification of, 80; sewage bacteria in, 61; sewage contamination of, 73, 74; shed, inspection of, 100; soil bacteria, in 61; storing of, 68,81 ; supplies, ancient, $56,-$ bacteriological examination of, 102 , - chemical examination of, 100, sanitary examination of, 99 ; table, 92; well-, bacteria in, 90, - brightness of, 91 , - number of bacteria in, 94, - pollution of, 91, - typhoid mortality from, 90 .

Waxes, 28.

Wells, artesian, 95; deep, 93; driven, 94.

Wickstead, 106.

Wilfarth, 211, 212.

Wine, mannitic fermentation of, 461 ; ropiness in, 459, 460; turning of, 458.

Winogradsky, 171, 195, 197, 198.

Wollny, 268.

Woolf method, 86.

Woronin, 212.

Wutrich, 318.

Wygert, 9.

Yeasts, 444; in vinegar, 470. 


\section{CYCLOPEDIA OF AMERICAN AGRICULTURE}

Edited by L. H. BAILEY

Of Cornell University, Editor of "Cyclopedia of American Horticulture," Author of "Plant Breeding," "Principles of Agriculture," etc.

WITH 100 FULL-PAGE PLATES ATD MORE THAN 2,000 ILLUS-

TRATIONS IN THE TEXT-FOUR VOLUMES-THE SET .

CLOTH, \$20 NET-HALF-MOROCCO,\$32 NET-CARRIAGE EXTRA

\section{Volume I-Farms}

The Agricultural Regions-The Projecting of a Farm-The Soil Environment-The Atmosphere Environment.

\section{Volume II-Crops}

The Plant and Its Relations - The Manufacture of Crop Products North American Field Crops.

\section{Volume III-Animals}

The Animal and Its Relations-The Manufacture of Animal Prod. uets-North American Farm Animals.

\section{Volume IV-The Farm and the Community}

Economics - Social Questions-Organizations-History - Litera. ture, etc.

"Indispensable to public and reference libraries.. . readily comprehear sible to any person of average education." -The Nation.

"The completest existing thesaurus of up-to-date facts and opinions on modern agricultural methods. It is safe to say that many years must pase before it can be surpassed in comprehensiveness, aceuracy, practical value, and mechanical excellenre. It ought to be in every library in the country."

- Record Herald, Chicago.

Published by

\section{THE MACMILLAN COMPANY}




\section{BOOKS ON AGRICULTURE}

On Selection of Land, etc.

Thomas F. Hunt's How to Choose a Farm. . . . . $\$ 175$ net

E. W. Hilgard's Soils : Their Formation, and Rela-

tions to Climate and Plant Growth ..... 400 net

Isaac P. Roberts' The Farmstead ......... . 150 net

On Tillage, Crops, etc.

F. H. King's The Soil . . . . . . . . . . 150 net

Isaac P. Roberts' The Fertility of the Land . . . . 150 net

Elwood Mead's Irrigation Institutions ...... . . 125 net

F. H. King's Irrigation and Drainage . . . . . . 150 net

Wm. E. Smythe's The Conquest of Arid America . . 150 net

Edward B. Voorhees' Fertilizers . . . . . . . . 1. 25 net

Edward B. Voorhees' Forage Crops ... . . . . 150 net

H. Snyder's Chemistry of Plant and Animal Life . . 125 net

H. Snyder's Soils and Fertilizers. Third edition . . . $12^{\mu}$ set

L. H. Bailey's Principles of Agriculture . . . . . $125 \mathrm{ne}^{t}$

W. C. Welborn's Elements of Agriculture, Southern and Western............. 75 net

J. F. Duggar's Agrioulture for Southern Schools . . 75 net

On Plant Diseases, etc.

George Massee's Plant Diserses . . . . . . . 160 net

J. G. Lipman's Bacteria in Relation to Country Life . 150 net

E. C. Lodeman's The Spraying of Plants . . . . . 125 net

H. M. Ward's Disease in Plants (English) ... . . 160 net

A. S. Packard's A Text-book on Entomology . . . . 450 net

On Production of New Plants

L. H. Bailey's Plant-Breeding . . . . . . . . 125 net

L. H. Bailey's The Survival of the Unlike . . . . 200 net

L. H. Bailey's The Evolution of our Native Fruits . 200 net

W. S. Harwood's New Creations in Plant Life . . . 175 net

On Garden Making

L. H. Bailey's Practical Garden-Book .. . . . 100 net

L. H Bailey's Garden-Making . . . . . . . 150 net

L. H. Bailey's Vegetable-Gardeining . . . . . 150 net

L. H. Bailey's Horticulturist's Rule Book . . . . 75 net

L. H. Bailey's Forcing-Book .......... I 25 net

A. Brench's Book of Vexetables ......, , , 178 at 
BOOKS ON AGRICULTURE, continued

On Fruit-growing, etc.

L. H. Bailey's Nursery-Book ......... \$1 50 net

L. H. Bailey's Fruit-growing .......... 150 net

L. H. Bailey's The Pruning-Book . ..... 150 net

F. W. Card's Bush Fruits............ 150 net

\section{On the Care of Live Stock}

Nelson S. Mayo's The Diseases of Animals .... 150 net

W. H. Jordan's The Feeding of Animals . . . . . 150 net

I. P. Roberts' The Horse . . . . . . . . . 125 net

George C. Watson's Farm Poultry . . . . . . . . 125 net

\section{On Dairy Work}

Henry H. Wing's Milk and Its Products . . . . . 150 net C. M. Aikman's Milk . . . . . . . . . . . . . 125 net

Harry Snyder's Dairy Chemistry . . . . . . 100 net

W. D. Frost's Laboratory Guide in Elementary Bacteriology . .. ....... 160 net

I. P. Sheldon's The Farm and the Dairy . . . . . 100 net

On Economics and Organization

L. H. Bailey's The State and the Farmer . . . . 125 net Henry C. Taylor's Agricultural Economies . . . . . 125 net I. P. Roberts' The Farmer's Business Handbook . . 125 net George T. Fairchild's Rural Wealth and Welfare. . 125 net S. E. Sparling's Business Organization. . . . . . 125 net In the Citizen's Library. Includes a chapter on Farming.

Kate V. St. Maur's A Self-Supporting Home . . 175 net Kate V. St. Maur's The Earth's Bounty . . . . . . 175 net

\section{On Everything Agricultural}

L. H. Bailey's Cyclopedia of 'American Agriculture:

Vol. 1. Farms, Climates, and Soils.

Vol. II. Farm Crops.

Vol. III. Farm Animals.

Vol. IV. The Farm and the Community.

Price of sets: Cloth, \$20 net; half-morocco, \$32 net.

For further information as to any of the above, address the publishers

\section{THE MACMILLAN COMPANY}




\section{BY HARRY SNYDER, B.S.}

Frefaeer of Apricultural Chemistry, Ualverdity of Minnesote, and Ghemilat of the Minnesota Azrieultaral Experiment Station

\section{The Chemistry of Plant and Animal Life}

Illustrated. Cloth. 12mo. 406 pages. \$1.25; by mail, \$1.35.

"The language is, as it should be, plain and simple, free from all needleas technicality, and the story thas told is of absorbing interest to every one, man or woman, boy or girl, who takes an intelligent interest in farm life." -The New Bnglend Farmer.

"Although the book is highly technical, it is put in popular form and madn comprehensible from the standpoint of the farmer; it deals laraely with those questions which arise in his experience, and will prove an invaluable id in countless directions." The Farmar's Voice.

\section{Dairy Chemistry}

Ilustrated. 190 pages. $\$ 1$ net; by mail, \$1.10. "The book is a valuable one which any dairy larmer, or, Indeed, anj one handling stock, may road with prolit."-Rural New Yorker.

\section{Soils and Fertilizers}

Third Edition. Illustrated. $\$ 1.25$ net; by mail, $\$ 1.39$

$A$ book which presents in a concise form the principles of soil fer. tility and discusses all of the topics relating to soils as outlined by the Committee on Methods of Tesehing Agrieulture. It containg 350 pages, with illustrations, and treats of a great variety of sub. jects, such as Physical Properties of Soils; Geological Vormation, etc.; Nitrogen of the Soil and Air; Farm Manures; Commereial Fertilizers, several chapters; Rotation of Crops; Preparation of Soil for Crops, etc.

\section{THE MACMILLAN COMPANY}




\section{MR. BOLTON HALL'S \\ Three Acres and Liberty}

The author discusses the possibilities of an acre; where to find idle land; how to select it, clear and cultivate it; the results to be expected; what an acre may produce; methods, tools, equipment, capital, hotbeds and greenhouses; other uses of land; flowers; poultry and novel live stock; and nearly every other imaginable topic of intensive farming in clear, definite statements which are easily verified. It is a practical book from cover to cover. Cloth. Illustrated. $\$ 1.75$ net, by mail, $\$ 1.88$.

\section{By ALLEN FRENCH}

\section{A Book of Vegetables and Garden Herbs}

A Practical Handbook and Planting Table for the Home Garden This book gives complete directions for growing all vegetables cultivable in the climate of the nortbern United States. Besides a description of each plant, its habit, value, and use, the book contains detailed cultural directions, covering the soil, plativing distances, times for sowing, thinning and transplanting, fertilizing, picking, winter protection, renewal, storage, and management of diseases and pests.

Cloth. 12mo. Illustrated. $\$ 1.75$ net, by mail, $\$ 1.88$.

\section{By KATE V. ST. MAUR \\ A Self-supporting Home}

"E, $\mathrm{n}$ chapter is the detailed account of all the work necessary for one month - in the vegetable garden, among the small fruits, with the fowls, guineas, rabbits, cavies, and in every branch of husbandry to be met with on the rmall farm." -Loutisville Courier-Journal.

Cloth. 12mo. Fully illustrated from photographs. $\$ 1.75$ net, by mail, $\$ 1.88$.

\section{The New Earth}

\section{Ry W. S. HARWOOD}

A Recital of the Triumphs of Modern Agrietilure in America. Mr. Harwood shows in a very entertaining way the remarkable progress which has been made during the past two generations along all the lines which have their focal point in the earth. Cloth. 12mo. Illustrated. $\$ 1.75$ pet, by mail, 1.88 .

\section{THE MACMILLAN COMPANY 64.66 Fifth Avenue \\ NEW YORK}




\title{
CYCLOPEDIA OF AMERICAN HORTICULTURE
}

\author{
By L. H. BAILEY
}

Ot Cornell University, assieted by WILHELM MILI.ER, and many Export

Cultivators and Botanists

FOUR VOLUMES - OVER 2800 ORIGITAL EI-

GRAVINGS-CLOTE - OCTAVO-\$20 NET PER

SET - HALF MOROCCO, \$32 NET PER BET

This great work comprises directions for the cultivation of horticultural crops and original descriptions of all the species of fruits, vegetables, flowers and ornamental plants known to be in the market in the United States and Canada. "It has the unique distinction of presenting for the first time, in a carefully arranged and perfectly accessible form, the best knowledge of the best specialists in America upon gardening, fruit-grow. ing, vegetable culture, forestry, and the like, as well as exact botanical information... . The contributors are eminent cultivators or specialists, and the arrangement is very systematic, clear and convenient for ready reference."

"Wo have here a work which every ambitions gardener wll wish to place on his shelf.boside his Nicholson and his Loudon, and for such users of it a too sdranced nomenclature would have been confusine to the last degres. With the ase names here given there is littlo liability to serious perplexity. There is a zrowing impatience with much of the controversy concerning revision of names of organisms, whether of plants or animals. Those investigators who sre busted Wth the ecological atpects of oreanisms, and also those who are chiefy concerned with the application of plants to the arts of agrieulture, horticulture, and $10 \mathrm{on}$, care for the names of organisms under eramination only so far as these aid in recognition and identification. To introduce unnecessary confusion is a sorions blunder. Protessor Bailey has avoided the risk of confusion. In thort. in ranas. trestment and editing, the Cyclopedia appesrs to be omphsticelly usofnl: . . work worthy of ranking by the side of the Century Dietionary. ${ }^{n}$-The Nation.

This work is sold only by subscription, and terms and further information may bo had of the publishers.

\section{THE MACMILLAN COMPANY A4-66 Fifth Arenue





